\begin{tabular}{l|}
\hline 2. To: (Receiving Organization) \\
Facility 0perations Design \\
Authority \\
\hline 5. Proj./Prog./Dept./Div.: \\
TWRS Safety \& Licensing \\
\hline
\end{tabular}

8. Originator Remarks:

Approval/Release (Interim)

11. Receiver Remarks:

11A. Design Basel ine Document?

3. From: (Originating Organization)

TWRS FSAR Development

6. Design Authority/ Design Agent/Cog. Engr.: L.J. Julyk/F.C. Han

\begin{tabular}{l|l} 
& 4 \\
& \\
\hline $\operatorname{cog}$. & \\
\hline
\end{tabular}

4. Related EDT No.:

$N / A$

7. Purchase Order No.:

$N / A$

9. Equip./Component No.: $N / A$

10. System/Bldg./Facility; HANFORD WASTE TANKS

12. Major Assm. Dwg. No.:

$N / A$

13. Permit/Permit Application No.: $N / A$

14. Required Response Date: $N / A$

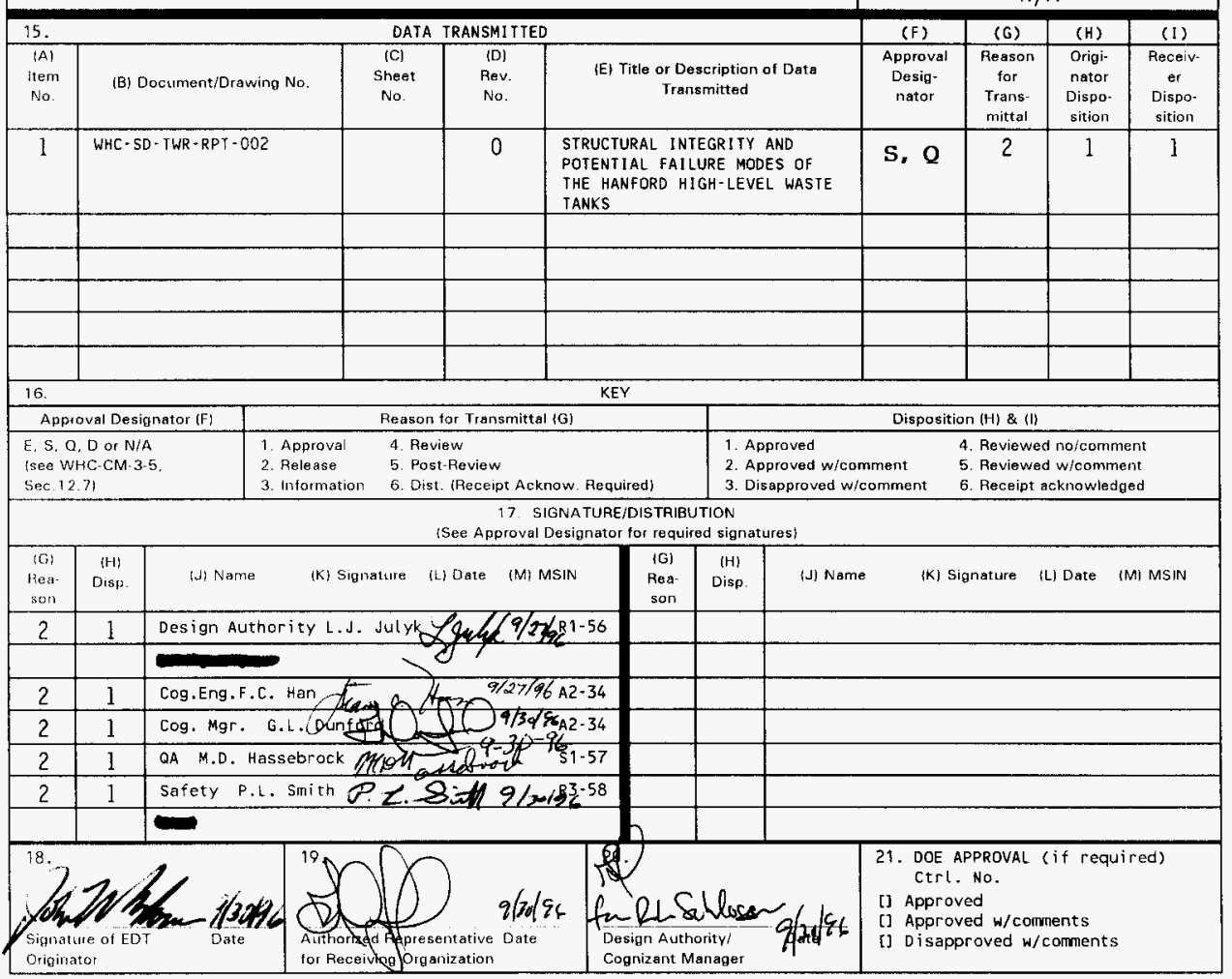




\title{
STRUCTURAL INTEGRITY AND POTENTIAL FAILURE MODES OF THE HANFORD HIGH-LEVEL WASTE TANKS
}

\author{
F. C. Han
}

Westinghouse Hanford Company, Richland, WA 99352

U.S. Department of Energy Contract DE-AC06-87RL10930

$\begin{array}{lll}\text { EDT/ECN: } & \text { EDT } 606492 & \text { UC: } 2030 \\ \text { Org Code: } & 74 E 20 & \text { Charge Code:N1FW3 } \\ \text { B\&R Code: } & \text { EW-31-20-07-1 } & \text { Total Pages: } 198\end{array}$

Key Words: Tank, Structura1, Concrete, Stee1, Loads, Thermal, Seismic, Accident, Analysis, Dome, Failure.

Abstract: Structural Integrity of the Hanford High-Level Waste Tanks were evaluated based on the existing Design and Analysis Documents. Al1 tank structures were found adequate for the normal operating and seismic loads. Potential failure modes of the tanks were assessed by engineering interpretation and extrapolation of the existing engineering documents .

TRAOEMARK DISCLAIMER. Reference herein to any specific commercial product, process, or service by trade name, trademark, manufacturer, or otherwise, does not necessarily constitute or imply its endorsement, recomendation, or favoring by the United States Government or any agency thereof or its contractors or subcontractors.

Printed in the united States of America. To obtain copies of this document, contact: WHC/BCS Document Control Services, P.O. BOx 1970, Mailstop H6-08, Richland WA 99352, Phone (509) 372-2420; Fax (509) 376-4989.
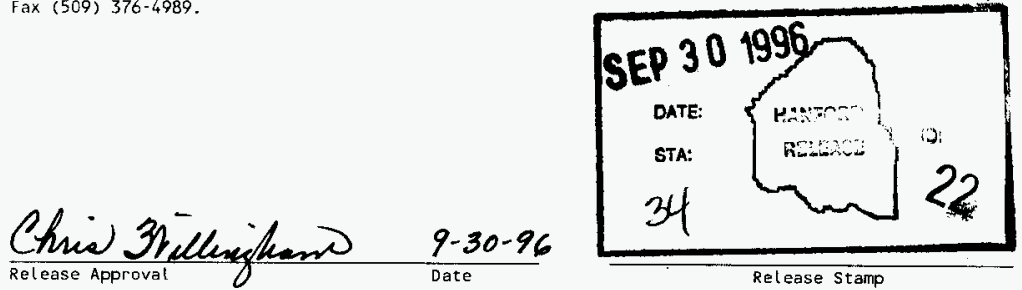

Approved for Public Release 
WHC-SD-TWR-RPT-002 REV 0

STRUCTURAL INTEGRITY AND POTENTIAL FAILURE MODES

OF THE HANFORD HIGH-LEVEL WASTE TANKS

Revision 0

WHC-SD-TWR-RPT-002

September 1996 
WHC-SD-TWR-RPT-002 REV 0

This page intentionally left blank. 


\section{EXECUTIVE SUMMARY}

The Hanford Site covers approximately $1,450 \mathrm{~km}^{2}\left(560 \mathrm{mi}^{2}\right)$ of semiarid 1 and that is owned by the U.S. Government and managed by the Department of Energy, Richland 0perations Office. As a result of reactor operations, chemical separation processes, and related activities for the production and purification of plutonium, high- and low-level radioactive waste has been accumulating at the Site since 1944. Currently there are approximately $231 \mathrm{ML}$ (61 Mgal) of waste stored at the site. The waste is stored in 177 steellined, reinforced concrete, underground tanks that are providing interim storage of the waste until further processing and permanent disposal options become available.

There are two types of underground waste storage tanks at Hanford, single-shell tanks (SSTs) and double-shell tanks (DSTs). The tanks are located in the 200 Area within the Hanford Site. A hundred and forty-nine SSTs having a single-shell liner of carbon steel housed within a cylindrical reinforced concrete structure were constructed between 1943 and 1964 with an estimated design 1 ife of 20 years (actual design life not specified in available documents). Hence, all SSTs have exceeded their design life. As many as 67 of the SSTs are known or assumed to have leaked releasing radioactive waste into the surrounding soil. Although not confirmed, these failures of the carbon steel liners are believed to be due to stress corrosion cracking aggravated by the lack of post-weld stress relieving and the presence of high nitrate concentrations in the waste (Anantatmula et al. 1994). All of the SSTs were removed from service (not allowed to receive additional waste) 
on or before November 21,1980 . In accordance with the Hanford Facility Agreement and Consent Order (Tri-Party Agreement) (Ecology et a1. 1994) interim stabilization of all SSTs is scheduled for completion by September 2000. A total of 115 of the SSTs have been interim stabilized by pumping interstitial and supernatant liquids to DSTs (Hanlon 1996). Waste retrieval of a11 SSTs is scheduled for completion by September 2018 (Ecology et al. 1994).

The remaining twenty-eight tanks are double-shell tanks (DSTs) constructed between 1968 and 1986. These are second generation tanks with an inner (primary) steel tank and an outer steel liner housed within a cylindrical reinforced concrete structure. The DST primary steel tanks were post-weld stress relieved and none of the DSTs have leaked. Two of the DSTs were designed for a 20-year life, two for a 40-year life, and the remaining 24 for a 50-year life. Current schedules for disposal of the waste stored in the SSTs and DSTs will require storage and pretreatment of the waste in DSTS through the year 2028 (Ecology et a1. 1994).

Although current scheduled dates for retrieval of the waste may be accelerated or extended, in the interim the generation of flammable gases, high concentrations of organic compounds/chemicals that could support an exothermic reaction at elevated temperatures, and high waste temperatures within some tanks has raised public health and safety concerns. In addition, many of the tanks are beyond their initial design life or will exceed their initial design life before final disposal of the stored waste is achieved. Thus, concerns have been raised on the ability of the tanks to maintain 
adequate structural integrity; in particular on the ability of the tanks to guard against or minimize airborne releases of the stored waste if the tanks are challenged by postulated accident load conditions.

The current mission of Tank Waste Remediation System (TWRS) at the Hanford Site includes storage management, retrieval, pretreatment, immobilization, interim storage and disposal, and tank closure operations (WHC 1966). The primary function of the tanks is to provide containment of the stored waste by maintaining leak tightness and structural stability until disposal of the waste has been achieved. Because many of the SSTs have a Tready leaked and all have been removed from service, the primary function of the SSTs is to prevent airborne release of the stored waste by maintaining structural stability until disposal of the remaining waste has been achieved. This supporting document has been prepared to provide an assessment of the structural integrity of the Hanford Site waste storage tanks for their design and actual operating load conditions and to identify potential failure modes under various postulated accident scenarios in support of the accident analysis found in Chapter 3.0 of the TWRS-FSAR.

Following introductory and background information describing the tank farm facilities, the scope of the evaluation contained herein consists of two parts. In the first part the structural integrity of the waste storage tanks is assessed for design, operating, and environmental load conditions on the basis of existing available analyses; including previous assessments of actual operating conditions for some tanks that were outside the original design envelope. The second part consist of identifying potential failure modes and associated limit loads of the tanks under various accident scenarios or 
beyond-design-basis loads. The emphasis of this assessment is on the 200-Area Hanford Site single- and double-shell tanks which contain the bulk of the stored waste. This report does not address ancillary tank facilities, i.e., tank appurtenances and buried piping.

This evaluation effort relies on the results from the existing design support documentation for the tanks; i.e., the structural analysis reports, design drawings, and material test data. Results from the various existing analytical reports were compiled and compared to appropriate structural design code allowables. In certain cases where the required information for a given load case or accident scenario was not available from the existing documents, simplified scoping calculations for a bounding load condition were generated to investigate the structural behavior of the tanks.

The existing supporting documents for the tanks were generated originally at various times during the past to address certain specific issues related to tank farm operations, either for an individual tank or a group of tanks. In this report the structural integrity of the tanks is assessed on a generic basis through an engineering interpretation and extrapolation process that considers the results from the relevant existing documentation.

In summary the report concludes, on the basis of existing design documents, that all tank structures covered in this evaluation are adequate for the normal operating and environmental loads. Structural responses for each of the postulated accident scenarios were estimated and the identified failure modes for these accidents provide a basis for the consequence analyses in the TWRS-FSAR. 
WHC - SD-TWR-RPT-002 REV 0

This page intentionally left blank. 


\section{CONTENTS}

1.0 INTRODUCTION ................... . . . . .

1.1 BACKGROUND ....................... . . . . . . .

1.2 PURPOSE . . . . . . . . . . . . . . . 1-2

2.0 TANK AND TANK FARM DESCRIPTIONS ............. 2-1

2.1 TANK FARM FACILITIES AND OPERATIONS ........... . . 2-1

2.1.1 Tank Farm Facilities.............. 2-1

2.1.2 Current Tank Farm Operations ...... . . . . . . . 2-4

2.2 HISTORICAL INFORMATION ................... 2-5

2.2.1 Tank Farm Design and Construction ......... 2-6

2.2.2 History of Operation .............. 2-8

2.3 FUTURE USE ........................... $2-10$

2.3.1 General ................. . . 2-10

2.3.2 Single-Shell Tanks ............... . . 2-11

2.3.3 Double-Shell Tanks ................ 2-11

3.0 TANK MATERIAL CONDITIONS . . . . . . . . . . . . . $3-1$

3.1 GENERAL . . . . . . . . . . . . . . . . . . . 3-1

3.2 CONCRETE MATERIAL . . . . . . . . . . . . . 3-1

3.2.1 SST Design Compressive Strength ......... 3-1

3.2.2 DST Design Compressive Strength ......... . . 3-1

3.2.3 Aging Effects ............... . . 3-1

3.2 .4 Temperature Effects ............ . . 3-2

3.2 .5 Corrosion Effects ............. . . . 3-5

3.2.6 Radiation Effects .............. . . . 3-6

3.3 REINFORCING STEEL . . . . . . . . . . . . . . . $3-6$

3.3.1 Strengths ................ . . 3-6

3.3.2 Aging Effects ............. 3-6

3.3.3 Temperature Effects . . . . . . . . . . . . . 3-6

3.3 .4 Corrosion Effects ............. 3-7

3.4 STRUCTURAL STEEL LINERS . . . . . . . . . . . . . 3-8

3.4 .1 General ............... 3-8

3.4.2 Single-Shell Tank Specifications . . . . . . . . . 3-8

3.4.3 Double-Shell Tank Specifications .......... 3-8

3.4.4 Aging Effects .............. . . 3-8

3.4.5 Temperature Effects ... . . . . . . . . 3-9

3.4 .6 Normal Corrosion Effects . . . . . . . . . . 3-9

3.4.7 Waste Corrosion Effects ....... . . . . 3-9

4.0 STRUCTURAL INTEGRITY AGAINST DESIGN LOADS . . . . . . . . . 4-1

4.1 HISTORICAL LOAD CRITERIA . . . . . . . . . . . . . . . 4-1

4.1.1 General ................. . . 4-1

4.1.2 Single-Shell Tanks .............. . . 4-1

4.1.3 Double-Shell Tanks . . . . . . . . . . . . . 4-1

4.2 CURRENT LOAD CRITERIA . . . . . . . . . . . . . 4-2

4.2.1 Tank Evaluation Criteria . . . . . . . . . . 4-2

4.3 EVALUATION LOADS .................. . . . . . . . . . . . .

4.3.1 General ................. . 4-3

4.3.2 Dead Loads . . . . . . . . . . . . . . . . . 4-4 


\section{CONTENTS (Continued)}

4.3.3 Live Loads .... . . . . . . . . . . . . . . 4-4

4.3.4 Soil and External Hydrostatic Pressure Loads . . . . . . 4-6

4.3.5 Environmental Loads . . . . . . . . . . . . . . . . . 4-6

4.4 TANK LOAD GROUPING .................... . . . . . 4-9

4.5 TANK STRUCTURAL EVALUATION .............. . . . 4-10

4.5.1 Tank Grouping ... . . . . . . . . . . . . . 4-10

4.5.2 Structural Evaluation of Single-Shell Tanks . . . . . 4-10

4.5.3 Structural Evaluation of Double-Shell Tanks . . . . . 4-20

5.0 ULTIMATE LOAD CAPACITY AND FAILURE MECHANISMS

UNDER ACCIDENT LOADS . . . . . . . . . . . . . . . . . 5-1

5.1 GENERAL . . . . . . . . . . . . . . 5-1

5.2 EXCESSIVE EXTERNAL TANK LOADS ............. . 5-1

5.2.1 Excessive Concentrated Load . . . . . . . . . . 5-1

5.2.2 Excessive Uniform Load . . . . . . . . . . . . . . 5-2

5.2 .3 Excessive Load Drop .............. . 5-3

5.3 EXCESSIVE INTERNAL TANK LOADS . . . . . . . . . . . . 5-4

5.3.1 General . . . . . . . . . . . . . 5-4

5.3.2 High Pressure Loads . . . . . . . . . . . . . 5-5

5.3.3 High Internal Vacuum . . . . . . . . . . . . . . . 5-10

5.3.4 Excessive Internal Waste ............ 5-12

5.3.5 Excessive Pressure in Annulus .......... . . 5-13

5.4 HIGH TEMPERATURE ACCIDENT LOADS . . . . . . . . . . . 5-13

5.4.1 Load Description . . . . . . . . . . . . . 5-13

5.4 .2 Tank Grouping . . . . . . . . . . . . . 5-14

5.4 .3100 -Series SST Failure Mode . . . . . . . . 5-14

5.5 POSTULATED EXTREME DETRIMENTAL CONDITIONS . . . . . . . . 5-14

5.5 .1 High-Heat Waste in Tank ............ . 5-14

5.5.2 Corrosion of the Tank Structure ........ . 5-15

5.5.3 Aging of Tank Structure ........... . . 5-16

5.5.4 Heavy Loads Suspended From the Dome ......... 5-17

5.5.5 Rebar Corrosion within the Dome . . . . . . . . . . 5-18

5.6 ABOVE DESIGN BASIS EARTHQUAKES ............ . . 5-18

5.6.1 Load Description . . . . . . . . . . . . . 5-18

5.6.2 Tank Grouping .......... . . . . . 5-19

5.6.3 200-Series SST Failure Mode . . . . . . . . . 5-19

5.6 .4 100-Series SST Failure Mode . . . . . . . . . 5-19

5.6 .5 DST Failure Mode . . . . . . . . . . . . . 5-20

5.6 .6 Delphi Findings . . . . . . . . . . . . 5-20

5.6.7 Probabilistic Safety Assessment Report . . . . . . 5-21

6.0 ENGINEERING NEEDS FOR ISSUE RESOLUTION . . . . . . . . . . 6-1

6.1 GENERAL . ...................... $6-1$

6.2 LOADS . . . . . . . . . . . . . . . . . . . . . 6-1

6.3 MATERIAL PROPERTIES . . . . . . . . . . . . . . . . 6-2

6.3.1 Thermal Effects ............. 6-2

6.3 .2 Corrosion ............... . . 6-2

6.4 STRUCTURAL ANALYSIS $\ldots \ldots \ldots$ 
WHC-SD-TWR-RPT-002 REV 0

CONTENTS (Continued)

7.0 CONCLUSIONS ....................... . . . . .

8.0 REFERENCES ..................... 8 8 . .

APPENDIXES

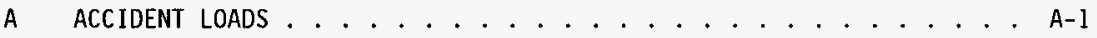

B POSTULATED EXTREME DETRIMENTAL CONDITIONS ........... B-l

C CALCULATIONS OF SECTION CAPACITIES FOR ACCIDENT

INTERNAL PRESSURES ...................... . . . . 


\section{LIST OF FIGURES}

1-1 DOE Hanford Site .................. . F-1

1-2 Location of 200 East and 200 West Area . . . . . . . . . . . F-2

2-1 DOE Hanford Site Tank Farm Locations............ . F-3

2-2 DOE Hanford Site Tank Farm Locations . . . . . . . . . . . . . F-4

2-3 Cross-Section of Single-She11 Tanks ............ F-5

2-4 Graphical Representation of the 100-Series Single-Shell Tanks . . F-6

2-5 Cross-Section of Double-She11 Tanks . . . . . . . . . F-7

2-6 Graphical Representation of Double-Shell Tanks . . . . . . . . F-8

2-7 Risers and Pit Covers of Tank Farm 241-SY . . . . . . . . . . . F-9

2-8 Current Tank Farm Operations, 200 West Area . . . . . . . . . F-10

2-9 Current Tank Farm Operations, 200 East Area . . . . . . . . . . F-11

3-1 Cross-Section of 241-SX-115 Showing Maximum Heat

3-2 Detail of Wall and Drilling Caisson ............. F-13

3-3 Load-Strain Relation of Reinforcement After Exposure
to Waste Solution . . . . . . . . F-14

4-1 Response Spectra - 0.25g . . . . . . . . . . F-15

4-2 Response Spectra - 0.20g . . . . . . . . . . . F-16

4-3 Response Spectra - $0.12 \mathrm{~g} \ldots \ldots \ldots$. . . . . . . F-17

4-4 Axisymmetric Temperature Isotherms ... . . . . . . . . F-18

4-5 Temperature Time-History . . . . . . . . . . . . F-19

4-6 241-A-106 Waste Temperature Thermal History . . . . . . . . . F-20

4-7 Typical P-M Diagram . . . . . . . . . . . . . . F-21

4-8 Tanks 241-AX, Finite Element Mode1 . . . . . . . . . . . F-22

4-9 Locations of P-M Diagrams . . . . . . . . . . . F-23

4-10 P-M Diagrams of Sections 1 and 2 .............. F-24

4-11 P-M Diagram of Section 3 . . . . . . . . . . . F-25 


\section{LIST OF FIGURES (Continued)}

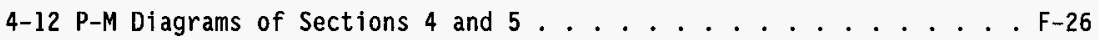

4-13 P-M Diagram of Section 6................... . F-27

4-14 P-M Diagrams of Sections 7 and 8 ................ . F-28

4-15 P-M Diagrams of Sections 9 and 10 . . . . . . . . . . . . . F-29

4-16 P-M Diagrams of Sections 11 and 12 . . . . . . . . . . . . F-30

5-1 Typical Dome Reinforcement of 2.9-ML Capacity SSTs . . . . . . . . F-31

5-2 Typical Dome Reinforcement of 3.8-ML Capacity SSTs . . . . . . . . F-32

5-3 Typical Wall Reinforcement of 2.9-ML Capacity SSTs . . . . . . . . F-33

5-4 Typical Wall Reinforcement of 3.8-ML Capacity SSTs . . . . . . . . F-34

5-5 Stress-Strain Curves for Steel Liner and Reinforcement . . . . . . . F-35

5-6 Primary and Secondary Steel Tanks of DSTs . . . . . . . . . . F-36

5-7 Typical Dome Reinforcement of DSTs . . . . . . . . . . . . . F-37 


\section{LIST OF TABLES}

2-1 Single-Shell Tank Design Parameters . . . . . . . . . . . . . T-1

2-2 Comparison of Nominal Capacity Million Gallon Double-She11 Tanks with Million Gallon Single-Shell Tanks.......... . T-2

2-3 Double-Contained Receiver Tanks ................. . T-3

2-4 Catch Tank Attributes . . . . . . . . . . . . . . . . T-4

2-5 Summary of Single-She11 Tank Design Documents . . . . . . . . . . T-6

2-6 Double-She11 Tank Materials and Specifications . . . . . . . . . T-8

3-1 Results Summary of Double-Shell Tank Useful Life Estimates Models................... . . T-15

4-1 Safety and Performance Category Correlation . . . . . . . . . . T-17

4-2 Original Specific Gravities of Single-Shell Tanks . . . . . . . . . T-18

4-3 Specific Gravity and Waste Level . . . . . . . . . . . . . . . T-18

4-4 Soil Density and Cover at Apex . . . . . . . . . . . . . . T-19

4-5 Seismic Anchor Value Correlation . . . . . . . . . . . . . . T-21

4-6 75-Ft. Diameter Tank Therma1-Creep and U1timate Load Input Data Analyses .................... . T-21

4-7 Sections in Tank for P-M Diagrams . . . . . . . . . . . . . T-22

4-8 Maximum Stresses in Steel Liner . . . . . . . . . . . . . . . T-23

4-9 Thermal-Creep Stresses in Steel Liner . . . . . . . . . . . . . T-25

4-10 Steel Properties for Thermal-Creep Analysis . . . . . . . . . . . T-25

5-1 Summary of FSAR Solvent Pool Fire Cases . . . . . . . . . . . . . T-27 


\section{LIST OF TERMS}

$\begin{array}{ll}\text { ASA } & \text { Accelerated Safety Analysis } \\ \text { AWF } & \text { aging waste facility } \\ \text { DCRT } & \text { double-containment receiver tank } \\ \text { DOE } & \text { U.S. Department of Energy } \\ \text { DOE-RL } & \text { U.S. Department of Energy, Richland Operations Office } \\ \text { DST } & \text { double-shell tank } \\ \text { FSAR } & \text { Final Safety Analysis Report } \\ \text { MISF } & \text { miscellaneous inactive storage facility } \\ \text { NPH } & \text { Natural Phenomena Hazards } \\ \text { PC } & \text { performance category } \\ \text { PCA } & \text { Portland Cement Association } \\ \text { PUREX } & \text { Plutonium Uranium Extraction Plant } \\ \text { SC } & \text { safety class } \\ \text { SSC } & \text { structure, system, or component } \\ \text { SST } & \text { single-shell tank } \\ \text { TPA } & \text { Tri-Party Agreement } \\ \text { TWRS } & \text { Tank Waste Remediation System } \\ \text { UBC } & \text { Uniform Building Code } \\ \text { WHC } & \text { Westinghouse Hanford Company }\end{array}$




\subsection{INTRODUCTION}

This supporting document has been prepared for the Tank Waste Remediation System's (TWRS) Final Safety Analysis Report (FSAR) Project to provide additional details regarding waste tank structural integrity and potential failure modes for various postulated accident scenarios that support the accident analys is found in Chapter 3.0 of the TWRS-FSAR (WHC 1996a). This supporting document was developed in accordance with the assumptions and bases stated in the TWRS-FSAR Project Plan (WHC 1996b). The findings presented herein for design, operational, and environmental loads were evaluated in accordance with U.S. Department of Energy (DOE) orders and standards. The findings for the postulated accident and beyond-design-basis loads support the consequence analyses contained within Chapter 3.0 of the TWRS-FSAR.

\subsection{BACKGROUND}

The Hanford Site is located in southeastern part of Washington state as shown in Figure $1-1$, covers approximately $1,450 \mathrm{~km}^{2}\left(560 \mathrm{mi}^{2}\right)$ of semiarid land, is owned by the U.S. Government and managed by the Department of Energy, Richland Operations office (DOE-RL). As a result of reactor operations, chemical separation processes, and related activities for the production and purification of plutonium, high- and low-level radioactive waste has been accumulating at the Hanford Site since 1944. Currently there are approximately $231 \mathrm{ML}$ (61 Mgal) of the waste stored at the Hanford Site (Baynes et a1. 1993). This waste is stored in 177 steel-1ined, reinforced concrete, underground tanks that are providing interim storage of the waste until further processing and permanent disposal options become available.

The tanks are arranged in groups called tank farms and are buried underground in the 200 East and West Areas of the Hanford Site as shown in Figure 1-2. The tank designs within a farm are basically identical with a few minor exceptions. However, two fundamentally different designs comprise the entire inventory of tanks. These are single-shell tank (SST) designs and double-shell tank (DST) designs. One hundred and forty-nine SSTs were constructed between 1943 and 1964. The remaining twenty-eight tanks are DSTs constructed between 1968 and 1986 .

The current mission of Tank Waste Remediation System (TWRS) at the Hanford Site includes storage management, retrieval, pretreatment, immobilization, interim storage and disposal, and tank closure operations (WHC 1966). The primary function of the tanks is to provide containment of the stored waste by maintaining leak tightness and structural stability until disposal of the waste has been achieved. Because as many as 67 of the 149 SSTs have already leaked, the primary function of the SSTs to provide containment of the stored waste by maintaining leak tightness has been compromised. However, to prevent airborne release of the stored waste material the structural stability of the SSTs must be maintained until disposal of the waste has been achieved. All of the SSTs were removed 
from service (not allowed to receive additional waste) on or before November 21, 1980. In accordance with the Hanford Facility Agreement and Consent Order (Tri-Party Agreement) (Ecology et al. 1994) interim stabilization of all SSTs is scheduled for completion by September 2000 . A total of 115 of the SSTs have been interim stabilized (containing less than $190 \mathrm{~kL}[50,000 \mathrm{gal}]$ of drainable interstitial liquids and less than $19 \mathrm{~kL}$ [5,000 gal] of supernatant 1iquid) (Hanlon 1996). Waste retrieval of all SSTs is scheduled for completion by September 2018. The DSTs are projected to be needed for storage and pretreatment of the waste from the SSTs and DSTs out to the year 2028 on the basis of current schedules for completion of waste disposal. Although these scheduled dates may be accelerated or extended, in the interim the generation of flammable gases, high concentrations of organic compounds/chemicals that could support an exothermic reaction at elevated temperatures, and high waste temperatures within some tanks has raised public health and safety concerns. In addition, many of the tanks are beyond their initial design life or will exceed their initial design life before final disposal of the stored waste is achieved. Thus, concerns have been raised on the ability of the tanks to maintain adequate structural integrity; in particular on the ability of the tanks to guard against or minimize airborne releases of the stored waste if the tanks are challenged by postulated accident load conditions.

\subsection{PURPOSE}

The purpose of this supporting document is to assess the structural integrity of the waste storage tanks for design and actual operating loads and to identify potential failure modes and effects for postulated accident and beyond-design-basis loads.

\subsection{SCOPE}

The emphasis of this assessment is on the structural integrity of the 200-Area Hanford Site single- and double-shell waste storage tanks. This report does not address ancillary tank facilities, i.e., tank appurtenances and buried piping. The engineering effort for this task involved the review and evaluation of existing tank structural analyses, design documents, and test data. Limited simplified calculations were performed as needed to supplement the evaluation process. However, no new engineering analyses were performed as part of this effort. In assessing the effects of postulated accidents and beyond-design-basis loads, a Delphi process was conducted (Leach 1996). The Delphi process elicits expert opinions in assessing the resolution of complex problems.

As stated in the project plan (WHC 1996b):

...analyses will be reviewed against the applicable requirements in DOE 5480.28, Natural Phenomena Hazards Mitigation, and mandatory DOE standards to that order. If these analyses are insufficient to demonstrate the structural integrity of the tanks under normal conditions or postulated accidents, tank failure will be conservatively assumed and the consequences calculated 
and any compensating structures, systems, and components (SSCs), administrative controls, or both will be jdentified.

DOE Order 5480.28 (DOE 1993a) has since been replaced with DOE order 420.1 (DOE 1995); however, the general requirements remain the same and the new order invokes the same mandatory standards.

This supporting document describes the tank farms and operations, provides historical information, and discusses future uses in Chapter 2.0; reviews the structural and material conditions of the tanks in Chapter 3.0; discusses the structural integrity of the tanks for design, operating, and environmental loads in Chapter 4.0; describes the ultimate load capacity and failure modes under postulated accident and beyond-design-basis loads in Chapter 5.0; discusses the need for issue resolutions in Chapter 6.0; provides conclusions in Chapter 7.0; and provides list of references in Chapter 8.0. 
WHC-SD-TWR-RPT-002 REV 0

This page intentionally left blank. 
WHC-SD-TWR-RPT-002 REV 0

\subsection{TANK AND TANK FARM DESCRIPTIONS}

\subsection{TANK FARM FACILITIES AND OPERATIONS}

\subsubsection{Tank Farm Facilities}

2.1.1.1 Tank Farms. There are 18 high-level waste tank farms containing 177 large waste storage tanks on the Hanford Site. The tank farms are located in the 200 East and West Areas of the Hanford Site. Their specific locations within the 200 East and West Areas are shown in Figures 2-1 and 2-2. Each tank farm has an unique identification label which consists of one or two alphabetical letters and each tank has a unique three digit designation. Thus, Tank 241-SY-101 is tank 101 of the SY Tank Farm and 241 designates that the structure is associated with a tank farm.

Twelve of the tank farms contain a total of 149 SSTs and are identified as $241-A,-A X,-B,-B X,-B Y,-C,-S,-S X,-T,-T X,-T Y$, and $-U$. These tanks provide single containment of highly radioactive waste and were constructed of steel-lined, reinforced concrete from 1943 through 1964 with a design service 1 ife estimate of 20 years (actual design life not specified in available documents) (Julyk 1995). The SST carbon-steel 1iners were not stress relieved after welding and fabrication operations were completed.

Beginning in 1968, new tank farms were built with tanks constructed of a double-sheli consisting of an inner steel tank and an outer steel-lined reinforced concrete shell structure. By 1986 a total of six new tank farms had been constructed containing 28 DSTs. The DST farms are known as 241-AN, $-A P,-A W,-A Y,-A Z$, and $-S Y$. Two of the DSTs were designed for a 20-year life, two for a 40-year 1 ife, and the remaining 24 for a 50-year 1 ife. The tanks within all six DST farms are similar in design and service conditions (Julyk 1995). However the tanks are not identical. There are some differences in design details; such as, the compressive strength of the concrete, the amount of reinforcement and its placement, the grade of steel and thickness of the inner (primary) steel tank, as well as differences in the base mat (foundation) details.

A more complete description of the tank farms and their tank construction is provided below.

2.1.1.2 Single-Shell Tanks. There are four general waste tank designs for the SSTs (Fisher and Shank 1994) based on capacity and identified here in as the 200-Series and the 100-Series Types l through 3, as shown in Table 2-1. Figure 2-3 shows cross-sections of each of the SST types. Figure 2-4 shows a graphical representation of the 100-Series SSTs.

The 200-Series SSTs are unique in size and shape, and were used as receiver tanks. They were constructed of a $6-\mathrm{m}(20-\mathrm{ft})$ diameter reinforced concrete cylindrical shell, a reinforced concrete base mat, and a reinforced 
concrete flat roof slab. The design waste storage capacity is $208 \mathrm{~kL}$ (55,000 gal). A large rectangular concrete pit that houses two condenser units is integrated with the roof slab. The 200-Series SSTs were constructed in an excavated site and backfilled with compacted soil to a height of 1.5 to $3.7 \mathrm{~m} \mathrm{(5} \mathrm{to} 12 \mathrm{ft}$ ) above the flat portion of the roof.

The 100-Series SSTs of Types 1 through 3 were constructed as a reinforced concrete cylindrical she11 with an inside diameter of $23 \mathrm{~m}$ (75 ft), a reinforced concrete base mat, and a reinforced concrete ellipsoidal dome roof. The SST Types 1 through 3 are of the same general construction with differences being primarily in tank height and volume. The design waste storage capacities for the 100-Series Types 1, 2, and 3 SSTs are $2 \mathrm{ML}$ (533,000 gal), 2.9 ML (758,000 gal), and $3.8 \mathrm{ML}$ (1 Mgal), respectively. The 100-Series Types 1 through 3 SSTs were also constructed in an excavated site and backfilled with compacted soil to a height of 1.5 to $3 \mathrm{~m}$ (5 to $10 \mathrm{ft}$ ) above the apex of the dome.

All of the SSTs have a welded, continuous, steel liner resting on the base mat that extends up along the inside face of the concrete shell wall. There was no post-weld heat treatment of the liner plate welds to relieve residual stresses caused by the welding. The liner stops just below the roof area where a concrete construction joint connects the cylindrical concrete wall to its roof. The steel liner is the primary waste containment barrier. The reinforced concrete structure is the secondary waste containment barrier and the load support structure that resist internal hydrostatic loads, external soil loads, and equipment loads.

2.1.1.3 Double-Shel1 Tanks. Four of the DSTs have a designed waste storage capacity of $3.8 \mathrm{ML}$ (1 Mgal). The remaining twenty-four tanks have a design capacity of $4.4 \mathrm{ML}(1.16 \mathrm{Mgal})$. All are referred to as having a nominal storage capacity of $3.8 \mathrm{ML}$ (l Mgal). The DSTs are all generally of the same design and can be considered of one general type. Table 2-2 compares the DSTs general design parameters with that of the 3.8-ML (1-Mgal) SSTs.

The DSTs were constructed of an external reinforced concrete cylindrical tank with an inside diameter of $24 \mathrm{~m}(80 \mathrm{ft})$, a reinforced concrete base mat, and a reinforced concrete elliptical dome roof. The internal tank was constructed with a $23 \mathrm{~m}(75 \mathrm{ft})$ inside diameter using structural steel plate. The roof of the internal tank also became an elliptical dome shape since it was attached to the inner surface of the concrete dome. The internal tank becomes the primary tank for containment of the stored liquid radioactive waste.

Like the SSTS, the DSTs have a continuous steel liner across the base mat which extends up the inner face of the cylindrical concrete wall, this steel liner is the secondary tank. However, unlike the SSTs, the DST steel liner is attached to the cylindrical concrete wall. In addition, instead of this liner stopping just below the haunch, it goes up into the haunch region of the concrete tank to a point of tangency with the primary (internal) tank. 
The primary tank flat bottom rests on an 20-cm- (8-in.-) thick layer of refractory insulating concrete which separates the primary tank and secondary tank liner. There is a nominal $76-\mathrm{cm}(30-\mathrm{in}$.$) annulus between the primary$ tank cylindrical wall and the secondary tank wall. The annulus contains equipment for leak detection, ventilation, and cooling.

Unlike the SSTs, the DSTs' primary steel tanks were all thermally stress relieved after welding to remove any residual stresses that may have occurred due to welding.

The DSTs were also constructed in an excavated site and backfilled with compacted soil to a height of 1.5 to $2 \mathrm{~m}$ ( 5 to $7 \mathrm{ft}$ ) above the apex of the dome. Figure 2-5 show a typical cross-section of a DST and Figure 2-6 shows a graphical representation of a DST.

2.1.1.4 Tank Dome Penetrations. As noted, the 200-Series SSTs do not have a dome roof; however, there are some penetrations, including two large penetrations for the ventilation system.

For 100-Series SSTs and DSTs there are a number of risers that penetrate each tank dome to allow access for instrumentation and equipment. Sizes of the risers range from 1.9 to $107 \mathrm{~cm}(0.75$ to $42 \mathrm{in}$.). Risers with diameters less than $51 \mathrm{~cm}(20$ in.) were fabricated from seamless carbon steel pipes. Risers with diameters greater than $51 \mathrm{~cm}$ (20 in.) were rolled from steel plate and seam welded. The risers are encased in the dome concrete with anchor studs. The anchor studs are welded to the riser and extend radially outward from the outer surface of the riser into the concrete. In addition, in the DSTs the risers are also welded to the primary tank dome. Some of the risers extend up through the soil to about $30 \mathrm{~cm}$ (12 in.) above the ground surface. others extend up into concrete pits that extend down from the ground surface to the top of the dome. The pits are capped at ground surface with reinforced concrete cover blocks. Figure 2-7 is a photograph of tank farm 24l-SY clearly showing the risers extending above the soil and the reinforced cover block over the concrete pits.

2.1.1.5 Other Tank Farm Systems. In addition to the SSTs and DSTs, there are other ancillary systems that are used to support the tank farm operations. These include the double-container receiver tanks (DCRTs), catch tanks, miscellaneous inactive storage facilities (MISFs), transfer lines, and equipment. Descriptions and structural assessments of these structures can be found in Chapters 2.0 and 4.0 , respectively of the TWRS-FSAR (WHC 1996a). This supporting document will not address these ancillary systems.

\subsubsection{Current Tank Farm Operations}

2.1.2.1 General. The TWRS's current operations scope (Baynes et a1. 1993) includes receipt; transfer and segregation of facility waste; waste concentration (evaporator); waste monitoring; waste tank stabilization; moving the tanks into a safe, clean, and interim stable mode; and disposing of all tank waste, including cesium and strontium capsules, as well as all facilities, systems, and components currently used for storing or maintaining the waste. Currently, approximately $136 \mathrm{ML}$ (36 Mgal) of highly radioactive waste is stored in the 149 SSTs, and approximately $95 \mathrm{ML}$ (25 Mgal) is stored 
in the 28 DSTs (Baynes et al. 1993). The scope also includes all additional structures, systems, components, skills, and processes necessary to execute the mission. Highly radioactive liquid wastes generated by other mission areas are included in the scope and will be becomes a TWRS responsibility once the waste is transferred to the farms.

2.1.2.2 Single-Shel1 Tanks. Operations to add waste to the SSTs stopped in November 1980 (Hanlon 1996). The SSTs are now in a long term process controlled in part by the Hanford Facility Agreement and Consent Order [the Tri-Party Agreement (TPA)] between the state of Washington Department of Ecology, U.S. Environmental Protection Agency and DOE (Ecology et al. 1994). Interim stabilization of all SSTs is scheduled for completion by September 2000 based on TPA milestone M-41-00. Interim stabilization is defined as the removal of available free liquid; it is considered achieved when a tank contains less than $190 \mathrm{~kL}(50,000$ gal) of drainable interstitial liquid and less than $19 \mathrm{~kL}(5,000 \mathrm{gal})$ of supernatant liquid. If the tank was jet pumped to achieve interim stabilization, then the jet pump flow must also have been at or below $0.003 \mathrm{~L} / \mathrm{s}(0.05 \mathrm{gpm})$ before the interim stabilization criteria is met. Currentiy, 115 SSTs have been classified as interim stabilized (Hanton 1996).

All of the SSTs must still be maintained in a condition where they continue providing containment until the waste can be transferred to the DSTs or disposed. Although the SSTs are not allowed to receive any additional waste they are still an active part of day-to-day maintenance activities and disposal operations, as we1l as, ongoing monitoring, surveillance and control activities.

2.1.2.3 Double-She11 Tanks. The DSTs and related facilities make up the primary waste management operations at the Hanford Site. Current waste operations result in the storage of waste in the DSTs that includes waste from the Plutonium Uranium Extraction (PUREX) Plant, Z Plant, B Plant, T Plant, 222-S Laboratory, 100 Areas, and 300 Areas. These operations provide for the segregation and concentration of radioactive material contained in liquid waste solutions. Transportation, containment, and processing of radioactive waste requires the performance of many different operations that involve hundreds of specific individual tasks. The DCRTs and catch tanks, including SSTs that are not yet in interim closure status, are part of the operations. Figures 2-8 and 2-9 provide a schematic of the flow of waste during current operations.

Liquid wastes are transferred to and from DSTs tank farm storage, chemical processing facilities, and related operational units (receiver vaults, evaporator/crystallizers). Transfers are made through the interconnected system of buried transfer lines, operating equipment, control/ transfer structures (DCRTs and catch tanks) and associated utilities. The purpose of transfers is to move liquid waste from one location to another in response to loss of tank integrity, processing requirements, changing storage needs, and disposal activities. 


\subsection{HISTORICAL INFORMATION}

Knowing and understanding the history of the Hanford Site waste tank farms is of significance in assessing the structural integrity and potential failure modes of the tank farm structure, system, or component (SSCS). The original design criteria and subsequent effects of aging, high temperatures, corrosion, radiation, etc., on material properties need to be understood. Accidental, normal, or operational loads, that may have resulted in general or localized damage need to be addressed. If these historical criteria and loading conditions can be established with some degree of confidence, the current structural integrity and potential failure modes can be determined.

\subsubsection{Tank Farm Design and Construction}

2.2.1.1 General. As would be expected, the design of waste storage tanks changed over the years. The tank designs began in 1943 as 208-kL $(55,000-g a 1)$ and 2-ML $(533,000-$ gal) SSTs using 21-MPa (3,000-psi) design strength concrete, 276-MPa (40,000-psi) yield strength reinforcing steel, and a welded steel liner having a yield strength of $228 \mathrm{MPa}(33,000 \mathrm{psi})$. When the last tanks were built in 1986, they were 3.8-ML (1-Mgal) DSTs with an outer reinforced concrete tank having a design strength of $34 \mathrm{MPa}(5,000 \mathrm{psi})$, reinforcing steel having a yield strength of $414 \mathrm{MPa}(60,000 \mathrm{psi})$, and a welded steel internal liner having yield strength of $344 \mathrm{MPa}(50,000 \mathrm{psi})$. The internal tank was constructed of welded steel plates also having a yield strength of $344 \mathrm{MPa}(50,000 \mathrm{psi})$ and was stress relieved to reduce any residual stresses due to welding. Tables 2-3 and 2-4 show a break down of each SST and DST farms' design specification, material strength, and years of construction. A summary of these tables is provided in the following two sections.

In addition to changes occurring over the years in the design of the tanks, the design requirements associated with codes and standards also changed as shown in Tables 2-3 and 2-4. For example, when the SSTs were built there were no design requirements for seismic loads, except for the Uniform Building Code (ICB0 1994) which was first published in 1927. However, the Uniform Building Code does not have requirements for buried tanks. Also, the analytical techniques and calculation tools have evolved from classic hand computation methods to highly computerized finite element analys is techniques.

2.2.1.2 Single-Shell Tanks. As noted in Section 2.1.1.2 above, there are four general design types of SSTs in the 149 total SSTs. The SSTs were constructed from 1943 through 1964 with a design service 1 ife of 20 years.

The 200-Series, 208-kL (55,000-gal) SSTs are located in tank farms B, C, $T$, and $U$. These tanks were constructed from 1943 through 1944 and are al 1 identical.

There are five 100-Series Type 1 SST farms (B, 8X, C, T, and U) containing the 2-ML $(533,000$-gal) tanks. Tanks in $B, C, T$, and $U$ tank farms were constructed in 1943 through 1944 from the same drawings. Tanks in the BX tank farm were constructed from 1946 through 1947. All of these tanks have the same geometry with only minor differences in number and sizes of reinforcing bars. 
There are four 100-Series Type 2 SST farms (BY, S, TX, and TY) containing the 2.9-ML (758,000-gal) tanks. These tank farms were constructed from 1947 through 1952 and all are essentially identical.

The remaining three 100-Series SST farms ( $A, A X$, and SX) contain the Type 3 (3.8-ML [1-Mgal]) tanks. The $A$ and SX tank farms were constructed during the years of 1953 through 1955 and the $A X$ tank farm 10 years 1 ater during 1963 though 1964. The newer AX tank farm tanks have several design features different from the tank designs of those tanks in the $A$ and $S X$ tank farms in that the dome radius is larger, the concrete strength is greater, and the steel liner is radiused at the wall to base mat junction.

Table 2-3 shows a break down of each SST farms' design specification, material strength, and years of construction.

2.2.1.3 Double-Shell Tanks. Construction of the 28 DSTs began in 1968 and was completed in 1986. Within each tank farm, all of the tanks are structurally identical; they were constructed from the same drawings. Between the farms, the tank designs are structurally similar with some variations in concrete and reinforcing strength, reinforcement arrangement in the haunch region, and some variation in the base mat design.

Four of DSTs were designated as aging waste facility (AWF) tanks. Aging waste, a neutralized current acid waste, is a high-level, first cycle solvent extraction waste from the PUREX Facility. Although these tanks have a nominal design waste storage capacity of $3.8 \mathrm{ML}$ (1 Mgal) their operational capacity was limited to $3.7 \mathrm{ML}(980,000 \mathrm{gal})$. Two of the AWF tanks are located in the AY tank farm and were constructed from 1968 through 1970 with a service life of 40 years. The other two AWF tanks are located in the AZ tank farm. These tanks were constructed from 1971 through 1977 with a service 1 ife of 20 years.

Three DSTs were constructed in the SY tank farm, six in the AW tank farm, seven in the AN tank farm, and eight in the AP tank farm. All of these tanks had the nominal storage capacity of $4.4 \mathrm{ML}$ (1.16 Mgal), with an operation limit of $4.4 \mathrm{ML}$ (1.14 Mgal) per tank, and a service life of 50 years.

In the first series of DSTs to be built, the 241-AY tank farm, the concrete design strength was $21 \mathrm{MPa}(3,000 \mathrm{psi})$ and reinforcing steel, steel liner, and the primary (internal) steel tank all had a yield strength of $414 \mathrm{MPa}(60,000 \mathrm{psi})$. When the last series of DSTs were built, the 241-AP tank farm, the concrete design strength was $34 \mathrm{MPa}(5,000 \mathrm{psi})$, the reinforcing steel yield strength was $414 \mathrm{MPa}(60,000 \mathrm{psi})$, and the primary tank and liner had a yield strength of $345 \mathrm{MPa}(50,000 \mathrm{psi})$. As noted above, Table 2-4 shows a break down of each DST farm design specifications, material strengths, and years of construction.

\subsubsection{History of Operation}

2.2.2.1 General. In March 1943, construction began on the Hanford Site, where the original mission was to produce plutonium for the world's first atomic weapons. The production of plutonium at the Hanford Site began in 1944 and continued until 1987. Over the last 50 years, numerous activities related to the production of weapons-grade plutonium, various defense missions, and 
research and development generated radioactive waste on the site. Much of this waste was then stored in the SSTs and the DSTs.

Because several plutonium recovery processes have been used at the Hanford Site and because of past practices in tank waste management, the chemical and radionuclide compositions of individual tanks are quite varied. The waste generated by the operations was neutralized with sodium hydroxide and sent to the SSTs and later DSTs for storage. Although the general contents of the 100-Series SSTs is known, because of the many different chemical processes used, combined with radiolytic decomposition, and chemical combination of decay products, etc., the actual distribution of the waste contents were not known in detail. Since that time, a sampling program has been and continues to be ongoing to characterize current tank contents. Detailed results for each SST are given in Supporting Document for the Historical Tank Content Estimate (WHC 1994a-i). These results are summarized in Historical Tank Content Estimate for the Southwest Quadrant of the Hanford 200-West Area (WHC 1994j). Detailed results for each DST are given in Supporting Document for the Southeast Quadrant Historical Tank Content Estimate Report (WHC 1995a-f). These results are summarized in Historical Tank Content Estimate for the Southeast Quadrant of the Hanford 200 Area (WHC 1995g).

2.2.2.2 Single-She11 Tanks. The first SST farms were placed in operation in 1944 and operations continued into the 1970's until the SSTs began being taken out of service due to leakage concerns and increased safety standards. Sixty-four SSTs (16 200-Series and 48 100-Series Type 1 SSTs) were constructed during World War II. By 1946, Tank Farms B and T were full and $U$ and $C$ were almost half full (Gerber 1996). New production demands continued to require more SSTs until 1964 when PUREX's production peaked. As shown in Table 2-3, the last SST farm to be constructed was AX from 1963 to 1964.

The tanks were originally designed for a waste temperature of around 104 to $121^{\circ} \mathrm{C}\left(220\right.$ to $\left.250^{\circ} \mathrm{F}\right)$. Information on waste tanks prior to 1974 was not documented or stored in a consistent and retrievable manner. Hence, much thermal data is now irretrievably lost. Significant data prior to 1974 was only found for four of the 12 SST farms (241-S, $-S X,-A$, and $-A X)$. The existing data shows that 19 of the tanks' waste temperatures exceeded $149{ }^{\circ} \mathrm{C}$ $\left(300^{\circ} \mathrm{F}\right)$, and five exceeded $177^{\circ} \mathrm{C}\left(350^{\circ} \mathrm{F}\right)$ at various times (Huisingh et al. 1994). The other SST farms primarily received wastes resulting from the bismuth-phosphate process. This process produced low heat-generating waste with resultant tank temperatures at or below $93^{\circ} \mathrm{C}\left(200^{\circ} \mathrm{F}\right)$, maximum measured temperatures ranged from 48 to $60^{\circ} \mathrm{C}\left(120\right.$ to $\left.140{ }^{\circ} \mathrm{F}\right)$

(Defigh-Price 1982). 
The SSTs that had waste temperatures exceeding $177^{\circ} \mathrm{C}\left(350^{\circ} \mathrm{F}\right)$ are 1 isted as follows (Defigh-Price 1982):

$\begin{array}{lc}\text { Tank } & \text { Temperature }{ }^{\circ} \mathrm{C}\left({ }^{\circ} \mathrm{F}\right) \\ 241-\mathrm{A}-101 & 204(399) \\ 241-\mathrm{A}-106 & 312(594) \\ 241-\mathrm{A}-104 & 221(430) \\ 241-\mathrm{A}-102 & 216(420) \\ 241-\mathrm{SX}-107 & 199(390)\end{array}$

These high temperatures can degrade the concrete properties of the concrete tanks as discussed later in Section 3.0.

Because the original design life of the SSTs is 20 years, the waste is now being stored in a number of tanks that have far exceeded their original design 1 ife. As many as 67 of the SSTs have (Baynes et a1. 1993), or are believed to have, leaked liquid waste to the underlying soil. It has been estimated that as much as $3.4 \mathrm{ML}(900,000 \mathrm{gal})$ has leaked from the tanks (Hanlon 1996). The leakage is believed to have occurred as a result of high stresses caused by buckling of the liner as a result of rapid temperature changes (Browne11 1958) and nitrate-assisted stress-corrosion cracking (Carlos and Hauptmann 1992, Anantatmula et a7. 1994). Although not confirmed, the buckling induced stresses in combination with the residual stresses due to welding during construction may have been sufficient for the high nitrate concentrations in the waste to induce stress corrosion cracking in the welds.

As a result of tank leakage and new safety standards, a 11 SSTs have now been removed from service (i.e., not allowed to receive additional waste on or after November 21, 1980, as noted above). Today, the SSTs contain various combinations of sludge, salt cake, and drainable liquid. The drainable liquid is that liquid contained within the sludge, salt cake, and residual supernatant heels. Most of the drainable liquid will be pumped to the DSTs to achieve interim stabilization of the SSTs by September 2000.

2.2.2.3 Double-Shell Tanks. As shown in Table 2-4, construction of the DSTs began in 1968 with the last ones being completed in 1986. The DST farms became operational between 1971 and 1986 .

The DSTs have been used to store liquid radioactive waste including transuranics, high-level, low-level, and Hanford Site facility waste. Currently, the DSTs primary function is to support the mission of waste treatment, and disposal. In general the historical operation of the DSTs has been much as it is today, as described above in Section 2.1.2.3. The OSTs have not experienced the high operational temperatures that were experienced by some of the SSTs. The waste temperatures in the DSTs have been within their design limits which are discussed in Section 4.3.3.4. In addition, because there is a $76-\mathrm{cm}(30-i n$.$) annulus between the primary tank and the$ secondary tank, the only location where the waste temperature can be transmitted directly to the concrete is at the base mat. However, the 
base mat concrete is protected somewhat by a $20-\mathrm{cm}$ (8-in.) thick layer of insulating (refractory) concrete with embedded radial, forced-air, cooling channels. Since the DSTs were constructed, the monitoring system in the annulus between the primary and secondary tanks has not detected any leaks from the primary tanks.

\subsection{FUTURE USE}

\subsubsection{General}

The prime function of the SSTs, DSTs, and AWF is to provide a safe containment barrier to prevent the release of waste to the environment. The tanks are to be provided with the necessary equipment to maintain functional integrity and support for the safe operation of the tanks within the farms. The ancillary equipment (e.g., the DCRTs and catch tanks) located within close proximity to specific tank farms will be included in the operational and administrative controls of the tank farm to which it belongs. Long range plans call for continued use of the tanks for interim storage and to have 211 of the waste removed and disposed of by the year 2028 .

\subsubsection{Single-Shel1 Tanks}

The SSTs are being interim stabilized. Those SSTs that have already been interim stabilized are inactive, and all transfer lines that could transfer high-level nuclear waste have been physically isolated from the tanks. For those SSTs that have not been interim stabilized, only the transfer lines into the tanks have been physically isolated from the tanks. Waste retrieval of all SSTs is scheduled for completion by September 2018 per TPA milestone M-45-05 and closure of all SSTs is scheduled for completion by September 2024 per TPA milestone M-45-06. As shown in Figure 2-8, tank farms 241-SX, and 241-S (except for one tank) have been stabilized, i.e., there are no transfer arrows shown.

\subsubsection{Double-She11 Tanks}

The DSTs are still needed in the longer term for storage and pretreatment of waste generated by other mission area cleanup-related work. The DSTs are active and are not physically isolated. Their mission is to support all Hanford Site activities leading to final disposal of all waste. As a result of TPA milestone M-50-00, all DSTs are scheduled to be closed by the year 2028 . 
WHC-SD-TWR-RPT-002 REV 0

This page intentionally left blank. 


\subsection{TANK MATERIAL CONDITIONS}

\subsection{GENERAL}

Tank structural integrity is influenced by the applied loads and the strength of the materials that resist these loads. In order to make an assessment of the structural load carrying capability, the condition of the structural materials must be established. The original design criteria and subsequent effects of aging, high temperatures, corrosion, radiation, etc., on material properties must be evaluated. This chapter discusses the material conditions of the tank structures.

\subsection{CONCRETE MATERIAL}

\subsubsection{SST Design Compressive Strength}

As shown in Table 2-3 the specifications for all of the SSTs called for concrete with a design compressive strength of $21 \mathrm{MPa}(3,000 \mathrm{psi})$ for the entire tank (dome, base mat, and walls) except for SSTs 241-AX which have a design compressive strength of $28 \mathrm{MPa}(4,000 \mathrm{psi})$.

\subsubsection{DST Design Compressive Strength}

In the case of the DSTs, Table 2-4 shows that the specifications for the first two tank farms built (241-AY and 241-AZ) called for a design compressive strength of $21 \mathrm{MPa}(3,000 \mathrm{psi})$. For tank farms 24l-SY and 241-AN, the specifications called for a design compressive strength of $31 \mathrm{MPa}(4,500 \mathrm{psi})$. For the remaining two DST farms (241-AW and 241-AP) the specifications ca17ed for a design compressive strength of $34 \mathrm{MPa}(5,000 \mathrm{psi})$ for the tank domes and walls and $31 \mathrm{MPa}(4,500 \mathrm{psi})$ for the base mat.

\subsubsection{Aging Effects}

Aging effects consist of material degradation mechanisms due to temperature, radiation, and corrosion over time. There are many factors that could cause the tank structural material to degrade. These factors include heat and chemical attacks generated from the waste. over a long period of time this degradation of the structural material could be significant and the structural integrity and useful life could be compromised. Therefore time is an important factor in the material degradation process. However, without the effects from elevated temperature exposure or chemical attack, the strength of concrete usually increases with age. It will enhance the structural load carrying capability beyond the specified design compressive strength. In practice designs the added strength of the concrete due to aging is rarely considered. For the structural evaluations of existing concrete tank structures the increased strength of the concrete due to aging can be considered an added factor of safety. Degradation effects due to temperature and corrosion are discussed in the following sections. 


\subsubsection{Temperature Effects}

Reinforced concrete structures are affected by temperature in two ways: material property degradation and the introduction of thermal stresses.

In general, the exposure of concrete to temperatures greater than 21 or $27{ }^{\circ} \mathrm{C}\left(70\right.$ or $80^{\circ} \mathrm{F}$ ) has a degrading effect on the physical properties of the concrete. However, for constant exposure at temperatures up to 66 or $93{ }^{\circ} \mathrm{C}$ (150 or $200^{\circ} \mathrm{F}$ ), the loss in strength is quite small; and for temperatures as high as 260 or $316{ }^{\circ} \mathrm{C}\left(500\right.$ or $\left.600{ }^{\circ} \mathrm{F}\right)$ for short periods of time, the degradation in structural properties is ordinarily tolerable (Davis 1967). The loss in strength for specimens of concrete subject to wide and frequent fluctuations in temperature has been observed to be two or three times as great as for constant exposure to high temperature, depending upon the severity of the thermal cycle or thermal shock (Davis 1967).

In addition to strength reduction, at elevated temperatures concrete experience certain other changes. These changes include reductions in the modulus of elasticity, changes in Poisson's ratio, and increased creep rate. Several test programs and studies (Davis 1967, Gillen 1978, Henager et al. 1988, and RHO 1982a) have been performed to investigate the effects of high temperature exposure on Hanford concrete. Test data were obtained from the tests of concrete specimens fabricated in the Portland Cement Association (PCA) laboratories using aggregates from the same source used in the construction of the Hanford Site waste storage tanks; core samples taken from the concrete dome of the 241-A, 241-T, and 241-U tanks, and from the wal1 of Tank 241-SX-115. Figures $3-1$ and $3-2$ show a cross section schematic of Tank 241-SX-115 and the drilling caisson used to obtain the wall samples.

Test data relating Hanford concrete property degradation to time at temperature were generated from controlled laboratory tests (PNL 1979 and PCA 1981). The database was used to establish concrete degradation equations as a function of time, temperature, and concrete strength (Henager et a1. 1988). The PCA test data for modulus of elasticity, compressive strength, and splitting tensile strength were generated from constant temperature tests with the following testing conditions:

- Temperatures: $121,177,232{ }^{\circ} \mathrm{C}\left(250,350\right.$, and $\left.450{ }^{\circ} \mathrm{F}\right)$

- Initial nominal strength: 21 and $31 \mathrm{MPa}(3,000$ and 4,500 psi)

- Time at temperature: 3 to 1,300 days.

The resulting best-estimate equations developed by Henager et al. (1988) for calculating the degraded properties of the Hanford concrete at elevated temperatures are shown below:

$$
\begin{aligned}
E_{c}= & 5.3947+0.1233 S-0.06751 T-0.1786 \ln (t+1) . \\
f_{c}= & 4416.338+490.919 S-4.714 T A-230.241 \ln (t+1) \\
& +1.273 \mathrm{~TB} \ln (t+1) .
\end{aligned}
$$




$$
\begin{gathered}
\text { WHC-SD-TWR-RPT-002 REV } 0 \\
f_{\text {st }}=448.1758+23.7436 s-0.6077 \text { TA }-18.4341 \ln (t+1)
\end{gathered}
$$

where

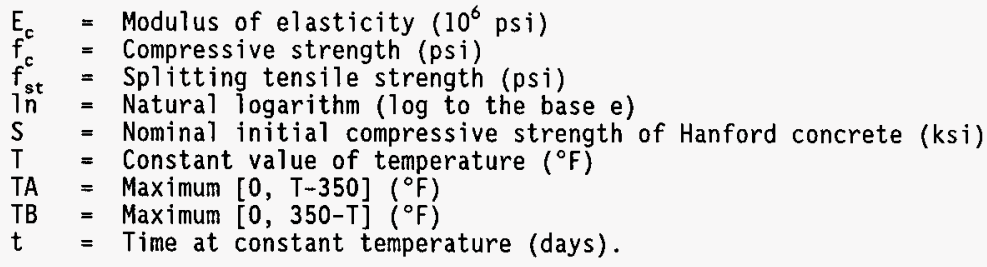

Henager et al. (1988) also provided confidence and tolerance bands for the above best-estimate equations. To allow for uncertainties in the PCA data and fitting process, Henager recommends that the uncertainty expressions (confidence and tolerance bands) be used in place of the best-estimate equations.

The above property degradation equations are empirical mathematical expressions established from the PCA laboratory test data for Hanford concrete. Note that data from core sample tests were not part of the database used to establish the above concrete property degradation equations. This is to be expected because the thermal history of the core sample specimens is not controlled.

Based on the adequacy of fit of the above equations to the PCA test data and the theoretical support for only gradual continual degradation of the concrete properties with long-term exposure to elevated temperatures from 121 to $232{ }^{\circ} \mathrm{C}\left(250\right.$ to $\left.450^{\circ} \mathrm{F}\right)$, Henager concluded that extrapolation to 50 years through application of the above equations is "reasonable." That is, the greatest percent reduction in strength and elastic modulus occurs over a relatively short time period during the initial exposure to the elevated temperature. This initial time period of greatest reduction in concrete properties decreases with increasing temperature. The subsequent reduction continues at a significantly reduced rate over long exposure times.

Earlier thermal analyses used the SAFECRACK (Rashid 1976) computer program in which a different set of concrete degradation equations were used. However, a comparison of the SAFECRACK equations with the PCA data indicated that the SAFECRACK predictions were close to the bulk of the data for concrete compressive strength of $21 \mathrm{MPa}(3,000 \mathrm{psi})$ and $31 \mathrm{MPa}(4,500 \mathrm{psi})$, and temperatures of 121,177 , and $232{ }^{\circ} \mathrm{C}\left(250,350\right.$, and $450^{\circ} \mathrm{F}$ ) (Henager et a 1.1988 ). However, the simplified form of these earlier SAFECRACK concrete degradation equations was not considered adequate for extrapolation out to 50 years from a statistical standpoint. This lead to the development of the Equations $3-1,3-2$ and $3-3$ which provide a better fit to the data thus allowing a more justifiable extrapolation. 
As discussed in Section 2.2.2.2, the SSTs were originally designed for a waste temperature of around 104 to $121{ }^{\circ} \mathrm{C}\left(220\right.$ to $\left.250^{\circ} \mathrm{F}\right)$. Existing data shows that at various times in the past 19 of the SSTs' waste temperatures exceeded $149^{\circ} \mathrm{C}\left(300^{\circ} \mathrm{F}\right)$ and five exceeded $177^{\circ} \mathrm{C}\left(350^{\circ} \mathrm{F}\right)$ (Huisingh

et al. 1994). In most cases these high temperatures only occurred for short periods of time. The worst case temperature occurred in Tank 241-A-106 which had once reached a peak waste temperature of $31{ }^{\circ} \mathrm{C}\left(594{ }^{\circ} \mathrm{F}\right)$ and had waste temperatures exceeding $204{ }^{\circ} \mathrm{C}\left(400^{\circ} \mathrm{F}\right)$ for approximately 2 years.

Temperatures in the concrete structures are lower than the waste temperatures. The highest temperatures in the concrete structure occur at the bottom center of the tanks and decrease radially along the base mat toward the outside wall and decrease vertically along the wall toward the dome. The above equations are based on test data that is within the temperature range experienced in the concrete structures but does require an extrapolation in time. The effects of elevated temperature on the concrete properties of the SSTs were considered in their structural analyses and are discussed in Chapter 4.0.

The DSTs have been operating at temperatures below their design temperatures. Because the thermal load is generated from the waste which is stored in the primary steel tank, the temperatures in the secondary reinforced concrete tank would be considerably lower than the waste temperature due to the annulus space between the two tanks. Based on the specified limits on operating temperatures for the DSTs and that these limits have not been exceeded, significant material property degradation of the concrete is not expected.

More recently, Kassir et a1. (1993) reviewed the effects of elevated temperature on the properties of concrete over a temperature range from ambient to $315^{\circ} \mathrm{C}\left(600^{\circ} \mathrm{F}\right)$. Kassir presented upper and lower bound curves for the residual (percent of initial value) compressive strength and elastic modulus of concrete as a function of temperature. There is a large variation in the results depending on a number of inherent variables that affect the behavior of concrete. These results are not specific to the Hanford concrete as they include test data from a greater variety of test conditions and concrete mix parameters.

In Moore and Peterson (1995), constitutive models for concrete and the effects of temperature on the behavior of concrete are reviewed further. Specific guidance is provided on strength and modulus degradation factors on the bases of a reassessment (Peterson 1994) of the Hanford concrete test database. Peterson (1994) developed an alternate approach in correlating the test data in order to address several limitations in the Henager correlation method. Although, the resulting correlations developed by Peterson are less general (only apply to specific discrete temperatures) and did not include the $232{ }^{\circ} \mathrm{C}\left(450{ }^{\circ} \mathrm{F}\right)$ test data, they appear to reflect a better representation of the test data. The degradation equations are expressed as degradation ratios measured relative to the undegraded property values. The correlations address short term and long term property degradation separately. The resulting compressive strength correlation is consistent (within about $\pm 6 \%$ ) with the Henager (1988) correlation. However, the elastic modulus correlation deviates more significantly from the Henager correlation. The Henager correlation systematically predicts a lower elastic modulus (about 50\% lower) than is predicted by Peterson's correlation. 
These conflicting results indicate a need to rigorously reassess the avajlable test data and methods of data correlation in order to establish a high confidence concrete property degradation correlation with exposure time at elevated temperatures. As pointed out in Moore and Peterson (1995), there is also a large variation in the creep behavior of concrete at elevated temperatures which needs to be addressed systematically for application to the Hanford waste storage tanks.

\subsubsection{Corrosion Effects}

The mechanisms responsible for the degradation of the high-level waste storage tanks were investigated (Schwenk 1992, Edgemon and Anantatmula 1995). The concrete could be degraded by aggressive chemical attack, leaching of calcium hydroxide, and reactions of aggregates and alkalis. However, these types of degradation are usually in small, localized areas and are considered insignificant to the overall concrete structural integrity. In the presence of acidic solutions, chemical attack can also increase the porosity and permeability of concrete, reduce its alkalinity, and subject it to further degradation which can result in reduced compressive strength and stiffness.

To ensure the safe storage of the waste, the SSTs were evaluated for continued service as part of DOE Waste Tank Evaluation Program (AR-005-10-02-G) (Kaar 1981). The test program was conducted to provide an estimate of the relative durability of reinforced concrete specimens exposed to a simulated Hanford waste solution with specified normality concentration $(\mathrm{N})$. The simulated Hanford waste solution composition consisted of $7 \mathrm{~N}$ sodium hydroxide, $3 \mathrm{~N}$ sodium nitrate, $3 \mathrm{~N}$ sodium nitrite, $2 \mathrm{~N}$ sodium aluminate, $0.1 \mathrm{~N}$ sodium chloride, $0.2 \mathrm{~N}$ sodium carbonate, $0.5 \mathrm{~N}$ sodium sulphate, and $0.1 \mathrm{~N}$ sodium fluoride (Kaar 1981). Test sections of concrete specimen were cast using aggregates from the same source used for Hanford waste storage tanks. The 91-cm- (36-in.-) long, 23-cm- (9-in.-) deep, 30-cm- (12-in.-) wide concrete specimens were reinforced with three \#4 deformed bars. The tests were conducted for compression and flexural specimens under the specified Toads and were exposed to the simulated waste solution in an oven at $82{ }^{\circ} \mathrm{C}$ $\left(180^{\circ} \mathrm{F}\right)$. The testing times varied from 3 months to 3 years. No evidence of reinforcing steel corrosion attack was observed. Although the solution reached the reinforcing steel of the flexural specimens during exposure, no changes in the reinforcing steel were found. Physical testing of the reinforcement indicated no effect from the exposure agent. Petrographic examination of the concrete showed no evidence of adverse reactions between the solution and the concrete (Karr 1981). Corrosion of reinforcing steel is discussed further in Section 3.3.4.

\subsubsection{Radiation Effects}

Potential degradation of concrete exposed to neutron and/or gamma radiation is manifested in many ways. Fast and slow neutrons usually cause aggregate expansion, decomposition of water, and thermal warming of concrete. Gamma radiation affects the cement paste portion of the concrete, producing 
heat and causing water migration. The degradation, due to nuclear heating and water loss from resulting temperature increase, is more serious than degradation associated with direct radiation damage. Degradation of concrete due to thermal effects is discussed in Section 3.2.4.

\subsection{REINFORCING STEEL}

\subsubsection{Strengths}

The design of reinforced concrete structures has been based on working stress and 41 timate strength methods. In the case of working stress design, the allowable design stress in the steel is $40 \%$ of the yield strength. For ultimate strength design, load factors are used and the allowable design stress in the steel is the yield strength. The reinforcing steel used in the tank structural design consists of two basic grades, Grade 40 and Grade 60 . Grade 40 steel has a minimum yield strength of $276 \mathrm{MPa}(40,000 \mathrm{psi})$ and Grade 60 has a minimum yield strength of $414 \mathrm{MPa}(60,000 \mathrm{psi})$.

\subsubsection{Aging Effects}

Aging effects on the steel could be caused by corrosive mechanisms over a long period of time. Degradation of the strength and physical properties of the steel from time alone are not significant. Corrosion effects on the steel are discussed in Section 3.3.4.

\subsubsection{Temperature Effects}

The yield strength of steel is reduced if subject to a high temperature environment. The strength-temperature relation varies with type of steel. However, within the operating temperature ranges of the waste storage tanks the reduction in strength for the steels of interest is small.

\subsubsection{Corrosion Effects}

Corrosion of steel only occurs when oxidation is allowed to take place. The oxidation is accelerated if significant amounts of moisture are present.

The Hanford Site is an arjd climate and averages only about $20 \mathrm{~cm}$ ( 8 in.) of precipitation annually (PNL 1995). In addition, the water table at the 200 East and West Areas is about $92 \mathrm{~m}(300 \mathrm{ft})$ below the surface. Thus, the tanks are located in a very dry environment.

When reinforcing steel is $\mathrm{placed}$ into concrete forms, specifications are required for a certain amount of protective concrete cover between the concrete surface and the reinforcement (ACI 1994). This cover is required to 
prevent oxidation of the reinforcing steel due to atmospheric or ground moisture. Thus, when reinforced concrete is in contact with a high humid environment, more cover is required. However, when properly designed and constructed, corrosion of the reinforcing steel does not occur uniess cracks in the concrete develop due to loads or differential displacements.

Corrosion could occur at the cracked sections of the concrete but it would be in small and localized areas. This potential, localized corrosion of the reinforcing steel would not cause the overall tank structural integrity to be compromised.

If the steel liner is damaged due to corrosion from the waste material, the reinforced concrete could be exposed to the waste solution attack. If the reinforcing steel is corroding, the corrosion products will typically fill a greater volume than that of the original metal. This will subject the concrete to additional stresses, which can eventually cause cracking of the concrete. Such a process can continue until the reinforcing steel is exposed directly to the corrosive environment, leading to rapid loss of structural strength and integrity. As discussed in Section 3.2.5, a lab test program was conducted on the effects of waste solution on the Hanford concrete. Examination of the reinforcing steel showed no evidence of rusting, cracking, or disruption of the mill scale on the steel. In addition, no differences were observed in load-strain plots of the reinforcing steel tested before and after exposure to the simulated waste (Figure 3-3) (Kaar 1981).

Based on the above discussion it is concluded that the SST reinforcing steel has not likely experienced significant strength degradation as a result of corrosion.

\subsection{STRUCTURAL STEEL LINERS}

\subsubsection{General}

The primary steel tank of the DSTs and secondary steel 1iner of the SSTs are subjected to corrosion due to the waste stored in tanks. The corrosion assessment draws its conclusion from laboratory studies, 1 iterature data, waste chemistry information, and some in-tank corrosion coupons. Little direct evidence of corrosion in the tanks is available.

\subsubsection{Single-Shell Tank Specifications}

The design specifications called for the steel liners of SST farms 241-B, $-C,-T,-U,-B X$, and $-A X$ to have a yield strength of $227 \mathrm{MPa}(33,000 \mathrm{psi})$.

The steel liner design specifications are unknown for tank farms 241-TX, -BY, $-S,-T Y,-S X$, and $-A$; however, at the time there were basically two grades of structural steel, one having a yield strength of $165 \mathrm{MPa}(24,000 \mathrm{psi})$ and one having a yield strength of $227 \mathrm{MPa}(33,000 \mathrm{psi})$. 


\subsubsection{Double-She11 Tank Specifications}

The design specifications for DSTs call for a steel primary tank and secondary tank 1 iner for tank farms 24l-AY and -AZ to have a yield strength of $221 \mathrm{MPa}(32,000 \mathrm{psi})$; tank farm SY to have a yield strength of $241 \mathrm{MPa}$ $(35,000 \mathrm{psi})$; and tank farms 24l-AW, -AN, -AP to have a yield strength of $345 \mathrm{MPa}(50,000 \mathrm{psi})$.

\subsubsection{Aging Effects}

Aging effects of the steel liner is the same as for reinforcing steel (see Section 3.3.2).

\subsubsection{Temperature Effects}

The temperature effects on the stee 1 iners is the same as it is on the reinforcing steel. However, while the material properties are not significantly affected by the temperatures that are within the operating ranges, the thermal stresses could have significant effects to the steel structures. Thermal stresses due to operating temperatures are discussed in Section 4.0.

\subsubsection{Normal Corrosion Effects}

Normal corrosion is defined as the corrosion due to water or moisture other than the waste materials. Normal corrosion is considered to have insignificant effects to the tank materials. Corrosion on the exterior face of the steel liner could be caused by moisture penetrating through the concrete wall. However, because the steel liner is protected by the secondary concrete wall, such corrosion is highly unlikely.

\subsubsection{Waste Corrosion Effects}

Carbon steels were used as the primary barriers of the nuclear waste stored in the underground tanks. Exposure to service conditions can cause degradation of these materials, manifested by loss of strength, loss of ductility, cracking, thinning, pitting, buckling, etc. Evaluations of degradation mechanisms of the steel and concrete materials of the major Hanford Site waste tank systems (Edgemon and Anantatmula 1995) and DST remaining useful life analyses (Abatt et al. 1995, Anantatmula and Ohl 1996) have been performed. The degradation mechanisms of SSTs and DSTs, and remaining useful 1 ife of DSTs were evaluated by examining the effects of past and current operating conditions, waste chemistries, high-heat loads, soil conditions, and in-situ mechanical loads. The most likely scenarios for failures of SSTs and DSTS were identified (Anantatmula et al. 1994, Edgemon and Anantatmula 1995). 
3.4.7.1 Most Likely Scenario for SST Failure. Nitrate-induced stress corrosion cracking is considered the primary threat to the integrity of SSTs due to the interaction between uninhibited waste and residual fabrication stresses in the heat affected zone of the carbon steel plate. The evaluation assumed that the principal cause of failures in the SSTs is stress corrosion cracking (Anantatmula et al. 1994).

3.4.7.2 Remaining Useful Life of SSTs. The corrosion degradation of the carbon steels, particularly SSTs, is manifested in either of two ways: (1) localized reductions in thickness and localized growth of throughwall flaws from pitting corrosion, stress-corrosion cracking, and possible crevice corrosion; and (2) a general reduction in liner thickness from uniform corrosion which as concluded in the evaluation is an improbable failure mechanism. In addition, it was concluded that stress-corrosion cracking probably occurred early in the life of most of the SSTs, mainly in weld heat affected zones (Anantatmula et a1. 1994).

In general, the carbon steel tanks, particularly the SSTs, may have sustained corrosion damage. Some of the SSTs probably sustained through-wall stress-corrosion cracks first, then sustained equally damaging pitting attack and general corrosion due to the increasing chemical concentration from stabilization of the waste. The DSTs also may have suffered localized corrosion attack and possibly uniform corrosion in the vapor phase regions. The DSTs have not leaked probably because of their improved design, required post-weld thermal stress relief, better control of waste chemistry, exposure to less severe thermal conditions.

The detail waste composition history of the SSTs is unclear. A significant number of fillings, retrievals, intermixing, and ex-tank evaporations and subsequent returns of a slurry-like mix occurred for a number of different wastes and it is not possible to accurately estimate the species and their distribution in the SSTs (Babad 1993). The nature and amount of waste tank species cannot be clearly identified and quantified at this time. An on-going waste sampling program is underway to characterize the current waste composition within the SSTs. Initial results are summarized in Historical Tank Content Estimate for the Southwest Quadrant of the Hanford 200-West Area (WHC 1994j). However, a clear estimate of possible corrosion mechanisms, and resulting damage, cannot be made at this time. Thus it remains possible, particularly since stabilization of the SSTs, that aggressive corrosion mechanisms could be acting (Wodrich et al. 1992). In summary, as many as 67 of the SSTs (Baynes et al. 1993) are known or assumed to have leaked significant amounts of liquid waste to the surrounding soil. The corrosion effects on the rest of the SSTs could be very severe and the remaining useful life is diminishing. As discussed in Section 2.2.2.2, all SSTs have now been removed from service.

\subsubsection{Most Likely Scenario for DST Failure. Localized pitting and} concentration cell corrosion caused by the formation of localized regions of aggressive waste are the most threatening degradation mechanisms identified. In general, the evaluation (Edgemon and Anantatmula 1995) concluded that the 
DSTs are appropriately designed if waste chemistry is appropriately controlled in accordance with specifications. Maintaining waste chemistry control requires periodic monitoring since the organic chemicals in the tanks age and consume both caustic and nitrite beneficial additives.

3.4.7.4 Remaining Useful Life of DSTs. Corrosion mechanisms that could degrade DST structural integrity have been identified and their potential as failure mechanisms discussed (Schwenk 1992, Edgemon and Anantatmula 1995). Future in-tank mixing may lead to erosion-corrosion; rates as high as $4 \mathrm{mil} / \mathrm{yr}$ have been estimated (Smith 1992). The DST corrosion database was developed from a relatively wide range of initial DST waste types and test conditions (Divine 1984). However, certain limitations exist such as lack of vapor-phase data, local variations of the composition near the bottom, and weldmentcontaining corrosion data. These limitations reduce the capability to accurately estimate present and future DST integrity and projected 1 ifetimes.

The Anantatmula and 0h1 (1996) study of the DSTs remaining useful life, estimated that the existing DSTs would not likely fail before the scheduled completion of waste retrieval from DSTs in the year 2028. Three models, based on controllable parameters (temperature, chemistry, and relative humidity), were presented for estimating the year in which the primary tank of a particular DST might breach due to pitting in the liquid or vapor region. The estimates for tank breach range from the year 2056 for pitting corrosion in the liquid region of tank 241-AW-104 to beyond the next millennium for pitting corrosion in the vapor region for several tanks (see Table 3-1). 


\subsection{TANK STRUCTURAL INTEGRITY FOR DESIGN LOADS}

\subsection{HISTORICAL LOAD CRITERIA}

\subsubsection{General}

The design criteria for structures, systems, and components (SSCs) at the Hanford Site have been defined in the Hanford Plant Standards. The specific standard relating to the design of tanks at the Hanford Site was the Standard Arch-Civil Design Criteria-Design Loads for Facilities (SDC 4.1) ${ }^{1}$. This standard has been in existence since revision 0 was published in April 1957 and, until recently, revision 12 was being followed to comply with DOE Order 6430.1A (DOE 1989). Prior to the issuance of the SDC 4.1, there was no general standard for design. More recently, WHC-CM-1-12, Design and Evaluation - Structural Design and Evaluation Criteria is being developed to comply with DOE Order 5480.28 (DOE 1993a), now DOE Order 420.1 (DOE 1995). This latter document refers to all of the DOE standards that are to be used to define the evaluation requirements in determining the structural integrity of the tanks.

\subsubsection{Single-Shell Tanks}

The earliest document found on the SSTs that discusses tank design loadings was Structural Evaluation-Underground Waste Storage Tanks (Edgar 1955). However, except for discussing the specific gravity of the tank waste and vapor pressure no other load cases were specifically presented. The tank dome design and temperature effects on the concrete were discussed but no design loads were given. According to Ramble (1983), explicit design criteria for the SSTs do not exist; nor do original design calculations for any operational and/or environmental conditions. Some post-construction evaluations were performed at various times confirming structural adequacy of certain tanks for the operational and environmental loads. Results of these evaluations are discussed in Section 4.5.2.

\subsubsection{Double-She11 Tanks}

When the DSTs construction started in 1968, the Hanford Plant Standards were in place and Standard Arch-Civil Design Criteria-Design Loads for Facilities (SDC 4.1) specified design loads of dead, live, thermal, pressure, wind, earthquake, and lateral earth pressure. The wind loads were for surface structures and were not applied to the tanks. The earthquake load was specified as $0.25 \mathrm{~g}$ peak horizontal ground acceleration. At the time of the

\footnotetext{
'SDC 4.1 has been superseded by GC-LOAD-01 effective March 15, 1996. However, GC-LOAD-01 does not change the technical requirements of SDS 4.1 , Rev. 12 and hence for this document SDC 4.1 will be referenced for convenience.
} 
DST design, this specified earthquake load was considered a safe shutdown earthquake load and the tanks were considered Category I structures. The original design calculations of DSTs and post-construction structural evaluations performed for certain tanks against operational and environmental loads are discussed in Section 4.5.3.

\subsection{CURRENT LOAD CRITERIA}

For the design of new and the evaluation of existing facilities for natural phenomena hazards, DOE has established performance categorization guidelines that establish load criteria. These guidelines are contained in DOE-STD-1021-93, Natural Phenomena Hazards Performance Categorization Guidelines for Structures, Systems, and Components (DOE 1993b). As defined in these guidelines, there are four performance categories. The performance category a SSC falls in determines the level of rigor required of the analysis or evaluation, and expected performance.

\subsubsection{Tank Evaluation Criteria}

4.2.1.1 Existing Criteria. The design criteria used at the Hanford Site have been changed several times in the past. The Hanford Plant Standard SDC 4.1 was originally issued in April 1957 and had been used for structural design and evaluation sitewide. SDC 4.1, revision 12 was issued in September 1993 and is the current criteria at the time of this evaluation. SDC 4.1, revision 12 is in compliance with DOE Order 6430.1A, Genera7 Design Criteria (DOE 1989). In accordance with DOE Order 6430.1A, the methods for evaluating loading intensities and design acceptance of the structural response to the natural hazard phenomena of earthquake, wind, and flood are outlined in the University of California Research Laboratory UCRL-15910, Design and Evaluation Guidelines for DOE Facilities Subjected to Natural Phenomena Hazard (LLNL 1988). The design requirements for non-reactor facilities subjected to natural phenomena hazard loads are specified in UCRL-15910 using "facility usage categories." Four usage categories are presented: (1) General Use, (2) Important/Low Hazard, (3) Moderate Hazard, and (4) High Hazard. For design purposes and application of these criteria, the design loads for facilities have been separated by safety class designation. For non-reactor facilities, four safety classifications of SCCS are defined, one for each of the UCRL-15910 usage categories. SDC 4.1, revision 12, uses safety class designation in accordance with the UCRL-15910. These requirements are contained in Nuclear Facility Safety Analysis Manual (WHC-CM-4-46).

4.2.1.2 Future Criteria. In January 1993 the DOE Order 5480.28, Natural Phenomena Hazards (NPH) Mitigation (DOE 1993), was issued. This order and its required standards contain a11 of the requirements for the design of new SSCS and the evaluation of existing SSCs. For design purposes and compliance of DOE Order 5480.28, the design loads and acceptance criteria for SSC s are required to be correlated to the performance category (PC) designation which is different from the designations of the safety class (SC) per Nuclear Facility Safety Analysis Manual (WHC-CM-4-46). However DOE Order 5480.28 has not been fully implemented for use on the Hanford Site. WHC is preparing a new Level 2 controlled manual, WHC-CM-1-12, Design and Evaluation - Structural Design and Evaluation Criteria, that represents the WHC site interpretation of 
the requirements in DOE Order 5480.28. This document will be released upon approval by DOE-Headquarters of the new Hanford Site seismic hazard analysis.

This report is prepared on the basis of SDC 4.1 , revision 12 . However, the new requirements given in the DOE Order 5480.28 are also discussed.

4.2.1.3 Safety Class and Performance Category Correlation. As discussed in Section 4.2.1, various design criteria designations exist in the current and previous DOE orders. The correlation among safety class designations in the various standards and the performance categories is shown in Table 4-1.

\subsection{EVALUATION LOADS}

\subsubsection{General}

The type of tank loadings and their corresponding definitions in this report follow American Society of Civil Engineers (ASCE), ASCE 7-88, Minimum Design Loads for Buildings and other Structures (ASCE, 1990), that is used by DOE-STD-1020-94 (DOE 1994). ASCE 7-88 defines four categories of loading: (1) dead loads, (2) live loads, (3) soil and hydrostatic pressure loads, and (4) environmental loads.

\subsubsection{Dead Loads}

Dead loads comprise the weight of all permanent construction, including walls, floors, roofs, ceilings, stairways, and fixed service equipment, plus the net effect of pre-stressing. For the tanks, this definition includes the reinforced concrete, the steel liners, and risers. The unit weight of the reinforced concrete and steel liners are shown below. The weight of the risers are negligible compared to the concrete and steel.

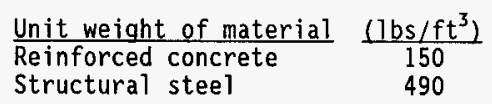

The dead load does not change during the life of the structure unless there is a modification of the structure's configuration.

\subsubsection{Live Loads}

Live loads are those loads produced by the use and occupancy of the building or other structure. For the tanks, this definition includes loads that might be applied to a tank from various activities (e.g., movable equipment and other loads that vary in intensity and occurrence). Live loads, 
in this case, also include what is often defined as a separate load, operating loads. Thus, live loads can be internal or external to the tanks. The external live loads are concentrated loads, such as a single crane on the surface, and uniform loads, such as snow or ash on the ground surface.

The internal loads are loads that change based on plant equipment and operation. In the case of the tanks, these loads are hydrostatic, thermal, internal pressures, and equipment.

4.3.3.1 Concentrated Loads. A concentrated load of $90 \mathrm{t}$ ( 100 tons) has been used in evaluation of the SSTs and a concentrated load of $45 \mathrm{t}$ (50 tons) was used for the evaluation of the DSTs. These concentrated loads are due to the assumed weights of cranes that would be required for lifting heavy equipment on top of the dome. The foot print area of the concentrated loads for both SSTs and DSTs is assumed to be $6 \mathrm{~m}(20 \mathrm{ft})$ in diameter. The difference in the concentrated loads for SSTs and DSTs are due to assumptions of crane weights that were used in the original design and evaluations.

In addition to the crane loads, heavy equipment such as mixer pumps need to be considered. Currently a test mixer pump weighing approximately $9,072 \mathrm{~kg}$ $(20,000$ lbs) exists in Tank 241-SY-101. Mixer pumps with varied weights may be placed in other tanks in the future. Load evaluations will be made prior to the field installation of the pumps.

4.3.3.2 Uniform Loads. No uniform load is specified for SSTs (Dougherty 1994). The uniform load is $1.9 \mathrm{kPa}$ (40 psf) for all DSTs (Heubach 1994) including aging waste facility (AWF) tanks 241-AY and -AZ (Aguirre 1994) although AWF tanks were originally analyzed for $4.8 \mathrm{kPa}$ (100 psf).

4.3.3.3 Internal Hydrostatic Loads. The hydrostatic loads inside the tanks are caused by the liquid waste. The hydrostatic pressures is a function of the height of the liquid free surface relative to the point of interest below the waste and the waste specific gravity which varies from tank to tank. The tanks were designed for a maximum design height of 1 iquid and a maximum design specific gravity value. The original specific gravities established for each SST farm are shown in Table 4-2. Over the years of operation, waste materials in certain tanks have changed from liquid to sludge or crust. Current Operational Safety Requirements (OSR) safety limits on the maximum specific gravity for the waste materials and waste levels are shown in Table 4-3, grouped by tank farms.

4.3.3.4 Thermal Loads. The thermal loads are caused by heat generated by the operation. In the case of the tanks, this load is generated by the radiation induced heat from the waste. The amount of heat applied to the tanks varies based on the chemistry of the waste, the changing level of waste, the amount of water injected into the waste for cooling, and the ventilation system. Elevated temperatures affect the tank structure in the following three areas: (1) thermal stresses in the structural members due to high temperature gradients and differential thermal expansion between the concrete and steel; (2) thermal creep of the structural members as a result of the long-term high 
temperature effect; and (3) structural material degradation due to high temperature exposure and the cyclic heating and cooling process. The structural behavior under thermal load is rather complex and is discussed in Section 4.5. The maximum waste temperatures for structural design are $177^{\circ} \mathrm{C}$ $\left(350^{\circ} \mathrm{F}\right.$ ) for a11 SSTs (WHC 1995h). The maximum waste temperatures for DSTs are $121{ }^{\circ} \mathrm{C}\left(250^{\circ} \mathrm{F}\right)$ for $241-\mathrm{AN},-\mathrm{AW},-\mathrm{AY}$, and $-\mathrm{AZ}$ tanks; $99^{\circ} \mathrm{C}\left(210^{\circ} \mathrm{F}\right)$ for 241-AP tanks; and $121{ }^{\circ} \mathrm{C}\left(250^{\circ} \mathrm{F}\right)$ for $241-S Y$ tanks. Current operating limit temperature for SSTs is $149^{\circ} \mathrm{C}\left(300^{\circ} \mathrm{F}\right)$. The operation limits for DSTs are $93{ }^{\circ} \mathrm{C}\left(200^{\circ} \mathrm{F}\right)$ maximum for $241-\mathrm{AN}$, - AW, and -SY tank farms; $82{ }^{\circ} \mathrm{C}$ (180 $\left.{ }^{\circ} \mathrm{F}\right)$ for 24l-AP tanks; and $149^{\circ} \mathrm{C}\left(300^{\circ} \mathrm{F}\right)$ maximum for AWF $241-A Y$ and $-A Z$ tanks (WHC 1995i).

4.3.3.5 Internal Pressure Loads. The internal pressures resulting from vapor space pressures vary with the waste levels in the tanks. For evaluation purposes, the internal pressure loads are enveloped within a range from -3.7 to $+15 \mathrm{kPa}(-15$ to +60 in. w.g.) for all tanks (Dougherty 1994, RHO 1978).

\subsubsection{Soil and External Hydrostatic Pressure Loads}

Soil loads on the tanks are the soil overburden on the top of the tank and lateral pressures along the outside of the tank wall. The soil loads are functions of the soil backfilling placement procedures during construction and depend on placement, compaction, and soil properties such as cohesion and friction angle.

External hydrostatic pressure loads are defined by ASCE 7-88 (ASCE 1990) as those pressures that result when a portion or the whole of the structureadjacent soil is below a free-water surface. In such cases, computations shall be based on the weight of the soil diminished by buoyancy, plus full hydrostatic pressure. Because of the Hanford Site semiarid climate, and the water table being $92 \mathrm{~m}(300 \mathrm{ft})$ below the surface, there is no need for consideration of this external hydrostatic pressure case.

Soil densities and depth of overburden backfills differ at various tank farms, The soil densities at various tank farms range from 1,762 to $2,002 \mathrm{~kg} / \mathrm{m}^{3}$ (110 to $\left.125 \mathrm{lb} / \mathrm{ft}^{3}\right)$. The depth of soil overburden at the apex of the tanks is 1.5 to $3 \mathrm{~m}$ (5 to $10 \mathrm{ft}$ ) for SSTs and 1.8 to $2.5 \mathrm{~m}$ (6 to $8.1 \mathrm{ft}$ ) for DSTs. A summary of the soil density and depth of overburden for each tank farm is provided in Table 4-4.

\subsubsection{Environmental Loads}

Environmental loads consist of wind loads, snow loads, rain loads, earthquake loads, flood load, and volcanic ashfall loads.

4.3.5.1 Wind Loads. The wind load can be caused by down burst, extreme straight winds, and tornadoes. However, since the waste tanks are buried underground, wind loads are not applicable; except for above ground facilities such as ventilation system including high-efficiency particulate air (HEPA) fi]ters. 
According to the Hanford Plant Standard SDC 4.1, the fastest-mile wind speed to be used for developing the extreme wind load at the Hanford Site is a straight wind of $145 \mathrm{~km} / \mathrm{h}(90 \mathrm{mph})$ at a height of $10 \mathrm{~m}(33 \mathrm{ft})$. The importance factor to be used in the wind load calculations is 1.0 and Exposure Factor is $\mathrm{C}$. The horizontal missile generated by the design wind speed is a $2 \times 4$ timber plank with a weight of $7 \mathrm{~kg}(15$ lbs) at $22 \mathrm{~m} / \mathrm{s}(50 \mathrm{mi} / \mathrm{h})$ and maximum trajectory height of $15 \mathrm{~m}(50 \mathrm{ft})$.

4.3.5.2 Snow Loads. Snow loads for the area are based on the Hanford Plant Standards SDC 4.1. A uniform load of $960 \mathrm{~Pa}(20 \mathrm{psf})$ is to be used for snow load calculations in accordance to ASCE 7-88 (ASCE 1990).

4.3.5.3 Rain Loads. As intended by the authors of ASCE 7-88, rain loads are those roof loads caused by heavy rains and do not consider ponding or flooding. Neither Hanford Plant Standard SDC 4.1 nor ASCE 7-88 specify rain loadings. However, in the structural evaluation, it is assumed that rain load is equivalent to the snow.

4.3.5.4 Earthquake Loads. The Hanford Site is located in the Pasco Basin in the Intermontane Plateau Physiographic Province. The site is an area of low magnitude seismicity that has been instrumentally monitored since 1969 . Seismotectonic studies were completed for the design and construction of the Fast Flux Test Facility. These studies culminated in a site-specific seismic design response spectra anchored at $0.25 \mathrm{~g}$ peak horizontal ground motion (Figure 4-1). The Fast Flux Test Facility was not licensed by the U.S. Nuclear Regulatory Commission; however, the U.S. Nuclear Regulatory Commission did review the final safety analysis report.

The Fast Flux Test Facility seismic design criteria were incorporated into the Hanford Plant Standards, "Architectural-Civil Design Criteria," SDC 4.1, revision 6 , in November 1973. The seismic design criteria given in the SDC 4.1 were used for seismic qualification of safety-related equipment and facilities at the Hanford Site until September 9, 1989 when the SDC 4.1 was revised to incorporate the design guidance of DOE Order 6430.1A (DOE 1989). A graded approach to the design of DOE non-reactor facilities was recommended, based on the hazard level of the facility. The postulated seismic load for a high-hazard facility is equivalent to the 5,000-year earthquake and, for a moderate hazard, is equivalent to the 1,000-year earthquake. A median Newmark and Hall spectral shape was recommended by the DOE design guidance.

A probabilistic seismic hazard study was completed for the various facility locations on the Hanford Site (Tallman 1989) to determine the 5,000and 1,000-year ground motions. Revision 11 of SDC 4.1 incorporated the DOE guidance and the results of the seismic hazard study. The response spectra for high- and moderate-hazard facilities are anchored to $0.2 \mathrm{~g}$ and $0.12 \mathrm{~g}$ peak horizontal ground motion and are illustrated in Figures $4-2$ and $4-3$, respectively. 
During 1993, the DOE-RL transmitted DOE Order 5480.28, Natural Phenomena Hazards (NPH) Mitigation (DOE 1993), to WHC for compliance. The order includes stringent new NPH criteria for the design of new facilities and the evaluation and upgrade of existing DOE facilities. The order requires that the facilities be classified into performance categories as discussed in Section 4.2.

In 1995 DOE issued DOE Order 420.1, Facility Safety (DOE 1995). This order contains the same NPH requirements as DOE Order 5480.28. It will supersede DOE Order 5480.28 when the effective date is established through contract revision. Seismic peak ground acceleration values for the current and tentative future implementation of DOE Order 5480.28 (or equivalent) seismic design criteria are shown in Table 4-5.

As discussed in Section 4.2.1.2 the tank farms are classified as Performance Category 3 (PC-3) facilities per DOE Order 5480.28. The corresponding Design Basis Earthquake for the tank structures located in the 200 Area of the Hanford Site is $0.26 \mathrm{~g}$ peak free-field horizontal ground acceleration. However, for existing SSCs that cannot meet this requirement, they may be evaluated for a seismic hazard exceedance probability of twice the recommended value for new SSCS in accordance with DOE-STD-1020-94 (DOE 1994). For existing SSCS located in the 200-Area of the Hanford Site this corresponds to a peak ground acceleration of $0.19 \mathrm{~g}$.

4.3.5.5 Flood Loads. There are two types of flooding that must be considered as defined by DOE-STD-1020-94 (DOE 1994), regional floods (i.e., river flooding) and local precipitation that effects roof design and site drainage.

The 200 East and West Areas where the tanks are located are on a plateau. This area of the Hanford Site is located above the highest elevation that would be reached by Columbia River flood waters during the probable maximum flood. Flood scenarios have also been reported for seismically induced failures of upriver dams on the Columbia River. Maximum flood water elevations for these scenarios are also below the elevation of the plateau. Thus, regional flooding is not a load case that needs to be considered.

Although no studies have been conducted to date to determine the likelihood of intense precipitation to cause severe flooding at the site, the 1.9-kPa (40-psf) live load the tanks are designed for would handle up to $18 \mathrm{~cm}$ (7.2 in.) of water. It would be unlikely to accumulate this much water over a tank since there are no dikes to prevent runoff.

4.3.5.6 Ashfall Loads. Volcanic ashfall is an expected natural phenomenon loading in the same category as extreme wind and earthquake. As specified in the Hanford Plant Standard SDC 4.1, revision 12, the design ashfall load is $1.15 \mathrm{kPa}$ (24 psf). 


\subsection{TANK LOAD GROUPING}

As discussed in Sections 2.1.1.2 and 2.1.1.3, the SSTs were grouped into four types and the DSTs were grouped into one type when discussing their general design features. In addition, there were two other distinct groupings, an SST grouping and a DST grouping. When determining the structural stability or failure modes to a particular load case, the evaluations, in a number of cases, can be limited to considering the response of a single SST or a single DST. However, because of the way the tanks were operated (some tanks have experienced higher waste temperatures than others and differences in waste composition affect the maximum load that can be generated under postulated accident conditions), it is impossible to state that the conditions for lose in structural stability or failure will be the same for all SSTs or for all DSTs. To analyze each and every tank for their own unique characteristics and the multitude of normal and accident loadings would be an enormous task that, based on the overall tank similarities, would not lead to a better understanding of tank performance under load. Thus, the tanks are placed in one or more groups in an attempt to group those tanks most similar depending on tank design, operating condition, and tank content.

\subsection{TANK STRUCTURAL EVALUATION}

\subsubsection{Tank Grouping}

For the evaluation of the tank structures subject to the normal operating and environmental loads as described in Section 4.3, the tanks are grouped into SSTs and DSTs based on the construction configuration of the tanks.

\subsubsection{Structural Evaluation of Single-Shell Tanks}

As described in Section 2.1.1.2, the SSTs consist of four different types based on capacity. The 200-Series SSTs were constructed of $6 \mathrm{~m}(20 \mathrm{ft})$ diameter reinforced concrete cylinder with a flat base mat and top cover. The 100-Series SSTs were constructed as a reinforced-concrete cylindrical shell with an inside diameter of $23 \mathrm{~m}(75 \mathrm{ft})$, a base mat, and an ellipsoidal dome. The capacities of the 100-Series SSTs vary with the height of the wall. All SSTs are lined with a carbon steel liner along the wall and the base mat.

Because the project plan does not include the engineering task of new structural analysis, the structural evaluation of the SSTs are based mainly on the results from previous work. As a result of a document search, the original design criteria and calculations were not found during the course of this structural assessment process. However, several reports were found that provided structural evaluations of the tanks. These reports were prepared for various purposes at various times during the operation of the tanks. The SST structural assessment contained herein was made on the basis of these existing 
documents. In order to minimize the repetition of outlining the findings from each of these existing reports, representative evaluations are discussed in the following sections. These representative evaluations of the SSTs include:

- Load Sensitivity Study. This report performed tank structural analyses on a broad basis that covered all SSTs by grouping the tanks in accordance with the geometry and capacity of the tanks. It is the only complete overa1l tank structural evaluation among all existing engineering reports for the SSTs.

- Analysis of Underground Waste Storage Tanks 241-AX. This report demonstrated detailed analytical techniques and loading considerations for the 3.8-ML (1-Mgal) tanks. It provides more specific information related to the structural analysis/evaluation process.

- Tank 241-C Structural Integrity Evaluation. This is the most recent structural analysis for a SST. Thorough assessments were made for the stresses of the tank structure, material properties, and safety margins under various loading conditions.

- U1timate Load Test of a 1/10th-Scale Model. A reinforced concrete model test was performed. This model test provided real structural behavior under the testing loads. Valuable information obtained from this test provided a good reference for the assessment of the structural integrity that was performed by the analytical approach.

4.5.2.1 Load Sensitivity Study. The most recent and complete investigation of the structural adequacy of the SSTs is reported in the Single-Shell Waste Tank Load Sensitivity Study (Ramble 1983). In this report, sensitivities of the tank structural behavior for both the 100- and 200-Series SSTs under various loads and load combinations were studied. Forces and bending moments of critical sections of the structural elements were compared against code allowables.

Each type of tank was analyzed for soil, equipment, hydrostatic, and thermal loads. The sensitivity of the structural behavior of the particular tank to each of the loads was determined by varying each load, one at a time, and calculating the resulting stresses. The margins of safety for each of the loads were also evaluated. The resultant stresses were then combined with the additional stresses predicted for a $0.25 \mathrm{~g}$ peak ground acceleration earthquake. Load combinations and design allowables used in the study were based on SDC 4.1 and ASME Section III, Division 2 of the ASME Boiler and Pressure Vessel Code.

Load sensitivities were investigated for the SSTs by both hand calculations and finite-element computer analyses. 


\section{A. Loading Cases}

Various loads were applied to the tank structures. These loads include the following loads: live loads, soil loads, hydrostatic loads, thermal load, and the seismic load. To obtain a clear understanding of the sensitivity of the tank structural behavior to the various loads, several increments of the live loads and soil depths were applied to the computer model in the structural analysis. Stress levels resulting from each increment of the load cases were evaluated and adequacy of the structural integrity of the SSTs was assessed.

- Live Loads. Live loads considered were $100,000,200,000$, and 400,000 lbs acting on a $30 \mathrm{ft}$ diameter circle over the center of the tank dome.

- Soil Loads. Soil loads were increased in increments of height above the dome at $6,15,25$, and $30 \mathrm{ft}$ as measured at the apex of the tank until dome or wall fai]ure stresses were reached. The unit soil weight was $115 \mathrm{lb} / \mathrm{ft}^{3}$; the lateral active soil pressure coefficient was 0.4 (Shannon \& Wilson 1974)

- Hydrostatic Load. The hydrostatic load cases consist of an empty tank and full tank at maximum design capacity. The specific gravity of the liquid waste was 2.0.

- Thermal Load. Three different analytical computer programs were used for the investigation of the thermal effects on the 200 -Series SSTs (75 ft diameter waste storage tanks). Each program has an unique capability in predicting the structural behavior of the tanks under thermal loads. These three computer programs are ANSYS (ANSYS 1982), SAFECRACK (Rashid 1980), and NONSAP-C (NONSAP-C 1978). ANSYS is a general purpose finite element computer program that has the capability of stress analysis of the steel and concrete structures. SAFECRACK is a finite element program developed for the non-linear analysis of the reinforced concrete structures to predict time-dependent stresses, displacements, and cracking mechanism. NONSAP-C is a finite-element structural analysis program developed to handle non-linear structural analysis problems involving time-dependent creep and time-dependent cracking in reinforced concrete structures. Thermal input data to each of the computer programs for the structural analysis vary according to its purpose and limitations.

Structural Analysis by ANSYS: Two thermal cases were considered: the ambient temperature in an empty tank and a $50,000 \mathrm{Btu} / \mathrm{h}$ heat load in the tank for 30 years (Campbell 1981). These thermal loads were combined with the other mechanical loads and seismic load to determine a worst case for the structural evaluation.

Structural Analysis by SAFECRACK: The tanks were analyzed for 
two different temperature distributions consisting of a maximum operating temperature distribution and a recorded, worst case, temperature distribution.

The maximum operating temperature distribution assumed a hot base of $387^{\circ} \mathrm{F}$, a fairly steep thermal gradient in the lower cylindrical wall, no thermal gradients through the tank haunch and dome, and a dome centerline temperature of $266^{\circ} \mathrm{F}$. This temperature distribution was obtained by a steady-state heat transfer analys is considering $26 \mathrm{ft}$ of waste contents with a heat generation of $0.265 \mathrm{Btu} / \mathrm{h}-\mathrm{ft}^{3}$. A surrounding soil conductivity of $0.2 \mathrm{Btu} / \mathrm{h}-\mathrm{ft}-{ }^{\circ} \mathrm{F}$ was used. A detailed temperature distribution for the inner face of the 24l-SX tank is shown in Figure 4-4. A time-temperature history over a period of approximately 26 years was also assumed to envelop the variations of the waste temperatures during the long term operation (Figure 4-5).

The worst-case temperature distribution was based on actual thermocouple measurements of Tank 241-A-106, which between 1963 and 1966 reached a peak waste temperature of $594^{\circ} \mathrm{F}$ and had waste temperatures exceeding $400^{\circ} \mathrm{F}$ for about 2 years. The thermal history of this tank is shown in Figure 4-6. This temperature distribution considered a maximum vertical wall temperature of $511^{\circ} \mathrm{F}$ just above the footing. The maximum vertical wall gradient was $112^{\circ} \mathrm{F} / \mathrm{ft}$ adjacent to the top $1.8 \mathrm{ft}$ of sludge resulting in a vertical gradient on the inside surface of $78.2^{\circ} \mathrm{F} / \mathrm{ft}$. The horizontal gradient was $2.1^{\circ} \mathrm{F} / \mathrm{ft}$ in the wall for a total differential temperature of $49.8^{\circ} \mathrm{F}$.

The thermal profiles evaluated for these scenarios were believed to be bounding in both maximum temperature and rates of change. The mathematical instability of the earlier thermal analysis models limited the thermal analyses in both the detail of the thermal histories and the rates of temperature application. More recent analyses have both better modeling tools and faster computers to complete more analyses in a shorter time. There are currently some outstanding thermal issues that have not been addressed related to the fill and drain cycling. These concern the through wall thermal gradients and the damage incurred to the upper wall sections of the single shell tanks from these high differential temperatures and high rates of temperature change. Mathematical models currently tried to date have not had the ability to accurately model these thermal conditions. The recommended means of evaluating this is identified in Section 6.0 .

The behavior of concrete under elevated temperature depends upon the magnitude and time history of the temperature. The analytical representation of the concrete's behavior is in the form of time-and temperature-dependent material property parameters, such as: creep strain, elastic modulus, ultimate compressive strength, tensile cracking strength, hardening modulus, poisson's ratio, and the plastic volume change parameter. In the structural analysis, equations for the calculation of key material properties (i.e., elastic modulus, compressive strength, splitting tensile 
strength, and creep strain) used in the SAFECRACK computer program was modified to include the results of experimental data determined by the PCA (Henager 1988).

Structural analysis by NONSAP-C: The 1 iquid waste in the tank is assumed to vary from 200 to $400{ }^{\circ} \mathrm{F}$ for $100+$ years. The assumed reference temperature (stress-free temperature for the concrete tanks) is $75^{\circ} \mathrm{F}$. The thermal history assumed that the concrete tank bottom center line exhibits the highest temperatures. The tank bottom temperature varies from $215^{\circ} \mathrm{F}$ at time zero to a peak value of $460^{\circ} \mathrm{F}$, then decreases to approximately $155^{\circ} \mathrm{F} 100$ years later. The concrete wall temperature rises to about $245^{\circ} \mathrm{F}$ for 1 year, increase to $380^{\circ} \mathrm{F}$ in 11.5 years, and then decrease to about $145^{\circ} \mathrm{F}$ in 100 years. The dome experiences the smallest thermal loading, rising to $150^{\circ} \mathrm{F}$ for 1 year, then increasing to $204^{\circ} \mathrm{F}$, and substantially decreasing below $125^{\circ} \mathrm{F}$ by the 100 year mark.

The peak temperature distribution for this analysis is assumed $460^{\circ} \mathrm{F}$ along the bottom base, $205^{\circ} \mathrm{F}$ along the dome, and an uniform gradient up the wall of about $8.5^{\circ} \mathrm{F} / \mathrm{ft}$ (Shippell 1980).

Seismic Load: The peak horizontal ground acceleration is $0.25 \mathrm{~g}$ and the corresponding vertical ground acceleration is $2 / 3$ of the horizontal acceleration. The tank structural seismic analysis was performed by utilizing AXIDYN (EERC 1969) and FLUSH (EERC 1975) computer programs. The results of this analys is were combined with those of the thermal-creep (SAFECRACK) analyses. The combined forces and bending moments were checked against the axial force and bending moment interaction diagrams ( $P-M$ Diagram) which were constructed from code allowables of the reinforced concrete sections. A typical P-M Diagram is shown in Figure 4-7.

\section{B. Findings of the Load Sensitivity Study}

- 200-Series SSTs. The results of the structural analysis indicate that the effects of the hydrostatic load are negligible. The stresses in the reinforced concrete structural members due to various normal operating loads are well within the code allowables. The overall structural integrity of these tanks have been found to be structurally adequate for the soil overburden, hydrostatic loads and seismic loads due to a $0.25 \mathrm{~g}$ peak ground acceleration. Since these tanks have never been subjected to elevated temperatures, the degradation of the concrete properties due to temperature does not affect the 1 ife of the structure.

- 100-Series SSTs. Two types of the SSTs were investigated in detail: the 3.8-ML (1-Mgal) and the 2-ML (533,000-gal) capacity tanks. The tank geometry of the 2.9-ML $(758,000-g a 1)$ capacity tanks differs from the other two types only in wall height and thickness. Also, the results of the tank analyses show very little difference between the 2-ML $(533,000-\mathrm{gal})$ and $3.8-\mathrm{ML}$ 
(1-Mgal) tanks; therefore, the 2.9-ML (758,000-gal) tanks are considered to be bounded by the other two types of tanks.

Results from the computer analyses indicate that the thermal and soil loads have the greatest effect on the structural integrity of the tanks, and that equipment, or live loads and hydrostatic loads have the least effect. The analyses treated a variety of thermal histories and heating rates. A summary of the input data for the thermal-creep and ultimate load analyses is shown in Table 4-6. These input data varied from maximum wall temperatures ranging from $250^{\circ} \mathrm{F}$ for 241-BY SSTs to $511^{\circ} \mathrm{F}$ for 241-A SSTs, heating rates from $2.9^{\circ} \mathrm{F} /$ day for $241-A X$ SSTs to $48.4^{\circ} \mathrm{F} / \mathrm{day}$ for 241-A SSTs and lengths of creep analys is from 15 days for 241-A SSTs to 3,752 days for 241-SX SSTs. The safety factor against the failure due to soil load at the end of the creep period is approximately 3.0 for all tanks. Based on the plot of the interaction diagram of the axial force and bending moment of the various concrete sections of the tanks it is found that the combinations of the seismic stresses and those calculated from the thermal-creep analyses are well within the code allowable limits.

As previously described the worst-case temperature distribution was obtained from actual thermocouple measurements of Tank 241A-106. A thermal-creep analysis was performed for this tank. Using the finite element model the tank was heated from ambient temperature at $75^{\circ} \mathrm{F}$ to maximum temperature in four time steps of 3-day duration each. Soil and live loads were kept at base load values for the first four steps, after which the soil load factor was increased to 3.0. Minor cracks of the concrete occurred in the haunch and lower wall area. Reinforcing steel stresses were below yield except for the four bottom elements where the wall connects to the base mat. It is concluded from the results of this analys is that the tank withstood this worst-case temperature distribution satisfactorily.

4.5.2.2 Tanks 241-AX Evaluations. In addition to the load sensitivity study described above several other structural evaluations for the SSTs were also performed at various times during the past. Most of these structural evaluations were performed in the $1960^{\prime}$ s and 1970's. Findings of these reports were either used or referenced in the Single-Shell Waste Tank Load Sensitivity Study (Ramble 1983) as described in Section 4.5.2.1.

A thermal-creep analys is was performed for the 241-AX tanks and the analytical approach, as part of the entire tank structural analysis, is described as follows:

Structural analysis of 241-AX tanks: The 241-AX SSTs were analyzed to assess their ability to withstand all credible load conditions during their use (RHO 1978). The purpose of the evaluation was to determine the combined effects of long-term dead, live, and thermal loads and the earthquake ground motions on the tank structures. In this report the stresses induced by the applied loads were combined with the results of a thermal-creep analysis in order to assess 
the overall adequacy of the structure.

Loadings considered in the analysis consist of gravity load, hydrodynamic loads, and seismic loads. A finite element model was established (Figure 4-8) and AXIDYN computer program was used.

- Dead, Live, and 0perating Loads. In this analysis, the dead and live loads were considered as gravity loads consisting of weight of a) 1 tank components, the weight of the waste with a specific gravity of 2.0 to a height of $9.29 \mathrm{~m}$ ( $30 \mathrm{ft} \mathrm{5-5/8} \mathrm{in.)} \mathrm{above} \mathrm{the} \mathrm{tank}$ bottom, an equipment load of $90 \mathrm{t}$ (100 tons) over a $9-\mathrm{m}(30-\mathrm{ft}$ ) diameter area at the crown of the tank above the ground surface, and an overburden soil cover of $2.4 \mathrm{~m}(8 \mathrm{ft})$ at the crown with an unit weight of $1151 \mathrm{~b} / \mathrm{ft}^{3}$. The operating loads include vapor pressure above the waste material, thermal, and creep effects. The vapor pressure was specified as ranging between -6 in. to +60 in. of water. Thermal load and creep effects are discussed in the thermal load subsection following the seismic load.

- Seismic Load. The seismic analysis was conducted in two parts. In one part, the interaction of the empty tank with the surrounding soil was considered; in the other, the effect of the sloshing liquid on the tank was examined. In this dynamic analysis, the time history of the responses was computed for the soil-tank finiteelement model subjected to a horizontal ground motion of $0.25 \mathrm{~g}$ and a vertical ground motion of $0.167 \mathrm{~g}$ with a damping factor of $5 \%$.

The motion of the tank under seismic excitation will cause sloshing of the liquid waste, resulting in hydrodynamic pressures on the tank. Hydrodynamic pressures were computed as input data for the finite-element model of the structural analysis.

- Thermal Load. In thermal analysis the temperature distribution, which varied from about $230^{\circ} \mathrm{F}$ on some regions of the dome outer surface to $350^{\circ} \mathrm{F}$ at the base was imposed in 20 increments extending over a heating period of 100 days. This gave a maximum heating rate of $2.85^{\circ} \mathrm{F} /$ day from a base temperature of $65^{\circ} \mathrm{F}$.

The therma1-creep analysis which covered a period of 2,000 days in the following sequence: mechanical loading at time zero, 100-day heating period, steady-state to 2,000 days followed by an increase of the mechanical loading (soil overburden plus live 10 ad) to $500 \%$ of the design values. The end of the 2,000-day period established the stationary creep and cracking condition of the structure, and the last load phase would determine the residual safety factor against the cracking condition of the structure. The tanks were initially analyzed for the soil overburden, lateral soil pressures, and the prescribed live loads. The tank was then analyzed for the thermal loading and continued to a point that stationary creep and cracking conditions were established. The tank was finally analyzed for seismic and hydromechanical loads, taking into consideration the cracking pattern in the tank due to the previous loading condition. The ultimate reserve capacity of the concrete section beyond the gravity and thermal-creep loads was evaluated in the form of reserve 
axial force-moment interaction diagrams.

- Summary of Findings for the 241-AX SSTs. Twelve sections in the concrete tank wall and dome were chosen for constructing the axial force-moment interaction diagrams (P-M Diagrams) (Figure 4-9). These sections include longitudinal, circumferential, cracked, and uncracked sections. The properties and stresses of the concrete sections are given in Table 4-7, including the initial thermal-creep stresses $(2,000$ days) in the steel and concrete and the total additional moments and forces from the seismic and hydromechanical analyses. Force-moment interaction diagrams were constructed and structural members were checked. By checking the forces and moments calculated for the chosen sections against the P-M interaction diagrams, it was found that all points lie within the boundaries of the respective curves (Figures 4-9 through 4-16) (RHO 1978). The maximum stresses in the steel liner (Table 4-8) and thermal-creep stresses in the steel liner (Table 4-9) indicated that all sections have adequate capacity under the established loading conditions.

4.5.2.3 Tank 241-C Evaluation. Another important structural evaluation is the Tank 241-C-106 structural integrity evaluation (Julyk 1994). This report is the culmination of tasks to characterize the in situ condition of tank C-106; these tasks include a historical review of related design documents, a thermal-history simulation, a material-property degradation simulation, and an assessment of the structural capacity. The quantitative demonstration of structural adequacy for all loading conditions to which the tank has been subjected during its lifetime was assessed. A time-history creep analysis based on the temperature-distribution history and fill-anddrain cycles was performed to establish the in situ condition of the tank. The in situ structural integrity is demonstrated by applying the design-byanalysis methodology to the provisions of ACI 349-90, Code Requirements for Nuclear Safety-Related Concrete Structures (ACI 1990). The reserve strength of the tank in its degraded state is determined by a nonlinear collapse-load analysis for a uniform surface load over a $10-\mathrm{ft}$ radius about the center of the tank. This load is increased until the dome offers little or no resistance to additional load. Calculations reported are for best-estimate and for lower-bound concrete materials as developed from the statistical evaluation of the Hanford-specific concrete test data of core specimens taken from tank farms 24l-A, -T, and $-U$ (Gillen 1978), PUREX Canyon Building, 202A (Abrams and Gillen 1981, Gillen 1982), and Tank 241-SX-115 (Defigh-Price 1984). The assessments were based on tank structure conditions predicted for 45 and 55 years of operating service (from 1947 to 1992 and 2002, respectively). The structural analys is included the surrounding soil, concrete cracking, thermal creep, and structural property degradation resulting from exposure to the predicted high-temperature service history for 
the tank. A 55-year upper-bound thermal history was developed and applied conservatively to the structural analysis to establish the 1992 and 2002 in situ structural conditions. The results of the evaluation demonstrated that the structure is adequate for the in situ load conditions with significant reserve load capacity (Julyk 1994).

4.5.2.4 Ultimate Load Test of a 1/10th-Scale Model. A 1/10th scale model of the 3.8-ML (1-Mgal) SST (24l-A tank farm) was constructed and tested to failure under incrementally increasing static compressive loading simulating the soil overburden load supported by the dome (ARH 1969). The model was instrumented extensively with strain gages and deflection gages. Prior to the final static load test sequence the model was subject to a $38^{\circ} \mathrm{C}\left(100^{\circ} \mathrm{F}\right)$ through wall thermal gradient that induced extensive cracking. The model was tested to failure at a compressive pressure of $259 \mathrm{kPa}\left(5,4001 \mathrm{bf} / \mathrm{ft}^{2}\right)$ including dead weight of concrete dome. At the ultimate load condition spalling was evident from both inside and outside surfaces in the wall region adjacent to the haunch. This test demonstrated that the reinforced concrete tank has a factor of approximately 4 against failure, i.e., cracking and spalling near the haunch region of the tank structure. The equivalent soil overburden for the failure mode is about $13.7 \mathrm{~m}(45 \mathrm{ft})$ high as measured at the apex of the tank dome while the operating limit for the soil overburden at the apex of the dome of the SSTs is $3 \mathrm{~m}(10 \mathrm{ft})$. Considerable safe margin exists for the normal operating conditions of the SSTs.

4.5.2.5 Structural Assessment of SSTs. As described in Sections 4.5.2.1 and 4.5.2.2, the structural integrity of the SSTs was evaluated by the analytical approach. Findings presented in the reports demonstrated that the SSTs have ample safety margin against the applied loads which include dead load, live load, operating load, and seismic load. Resultant stresses in various structural components are all within the code allowable limits. Based on these analytical data it can be concluded that the structural integrity of the SSTs will not be compromised under any of the defined loads for the normal operating condition. The force-moment interaction diagrams constructed for the reinforced concrete sections showed that the structure has sufficient reserve capacity to resist the seismic load. Thermal-creep is a important factor that would affect the tank structural integrity in long term high temperature condition. However, the analyses have used degraded concrete properties in the calculations and the results showed that the all stresses are within the code allowable limits.

In the Single-Shell Waste Tank Load Sensitivity Study, a time-temperature history for a period of approximately 26 years was assumed. During this period several heating-cooling cycles were postulated. Also, in the Tank 241-C-106 structural integrity evaluation as described in Section 4.5.2.2 the thermal analysis considered the fill and drain cycle of the waste. The thermal effects to the structure due to heating and cooling cycles were investigated. Combined stresses due to mechanical loads and thermal loads are found acceptable. However, the thermal transient associated with the moving boundary of the free surface of the waste level as the waste level rises and falls along the tank wall was not addressed. 
Cracks at the lower portion of the wall and haunch region are expected. However, the tank structure is not predicted to fail or collapse due to the design loads or the operating loads.

\subsubsection{Structural Evaluation of Double-Shell Tanks}

All DSTs have similar features and configurations and are considered as the same type. In order to ensure the safe operation of these tanks, several post-construction structural evaluations have been performed. Stress analyses were conducted for various loading conditions of the tanks. Some analyses were performed for the general tank structural evaluation and some for the specific purposes such as seismic qualification, hydrogen mitigation, and mixer pumper installation. Several reports are found to have very detailed and valuable information that can be used for the assessment of the structural integrity of the DSTS. Following is a brief description of the loads and findings that were presented in these reports.

4.5.3.1 Existing Structural Analyses for Double-Shell Tanks. Several existing structural reports for the DST evaluations were reviewed. The analyses that were performed for the 241-AW and 241-SY tanks are considered representative because of their scope of evaluation and completeness of loading consideration. In addition, an accelerated safety analys is for the tank structures is discussed in this section.

A. Structural Analysis of 241-AW. The structural analyses for the 24l-AW were performed to evaluate the design criteria and the structural integrity of the underground waste storage tanks (JABE 1976a, JABE 1976b, and RHO 1978). Loads, analytical techniques, and results are described in the following subsections. There are six tanks in this farm and these tanks are also identical to tanks in the 241-AZ and -SY tank farms. All DSTs provide dual containment for the liquid waste.

The purpose of this evaluation was to determine the combined effects of long term dead, live, and thermal loads and the earthquake ground motions on the tanks.

An axisymmetric finite-element model of the secondary concrete tank with the surrounding soil was used for the computer analysis. The axisymmetric finite-element model of the tank with the surrounding soil consists of shell and solid elements. The soil-tank model was used for the dynamic analysis of the tank-soil interaction during an earthquake and static analysis under gravity loads. The soil boundary was at $61 \mathrm{~m}(200 \mathrm{ft})$ below grade, and $91 \mathrm{~m}$ $(300 \mathrm{ft})$ from the axis of symmetry. A separate axisymmetric finite-element model without soil was used for the analysis of the primary steel tank.

The tank structural integrity was investigated by three analyses:

- Dynamic Analysis. The interaction of the tank with the surrounding soil and the effect of the sloshing liquid on the tank. It is assumed that the responses of the tank to these two earthquakeinduced phenomena are not coupled and may be computed separately. The time history of response was computed for the soil tank finite 
element model subject to a time history of earthquake motion at its base. The design earthquake has been specified as a time history of free-field ground motion at the surface. The equivalent safe shutdown earthquake motions at the base of the soil-tank model were computed by a deconvolution procedure.

- Gravity Analysis. Same model used in the dynamic analysis was used in the analysis of gravity loads which include dead, live, and soil.

- Nonl inear Thermal-Creep Analys is of the Concrete Tank. A finiteelement model of the tank and dome, including the secondary steel liner was used for this analysis.

The following loads were considered in the analysis:

- Gravity Load. Wejght of tank and soil, liquid weight (3.8 ML [1 Mgal]), specific gravity 2.0), live load on surface (1.9-kPa [40-psf]) uniform load and a concentrated $10 \mathrm{ad}$ of $45 \mathrm{t}$ (50 tons) at central region of the axis of symmetry).

- Hydromechanical Load. Acting on the primary steel tank which then transfers them to the surrounding soil through connections to the concrete tank dome and base slab which provides the rigid support of the steel tank. Hydromechanical load consists of the following two types of pressures:

- Hydrostatic pressure - Specific gravity is assumed 2. Vapor pressure ( $+60 \mathrm{in}$. and $-6 \mathrm{in}$. of water vapor pressure)

- Hydrodynamic pressure - It is assumed that the tank is rigid; the liquid is nonviscous, incompressible, and homogenous; the displacement, velocities, and slopes of the free surface of the liquid are all small; and flow field is irrotational.

- Thermal Load. It was assumed that the reference temperature was $21{ }^{\circ} \mathrm{C}\left(70^{\circ} \mathrm{F}\right)$; liquid temperature was $177^{\circ} \mathrm{C}\left(350^{\circ} \mathrm{F}\right)$ for a long period of time. The base plate and most of the cylindrical wall region of the primary steel tank that is in direct contact with the liquid will reach and remain at the same temperatures as that of the liquid.

Concrete is subject to creep under sustained loading, especially under elevated temperature conditions.

- Seismic Load. Horizontal peak ground acceleration is $0.25 \mathrm{~g}$, vertical ground acceleration is $0.167 \mathrm{~g}$, and $5 \%$ damping factor. A synthetic free-field ground acceleration time history correlated to the safe shutdown earthquake design response spectrum developed by URS/John A. Blume \& Associates and was used in the dynamic analyses. 
WHC-SD-TWR-RPT-002 REV 0

The seismic analysis consisted of two parts: Interaction of the empty tank with the surrounding soil and effect of the sloshing liquid on the tank. Coupling between the liquid motion and the tank motion was assumed to be negligible because the frequency differences of the two motions are large. This assumption was considered conservative.

- Summary and Conclusion. Stresses in the primary tank are within their allowable values. The stresses in concrete and rebar of the concrete tank are also within their respective allowable values with the exception of a few localized areas. The structure integrity in the regions where these stresses exceed the allowable stresses is not compromised. The center of the dome may show some slight increase in deflection but there are redundant load carrying paths in the frame bending action of the haunch and the lateral confinement provided by the passive pressure of the soil that were neglected in these original analyses that have been identified in subsequent analyses. The increased flexural bending in the footing results in a little greater soil pressure directly below the wall but does not jeopardize the support of the wall and dome structure.

Cracking in the dome and upper wall region of the concrete tank is expected under thermal and creep loads. Satisfactory reinforcement exists to limit this cracking.

Thermal-creep analysis results indicated possible local buckling in the secondary 1 iner in the haunch area. The analytical procedures used in the report (RHO 1978) are summarized as follows:

- Material Properties. The discussion of the equations for concrete material properties used in the thermal-creep analys is is provided in the RHO 1978. Material properties of steel 1 iner and reinforcement are shown in Table 4-10.

- Loading Conditions. Steady-state temperature distribution with temperatures ranging from $94^{\circ} \mathrm{C}\left(202^{\circ} \mathrm{F}\right)$ in the dome to a maximum of $176^{\circ} \mathrm{C}\left(349^{\circ} \mathrm{F}\right)$ in the cylinder. This temperature distribution was interpolated for each element in the grid. The difference of $82{ }^{\circ} \mathrm{C}$ $\left(147^{\circ} \mathrm{F}\right)$ between maximum and minimum temperatures created an axial thermal gradient that exceeded $2.1^{\circ} \mathrm{C} / \mathrm{cm}\left(1.5^{\circ} \mathrm{F} / \mathrm{in}.\right)$ at some locations in the haunch region and would cause cracking of the concrete in the haunch area.

The overburden loading consisted of soil backfill of $2 \mathrm{~m}(6.5 \mathrm{ft})$ above the dome crown, and live loadings of $1.9-\mathrm{kPa}$ (40-psf) uniform plus 45-t (50-ton) concentrated. Rankine active soil pressure coefficient of 0.4 was assumed to act on the cylindrical portion of the structure.

- Determination of U1timate Load. The ultimate load analysis of the structure was conducted at the end of the creep analysis period, namely, after 10 years. At that time, the overburden loading was assumed to increase uniformly. By increasing the load factor to two (soil depth to $4 \mathrm{~m}[13 \mathrm{ft}]$ ) the structure responded in a wellbehaved manner with the exception of stresses exceeding the cracking 
limit at some isolated points in the structure. However, when the load factor was increased to 3 , the structure experienced excessive deflection at the haunch and dome crown areas. As a result of this condition and presence of the cracks extending throughout the cross section, an effective hinge forms. On the basis of this analysis, a load factor of 3 could not be attained without producing the hinge mechanism. Therefore, a load factor of 2 is regarded as the highest safety factor that can be assured before the hinge mechanism is formed.

B. Structural Analysis of 241-SY. Similar to the above analysis, a structural analysis was performed for 24l-SY (ARH 1974). Far-field boundary conditions in the computer model were fixed in the vertical direction at $74 \mathrm{~m}(155 \mathrm{ft})$ below the base and radially $73 \mathrm{~m}(240 \mathrm{ft})$ from the axis of symmetry.

- Thermal Load Used in the Analysis. Reference temperature at $70^{\circ} \mathrm{F}$, and liquid waste in the tank sustained at $250^{\circ} \mathrm{F}$ over a long period.

An evaluation of the results indicates that the stresses in the primary steel tank are within their allowable value. The stresses in the concrete and reinforcing steel of the concrete tank are also within their respective allowable values with the exception of a few localized areas. The structure integrity in the regions where these stresses exceed the allowable stresses is not compromised. The center of the dome may show some slight increase in deflection but there are redundant load carrying paths in the frame bending action of the haunch and the lateral confinement provided by the passive pressure of the soil that were neglected in these original analyses the have been identified in subsequent analyses. The increased flexural bending in the footing results in a little greater soil pressure directly below the wall but does not jeopardize the support of the wall and dome structure.

\section{Results of Analysis.}

Primary steel tank - Analyzed as a part of the overall soil-tank model for gravity loads and earthquake ground motion. It was analyzed separately for hydrostatic and hydrodynamic loads as well as thermal loads. The circumferential stress is dominated by hoop tensile force caused by hydrostatic pressures. Under long-term loads (gravity thydrostatic+thermal) the maximum hoop stress is $15.3 \mathrm{ksi}$ at lower portion of the wall and with addition of seismic load stresses increase to $20.1 \mathrm{ksi}$. The longitudinal stress under Tong term loads is maximum at the base of the base knuckle having a value of $13.1 \mathrm{ksi}$ which increases to $19.3 \mathrm{ksi}$ when seismic load stresses are added. The primary tank steel is specified as ASTM 516 Grade 65 . The allowable stress for such steel at temperature around $250^{\circ} \mathrm{F}$ is $21 \mathrm{ksi}$. Thus the maximum computed stresses in the primary steel tank are less than this allowable value. Maximum displacements of $0.165 \mathrm{in}$. and $0.104 \mathrm{in}$. under hydrostatic and hydrodynamic pressures, respectively, occur near one third up from the base. 
Secondary concrete tank - The secondary concrete tank was analyzed for gravity loads and soil-structure interaction due to earthquake ground motion as a part of the overall soil tank model using the computer program AXIDYN. The dome and cylindrical wall portion of it was anatyzed separately for thermal loads and creep using the SAFECRACK computer program. The results of this thermal-creep analysis, including the effect of gravity loads of the concrete tank dome and wall are discussed in the Appendix A of the structural analysis for 241-SY (ARH 1974). This thermal-creep analysis considered the nonlinear behavior of concrete. Gravity loads including the active lateral soil pressure on the tank wall were included as initial mechanical loading in the thermal-creep analysis. The effect of thermal loads and creep on the base slab is considered negligible and was ignored. The effect of hydromechanical loads which act directly on the primary steel tank was found to be negligible on the secondary concrete tank and was ignored. The lateral displacements in the tank region of the soil-tank model under earthquake motion are maximum at approximately the same time, 6.56 seconds after the start of the earthquake motion. A relative lateral displacement of $0.136 \mathrm{in}$. between the top and bottom of the tank wall was predicted. The maximum lateral accelerations due to the earthquake motions are $0.15 \mathrm{~g}$ at the base of the tank, $0.21 \mathrm{~g}$ at the roof of the tank, and $0.295 \mathrm{~g}$ at the soil surface close to the right vertical boundary.

The internal forces that were developed in the concrete tank under earthquake loading were found generally much smaller than the corresponding responses under dead load.

Results from the SAFECRACK analysis under initial mechanical loading (i.e., gravity and soil pressure), indicate an upward displacement of $0.03 \mathrm{in}$. at the dome crown and an inward horizontal motion of $0.12 \mathrm{in}$. at the base of the wall. Due to long-term creep effects, the displacement at the crown of the dome stabilizes to $0.23 \mathrm{in}$. upwards and at the base of slab to $0.34 \mathrm{in}$. outward.

During heating, the SAFECRACK analysis indicates that, by the time temperatures reach their peaks, radial and meridional cracking has occurred in regions near the dome and haunch. The maximum compressive stress in the concrete is less than 1,600 psi, except in very localized region at the dome crown soffit, where it is 2,600 psi. Maximum stresses in the steel reinforcement are less than $24.2 \mathrm{ksi}$ compressive and less than $7 \mathrm{ksi}$ tensile. The analys is further indicates that after long-term creep, when stable conditions are established, the cracking spreads somewhat but remains in the same general region. Under this condition, the stress in the concrete is less than 1,000 psi, whereas stresses in the reinforcing steel are less than $24.2 \mathrm{ksi}$ compressive and $4.0 \mathrm{ksi}$ tensile. The high compressive stress $(24.2 \mathrm{ksi})$ in the reinforcing steel after heating and long-term creep effects is confined to a very sma?l area near the dome crown, being less than $13 \mathrm{ksi}$ elsewhere. 


\section{Independent Seismic Analysis.}

Dome - The computed maximum stress is $5.4 \mathrm{ksi}$ in the hoop steel in the cracked concrete region near the dome haunch. The maximum stress in the uncracked region of the dome is less than $120 \mathrm{psi}$ compressive in the concrete and $1.7 \mathrm{ksi}$ tensile or compressive in the reinforcing steel.

Tank wall - The maximum compressive stress in the concrete is less than $400 \mathrm{ps} i$, the maximum stress in the reinforcement steel is $11.5 \mathrm{ks} i$ (indicating some flexural cracking in the concrete at the base of the wall in the longitudinal direction).

Slab - The highest longitudinal stress in the slab under long-term loading occurs in a localized region near the tank wall where the stress in the bottom reinforcement steel is $35.8 \mathrm{ksi}$ tensile and 2,000 psi compressive in the concrete. Addition of seismic stresses increase these values to $42.7 \mathrm{ksi}$ and $2,475 \mathrm{psi}$, respectively. Elsewhere in the base slab, the stresses are substantially smaller.

The allowable compressive stresses in the concrete are 2,025 psi $(0.45 \times$ compressive strength) for long-term loads and 2,700 psi when seismic loads are included. Thus, the compressive stresses in the concrete are within allowable values everywhere in the tank except in a very localized region at the dome crown soffit for a short period during and after heating.

Reinforcement steel is specified as ASTM 615-68 Grade 60 with minimum yield strength of $60 \mathrm{ksi}$ and allowable stress of $24 \mathrm{ksi}$ for long-term loads and $32 \mathrm{ksi}$ when seismic stresses are included. The calculated stresses in reinforcement steel exceed these allowable values in a couple of localized regions at the dome crown and in the base slab near the tank wall, though they are well within the yield strength of the steel.

The maximum in-plane shear stress caused by seismic ground motion is at the base of the cylindrical wall. The calculated maximum in-plane shear stress is 395 psi which is smaller than the code allowable shear stress.

\section{Summary and Conciusion}

The DST structures have adequate capability to resist the normal operating loads. Results of the seismic analysis and thermal-creep analys is demonstrated that the stresses and deflection of the tank are all within the code allowables. The stress levels in the concrete and reinforcing steel are not truly indicative of the section capacity to resist load. More recent analyses have evaluated the section capacities as well as the trend of the capacity under changes in location, type and magnitude of the applied load. The responses shown in the ASA analyses (Scott 1995) are more indicative of the inherent conservatism and stability of the DSTs. Cracking in the dome and upper wall regions of the concrete tank is expected under thermal and creep loads. Adequate reinforcement exists to limit this cracking. 
C. Accelerated Safety Analysis (ASA) Structural Analyses. The ASA structural analyses were conducted in two phases. Phase I report (Becker 1994) documented the ASA sensitivity evaluations and findings (Hyde et al. 1994) and Phase II (Scott 1995) was a structural analys is of the DSTs utilizing the ASA Phase I model to verify the current DSTs' analysis of record for the maximum load combination. The bounding normal and operating loads are incorporated into the analysis process to determine the maximum combined stresses in the tank. Degraded material properties and structural elements are accounted for in the analysis process. The analyses were focused on the following two tasks:

Task 1: Determine the worst case load combination for the DSTs and compare the resulting stresses to the ACI code allowables.

Task 2: Apply the maximum load combination to the ASA model with the thermally degraded concrete properties and creep associated with the maximum temperature.

The evaluation concentrated on the structural capacity of the upper portion of the DST secondary concrete structure which resists the overburden and lateral soil loads. Results of the analyses were checked against the axial force-moment interaction diagrams at specific concrete sections which were constructed on the basis of code allowables. The structural integrity of the DSTs was determined to be adequate under the normal operating load, seismic load, and thermal load.

4.5.3.2 Structural Assessment of DSTs. Based on the detailed descriptions of the DST structural analyses presented in Section 4.5.3.1, it is concluded that the DST tanks have adequate safety margin to resist the normal operating loads and the design basis earthquake. Stresses in the various components such as primary tank, secondary tank, and secondary liner due to combined loads consisting of the loads described in Section 4.3 are all within the code allowables. Cracking of concrete in the haunch region is expected. However these cracks are local, and with the sufficient reinforcing steel in the concrete the tank structure would not be compromised. 
WHC-SD-TWR-RPT-002 REV 0

This page intentionally left blank. 


\subsection{ULTIMATE LOAD CAPACITY AND FAILURE MODES UNDER ACCIDENT LOADS}

\subsection{GENERAL}

The complexity of the accident loads and the fact that the tank materials would be taken to their ultimate capacity into areas were mathematical formulations are weak at best, required an approach quite different than was taken above to compare tank structural integrity against design loads. Thus, when evaluating the tanks for accident loads, gross tank capacity was examined and judgements were made as to failure modes based on previous static and dynamic analysis, engineering judgement, additional simplified analysis, and a Delphi (expert opinion) process.

In order to evaluate the potential consequences of the various postulated accident scenarios, structural capacity and failure modes of the SSTs and DSTs were investigated. Because detailed structural analysis is not included in the current project plan, only bounding accident loads were considered in the structural failure mode assessment.

\subsection{EXCESSIVE EXTERNAL TANK LOADS}

\subsubsection{Excessive Concentrated Load}

5.2.1.1 Load Description. An excessive concentrated load is assumed to be induced from large equipment, such as a crawler-mounted crane, that is moving over a tank structure to perform necessary maintenance. The effect of a concentrate load on the tank structure is depending on the intensity and location of the load. Load intensity is a function of the total weight of the equipment and the size of its laydown area. The location of the load is assumed to be on the soil at grade directly above the tank. The concentrated load discussed here is actually distributed over a relative small area.

5.2.1.2 Tank Groupings. The tanks are grouped into 200-Series SSTs, 100-Series SSTS, and DSTs on the basis of tank structural configurations.

5.2.1.3 200-Series SST Failure Mode. Based on previous structural analyses (RHO 1978 and Ramble 1983) that proposed operating design limit for a concentrated load of $45 \mathrm{t}$ (50 tons) distributed over an area with a $3-\mathrm{m}$ $(10-\mathrm{ft})$ radius, it was estimated (Wagenblast 1996) that this type of SSTs would fail at about $270 \mathrm{t}$ (300 tons). The predicted failure mode included cracks in the flat roof structure and some concrete and soil falling into the tank.

5.2.1.4 100-Series SST Failure Mode. Various load areas were used in previous structural analyses of the SSTs. A concentrate load of $90 \mathrm{t}$ (100 tons) over an area with a radius of $9 \mathrm{~m}(30 \mathrm{ft}$ ) was used in the structural analysis of the waste storage tanks 24l-AX (RHO 1978). Concentrated loads varying from $45 \mathrm{t}$ (50 tons) to $180 \mathrm{t}$ (200 tons) over an area with a $3-\mathrm{m}(10-\mathrm{ft})$ radius were used in the Ramble (1983) structural load sensitivity study. Results of these analyses indicate that the SSTs have 
adequate safety margin when compared with ACI code allowables. Normally a structure which satisfies the code requirements would have a factor of safety between 2 to 3 against failure. Based on this findings and the $180-t$ (200-ton) concentrate load used in the Ramble (1983) structural analysis it is assumed (Leach 1996) that the concentrate load that could cause the tank to fail is in the range of 270 to $540 \mathrm{t}$ (300 to 600 tons) over a laydown area with a $3-m(10-f t)$ radius.

The predicted failure mode is a flattening of the tank dome and eventual shearing through a $3-\mathrm{m}(10-\mathrm{ft})$ radius area centered at the crown of the dome. Thus, the concentrated load, concrete, and some soil would drop into the tanks.

5.2.1.5 DST Failure Mode. The reinforced concrete tank structure of the DSTs would have the same factor of safety against failure as expected for the SSTs. However, within the concrete tank of the DST there is a primary steel tank supported and attached to the concrete tank dome. This primary steel tank provides additional stiffness to the overall structure and would have a higher load carrying capacity. It is assumed (Leach 1996) that the for DSTs the concentrated load that would cause the tank to fail is in the range of 360 to $720 \mathrm{t}$ (400 to 800 tons) over an area with a $3-\mathrm{m}(10-\mathrm{ft})$ radius.

The predicted failure mode is a flattening the tank dome and eventual shearing through a 10-ft radius area centered at the crown of the dome. Thus, the concentrated load, concrete, and some soil would drop into the tanks.

\subsubsection{Excessive Uniform Load}

5.2.2.1 Load Description. Placing 3 to $15 \mathrm{~m}(10$ to $50 \mathrm{ft}$ ) of additional soil over the tanks would be considered an excessive uniform load.

5.2.2.2 Tank Groupings. Again the tanks can be grouped as in Section 5.2.1.2.

5.2.2.3 200-Series SST Failure Mode. Based on previous structural analyses (Ramble 1983) that proposed an operating design limit for uniform load of $3.7 \mathrm{~m}(12 \mathrm{ft})$ of soil cover, it was estimated (Wagenblast 1996) that the flat roof structure would fail at about $96.5 \mathrm{kPa}$ (14 psi). The failure mode would be cracks in the flat roof structure and some concrete and soil falling into the tank.

5.2.2.4 100-Series SST Failure Mode. Previous structural analyses (Ramble 1983) proposed a maximum soil depth of $3 \mathrm{~m}$ (10 ft) for 100-Series SSTs. Tank structural analyses indicate that the safety factor against dome failure is on the order of 3 for a $2 \mathrm{~m}(7 \mathrm{ft})$ soil overburden with a soil density of $115 \mathrm{lb} / \mathrm{ft}^{3}$. Thus, the equivalent uniform soil pressure at failure is estimated as 


$$
P_{\text {soil }} \text { failure }^{=}=3\left(h_{\text {anal }}+h_{\text {eq }}^{\text {dome }}\right) \gamma_{\text {anal }}
$$

where

$$
\begin{array}{ll}
P_{\text {soil }} \text { failure } & =\text { equivalent uniform soil pressure at failure } \\
h_{\text {anal }} & =\text { uniform height of soil above dome apex used } \\
& \text { in analysis }=7 \mathrm{ft} \\
h_{\text {eq }} \text { dome } & =\text { equivalent uniform soil height between dome haunch } \\
& \text { and dome apex which is approximately equal to } \frac{1}{2} h_{\text {haunch }} \\
h_{\text {haunch }}= & \text { height of haunch }=8.7 \mathrm{ft} \text { for SSTs } \\
\gamma_{\text {anal }} & \text { soil density used in analysis }=1151 \mathrm{bf} / \mathrm{ft}^{3} .
\end{array}
$$

Or,

$$
P_{\text {soil }} \text { failure }=3,915 \mathrm{lbf} / \mathrm{ft}^{2} \text {. }
$$

If the in-place soil density is different than the soil density assumed in the analysis then the soil height above the apex of the dome at failure becomes

$$
h^{\text {failure }}=p_{\text {soil }}^{\text {failure }} / \gamma_{\text {in-place }}-h_{\text {eq }}^{\text {dome }}
$$

where

$$
\begin{array}{ll}
\mathrm{h}^{\text {failure }} & \text { soil height above dome apex at dome failure } \\
\gamma_{\text {in-place }} & \text { in-place soil density. }
\end{array}
$$

For an in-place soil density of $1251 \mathrm{bf} / \mathrm{ft}^{3}$ the soil height above the dome apex at dome failure becomes

$$
h^{\text {failure }}=27 \mathrm{ft}
$$

which is $17 \mathrm{ft}$ above the current limit.

For loads greater than the failure load the predicted failure mode is failure in hoop tension in the haunch region or failure of the upper wall region of the concrete tank. The dome rebar would spall (lose its concrete cover), particularly in the wall to dome haunch and dome center regions. The dome would begin to flatten and may snap through with increasing load eventually breaking up with pieces of concrete and soil falling into the waste. The amount of debris entering the tank would depend on how much of an overload was applied to the dome.

5.2.2.5 DST Failure Mode. The Dots have a primary tank which is anchored to the bottom face of the concrete tank dome by a $0.6 \mathrm{~m}(2 \mathrm{ft})$ square pattern of studs. The compressive strength of the DST concrete is 30 to $60 \%$ higher than that of the SSTs. However, it is estimated that the soil overburden failure threshold depth of $6.4-\mathrm{m}(27-\mathrm{ft})$ for SSTs may be conservatively applied to the Dots. The failure mode would be similar to that of the SSTs but a smaller percentage of debris is expected to fall into the tank because of the attached ductile primary tank. 


\subsubsection{Excessive Load Drop}

5.2.3.1 Load Drop Description. Impact loads may be generated on the soil above the tank or in the pump pit from dropping objects lifted above the surface by a crane or other lifting device. It is assumed that the drop is a free-fa11 drop. In general, loose of tank structural integrity may be due to a local failure (perforation) or due to the subsequent global response of the structure. The potential for tank failure under this load condition depends on the mass of the projectile, the initial velocity of the projectile on impact, the frontal area of the projectile at the point of impact, the stiffness of the projectile relative to the target structure, and the effective mass of the target relative to the projectile mass. A relatively hard projectile will be more likely to perforate the target structure rather than cause a global response type failure.

5.2.3.2 Tank Groupings. Again the tanks can be grouped as in Section 5.2.1.2.

5.2.3.3 200-Series SSTs Failure Mode. The 200-Series SSTs were analyzed for an assumed drop load induced by equipment weighing 9,072 kg (20,000 1bs) and an impact area with a $61-\mathrm{cm}(2-\mathrm{ft}$ ) diameter (Wagenblast 1996). Two cases were investigated: in the first case the equipment was assumed to be dropped directly on the center of the vertical walls of the rectangular pit structure that houses the condenser stacks, and in the second case the equipment was assumed to be dropped on the soil at grade adjacent to the rectangular pit structure attached to the roof slab. The simplified hand calculations were based on a conservative assumption that the rectangular pit wall and roof slab can be idealized as a "T" beam simply supported at the ends. The roof slab structure was predicted to fail in bending if the $9,072-\mathrm{kg}(20,000-1 \mathrm{bs})$ equipment is dropped directly on the center of the rectangular pit wall from essentially any height. The roof concrete structure and soil would fall into the tank. In the case where the $9,072-\mathrm{kg}(20,000-1 \mathrm{bs})$ equipment is assumed to be dropped from a height of $6 \mathrm{~m}(20 \mathrm{ft})$ on the soil at grade adjacent to the rectangular pit, no damage to the tank structure was predicted (Wagenblast 1996).

5.2.3.4 SST Failure Mode. The mixer pump safety assessment (Sullivan 1995) considered several load drop accident scenarios which enveloped various heights of the equipment drop and locations of impact. As a worst case, the equipment was assumed to drop into the pump pit and hit directly on the concrete pit floor above the dome. Sullivan shows that

- $2.5 \times 10^{5} \mathrm{~J}(187,500 \mathrm{ft}-7 \mathrm{~b})$ drop onto the pump pit floor will cause perforation of the concrete pit floor and partial penetration into the dome concrete.

- $3.4 \times 10^{5} \mathrm{~J}(250,000 \mathrm{ft}-1 \mathrm{~b})$ drop onto the soil above the dome results in a penetration depth of $2 \mathrm{~m}(6.5 \mathrm{ft})$; the minimum depth of soil above the dome at the dome apex. 
Based on the information given above, it was conservatively concluded that equipment drops greater than $2.7 \times 10^{5} \mathrm{~J}(200,000 \mathrm{ft}-1 \mathrm{~b})$ striking directly on the concrete pit floor above the dome might lead to perforation of the dome. Concrete adjacent to the point of impact would spall off from the dome. The extent of the spalling might extend outward to a distance of approximately a $1.5-\mathrm{m}$ (5-ft) radius from the impacted area. The analysis by Sullivan (1995) is conservative. It limits the local damage to the pit floor with only minimal penetration into the dome concrete.

If the equipment is dropped onto the soil at grade, the soil would act to spread the impact force to a much larger area of the tank dome and absorb much of the energy. The dome would not fail if the equipment is dropped on the soil above the tank with an impact energy of $2.7 \times 10^{5} \mathrm{~J}(200,000 \mathrm{ft}-1 \mathrm{~b})$ because the soil would decelerate the mass and spread the load.

5.2.3.5 DST Failure Mode. The structural behavior of the DSTs due to equipment or pump drop load is similar to the drop case for SSTs, except the primary steel tank is ductile and large deflection of the steel tank is expected before perforation. Hence, a greater impact energy would be required to perforate the dome of a DST. In addition less concrete debris would likely fall into the waste below than in the case of a SST.

\subsection{EXCESSIVE INTERNAL TANK LOADS}

\subsubsection{General}

Excessive internal tank loads consist of those loads that are beyond the original design load categories and the magnitudes or intensities of the forces and pressures generated within the tank structure as a result of an accident exceeded the original structural design criteria. Specifically, the excessive internal tank loads include high internal pressures and external pressures (vacuum) due to various accidents such as hydrogen deflagration, solvent fire, organic salt-nitrate reaction, gasoline fire in the annulus, and significant amounts of water or waste leaked into the annulus.

General descriptions of the accident scenarios are briefly discussed as follows:

Flammable Gas Deflagration. The flammable gas deflagration accident scenario considers the deflagration of flammable gasses whose concentration within the dome vapor space exceeds the lower flammability limit. The flammable gas deflagration is relatively quick (seconds to minutes) in duration, and hence adds little overall thermal energy to the tank system. Potential effects to the structure due to heating of the tank are insignificant.

Flammable gas generated and retained within SSTs and DSTs can be released slowly under steady-state conditions or suddenly as a spontaneous gas release event. Assumptions regarding the generation, retention, and episodic release 
of the gasses lead to wide uncertainty in the quantity of flammable gas and the extent of mixing with oxygen in the tank dome vapor space prior to deflagration from a potential ignition source. These assumptions significantly affect the calculated deflagration rates and consequent tank pressures.

Following a deflagration, the tank gas space is hot, and may include condensable combustion products, such as water. As the tank cools, it is possible that the cooling contraction of the gas would exceed the inleakage ability to maintain the dome space pressure. This might lead to the formation of a vacuum in the tank.

Organic Salt-Nitrate Reaction. Organic nitrate compounds are known to exist in some tanks. If ignited, the burning of these compounds can generate significant temperatures and pressures depending on the vent capacity of the tanks.

The organic salt-nitrate reaction could only happen in some of the dry SSTs. Those SSTS that are wet and contain liquid could not initiate an accident of this type. All DSTs contain liquid and would not have this kind of accident.

Solvent Fire. Solvent pool fire within the tank could be ignited by lighting or other initiator. It is assumed that the resulting puddle fire is $0.28 \mathrm{~m}^{3}\left(3 \mathrm{ft}^{2}\right)$ and contains sufficient solvent to burn in $0_{2}$. A bounding pressure and temperature were established for structural evaluation.

Gasoline Fire. It is assumed that a transient pressure is caused by $76 \mathrm{~L}$ $(20 \mathrm{gal})$ of gasoline being spilled into the annulus of the DSTs. Further, it is assumed that the gasoline is ignited and produces a transient pressure in the annulus.

Excessive Internal Waste. Waste material could be accidentally filled into the tanks exceeding the allowable level. The excessive waste would result in higher hydrostatic pressures on the tank and higher temperatures in the dome region of the tank structure.

\subsubsection{High Pressure Loads}

5.3.2.1 Load Description. High internal pressure loads in the tanks were calculated for the following three accident scenarios:

- Hydrogen Deflagration. Peak pressures for a hydrogen deflagration within the waste storage tanks are based on the stored gas volumes in the various tanks during a gas release event and the concentration of hydrogen in the released gas. The calculated peak internal pressure due to a hydrogen deflagrations for DSTs is $10.6 \mathrm{~atm}$ absolute $(1 \mathrm{~atm}=14.7 \mathrm{psi})$ or $141 \mathrm{psig}$ and the peak pressure for 100-Series SSTs is $7.5 \mathrm{~atm}$ absolute or $88 \mathrm{psig}$ assuming that there is no vent path during the accident (see Appendix B). The peak pressure for the 200-Series SSTs is assumed as 120 psig (Wagenblast 1996). 
- Solvent Fire. Bounding peak pressures were calculated for the waste storage tanks for a solvent fire. These pressures are 29 psig for the 100-Series SSTs, 30.8 psig for DSTs, and 18.3 psig for the DCRTs (Table 5-1) (Grigsby 1996). No design data has been established for the 200-Series SSTs.

- Organic Salt-Nitrate Reaction. The organic salt-nitrate reaction accident could only happen in some of the dry 100-Series SSTs. Those SSTs that are wet and contain liquid could not initiate a organic salt-nitrate reaction. All DSTs contain liquid and would not have this kind of accident. Based on the results of the organic salt-nitrate reaction analysis for a selected SST, the maximum calculated internal pressure is $25.7 \mathrm{kPa}$ (11 psig) and the temperature is $687^{\circ} \mathrm{C}\left(1,268{ }^{\circ} \mathrm{F}\right)$ at 3,000 seconds (50 minutes) (Lee 1996).

- Gasoline Fire. The transient pressure for the gasoline fire accident is caused by the ignition of $76 \mathrm{~L}(20 \mathrm{gal})$ of gasoline that are spilled into the DST annulus. The gasoline is then vaporized and ignited. It is assumed that a peak pressure of 140 psig could be generated instantaneously (Wagenblast 1996).

5.3.2.2 Tank Groupings. Specific loading conditions were established based on the contents and configurations of the tank structures grouped into 200-Series SSTs, 100-Series SSTS, and DSTs. Same groupings are used for the tank failure mode assessment.

5.3.2.3 200-Series SST Failure Mode. A peak pressure of 120 psig was assumed in the evaluation and found that the reinforced concrete tank structure would likely fail and cause an unobstructed opening or path between the waste and the atmosphere (Wagenblast 1996).

5.3.2.4 100-Series SST Failure Mode. Tank structural behavior under pressure load is dependent on the details of the deflagration. Potential tank failure modes depend on factors such as pressurization rate, peak pressure, and duration of pressure pulse. High-pressure loads generated within the SSTs could be due to hydrogen deflagration or solvent fire. The primary features that distinguish these scenarios from the organic salt-nitrate reaction is the pressurization rate and the duration of the event. The gas and liquid deflagrations are relatively quick in duration, although the solvent fire is slow compared to the hydrogen deflagration. Hence, little overall thermal energy is added to the tank system. Potential effects due to heating of the tank structure are not significant.

Based on existing analyses for the SST static internal pressure capacity (WHC 1994k) the predicted limiting pressure is approximately 11 psig for the 3.8-ML (1-Mgal) tanks and 15 psig for the 2-ML $(533,000-$ gal) tanks. At these pressures, some cracking and over stressing of rebar in the dome would occur. This failure would lead to self venting through the soil. Any release through this path would be filtered and distributed by the compact sand and gravel soil overburden. 
The pressurization of the SST due to solvent fire is relatively slow comparing to the Hydrogen deflagration. Based on the solvent fire transient analysis the peak pressure is $29 \mathrm{psig}$ and pressurization time is approximately 100 seconds assuming a 50-in. diameter flapper vent opens at a differential pressure of 1 psi. As described above, the concrete dome would start to crack at a pressure of 11 to $15 \mathrm{psig}$ and the pressure within the tank could not buildup beyond the limiting pressures due to venting, assuming that the pressurization rate is sufficiently slow. The tank structure is believed to be able to withstand the soil overburden during and after the accident.

In the case of a hydrogen deflagration, the pressure intensity and pressurization rate are high. It is a transient load and has significant dynamic effects on the tank structures.

The peak internal pressure for the 100-Series SSTs is $88 \mathrm{psig.} \mathrm{An}$ assessment of the structural integrity is discussed as follows:

All 100-Series SSTs have the same diameter of $75 \mathrm{ft}$. The tank waste storage capacity is determined by the height of the wall. The transient pressures in the various tanks would have the same dynamic effect and result in the same uplift force because the projected areas of all the domes are the same. Based on the existing structural analysis the maximum internal pressure used in the SST structural design was $7.5 \mathrm{psig}(\mathrm{HW}-37519)$. Because soil pressures are significant loads at the time of the construction, the rebars were provided mainly to resist the soil overburden on the dome and lateral soil pressure on the cylindrical wall. The rebar quantity in the dome is light. Only a minimum amount of vertical rebars were provided in the wall. Due to lack of analytical data for the transient pressure analys is for the SSTs, an assessment of the peak pressure due to hydrogen deflagration and the tank structural capacity based on engineering judgement was performed.

The SSTs have two areas that are potentially vulnerable to the high transient pressure load. These areas are the upper wall region and the central dome region. The section capacity of the upper wall region right below the haunch was checked against the uplift force induced by the internal pressure. In a typical shell type structure such as the waste storage tank, in a pressure load case, membrane stresses normally govern the structural design except locations at the discontinuities such as junction of the wall and base mat, and spring line or haunch region where bending moments are significant.

The engineering drawings and some evaluation analyses of the SSTs were reviewed and it is confirmed that the weakest sections are locations in the central region of the dome and the upper portion of the wall. The vertical rebars provided in these regions are rather light. Typically in the dome central region the rebar pattern is $\# 6$ rebar at approximately $12 \mathrm{in}$. on center, each face, in hoop direction $\left(0.88 \mathrm{in}^{2} / \mathrm{ft}\right)$. The radial rebars in the dome range from \#6 at $24 \mathrm{in}$. on center, each face, $\left(0.44 \mathrm{in}^{2} / \mathrm{ft}\right)$ to $\# 6$ at $12 \mathrm{in.}$. on center, each face $\left(0.88 \mathrm{in}^{2} / \mathrm{ft}\right.$ ) (Figures $5-1$ and $5-2$ ). In the upper wall region, for the 3.8-ML (1-Mgal) tanks, such as tanks 241-A and 241-AX, the verticat rebar areas are \#8 at $20 \mathrm{in}$. on center, each face $\left(0.95 \mathrm{in}^{2} / \mathrm{ft}\right)$ and $\# 8$ at $18 \mathrm{in}$. on center, each face $(0.94 \mathrm{in.} / \mathrm{ft})$ respectively (Figure 5-3). For 2.9-ML (758,000-gal) tanks, the rebar areas range from $0.66 \mathrm{in}^{2} / \mathrm{ft}$ (3/4-in. diameter at $12 \mathrm{in}$. each face for $24 \mathrm{l}-\mathrm{TY}$ ) to $0.88 \mathrm{in}^{2} / \mathrm{ft}$ 
(\#6 at 16 in. each face for 241-TX) (Figure 5-4). The required rebar area for the net uplift force for a $75 \mathrm{ft}$ diameter tank due to the peak pressure of $88 \mathrm{psig}$ is $2.8 \mathrm{in}^{2} / \mathrm{ft}$ which is much greater than the available rebar areas of any of the SSTs. As stated above all 100-Series SSTs have the same diameter. Thus they all have the same uplift force under the same internal pressure load. The net uplift force for each tank may vary somewhat due to small height differences of the soil overburden which counteracts the internal pressure. However, the variation of the soil load is insignificant in calculating the required rebar areas for the transient pressure load. The required rebar area was calculated using the ultimate tensile strength of $70,000 \mathrm{psi}$ (Figure 5-5). Based on this calculation, the required rebar area is found to be greater than the available rebar area by a factor of about 3 . It is concluded that the rebar will fail in tension in both the dome and the upper wall at an internal transient pressure of 88 psig. If dynamic factors are considered, the required rebar area would be even larger. It is likely that the entire dome would be blown away at this high pressure.

No temperature data is available for the structural evaluation. However, during the hydrogen deflagration the thermal effect of the structure is judged to be negligible based on the following two assumptions: (1) it is a short duration, and (2) tank structure has already failed by the high transient pressure.

5.3.2.5 The DST Failure Mode. The structural integrity of DST was assessed for the peak internal pressure of 141 psig in two parts. Note that this pressure is greater than that assumed in the Delphi (Leach 1996) assessment discussed in Section 5.3.2.7 below.

Part 1 - Overall Structural Stability: One of the unique design features of the DST tank structure is the sliding connection at the junction of the wall and base mat which was designed to accommodate the differential thermal expansion due to heat generated within the stored waste. In order to allow the relative movement between the wall and the base mat due to thermal effects the joint was designed as a non-rigid connection. Reinforcing steel dowels between the base mat and the wall were not provided. Steel plates were attached at the bottom of the wall and top of the base mat. Dry graphite was placed at the interface to allow movement. The only connection between the wall and the base mat is the secondary steel liner plate which covers the base mat and is anchored in the vertical wall (Figure 5-6). The uplift force resulting from the peak pressure in the primary tank could potentially push the secondary concrete tank out of the soil. The structural stability subject to the uplift force and the downward counteracting force acting on the tank structure were investigated.

Simplified hand calculations (Appendix C) were performed for both the uplift force and counteracting force acting on the tank. An assessment was made for the structural stability of the tank under the peak pressure load during a hydrogen deflagration accident. 
Based on the simplified static hand calculations, it was found that the concrete tank structure could be uplifted from the base mat to a certain height but very unlikely be pushed out of the soil by the pressure load. The height of the uplift is judged to be limited by the secondary liner which could be stretched to the breaking point at an estimated strain of approximately $15 \%$. At this time, the pressure would probably decrease to a lower level due to (1) increase of tank volume as a result of tank expansion and uplift and (2) crack or opening in the dome which is addressed in Part 2 of this investigation. Under the high uplift force, the secondary liner plate at the junction of the concrete wall and the base mat would be deformed and deflected upward. The stresses in the plate are bi-axial. For simplicity, only the radial tension in the plate was assumed in the calculations. Assuming the uplift force is uniformly distributed on the cross section of the secondary liner plate, the stress was found to be greater than the tensile strength of the secondary liner plate. It is concluded that the secondary liner plate could fail. The height of the uplift of the tank could be limited by the full stretch of the corner plate assembly of the tank and other counteracting forces as the peak pressure decreases. Due to the frictional force between the exterior face of the concrete wall and the soil and deformation of the secondary liner plate, it is judged that after the tank is lifted it would not drop back down to its original position.

The above assessment was based on the approach that, at the time of the $\mathrm{H}_{2}$ deflagration, the primary tank could be stretched under the high pressure $10 a d$. Because the secondary concrete tank is not tied to the base mat, the pressure acting on the dome becomes the uplift force of the concrete tank. Assuming the primary tank dome would not fail at this pressure, this uplift force would quickly be transmitted through the dome, haunch, wall and secondary liner, and to the base of the wall. Since there are no dowels in the concrete, the uplift force will be carried by the secondary liner at the base. The secondary liner at the junction of the wall and base mat is a curved bent plate which runs along the joint of the wall and base mat to a complete circle. The bent steel plate will be straightened and deflected upward under the uplift force. The calculated stress in the steel plate exceeded the tensile strength of the material and could cause the liner plate to fracture. This simplified static hand calculation demonstrates that the secondary liner which is anchored in the concrete wall with studs and structural steel angles could fail in tension and cause the concrete tank to have an uplift during an accident event such as hydrogen deflagration.

Part 2 - Dome Failure Mode: Under the pressure load, the dome will expand outward in a radial direction. At locations where expansion is constrained, high strain will be developed in the steel plate, particularly in the areas of discontinuities such as the transition seams between liner plate and insert plates, penetrations, and stiffeners. Concrete will be cracked under tension.

The existing stress analysis for Tank 24l-SY-101 (Christensen 1993) showed that the primary tank dome would exceed the yield strain at the junction of a 4-in. diameter riser and the transition seam between the 1/2-in. insert plate and $3 / 8-i n$. dome plate under a pressure load of $60 \mathrm{psig.} \mathrm{At} \mathrm{an}$ 
internal pressure of 141 psig the load acting on the dome is increased by a factor of 2.3. Due to 1ack of analytical data for tanks under such a high transient pressure load, an assessment of the structural response was made based on the engineering judgement. In the event of a hydrogen deflagration the tank would be pressurized to a peak pressure of $141 \mathrm{psig}$ in a fraction of a second.

Excessive strains would be developed in the areas of discontinuities. The most likely section to initiate a crack or tear is at the transition seam of the $1 / 2$ in. insert $\mathrm{pl}$ ate and $3 / 8 \mathrm{in}$. general dome plate located along the circle with a radius of about $6 \mathrm{ft}$ from the center line of the tank. As soon as the seam cracks under the dynamic pressure it will propagate along the seam line until the entire insert plate is bent up or blown away. The dome will fail by opening up a hole along the transition seam of the primary tank. Further, because of the ripping and tearing of the plate along the failed edge, damage of the remaining portion of the steel plate could occur at certain weakened locations. Some radial cracks would be developed farther out toward the haunch region. Concrete above the steel liner would be shattered and the rebars significantly deformed. The overburden soil would be blown away. It is estimated that the dome opening with serrated edge due to hydrogen deflagration could reach to the region of the dome rebar transition zone at a radius of $27 \mathrm{ft}$ from the center 1 ine of the tank. The dome rebar transition zone is the location where the dome radial rebars are spliced with the haunch radial rebars (Figure 5-7). Typically, the dome radial rebars are \#6 at approximately $10 \mathrm{in.}$ on center, each face, and the haunch radial rebars are \#9 at approximately 6 in. on center, each face. Since all splices are placed at the same radius without staggering the rebar lengths, the transition zone is believed to be the potential weak section in the concrete dome.

Beyond the transition zone toward the haunch region the concrete dome is thicker and has heavier reinforcement. The strength of the section is also higher. It is therefore concluded that during the hydrogen deflagration the center portion of the dome would be blown open and then the remaining steel liner would be cracked and deflected outward to a radius of approximately $27 \mathrm{ft}$ from the tank center line. Concrete above the damaged liner would be cracked and shattered. The soil overburden would be blown away. The sequence of the structural responses during the accident event as described here may seem to last a long time but all this could happen instantaneously. The portion of the dome beyond the rebar transition zone and the haunch would remain in $\mathrm{place}$ with rebars exposed in certain areas after the accident.

5.3.2.6 Caveat. The caveat of the SST and DST failure mode conclusions is that since the hydrogen deflagration is a transient pressure load, the simplified static hand calculations can only provide an estimate of the failure mechanism and an engineering judgement of the structural behavior. In order to determine the detailed structural response during the transient pressurization of the tanks, a dynamic analysis using a finite-element method should be performed to obtain the more accurate analytical data for the structural assessment. 


\subsubsection{Delphi Panel Assessment. Findings of Delphi Structural Panel are} described as follows:

- For SSTs, the expected failure mode from gas or liquid deflagration events large enough to cause pressure to increase to 11 to $12 \mathrm{psig}$ is cracking of the upper wall and dome. Unfiltered release would take place through open risers, including lifting of cover blocks. When the pressure exceeds $11 \mathrm{psig}$ to $12 \mathrm{psig}$, additional release of gases through the soil would occur.

- For DSTs, the primary tank further reduces the potential for release. These tanks are not likely to fail until pressure reaches about 55 to 60 psig. Below this pressure the primary tank will bulge, lifting the entire concrete dome and side walls. The ultimate failure mode may cause the rapid 'can-opener' partial opening of a flap in the tank dome starting at the transition seam joint of the 1/2-in. plate and $3 / 8-i n$. plate at the dome.

\subsubsection{High Internal Vacuum}

A quasi-static vacuum condition was postulated as a post solvent fire load case. This vacuum is caused by a solvent pool fire on the waste surface, followed by cooling of the gases inside the tank.

5.3.3.1 Load Description. It was postulated in the solvent fire accident analysis that the solvent is ignited by an initiator and burns until low oxygen extinguishment. During the fire the heated headspace gases expand and vent through a $127-\mathrm{cm}(50-\mathrm{in}$.) diameter flapper vent opening. After the fire is extinguished the pressure drops and the flapper vent closes, thus creating a vacuum condition. The bounding vacuum is $-6.8 \mathrm{psig}$ for the 100 -Series SSTs and -8 psig for the DSTs (Table 5-1) (Grigsby 1996). A bounding vacuum of -8 psig was assumed in the 200-Series SST failure mode assessment (Wagenblast 1996).

5.3.3.2 Tank Groupings. Based on the vacuum loads and structural configurations, tanks are grouped into 200-Series SSTs, 100-Series SSTs, and DSTs.

5.3.3.3 200-Series SST Failure Mode. The tank structure was designed to resist the lateral soil pressure on the side and soil overburden at top. Adequate rebars were provided and the structure has ample margin to take the additional external pressure load. Under a vacuum of -8 psig which is equivalent to an external pressure load, the structural integrity of the dome and wall would not be compromised. However the bottom slab is only 7-in. thick and could fail but is not expected to result in an opening of the tank to the atmosphere (Wagenblast 1996).

5.3.3.4 100-Series SST Failure Mode. Similar to the 200-Series SSTs the tank structure has adequate margin to resist the vacuum of $-6.8 \mathrm{psig.} \mathrm{In}$ Section 5.2.2.4 it has been demonstrated that the SSTs have a load carrying capacity of $17 \mathrm{ft}$ of soil in addition to the existing soil overburden. Further, the calculations performed for the structural load capacity confirmed that the tank structure has greater pressure resisting margin than 
the bounding vacuum of $-8 \mathrm{psig}$ (Wagenblast 1996). The bottom slab of the 100-Series SSTs is thicker than the 200-Series SSTs and has much greater strength to resist the uplift pressure from the bottom. It is therefore concluded that the overall tank structure would not be compromised in case of a post solvent fire vacuum event.

5.3.3.5 DST Failure Mode. The DSTs consist of a primary tank and a steel liner attached to the secondary reinforced concrete tank. Based on the structural evaluation of the DSTs for the vacuum condition the primary tank is expected to buckle at a negative pressure of 1 to 2 psig (Wagenblast 1996). At a vacuum of -8 psig the primary tank would fail and the anchor studs in the dome would be pulled out of the concrete or ripped from the steel plate. Some cracks and tearing of the primary tank are expected. As soon as the primary tank opens due to buckling, the secondary tank would be subject to the negative pressure. The DST secondary tank has a similar geometrical configuration as the SSTS. It has a higher concrete strength and more rebars. The structural capability to resist negative pressure is greater than for the SSTs. It is concluded that under the vacuum of -8 psig the primary tank would fail but the structural integrity of the secondary tank would not be compromised.

5.3.3.6 Delphi Panel Assessment. Delphi Structural Panel assessed the SSTs and DSTs for the post-fire vacuum condition and concluded that the tanks should not fail under vacuum. The tank may be subject to buckling from external pressure on the side of walls. Buckling of this nature would cause the walls to crack, spall, and possibly move; potentially leading to local loss of dome support and local slumping. The panel could not envision a substantial potential for a failure mode leading to atmospheric release from this type of external pressure failure. The panel also concluded that tank failure due to vacuum following a gas or liquid deflagration is not likely.

\subsubsection{Excessive Internal Waste}

5.3.4.1 Load Description. This accident scenario assumes that the waste has overfilled the tanks, i.e., the waste level exceeds the original design level. The internal hydrostatic pressure is a function of the specific gravity and the depth of the waste from the free surface of the waste to the point of interest within the waste. For the 200-Series SSTs, the waste material could be overfilled up to the bottom face of the flat roof slab. The 100-Series SSTs have a dome type of roof and the waste material could be overfilled up to the bottom face at the dome apex or up into the risers. The hydrostatic pressure from the waste acts against the steel liner and is resisted by the reinforced concrete wall which is surrounded by the backfill soil. The lateral soil pressures on the exterior face of the concrete tank wall works to counteract the internal hydrostatic pressure from the waste. The lateral soil pressure is a function of the depth of soil from the soil surface at grade to the point of interest along the tank wall. Waste in the DSTs is stored within the primary steel tank which has a dome type roof. The waste material could be overfilled up to the bottom face at the dome apex or up into the risers. The hydrostatic pressure from the waste acts against the primary stee] tank 
and the net lateral pressure on the primary tank wall is a function of the waste hydrostatic pressure and the annulus air pressure between the primary tank and the secondary tank.

5.3.4.2 Tank Groupings. Tank grouping is based on the design configurations and the loading conditions. The three groups are: 200-Series SSTs, 100-Series SSTs, and DSTs.

5.3.4.3 200-Series SST Failure Mode. These tanks are buried $3.7 \mathrm{~m}(12 \mathrm{ft})$ below grade. The internal height between the bottom and the flat roof is $7.6 \mathrm{~m}(25 \mathrm{ft})$. Assuming the specific gravity of the waste is 2 , the maximum hydrostatic pressure at the bottom is $149 \mathrm{kPa}(21.6 \mathrm{psi})$. The iateral soil pressure at the same level is $101 \mathrm{kPa}(14.7 \mathrm{psi})$ for a soil density of $1,842 \mathrm{~kg} / \mathrm{m}^{3}\left(115 \mathrm{lb} / \mathrm{ft}^{3}\right)$ and a Rankine coefficient of earth pressure of 0.5 . Considering the lateral soil pressure which counteracts the internal hydrostatic pressure from the waste, the differential pressure at the base is only $48 \mathrm{kPa}(6.9 \mathrm{psi})$. For this pressure load the required rebar area per one foot section is $1.61 \mathrm{~cm}^{3}\left(0.25 \mathrm{in}^{2}\right)$. The available rebar area in the wall is $5.7 \mathrm{~cm}^{3}\left(0.88 \mathrm{in}^{2}\right)$. The tank structure is found to have sufficient safety margin under this pressure load and is not expected to fail.

5.3.4.4 100-Series SST Failure Mode. This group of tanks are approximately 5 to $10 \mathrm{ft}$ below grade. The internal hydrostatic pressures due to the waste are calculated as $13 \mathrm{psi}$ and $40.7 \mathrm{psi}$ at the springline and base level respectively. The calculated external soil pressures are 8.9 psi and 22.6 psi at the corresponding levels. The maximum differential pressure between the waste and the soil is $18.1 \mathrm{psi}$ at the base level. The required hoop rebar area per one foot section of the wall for this pressure is $1.22 \mathrm{in}^{2}$. The available rebar area in the wall is 7.58 in $^{2}$ (4 rows of \#8 at 5 in.). It is concluded that considerable rebars were placed in the wall for the soil load during the construction and these rebars have sufficient margin to resist the pressure from the waste. Further, when the tank is expanding outward due to the hydrostatic pressure, the counteracting soil pressure becomes passive soil pressure which is considerably greater than the soil pressure based on the at rest soil condition. It is not expected that the tank integrity would be compromised in case of waste overfill.

5.3.4.5 DST Failure Mode. The waste stored in the DSTs is contained in the primary tank which has an internal pressure capacity of around 60 psia. The calculated internal pressure due to overfill of the waste is $40.7 \mathrm{psi}$. It is clear that the primary steel tank has ample margin to resist the pressure in case of waste overfill.

\subsubsection{Excessive Pressure in Annulus}

5.3.5.1 Load Description. As described in Section 5.3.2 a fire accident caused by spilling about $76 \mathrm{~L}(20 \mathrm{gal})$ of gasoline into the annulus of the DSTs is postulated. The transient pressure due to ignition of the gasoline is assumed to reach 140 psig instantaneously in the annulus. This pressure would become an external pressure to the primary tank and internal pressure to the secondary tank. 
5.3.5.2 Tank Grouping. This accident assumes that gasoline is spilled into the annulus of the DSTs which is the only group for this load case.

5.3.5.3 DST Failure Mode. The transient pressure of 140 psig due to a gasoline fire in the annulus is an external pressure on the primary tank. An evaluation of the ultimate buckling stresses of the various thicknesses of the steel plates was performed. Results of the simplified hand calculations show that the limiting buckling stresses are $0.6 \mathrm{psi}$ at the dome, $2 \mathrm{psi}$ at the haunch region, and $1.6 \mathrm{psi}$ at the cylindrical wall (Wagenblast 1996). It is concluded that the primary tank would buckle. As soon as the primary tank has failed, the gases would expand to the entire tank and the pressure intensity would drop considerably. The volumes of the annulus space and the plenum are about equal and were calculated as 20,000 $\mathrm{ft}^{3}$ each. The volume of the gases after the primary tank failure is nearly doubled. It is estimated that the internal pressure acting on the secondary tank is in the neighborhood of 70 psi, about one half of the initial pressure. With the primary tank failed, the secondary tank would behave like a SST and it is judged that the dome could fail by opening up a crack along the dome rebar transition zone at a radius of approximately $27 \mathrm{ft}$ from the apex of the dome where the central radial rebars are spliced with the haunch radial rebars and is a weakened section.

\subsection{HIGH TEMPERATURE ACCIDENT LOADS}

\subsubsection{Load Description}

It is postulated that during a organic salt-nitrate reaction fire the temperature could reach $687^{\circ} \mathrm{C}\left(1,268{ }^{\circ} \mathrm{F}\right)$ at 3,000 seconds (50 minutes). At the bottom layer of the rebar in the dome, $2.5 \mathrm{~cm}$ (approximately 1 in.) from the surface, the temperature could reach to $297{ }^{\circ} \mathrm{C}\left(566^{\circ} \mathrm{F}\right.$ ) at 3,000 seconds and $377{ }^{\circ} \mathrm{C}\left(710^{\circ} \mathrm{F}\right)$ at 4,000 seconds (1.1 hours). At a depth of $5 \mathrm{~cm}$ (approximately 2 in.) from the surface the temperature could reach to $267^{\circ} \mathrm{C}$ $\left(512^{\circ} \mathrm{F}\right.$ ) at 4,000 seconds and continue to rise with time (Lee 1996).

\subsubsection{Tank Grouping}

Based on the accident analysis for the organic salt-nitrate reaction scenario this load case is limited to the 100-Series SSTs.

\subsubsection{0-Series SST Failure Mode}

The thermal load affects the reinforced concrete structures in the following three ways: (1) material degradation, (2) material property change, and (3) temperature induced stresses. At elevated temperatures (above about $\left.93{ }^{\circ} \mathrm{C}\left[200^{\circ} \mathrm{F}\right]\right)$ the strength and elastic modulus of concrete can degrade. Hence, the overall load carrying capacity of the structure could be weakened. Typically thermal stresses consist of stresses induced by a through thickness temperature gradient and stresses induced by the restrained thermal expansion of the structure. Based on the temperatures calculated in the accident analysis (Appendix A) the tank structure would be exposed to temperature 
beyond the normal range. When the structure is subject to a high temperature inside the tank the bottom layer of the concrete could spall off the dome exposing the rebar directly to the high temperature. Under these circumstances, the rebar would be subjected to a differential thermal expansion with the concrete and could potentially lose its bond to the concrete. Meanwhile the effective depth of the section is reduced and the sectional capacity of the dome would be compromised. With the weakened section and increased thermal stress it is likely that the dome would fail by developing extensive cracks in the thinnest region near the apex. Since the dome would have already cracked under the internal pressure, added degradation of the dome due to thermal effects would increase the severity of the damage. Chunks of the protection layer of the concrete would fall off the dome but it is not expected that the dome would collapse.

\subsection{POSTULATED EXTREME DETRIMENTAL CONDITIONS}

For the purpose of a sensitivity study, the following detrimental conditions are postulated and the likely structural behavior and potential failure mode are estimated.

\subsubsection{High-Heat Waste in Tank}

A. Assumption: It is assumed that the waste temperature exceeds $232{ }^{\circ} \mathrm{C}$ $\left(450^{\circ} \mathrm{F}\right)$ for many years.

\section{B. Assessment}

- SSTs - For a Tong-term steady condition as assumed, the temperature in the reinforced concrete tank structure would reach a level close to the waste temperature. This would cause the steel liner plate and the reinforced concrete structure to degrade. The tank wall below the waste level would suffer the most due to this elevated temperature and a significant portion of the wall would be cracked and fail. Liquid waste would be leaked out through these cracks or passages into the adjacent soil. The upper portion of the tank structure would have less damage than the lower portion of the wall. It is likely that the dome would experience the least damage. There might be some small displacement and settlement of the overall tank structure but the upper wall and dome would probably stay intact with some thermal cracks, particularly in the haunch area.

For thermal conditions enveloped by the postulated high temperatures, the tank structural integrity would likely be compromised. 
- DSTs - Since the primary tank is not constrained at the bottom, except for the friction force between the steel plate and the refractory insulation concrete pad, the tank is basically free to expand. At the top of the primary tank, compressive stress would be developed due to constraint by the anchors at the dome. However, this constraint force would cause the concrete tank to crack due to the tensile constraint forces developed by the expanding primary steel tank. Once cracked, the thermal stresses are relieved. The cracks would not lead to failure because the reinforcement steel in the concrete is designed as a "cracked section." This means that if the concrete section has cracks, the bending loads are balanced by the resisting force couple created by the concrete in compression (closed cracks can carry compression loads) and the reinforcing steel in tension across the cracks. The overburden loads are carried in the concrete dome and walls in compression and bending. The shear loads can still be carried by cracked sections through "shear friction." The secondary steel liner and reinforced concrete wall would be subjected to an increase in temperature but nowhere near the temperatures induced in the SSTs of which the liner plate has direct contact with the waste. The areas of discontinuities such as bottom of the tank wall and haunch, would develop some thermal cracks but the dome would not collapse.

\subsubsection{Corrosion of the Tank Structure}

\section{A. Assumption}

a. Small area corrosion - The sizes of corroded area are small, holes less than a few inches in diameter.

b. Large area corrosion - Large areas of steel and concrete are corroded resulted in significant loss of materials, an area of the entire inside face of the wall with a depth of $15 \mathrm{in}$.

\section{B. Assessment}

- SSTs and DSTs

a. Small area corrosion - Damages resulting from the corrosion in this category would cause leakage of the liquid waste through the corroded passage into the adjacent soil but would not cause failure of the tank structure. Also, the damage would be localized and would not cause the dome to collapse.

b. Large area corrosion - In case of significant damage to the tank liner and wall as described in the assumption, the wall structure would loose its strength to resist the applied loads. Fracture and failure in the corroded area (below the waste level) of the wall could cause the tank to develop some displacement and settlement. The upper wall and dome which are not subject to the same corrosive environment as the lower 
portion of the tank, would have less damage. It is believed that the surrounding soil would tend to hold the tank in its position through friction induced forces between the outside face of the wall and soil. The haunch of the tank would function as a tension ring girder to keep the dome from collapsing.

\subsubsection{Aging of Tank Structure}

Factors that could cause degradation of tank structure consist of corrosion, thermal effects, and changes of waste level and specific gravity over time.

A. Corrosion: Pitting and stress-corrosion cracking produce local deteriorations of the structural members that could lead to loss of containment of the liquid waste in the tanks. The uniform corrosion would result in thinning of the steel plate. Both of these types of corrosion, local and global reduction in thickness, could result leakage of the waste material but would not cause dome collapse as described in Section 5.5.2.

- SSTs - The steel liner plate at the inside face of the reinforced concrete tank is a leak barrier. It is not designed as a structural member. Corrosion of the steel liner could create a leak passage but would not compromise the structural integrity of the concrete tank.

- DSTs - The primary steel tank of the DSTs are subject to the corrosive waste material and may result in cracking due to stress-corrosion cracking and holes due to pitting. The liquid waste could leak into the annulus and again cause damage in the secondary liner. Eventually the waste material could leak to the adjacent soil through cracks in the concrete. However, these are local effects and would not cause dome collapse. Similarly, the uniform corrosion could cause the primary steel tank to fail but would not cause the dome collapse.

\section{B. Thermal Effects}

- SSTs - The 241-AX tanks were analyzed for a thermal loading consisting of a temperature rise from $65{ }^{\circ} \mathrm{F}$ to a maximum of $350^{\circ} \mathrm{F}$ in 100 days. The analys is was then continued for a sufficient duration such that stationary creep and cracking condition were established. As a resuit of the analysis for the load combination of all other design loads, the structure was found adequate for these loading conditions.

In the Single-Shell Waste Tank Load Sensitivity Study (Ramble 1983), a bounding thermal case was assumed for the tank structural analysis. In this case the liquid waste was assumed to vary from 93 to $204{ }^{\circ} \mathrm{C}\left(200\right.$ to $400{ }^{\circ} \mathrm{F}$ ) for 100 years. A maximum content of $3.8 \mathrm{ML}$ (1 Mgal) of waste was assumed. This equates to an approximate waste height of $9 \mathrm{~m}(30 \mathrm{ft})$ and a waste specific gravity of 1.7 was used in the analysis. The tank structure was 
found to be adequate for the design loads that included the assumed thermal condition.

It is believed that this could be considered as a bounding case that envelopes the temperature variations due to changes of waste levels and thermal cycling effects over time. The established specific gravities for the waste range from 1.0 to 2.0. Since the hydrostatic pressure due to the liquid waste is not a governing load in tank design, it is judged that a specific gravity of 2.0 would not change the results significantly as compared to the specific gravity of 1.7 which was used in the analysis.

The aging effect could result in some damage in the tank structure but would not cause dome collapse.

- DSTs - Various temperatures were used in the DST analyses. It is believed that a waste temperature of $350{ }^{\circ} \mathrm{F}$ could be used as a bounding temperature. Since the reinforced concrete tanks are similar to the SSTs, it is judged that the structural behavior would be close to the SSTs.

The aging effect could result in some damage in the tank structure but would not cause dome collapse.

\subsubsection{Heavy Loads Suspended From the Dome}

\section{A. Assumption}

a. There are 22 airlift circulators, $15 \mathrm{~cm}(6$ in.) in diameter. Assume waste buildup $30 \mathrm{~cm}$ (12 in.) in diameter over $4.6 \mathrm{~m}$ $(15 \mathrm{ft})$. Use SpG of 1.7 . Load is $9,071 \mathrm{~kg}(20,0001 \mathrm{bs})$.

b. Pump is installed in $1.1 \mathrm{~m}$ (42-in.) diameter riser. Assume $1.1-\mathrm{m}(42-\mathrm{in}$.$) diameter waste buildup over 4.6 \mathrm{~m}(15 \mathrm{ft})$ on the pump shaft. Use SpG of 1.7. Load is $6,803 \mathrm{~kg}$ (15,000 ibs).

c. The weight of steam coil assemblies suspended from the $A Y$ and AZ tank domes is about $10,000 \mathrm{~kg}(22,000 \mathrm{lbs})$.

B. Assessment: The airlift circulators are supported from the dome and the total weight is approximately $9,071 \mathrm{~kg}(20,000 \mathrm{lbs})$. The steam coil weighs about $9,979 \mathrm{~kg}(22,000$ lbs $)$. The pump is assumed to have a weight of about $9,071 \mathrm{~kg}(20,000 \mathrm{lb})$. With the waste weight of $6,803 \mathrm{~kg}(15,000 \mathrm{lbs})$ attached to the pump the overall total weight is $34,927 \mathrm{~kg}(77,000 \mathrm{lbs}$ ) which is about $77 \%$ of the concentrated design load of $45 \mathrm{t}$ (50 tons) for DSTs. This load is not expected to compromise the tank structural integrity. 


\subsubsection{Rebar Corrosion within the Dome}

A. Assumption:

a. Small area corrosion - The sizes of corroded area are small, holes less than a few inches in diameter.

b. Large area corrosion - Large area of concrete and rebar are corroded resulting in significant loss of materials, an area of the entire inside face of the wall with a depth of $38 \mathrm{~cm}$ (15 in).

B. Assessment: For small area corrosion, the weakening of the structure in the corroded area are local in nature and would not cause dome collapse. In case the dome corrosion reaches to the extent as assumed in A.b, significant structural materials, both concrete and reinforcement steel, would fall from the dome. The structure would not have the required section capacity to resist the load. Under this condition, the dome could fail in many ways depending upon the loading conditions. Since the corrosion is typically a slow process, cracking begins at the weakest section which is presumably near the apex region. Holes would be formed due to loss of materials and soil above the dome would fall into the tank. If the corrosion continues to cause more deterioration of the dome structure, a larger hole would be created. Eventually a large portion of the dome would fall off into the waste. If the wall below the haunch were deteriorated to the point that it could not support the haunch then the entire dome could collapse. This scenario is based on the assumption that the corrosion would deteriorate the material as much as $38 \mathrm{~cm}$ ( $15 \mathrm{in}$.) into the dome and no preventive action would be taken to mitigate the corrosion or transfer the waste to a safer location over a long period of time. It is concluded that this scenario is not a credible event.

\subsection{BEYOND DESIGN BASIS EARTHQUAKES}

\subsubsection{Load Description}

The design basis earthquake load for the waste storage tanks was discussed in Section 4.3. The tank structural responses to the above design basis earthquakes vary with the magnitudes of the free-field peak ground accelerations. The failure modes of the tank structure due to seismic excitation could be interpreted in many ways depending on the definition of the failure pattern and potential consequences. In this part of the discussion, the failure mode is defined as that induced from the seismic excitation. Any section of the concrete structure experiencing significant cracking to a degree that the concrete section could not resist the applied load and could not function as a continuous integral part of the concrete structure is considered to have failed. The on-set ground acceleration for this failure mode is assumed as the limiting earthquake load. 


$$
\text { WHC-SD-TWR-RPT-002 REV } 0
$$

\subsubsection{Tank Grouping}

The tanks are grouped into 200-Series SSTs, 100-Series SSTs, and DSTs based on their design configurations.

\subsubsection{0-Series SST Failure Mode}

In Appendix A, an assessment of the 200-Series SSTs was made by using the simplified hand calculations and engineering judgement which is mainly based on the review of code requirements and safety margins built into the design from the safety factors and inelastic capacity of the structural members. The estimated onset peak vertical ground acceleration is $0.48 \mathrm{~g}$. It is assumed that the flat roof would collapse at a vertical ground acceleration of $0.48 \mathrm{~g}$ and result in a hole on top of the tank. If the ground motion is measured in terms of horizontal ground accelerations, then the limiting horizontal ground acceleration that would cause the roof to collapse is $0.72 \mathrm{~g}$, assuming that the vertical is two thirds of the horizontal.

\subsubsection{0-Series SST Failure Mode}

The original design criteria for the SSTs were not found during this evaluation. However as discussed in Section 4.5.2, several post-construction evaluations of the tank structure were performed for the various load combinations including the seismic load. The peak free-field horizontal ground acceleration used in these evaluations is $0.25 \mathrm{~g}$. Resultant stresses in the tank structure in all these analyses were found well within the code allowable limits of which an inherent code safety factor of 1.5 to 2.0 is expected. Further, in the case of making an estimate of the onset load of structural failure, the inelastic capacity of the structural materials should be taken into consideration. Assuming the inelastic factor is around 2.0, an overall load factor of 3.0 to 4.0 could be used for calculating the onset load of structural failure. The ground accelerations calculated from these factors are based on a ground acceleration of $0.25 \mathrm{~g}$ are $0.75 \mathrm{~g}$ and $1.0 \mathrm{~g}$. Because some of the SSTs have experienced high operating temperatures, an onset ground acceleration of $0.6 \mathrm{~g}$ for SSTs is judged to be appropriate.

Based on the existing structural seismic analyses, higher loads are applied by the interaction of the soil and tank at the wall near the base mat. This leads to initial failures at that location. Since the seismic response is non-axisymmetrical, load intensities vary both horizontally and vertically along the wall and the dome. At a horizontal ground acceleration of $0.6 \mathrm{~g}$ the failure mode of the tank structure is likely a localized area with deep cracks in the wall near the footing due to base shear, resulting in some failure in the liner in the same general location. Dome cracking on both the inner and outer face would occur due to the vertical excitation. No continuous large, through-the-thickness cracking is expected. Some spalling may occur due to the high dynamic compressive stresses on the inner wall. 


\subsubsection{DST Failure Mode}

Similar to the SSTS several DST seismic analyses demonstrated that the response of the tanks satisfy the code requirements. Due to relative lower operating temperatures that the DSTs have experienced, the concrete degradation due to thermal load is believed to be less than the SSTS. Based on the same factors used in estimating the ground acceleration for the SST failure mode, the onset ground acceleration for the DSTs is assumed to be at $0.8 \mathrm{~g}$ which is higher than the $\mathrm{g}$-level used for SSTs due to less degradation in the DST concrete.

The failure mode of DSTs at $0.8 \mathrm{~g}$ would be localized. Cracks would develop in the dome, wall, and footing. The primary tank would remain intact at the dome, thus no release would occur at the dome. No open crack failure is predicted in the dome. Possible leak at weld cracks of primary tank due to high stress concentrations at the bottom and corners. Damage to secondary liner at base due to tank wall movement inward and outward resulting in failure at the connection between the base mat and wall is possible.

\subsubsection{Delphi Findings}

A Delphi expert panel evaluated the tank structure of SSTs and DSTs for the seismic loads. Their findings are similar to the above described assessments.

Following are Delphi Structural Panel's conclusions (Leach 1996):

The SSTs begin to fail at an acceleration level of about $0.6 \mathrm{~g}$. This failure mode is defined as follows:

- Localized shear failure of the wall near the footing

- Failure of the liner at some locations due to wall failure near footing

- Dome cracking on both the inner and outer face

- No continuous large through-the-thickness cracking of dome

- Some spalling on inner wall of dome due to high dynamic compressive stress.

The DSTs begin to fail at an acceleration level of about $0.8 \mathrm{~g}$. This failure mode is defined as follows:

- Base of wall shear damage; wall may "walk"

- Dome cracking

- Primary liner holds; no release from the dome 
- Possible leakage may occur, and welds may crack

- Secondary liner at the wall base would be damaged.

These conclusions and the evaluation results were presented in Sections 5.6.4 and 5.6.5 and are in close agreement.

\subsubsection{Probabilistic Safety Assessment Report}

A probabilistic safety assessment report (MacFarlane 1995) presented the results of a risk evaluation of all 177 waste storage tanks. The basis used to determine the failure mode and the corresponding ground acceleration in this risk evaluation was obtained from the assessment of the 24l-AX probabilistic capacity (EQE 1993) which defined the failure mode as the circumferential tensile failure of the tank dome near the haunch. It further stated that this failure mode is controlled largely by the horizontal seismic input. Loads from vertical seismic input and hydrodynamic response of the tank contents were found to have no impact on the failure mode and only a small impact on the estimate of the factor of safety. This definition of failure mode is assuming that the circumferential tensile stress which causes dome failure near the haunch is continuous along the dome circumference. Since seismic loads are non-axisymmetrical, any structure subject to the seismic excitation during an earthquake event would have compression on one side and tension on the opposite side. It is not likely to have either tensile or compressive stress all around in the structure at the same time. The risk evaluation assumed that the SST dome would collapse due to circumferential tensile failure caused by a horizontal ground acceleration of $0.43 \mathrm{~g}$. The dome collapse here is defined as the entire dome shearing off and falling straight down into the tank as a complete section. This assumption is very conservative. In Section 5.6.4 of this report the on-set ground acceleration for tank failure (shear cracks at lower wall near the base mat) is $0.6 \mathrm{~g}$. The difference in $\mathrm{g}$-levels $(0.43 \mathrm{~g}$ versus $0.6 \mathrm{~g})$ that cause the tank failure is solely dependent upon the conservatism considered in the assumptions. A more conservative approach would result in lower g-level and vice versa. The $0.6 \mathrm{~g}$ ground acceleration is based on the evaluation of the existing analytical data and typical structural behavior of the tanks during a seismic excitation and is considered an adequate load for the SST failure mode.

Similarly the $0.8 \mathrm{~g}$ ground acceleration for the onset of failure of the DSTs as discussed in Section 5.6.5 is an appropriate and justifiable seismic load. 
WHC-SD-TWR-RPT-002 REV 0

This page intentionally left blank. 


\subsection{ENGINEERING NEEDS FOR ISSUE RESOLUTION}

\subsection{GENERAL}

In order to continue safe operation of the Hanford Site waste storage tanks, the tank structural integrity must be ensured for present and future waste conditions and operation requirements. The essential factors that affect the structural integrity include loads, material properties, and structural configurations. For the waste storage tanks, the structural configurations are fixed. The only two variables that have impact to the tank structures are loads and material properties. Brief discussions of the engineering needs are provided in the following sections.

\subsection{LOADS}

Loads consist of mechanical loads and thermal loads. Since all tanks are operated within the established load limits it is not expected that current and future loads would significantly compromise the structural integrity. However, as discussed in Chapter 4.0 , thermal loads have the greatest effects to the structural integrity of the tanks. The waste temperatures, particularly the high-heat tanks, should be closely monitored. A program that establishes the current status of the waste temperatures and distributions on the tank structures and continue to monitor and record the temperature variations in the future operation would enhance the engineering ability to readily determine the realistic safety margins at a given time as required for the tank operation. The program should include the following:

- Establish the best estimated historical thermal data based on the temperatures and waste levels reported in WHC-SD-WM-TI-591, Rev. 0 , (Huisingh 1994). Governing temperature-time history and distribution of the past and current thermal information are required for generating a continuous database to be used for future thermal monitoring activities and evaluations of material degradation, thermal creep, and thermal stress of the tank structures.

- Develop a thermal monitoring and survey plan for collecting the temperature data of the tanks, particularly the high-heat tanks. Waste temperatures should be taken at locations of discontinuities of the structure, such as the junction of the wall and the base mat and the springline. Soil temperatures surrounding the tanks should also be collected to verify the assumptions used in the existing analyses and for future use.

- There are currently some outstanding thermal issues that have not been addressed related to the fill and drain cycling. These concern the through wall thermal gradients and the damage incurred to the upper wall sections of the single shell tanks from these high differential temperatures and high rates of temperature change. Mathematical models currently tried to date have not had the ability to accurately model these thermal conditions. 


\subsection{MATERIAL PROPERTIES}

Material degradation due to thermal effects and corrosion could compromise the tank's structural integrity if unmitigated. Methodology of predicting the degraded material properties should be developed to ensure that appropriate material properties are used in the tank structural integrity evaluation in the future.

\subsubsection{Thermal Effects}

As discussed in Chapter 3.0, a set of fitted equations were developed based on test data of PCA samples using Hanford concrete mix parameters (Henager 1988). These equations have been established and used for tank structural analyses. However, there is another set of equations for predicting the material properties for long-term thermal effects being developed by a different approach (Peterson 1994). In order to maintain a consistent and clear track of thermal evaluation, only one set of equations should be used on site. A thorough investigation of the test data and methodology used for these two sets of equations should be conducted. Results of this investigation should be documented and the equations, rules, and provisions should be incorporated into the official engineering procedures.

\subsubsection{Corrosion}

Corrosion of primary steel tank and secondary liner of DSTs and the stee? liner of SSTs could compromise the containment integrity of the waste storage tanks. A program should be developed to monitor the corrosion of these steel structures. The program should include the following two investigative activities (Jensen and Oh1 1996):

- Determination of the current condition. Develop a plan to assess the current condition of the steel structures by field survey, inspection, testing, and analysis of the gathered corrosion data.

- In conjunction with planned annuli NDT examinations, a program for visual inspections of the tank interiors and sampling of the waste chemical contents should be developed for all tanks to generate a broad database. A consistent corrosion prediction methodology using the database should be established for the assessment of the useful life of the tanks structures.

In addition, to minimize future leaks of sound SSTs that are not going to be interim stabilized in the near future and are suspected of having liquids that do not meet the tank waste specifications (Anantatmula et al. 1994)

- Add a corrosion inhibitor (e.g., sodium hydroxide) to assure that the stored waste is in the passive region. 


\subsection{STRUCTURAL ANALYSIS}

Most accident loads are dynamic in nature. Input for the structural evaluation of these loads are limited to either bounding case or peak loads. Detailed structural responses under dynamic loads are often desirable. In order to provide sound analytical justification to the structural failure mechanism for those accident loads, more accurate prediction by computerized analysis is required, particularly the accidents that are transient/dynamic in nature. It is recommended that analytical data be generated for the following accident loads.

- Drop Load Case. Impact analys is by finite-element method is required. Equipment weight, height, and the impact area that would be dropped should be defined. Expected results of this analysis would be impact energy, structural response in terms of velocity and displacement, and post-accident condition of the structure.

- Hydrogen Deflagration, Solvent Fire, and Organic Salt-Nitrate Reaction Load Cases. Transient pressure and thermal analysis by finite element method is required. Transient pressure and thermal time history data should be generated and provided for the structural evaluation. Expected output of this analys is would be stresses and strains at various critical sections of the concrete structure and post-accident structural conditions.

- Thermal Effects Due to High Waste Temperature. Long-term thermal load should be identified and a thermal model established for the computer analysis. Elevated temperature-time history and thermally degraded concrete properties should be defined for input of the analysis. Expected output should be temperature gradients and thermal stresses at the critical sections of the concrete structure. 
WHC-SD-TWR-RPT-002 REV 0

This page intentionally left blank. 


\subsection{CONCLUSIONS}

The structural integrity and the potential failure modes of the SSTs and DSTs were evaluated. The structural integrity was assessed mainly based on the existing documents consisting of research and analysis of the material properties, loadings, and the structural capability under the combined effects of normal operating loads and ground motions during a seismic event. The potential failure modes of the tank structures were estimated by using the existing analytical data, hand calculations, and engineering judgement.

In the structural integrity evaluation, it was found that both the SSTs and the DSTs have a considerable safety margin under the operating conditions. The structural stresses induced by the mechanical loads including dead load, live load, soil load, pressures, and seismic responses are well within the code allowable limits. The thermal load has the greatest impact on the tank structures. Elevated temperatures affect the concrete structure in three ways: material degradation, thermal induced secondary stresses, and thermalcreep due to long term concrete exposure to the high temperatures. Several programs were conducted to investigate the thermal effects to the concrete properties and thermal stresses. As discussed in Chapters 3.0 and 4.0 of this report, equations for estimating the degraded concrete properties as a function of temperature and time were established. Structural analyses based on the bounding temperature-time history and the degraded material properties corresponding to the time-history were performed. Results indicate that tank structures have the appropriate capability to resist the combined mechanical and thermal loads. It is concluded that the Hanford Site waste storage tanks are adequate for the normal operating loads with current restrictions in place.

The second part of the evaluation is to make an estimate of the potential failure modes of the tanks for various accident scenarios consisting of the following load cases: excessive concentrated load due to heavy equipment above the tank; excessive uniform load above the tank; excessive load drop on the dome; internal pressures and thermal loads due to flammable gas deflagration, organic salt-nitrate reaction, and solvent fire; high internal vacuum as a result of post solvent fire cooling effect; and, beyond design basis earthquake. Both SSTs and DSTs have considerable safety marg in against concentrated and uniform loads above the tanks. The on-set concentrated load to initiate the failure of SSTs is estimated to be in the range of 300 ton to 600 ton, and for DSTs is between 400 ton and 800 ton. The maximum uniform load that would cause dome failure of both the SSTS and DSTs is equivalent to additional $5.2 \mathrm{~m}(17 \mathrm{ft})$ of soil overburden on top of dome. The tank structure would behave differently for a highly dynamic transient internal pressure and a slowly building internal pressure. However under the postulated pressure loads as discussed in Section 5.0, the tank structure would likely fail and result in cracks and openings in the dome. The worst case of a drop load condition was assumed as a drop into the pump pit. The pit floor would be perforated if an equipment such as a vertical pump having an impact energy of 200,000 ft-1bs and a impact area corresponding to a $2 \mathrm{ft}$ diameter area dropped directly onto a 15-in. thick bare concrete pit floor. The pit floor rests on top of the 15-in. thick dome. In the case of a high vacuum condition (between 6 to 8 psig) the structural integrity of the reinforced concrete tank would not be compromised. However the primary tank 
of a DST would 1ikeiy fail due to high buckling stresses. When the tank structure is subjected to the high temperatures the tank structure would suffer certain degree of damage depending on the through-the-wall temperature gradients but unlikely cause the dome to collapse. The SSTs would be able to withstand a beyond-design-basis earthquake excitation of $0.6 \mathrm{~g}$ and the DSTs would withstand an earthquake excitation of $0.8 \mathrm{~g}$. Under these ground accelerations cracks in the wall of both SSTs and DSTs are expected. The resulting failures associated with the accident scenarios are addressed in Chapter 5.0, herein. Resulting offsite release consequences are addressed in the TWRS-FSAR.

In addition to the effects of loads and thermal degradation of concrete to the structural integrity, corrosion of structural steel is a major concern for the safe operation of the waste storage tanks. Many SSTs have been identified as leakers. Exact conditions of the steel 1 iner plates are not known but stress-corrosion cracking is believed to be the cause for the SST leakage. No leaks have been found in the DSTs. However, pitting corrosion and stress-corrosion cracking could breach the containment of the tank and shorten their service life. Inspection of the walls and knuckle regions for leaks by visual and ultrasonic methods will provide adequate basis for timeto-future-leakage estimates. 


\subsection{REFERENCES}

Abrams, M. S. and M. P. Gillen, 1981, Nondestructive and Laboratory Tests, 202-A Purex Canyon Building, RHO-R-29, Rockwell Hanford Operations, Richland, Washington.

ACI, 1990, "Code Requirements for Nuclear Safety Related Concrete Structures," ACI 349, ACI Manual of Concrete Practice, American Concrete Institute, Detroit, Michigan.

ACI, 1994, "Building Code Requirements for Reinforced Concrete, "ACI 318, ACI Manual of Concrete Practice, American Concrete Institute, Detroit, Michigan.

Aguirre, H., 1994, Aging Waste Facility Interim Operational Safety Requirements, WHC-SD-WM-0SR-004, Rev. 0, Westinghouse Hanford Company, Richland, Washington.

Anantatmula, R. P., E. B. Schwenk, and M. J. Danielson (PNL), 1994, Characterization of the Corrosion Behavior of the Carbon Stee 7 Liner in Hanford Site Single-Shell Tanks, WHC-EP-0772, Rev. 0, Westinghouse Hanford Company, Richland, Washington.

Anantatmula, R. P., and P. C. Oh1, 1996, DST Remaining Useful Life Estimate, WHC-SD-WM-ER-585, Rev. 0, Westinghouse Hanford Company, Richland, Washington.

ANSYS, 1982, Engineering Analysis System, Swanson Analysis Systems, Inc., Houston, Pennsylvania.

ARH, 1969, Model Test of Waste Disposal Tanks, ARH-R-47, test performed by Wiss, Janney, Elstner and Associates for Atlantic Richfield Hanford Company, Richland, Washington.

ARH, 1974, Analysis of Underground Waste Storage Tanks 241-SY at Hanford, Washington, ARH-R-172, John A. Blume \& Associates, Engineers, San Francisco, Cal ifornia.

ARH, 1976, Analysis of Underground Waste Storage Tanks 241-AW at Hanford, Washington, ARH-R-219, URS/John A. Blume and Associates, Engineers, At lantic-Richfield Hanford Company, Richland, Washington.

ASCE, 1990, Minimum Design Loads for Buildings and other Structures, ASCE 7-88, American Society of Civil Engineers, New York, New York.

Babad, H., 1993, Tank Waste Chemistry - A New Understanding of Waste Aging, Hanford Technical Exchange, Richland, Washington.

Baynes, P. A., et al., 1993, Tank Waste Remediation System Mission Analysis, WHC-EP-0627, Rev. 0, Westinghouse Hanford Company, Richland, Washington. 
Becker, D. L., 1994, Accelerated Safety Analyses - Structural Analyses Phase I, Structural Sensitivity Evaluation of Single- and Double-Shell Waste Storage Tanks, WHC-SD-WM-SARR-012, Westinghouse Hanford Company, Richland, Washington.

Brownel1, L. E., 1958, Instability of Steel Bottoms in Waste Storage Tanks, Hanford Atomic Products Operation, HW-57274, General Electric-Hanford Atomic Products Operation, Richland, Washington.

Campbe11, G. D., 1981, Heat Transfer Analysis for In-Situ Disposal of Nuclear Waste in Single- and Double-Shell Underground Storage Tanks, RHO-LD-171, Rockwell Hanford Operations, Richland, Washington.

Carlos, W. C., and J. P. Hauptmann, 1992, Comparison of Design, Materials, Fabrication and Waste Environments of the Hanford Site and Savannah River Plant Single-She7l Steel Waste Tanks, WHC-SD-WM-SMSL-015, Westinghouse Hanford Company, Richland, Washington.

Christensen, G. M., 1993, Flammable Gas Safety Issue Review - Tank 241SY101, WHC-EP-0578, Westinghouse Hanford Company, Richland, Washington.

Davis, H. S., 1967, "Effects of High-Temperature Exposure on Concrete," Materials Research and Standards, Vol. 7, No. 10, 1967, pp. 452-459.

Defigh-Price, C., 1982, Status of Tank Assessment Studies for Continued In- . Tank Storage of Hanford Defense Waste, RHO-RE-ST-4P, Rockwel] Hanford Operations, Richland, Washington.

Divine, J. R., and W. M. Brown, 1984, Tank Corrosion Study High Temperature Corrosion Tests, (Four, Eight, and Twelve Months Evaluation), Letter Reports to Rockwe1l International, Pacific Northwest Laboratory, Richland, Washington.

DOE, 1986, Safety Analysis and Review System, DOE Order 5481.1B, U.S. Department of Energy, Washington, D.C.

DOE, 1989, General Design Criteria for U.S. Department of Energy, DOE Order 6430.1A, U.S. Department of Energy, Washington, D.C.

DOE, 1992, Nuclear Safety Analysis Reports, DOE Order 5480.23, U.S. Department of Energy, Washington, D.C.

D0E, 1993a, Natural Phenomena Hazards Mitigation for Department of Energy Facilities, DOE Order 5480.28 , U.S. Department of Energy, Washington, D.C.

DOE, 1993b, Natural Phenomena Hazards Performance Categorization Guidelines for Structures, Systems, and Components, DOE-STD-1021-93, U.S. Department of Energy, Washington, D.C.

DOE, 1994, Natural Phenomena Hazards Design and Evaluation Criteria for Department of Energy Facilities, DOE-STD-1020, U.S. Department of Energy, Washington, D.C. 
DOE, 1995, Facility Safety, DOE Order 420.1, U.S. Department of Energy, Washington, D.C.

Dougherty, L. F., 1994, Single-Shell Tank Interim Operational Safety Requirements, WHC-SD-WM-0SR-005, Rev. 0, Westinghouse Hanford Company, Richland, Washington.

EERC, 1969, Dynamic Stress Analysis of Axisymmetric Structures Under Arbitrary Loading, EERC 69-10, Earthquake Engineering Research Center, College of Engineering, University of Cal ifornia, Berkeley, California.

EERC, 1975, A Computer Program for Approximate 3-D Analysis of Soi7-Structure Interaction Problems, EERC 75-30, Earthquake Engineering Research Center, College of Engineering, University of California, Berkeley.

Ecology, EPA, and DOE, 1994, Hanford Federal Facility Agreement and Consent Order, 2 vols., as amended, Washington State Department of Ecology, U.S. Environmental Protection Agency, and U.S. Department of Energy, 01 ympia, Washington.

Edgemon, G. L., and R. P. Anantatmula, 1995, Hanford Waste Tank System Degradation Mechanisms, WHC-SD-WM-ER-414, Rev. 0, Westinghouse Hanford Company, Richland, Washington.

EQE, 1993, Probabilistic Capacity of the 241-AX Underground Waste Storage Tanks to Withstand Seismic Excitation, D. A. Wesley and D. G. Honegger, EQE Project Number: 52205.01, EQE Engineering Consultants, San Francisco, California. (this report is included as Appendix $B$ in MacFarlane et al. 1995)

Fisher, T. W., and D. J. Shank, 1994, Single- and Double-Shell Waste Tank Design Comparisons at Hanford, Washington, WHC-SD-WM-TI-598, Rev. 0, Westinghouse Hanford Company, Richland, Washington.

GC-LOAD-01, 1996, A/E Standard-Civil/Structural, Design Loads for Facilities, GC-Load-01, Rev. 1, ICF Kaiser Hanford Company, Richland, Washington.

Gerber, M.S., 1996, Historical Overview of Wastes Disposed to the Soil Column and to Tanks at the Hanford Site, EE.33, Collection of Viewgraphs, Westinghouse Hanford Company, Richland, Washington, August.

Gillen, M. P., 1978, Strength and Elastic Properties of Concretes from Waste Tank Farms, RHO-C-22, Construction Technology Laboratories, Port 1 and Cement Association, Rockwell Hanford Operations, Richland, Washington.

Gillen, M. P., 1982, Strength and Elastic Properties Tests of Hanford Concrete Cores - 241-SX-115 Tank and 202-A PUREX Canyon Building, RHO-RE-CR-2, Rockwell Hanford Operations, Richland, Washington.

Grigsby, J. M., 1996, Final Unmitigated Pressure Transient Results for Solvent Fires in SSTS, DSTS, and DCRTS, [memo to F. C. Han (WHC), Apri1 16], $G$ \& $P$ Consulting, Inc., Richland, Washington. (included in Appendix A). 
Han1on, B. M., 1996, Waste Tank Summary Report for Month Ending May 31, 1996 , WHC-EP-0182-99, Westinghouse Hanford Company, Richland, Washington.

Henager, C. H., et al., 1988, Modeling of Time-Variant Concrete Properties at Elevated Temperatures, PNL-7779, Pacific Northwest Laboratory, Richland, Washington.

Heubach, E. C., 1994, Double-Shell Tank Interim Operational Safety Requirements, WHC-SD-WM-OSR-016, Rev. 0, Westinghouse Hanford Company, Richland, Washington.

Huisingh, J. S., N. D. Ha, and B. D. Flanagan, 1994, Maximum Surface Level and Temperature Histories for Hanford Waste Tanks, WHC-SD-WM-TI-591, Rev. 0, Westinghouse Hanford Company, Richland, Washington.

Hyde, L. L., et al., 1994, Structural Sensitivity Evaluations of Single- and Double-Shell Waste Tanks for Accelerated Safety Analysis - Phase I, WHC-SD-WM-DA-150, Rev. 0, Westinghouse Hanford Company, Richland, Washington.

ICB0, 1994, Uniform Building Code, International Conference of Building officials, Whittier, California.

JABE, 1976a, Structural Evaluation of Proposed 241-AW Tanks: Phase I Investigation of Effect of Criteria Changes, JABE-VITRO-05, San Francisco, California.

JABE, 1976b, Analysis of Underground Waste Storage Tanks 241-AW at Hanford, Washington, JABE-VITRO-07, San Francisco, California.

Jensen, C. E., and P. C. Ohl, 1996, Tank Waste Remediation System Life Management Program, WHC-SD-WM-PLN-068, Rev. 1, Westinghouse Hanford Company, Richland, Washington.

Julyk, L. J., et al., 1995, Structural Acceptance Criteria for the Evaluation of Existing Double-Shell Waste Storage Tanks Located at the Hanford Site, Richland, Washington, WHC-SD-WM-DGS-003, Rev. 0, West inghouse Hanford Company, Richland, Washington.

Karr, P. H. and D. C. Stark, 1981, Interim Report on the Effects of Waste Solutions on Reinforced Hanford Concrete, RHO-C-52, Rockwell Hanford Operations, Richland, Washington.

Kassir, M. K., K. K. Bandyopadhyay, and M. Reich, 1993, Thermal Degradation of Concrete in the Temperature Range from Ambient to $315^{\circ} \mathrm{C}\left(600^{\circ} \mathrm{F}\right)$, BNL 52384, prepared for the U.S. Department of Energy, by Brookhaven National Laboratories, Associated Universities, Inc., Upton, New York.

Lee, S. J., 1996, Cracked Dome Area During Solid Organic Reaction, [letter to F. C. Han (WHC), April 3], Fauske \& Associates, Inc., Burr Ridge, Illinois. (included in Appendix A). 
Leach, C. E., et a1., 1993, Hanford Site Tank Farm Facilities Interim Safety Basis, WHC-SD-WM-ISB-001, Rev. 0, Vol. 1 and 2, Westinghouse Hanford Company, Richland, Washington, July.

Leach, L., 1996, DELPHI Expert Panel Evaluation of Hanford High-Level Waste Tank Failure Modes, Fragilities, and Release Quantities, WHC-SD-TWR-RPT-003, Rev. 0, Westinghouse Hanford Company, Richland, Washington.

LLNL, 1988, Design and Evaluation Guidelines for Department of Energy Facilities Subject to Natural Phenomena Hazards, UCRL 15910, Lawrence Livermore National Laboratory, Livermore, California.

MacFarlane, D. R., et al., 1995, Probabilistic Safety Assessment for Hanford High-Level Waste Tanks, LA-UR-95-1900, Los Alamos National Laboratory, Los Alamos, New Mexico.

Moore, C. J., and W. S. Peterson, 1995, Concrete Structural Analysis Tools and Properties for Hanford Site Waste Tank Evaluation, WHC-SD-WM-DA-207, Rev. 0, prepared by ICF Kaiser Hanford Company, for Westinghouse Hanford Company, Richland, Washington.

NONSAP-C, 1978, A Nonlinear Stress Analysis Program for Concrete Containments Under Static, Dynamic and Long-Term Loadings, NUREG/CR-0416, LA-7496-MS, prepared for Division of Reactor Safety Research, Office of Nuclear Regulatory Research, U.S. Nuclear Regulatory Commission, Washington, D.C.

Peterson, W. S., 1994, Evaluate of Strength and Modulus Degradation Due to Temperature Effects on Hanford Concrete, WHC-SD-WM-DA-153, Rev. 0, Westinghouse Hanford Company, Richland, Washington.

PCA, 1981, Effects of Long-Term Exposure to Elevated Temperature on the Mechanical Properties of Hanford Concrete, RHO-C-54, prepared by Portland Cement Association for Rockwell Hanford Operations, Richland, Washington.

Pianka, E. W., 1994, Soil Weight at Hanford Waste Storage Tank Locations, WHC-SD-WM-SOIL-001, Rev. OB, Westinghouse Hanford Company, Richland, Washington.

Pianka, E. W., 1995, Soil Load above Hanford Waste Storage Tanks, WHC-SD-WM-TI-665, Rev. OB, Westinghouse Hanford Company, Rich1 and, Washington.

PNL, 1979, Strength and Elastic Properties of 1580-day Hanford Concrete Cylinders at Room Temperature and $350^{\circ} \mathrm{F}$, prepared by Construction Technology Laboratories, A Division of the Portland Cement Association, Skokie, Illinois, for Battelle Pacific Northwest Laboratory, Richland, Washington.

PNL, 1995, Climatological Data Summary 1994, with Historical Data, PNL-10553, Pacific Northwest Laboratory, Richland, Washington. 
Ramble, A. L., 1983, Single-Shell Waste Tank Load Sensitivity Study, SD-RE-TI-012, Rev. A-0, Rockwe11 Hanford Operations, Richland, Washington.

Rashid, Y. R., 1976, Thermal-Creep and U7timate Load Analysis of the 241-AX Structure, ARH-C-11, Richland, Atlantic Richfield Hanford Company, Richland, Washington.

Rashid, Y. R., 1980, Modeling and Analysis of Underground Nuclear Waste Containment, ANA 80-1, Anatech International Corporation, La Jolla, California.

RH0, 1978, Analysis of Underground Waste Storage Tanks 241-AX at Hanford, Washington, RHO-R-6, URS/John A. Blume and Associates, San Francisco, California.

RH0, 1982a, Long Term Effects of Waste Solutions on Concrete and Reinforcing Steel, RHO-RE-CR-8P, Rockwell Hanford 0perations, Richland, Washington.

Schwenk, E. B., 1992, Tank Wall Measurement Technical Study and Specification, WHC-SD-W151-ES-002, Westinghouse Hanford Company, Richland, Washington.

Scott, M. A., 1995, ASA Structural Analyses Phase II, ACI Code Evaluations of The Maximum Loads in The Concrete Dome, Haunch and Upper Wall of DoubleShell Waste Storage Tanks, WHC-SD-WM-SARR-032, Westinghouse Hanford Company, Richland, Washington.

SDC 4.1, 1993, "Standard Arch-Civil Design Criteria-Design Loads for Facilities, "Hanford Plant Standards, SDC 4.1, Rev. 12, U.S. Department of Energy - Richland 0perations office, Richland, Washington. (superseded by GC-LOAD-01 effective March 15, 1996)

Shannon \& Wilson, 1974, Foundation Investigation, Proposed 241-SY Storage Tanks, U.S. Atomic Energy Commission Hanford Reservation, Richland, Washington.

Shippe11, R. T., G. H. Beeman, and C. A. Williams, 1980, Continued Analysis of the Load-Displacement Behavior Study of the 104-SX Tanks on the 241-SX Tank Farm, Hanford, Washington, EM-ST1A-022, REP-080180, Battelle Pacific Northwest Laboratory, Richland, Washington.

Smith, H. D., 1992, Corrosion Studies of Carbon Steel under Impinging Jets of Simulated Slurries of Neutralized Current Acid Waste and Neutralized Cladding Removal Waste, PNL-7816, Pacific Northwest Laboratory, Richland, Washington.

Sullivan, L. H., 1995, A Safety Assessment for Proposed Pump Mixing Operations to Mitigate Episodic Gas Release in Tank 241-SY-101: Hanford Site, Richland, Washington, LA-UR-92-3196, LoS Alamos National Laboratory, Los Alamos, New Mexico.

Tallman, A. M., 1989, Natural Phenomena Hazards, Hanford Site, Washington, WHC-SA-0606A, Westinghouse Hanford Company, Richland, Washington. 
TID-7024, 1963, Nuclear Reactors and Earthquakes, prepared by Lockheed Aircraft Corporation and Holmes \& Narver, Inc., for the Division of Reactor Development, U.S. Atomic Energy Commission, Washington, D.C.

Wallace, D. A., et al., 1994, Seismic Evaluation of Tank 241-C-106 in Support of Retrieval Activities, WHC-SD-W320-ANAL-002, Rev. 0 and 0A, Westinghouse Hanford Company, Richland, Washington.

Wagenblast, G. R., 1996, The Effects of Structural Loads on DCRTs, Catch Tanks, and 200 Series Tanks, WHC-SD-WM-TI-775, prepared by ICF Kaiser Hanford Company for Westinghouse Hanford Company, Richland, Washington.

WHC, 1966, TWRS Mission Analysis, WHC-SD-WM-MAR-008, Westinghouse Hanford Company, Richland, Washington.

WHC, 1990, Summary Status on the Seismic Evaluations of Hanford Site Radioactive Waste Storage Tanks, WHC-EP-0373, Westinghouse Hanford Company, Richland, Washington.

WHC, 1994a, Supporting Document for the Historical Tank Content Estimate for A Tank Farm, WHC-SD-WM-ER-308, Rev. 0, prepared by ICF Kaiser Hanford Company for Westinghouse Hanford Company, Richland, Washington.

WHC, 1994b, Supporting Document for the Historical Tank Content Estimate for AX Tank Farm, WHC-SD-WM-ER-309, Rev. 0, Prepared by ICF Kaiser Hanford Company for Westinghouse Hanford Company, Richland, Washington.

WHC, 1994c, Supporting Document for the Historical Tank Content Estimate for $B$ Tank Farm, WHC-SD-WM-ER-310, Rev. 0, prepared by ICF Kaiser Hanford Company for Westinghouse Hanford Company, Richland, Washington.

WHC, 1994d, Supporting Document for the Historical Tank Content Estimate for BX Tank Farm, WHC-SD-WM-ER-311, Rev. 0, prepared by ICF Kaiser Hanford Company for Westinghouse Hanford Company, Richland, Washington.

WHC, 1994e, Supporting Document for the Historical Tank Content Estimate for BY Tank Farm, WHC-SD-WM-ER-312, Rev. 0, prepared by ICF Kaiser Hanford Company for Westinghouse Hanford Company, Richland, Washington.

WHC, 1994f, Supporting Document for the Historical Tank Content Estimate for C Tank Farm, WHC-SD-WM-ER-313, Rev. 0, prepared by ICF Kaiser Hanford Company for Westinghouse Hanford Company, Richland, Washington.

WHC, 1994g, Supporting Document for the Historical Tank Content Estimate for $S$ Tank Farm, WHC-SD-WM-ER-323, Rev. 0, prepared by ICF Kaiser Hanford Company for Westinghouse Hanford Company, Richland, Washington.

WHC, 1994h, Supporting Document for the Historical Tank Content Estimate for SX Tank Farm, WHC-SD-WM-ER-324, Rev. 0, prepared by ICF Kaiser Hanford Company for Westinghouse Hanford Company, Richland, Washington. 
WHC, 1994i, Supporting Document for the Historical Tank Content Estimate for U Tank Farm, WHC-SD-WM-ER-325, Rev. 0, prepared by ICF Kaiser Hanford Company for Westinghouse Hanford Company, Richland, Washington.

WHC, 1994j, Historical Tank Content Estimate for the Southwest Quadrant of the Hanford 200-West Area, WHC-SD-WM-ER-352, Rev. 0, prepared by ICF Kaiser Hanford Company for Westinghouse Hanford Company, Richland, Washington.

WHC, 1994k, Static Internal Pressure Capacity of Hanford Single-Shell Waste Tanks, WHC-SD-WM-TI-623, Rev. 0, Prepared by ADVENT Engineering Services, Inc. for Westinghouse Hanford Company, Richland, Washington.

WHC, 1995a, Supporting Document for the Southeast Quadrant Historical Tank Content Estimate Report for AN-Tank Farm, WHC-SD-WM-ER-314, Rev. 0 , C. H. Brevick, L. A. Gaddis and W. W. Pickett, prepared by ICF Kaiser Hanford Company for Westinghouse Hanford Company, Richland, Washington.

WHC, 1995b, Supporting Document for the Southeast Quadrant Historical Tank Content Estimate Report for AP-Tank Farm, WHC-SD-WM-ER-315, Rev. 0, C. H. Brevick, L. A. Gaddis and W. W. Pickett, prepared by ICF Kaiser Hanford Company for Westinghouse Hanford Company, Richland, Washington.

WHC, 1995c, Supporting Document for the Southeast Quadrant Historical Tank Content Estimate Report for AW-Tank Farm, WHC-SD-WM-ER-316, Rev. 0, C. H. Brevick, L. A. Gaddis and W. W. Pickett, prepared by ICF Kaiser Hanford Company for Westinghouse Hanford Company, Richland, Washington.

WHC, 1995d, Supporting Document for the Southeast Quadrant Historical Tank Content Estimate Report for AY-Tank Farm, WHC-SD-WM-ER-317, Rev. 0 , C. H. Brevick, L. A. Gaddis and W. W. Pickett, prepared by ICF Kaiser Hanford Company for Westinghouse Hanford Company, Richland, Washington.

WHC, 1995e, Supporting Document for the Southeast Quadrant Historical Tank Content Estimate Report for AZ-Tank Farm, WHC-SD-WM-ER-318, Rev. 0, C. H. Brevick, L. A. Gaddis and W. W. Pickett, prepared by ICF Kaiser Hanford Company for Westinghouse Hanford Company, Richland, Washington.

WHC, 1995f, Supporting Document for the Southeast Quadrant Historical Tank Content Estimate Report for SY-Tank Farm, WHC-SD-WM-ER-319, Rev. O, C. H. Brevick, L. A. Gaddis and W. W. Pickett, prepared by ICF Kaiser Hanford Company for Westinghouse Hanford Company, Richland, Washington.

WHC, 1995g, Historical Tank Content Estimate for the Southeast Quadrant of the Hanford 200 Areas, WHC-SD-WM-ER-350, Rev. 0, C. H. Brevick, L. A. Gaddis and W. W. Pickett, prepared by ICF Kaiser Hanford Company for Westinghouse Hanford Company, Richland, Washington.

WHC, 1995h, Single Shell Tanks Interim Operational Safety Requirements, WHC-SD-WM-OSR-005, Rev. OB, Westinghouse Hanford Company, Richland, Washington. 
WHC, 1995i, Double Shell Tanks Interim Operational Safety Requirements, WHC-SD-WM-OSR-016, Rev. OB, Westinghouse Hanford Company, Richland, Washington.

WHC, 1996a, Tank Waste Remediation System Final Safety Analysis Report, WHC-SD-WM-SAR-067, Rev. A, Westinghouse Hanford Company, Rich7and, Washington.

WHC, 1996b, Tank Waste Remediation System Final Safety Analysis Report Project Plan, WHC-SD-WM-PLN-113, Rev. 0, Vols. I and II, Westinghouse Hanford Company, Richland, Washington.

WHC-CM-1-12, 1996, Design and Evaluation - Structural Design and Evaluation Criteria, Draft, Westinghouse Hanford Company, Richland, Washington.

WHC-CM-4-46, 1996, Nuclear Facility Safety Analysis Manual, Westinghouse Hanford Company, Richland, Washington.

Wodrich, D. D., R. E. Van der Cook, and J. G. Hill, 1992, Presentation at High Level Waste Tank System Structural Integrity Workshop, Westinghouse Hanford Company, Richland, Washington. 
WHC-SD-TWR-RPT-002 REV 0

This page intentionally left blank. 
Figure 1-1. DOE Hanford Site.

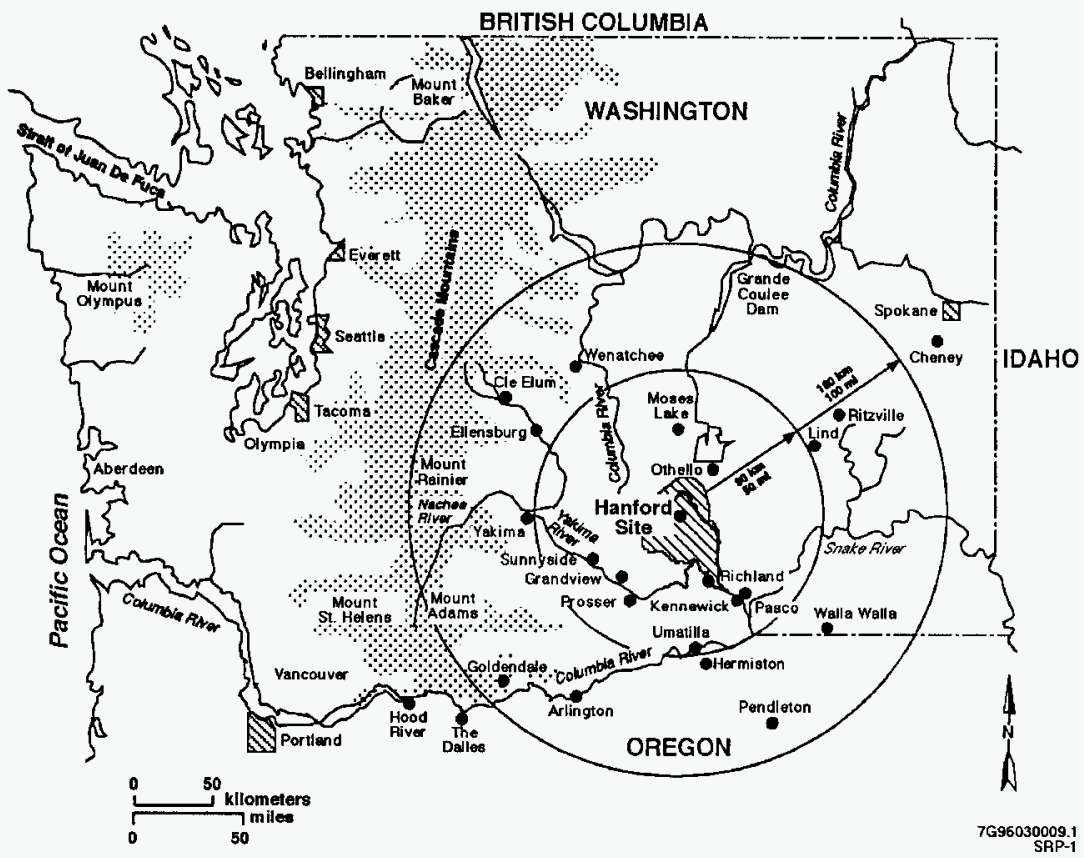


Figure 1-2. Location of 200 East and 200 West Area.

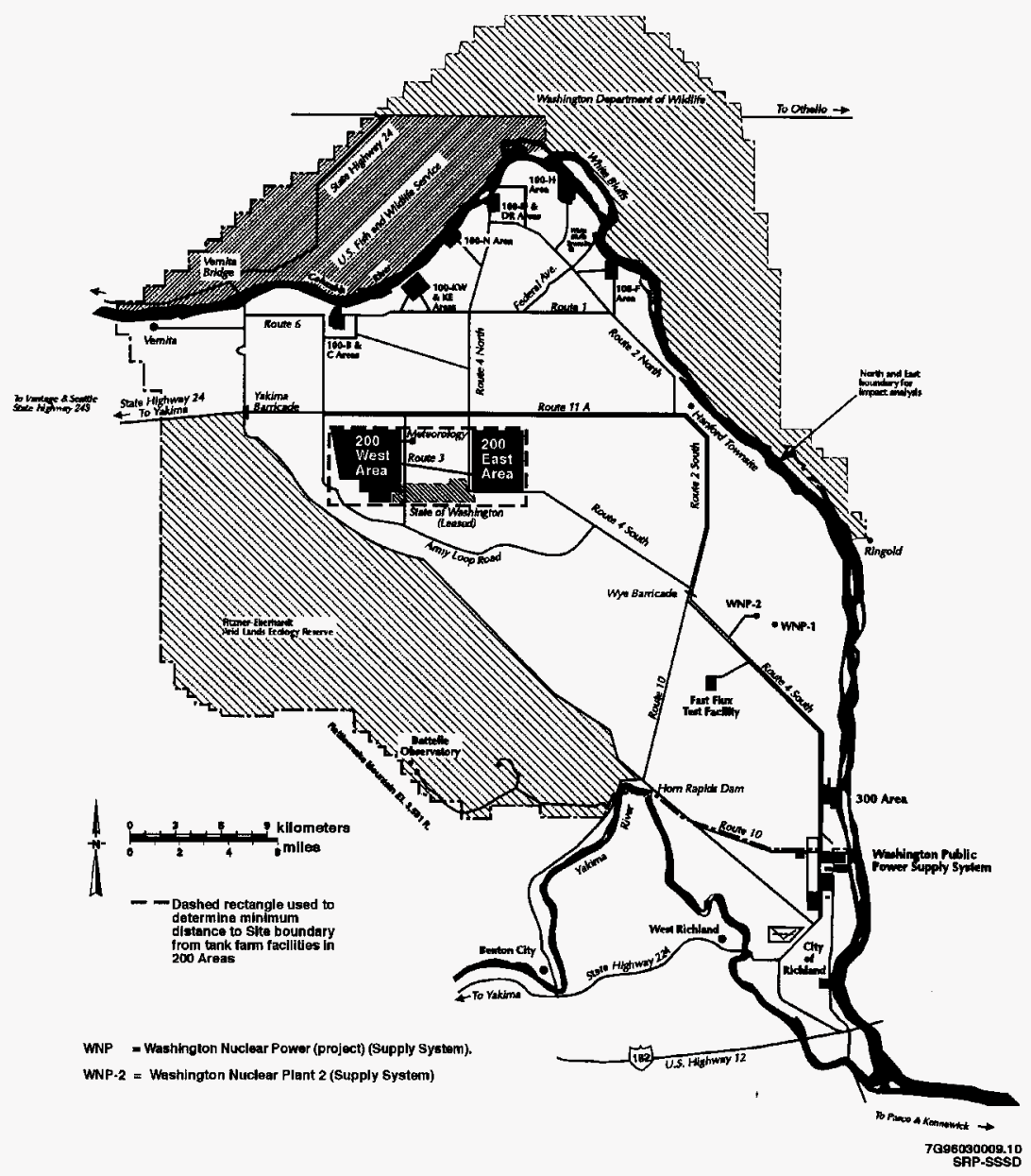


WHC-SD-TWR-RPT-002 REV O

Figure 2-1. DOE Hanford Site Tank Farm Locations.

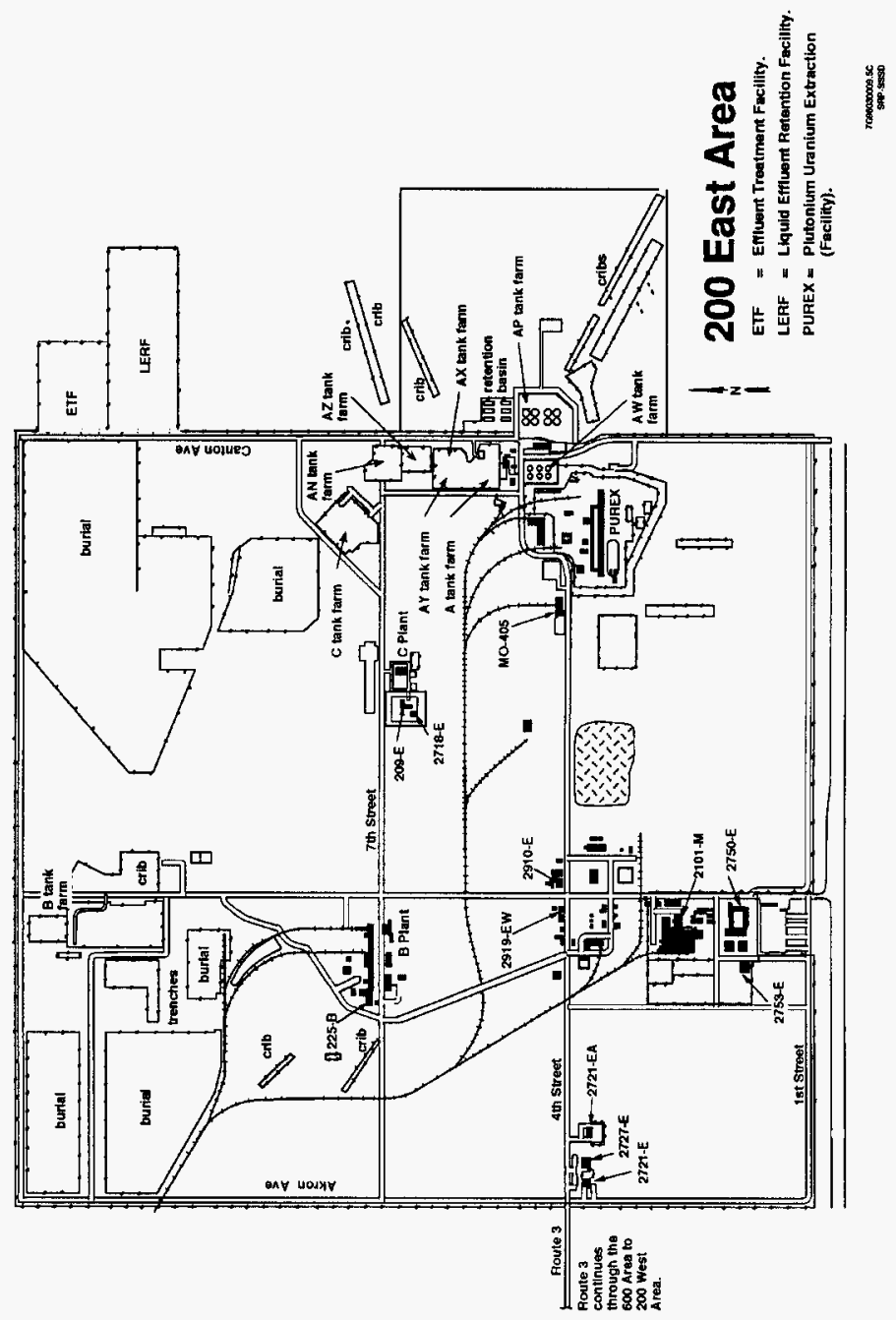


WHC-SD-TWR-RPT-002 REV 0

Figure 2-2. DOE Hanford Site Tank Farm Locations.

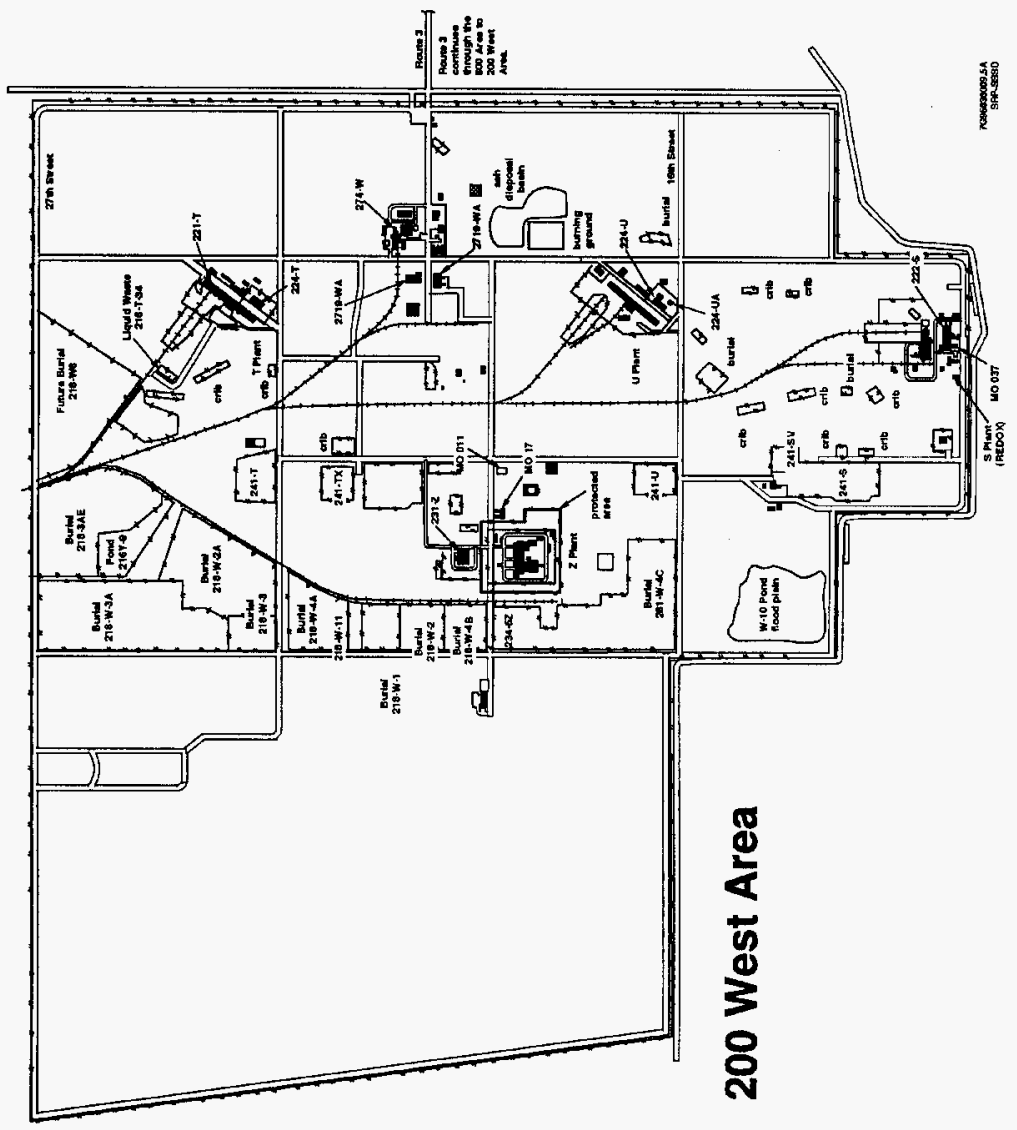


Figure 2-3. Cross-Section of Single-She11 Tanks.

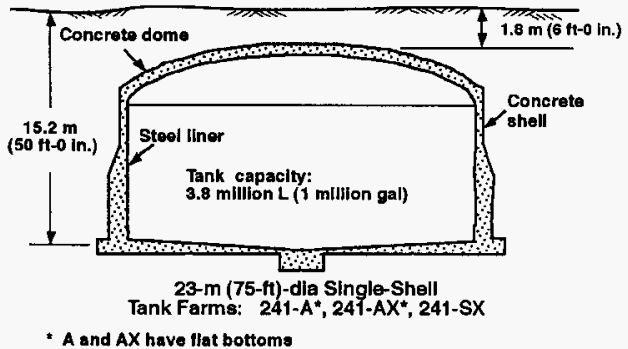

- $A$ and $A X$ have flat bottom
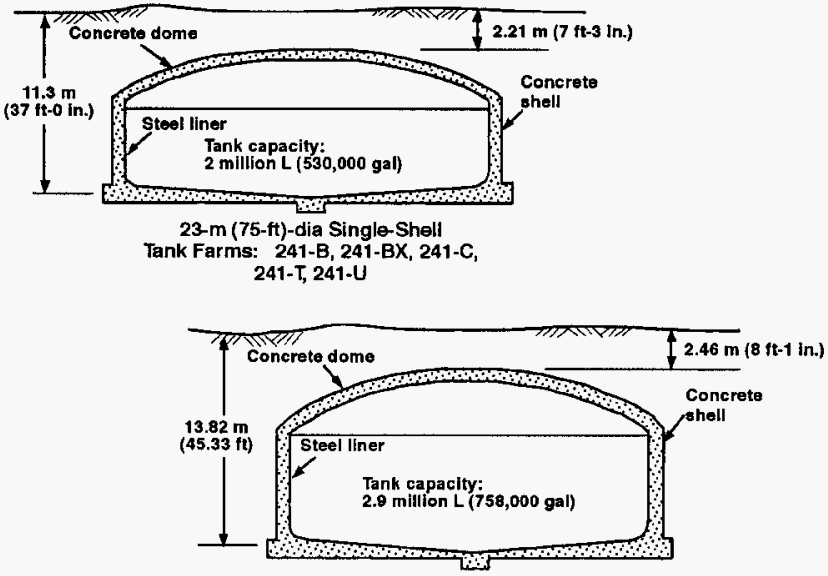

23-m (75-ft)-dia Single-Shell

Tank Farms: 241-BY, 241-S,

241-TX, 241-TY

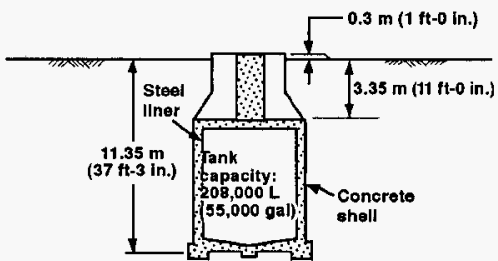

6.1-m (20-ft)-dia Single-Shell

Tank Farms: 241-B, 241-C,

241-T, 241-U

7606030010.3
R2 SRP-ESSD 


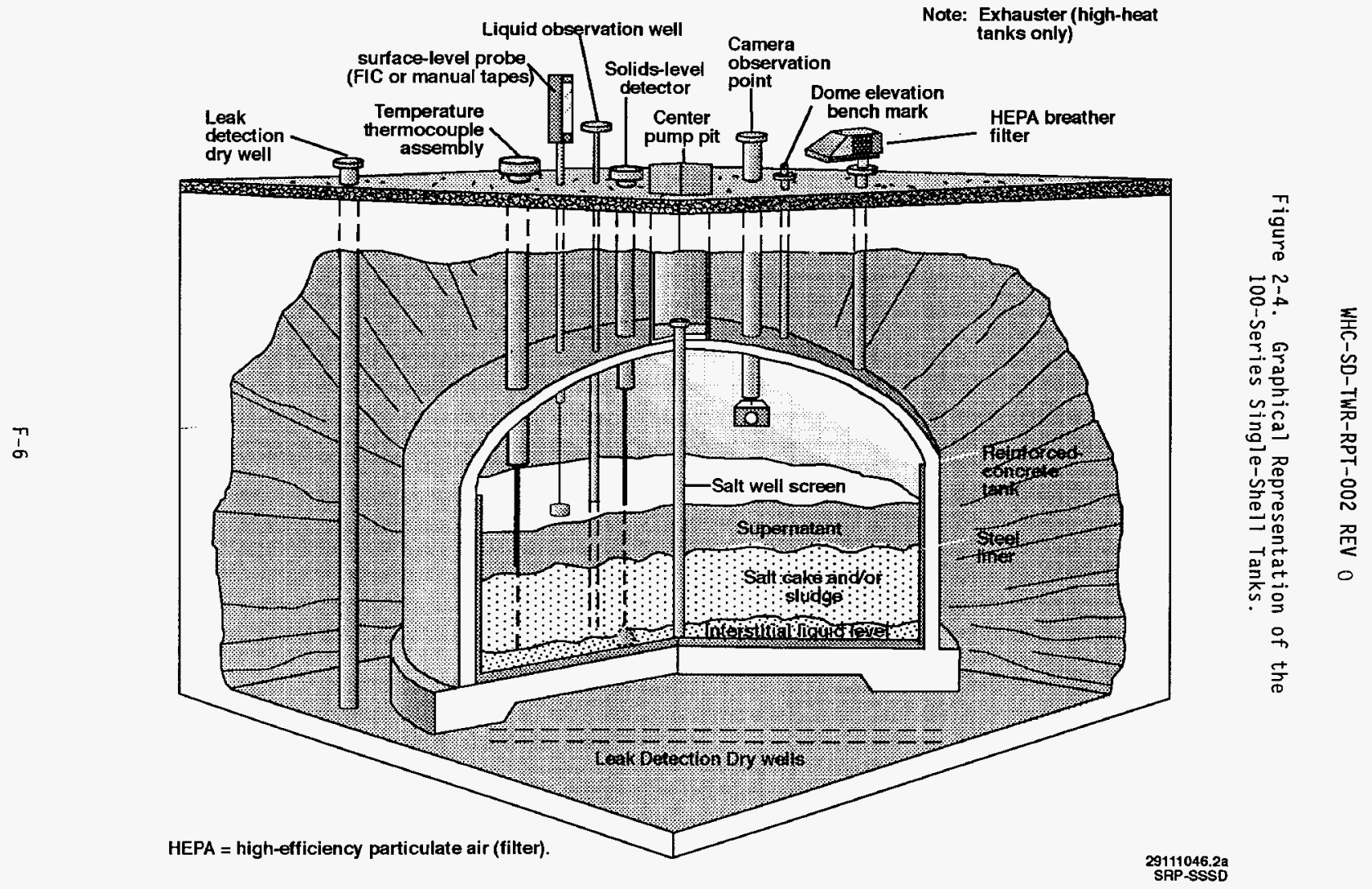


WHC-SD-TWR-RPT-002 REV 0

Figure 2-5. Cross-Section of Double-Shell Tanks.

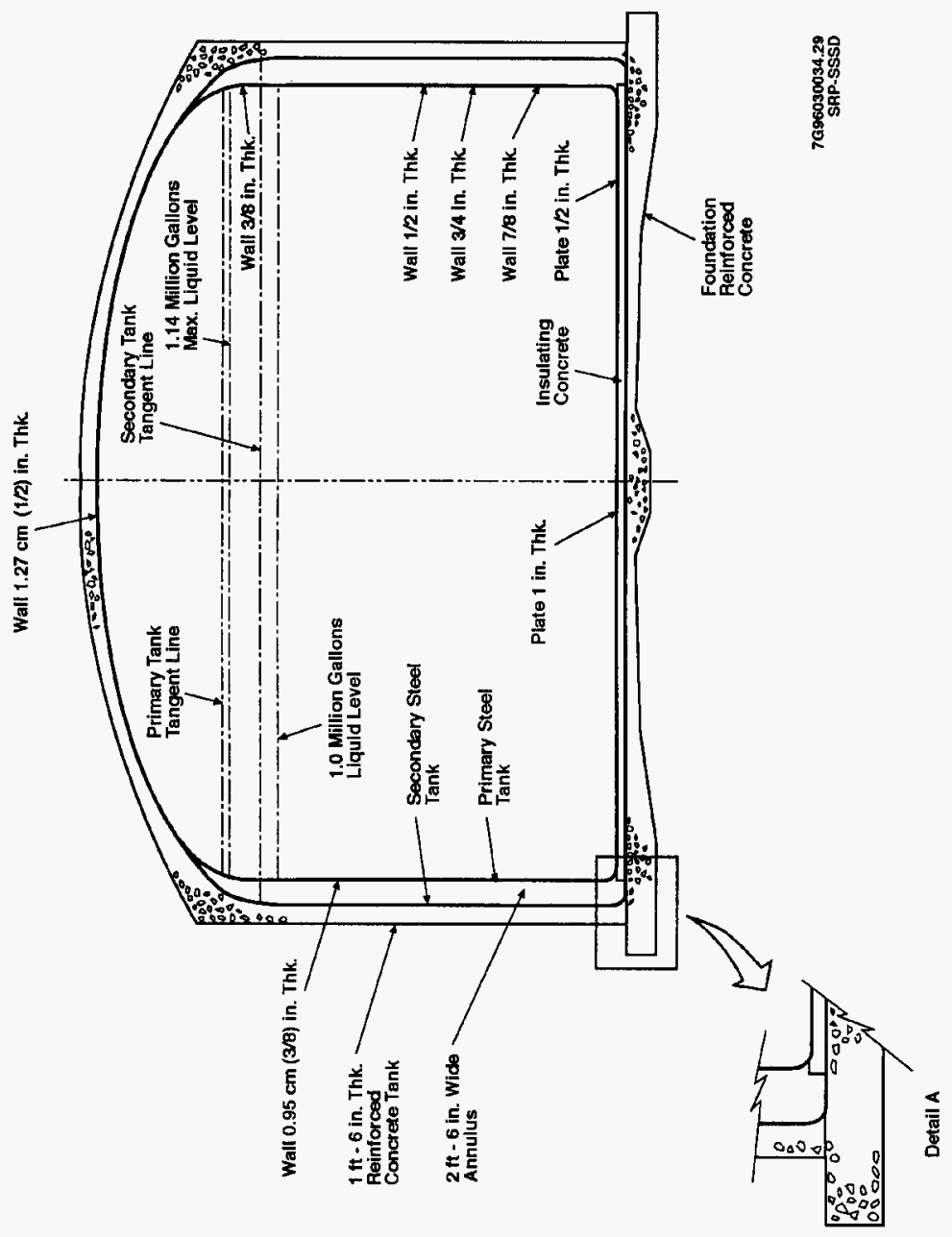


WHC-SD-TWR-RPT-002 REV 0

Figure 2-6. Graphical Representation of Double-Shell Tanks.

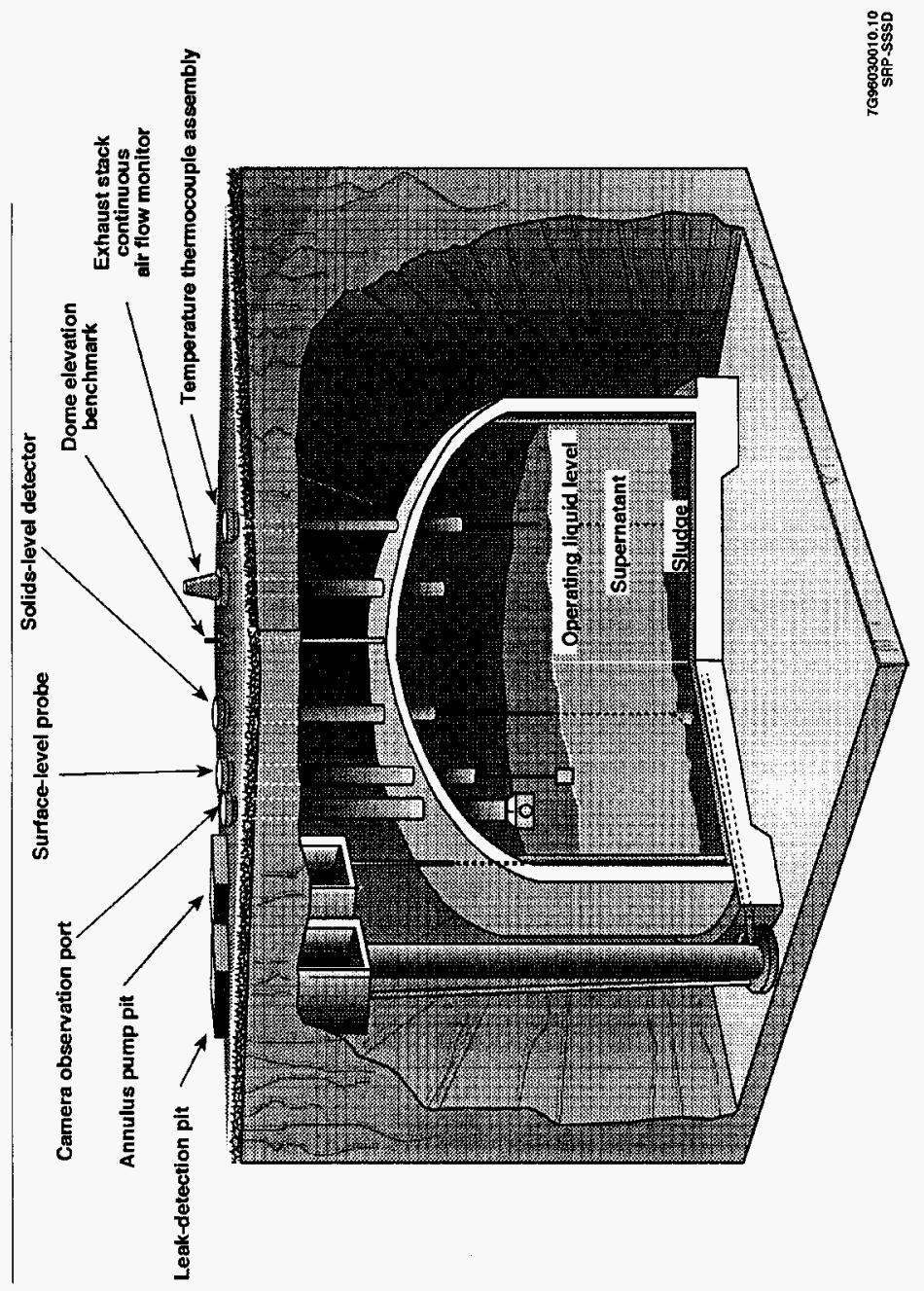

F- 8 


\section{WHC-SD-TWR-RPT-002 REV 0}

Figure 2-7, Risers and Pit Covers of Tank Farm 241-SY.

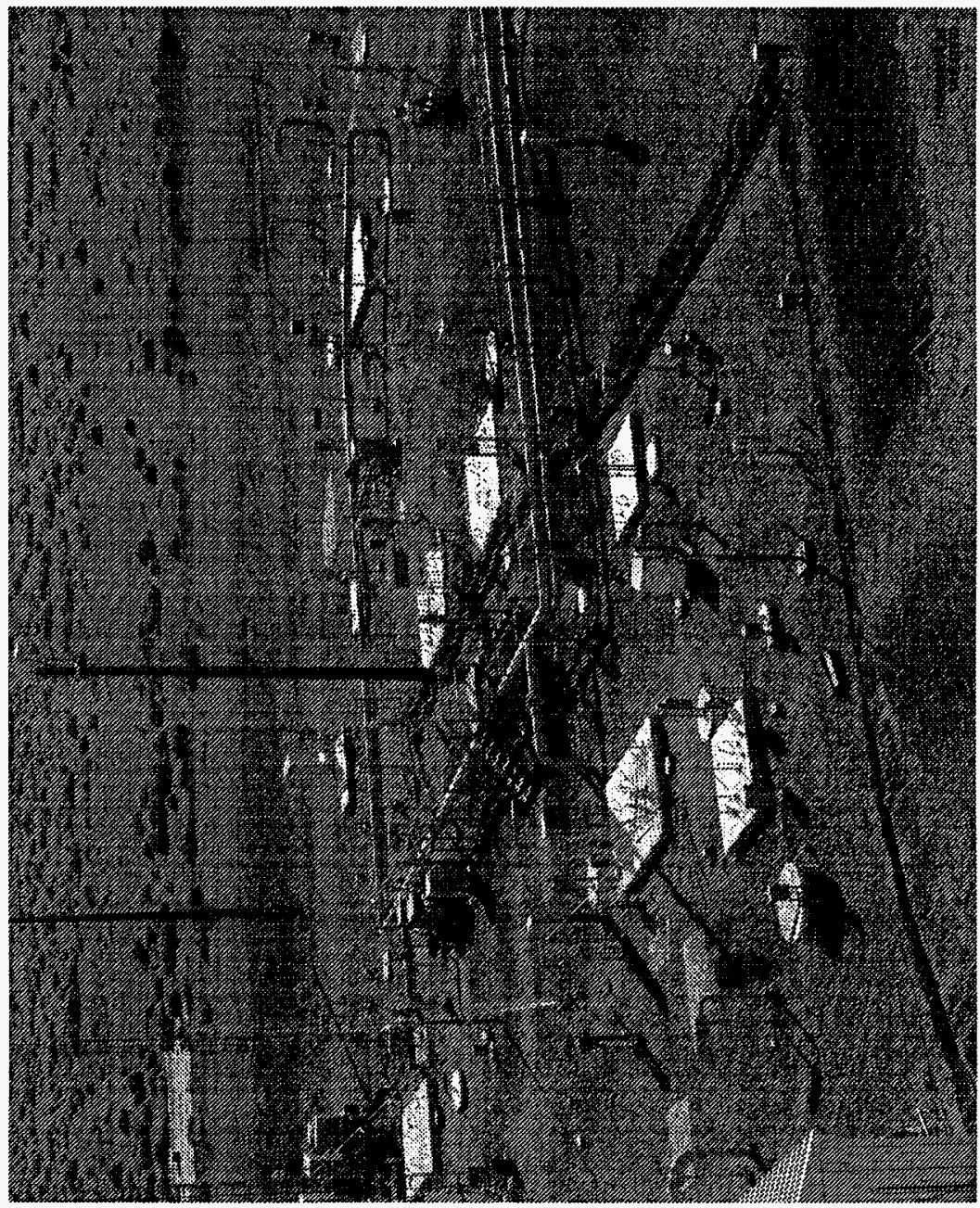


Figure 2-8. Current Tank Farm Operations - 200 West Area.

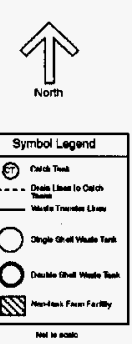
200 West Area

Tank Farm Facilities
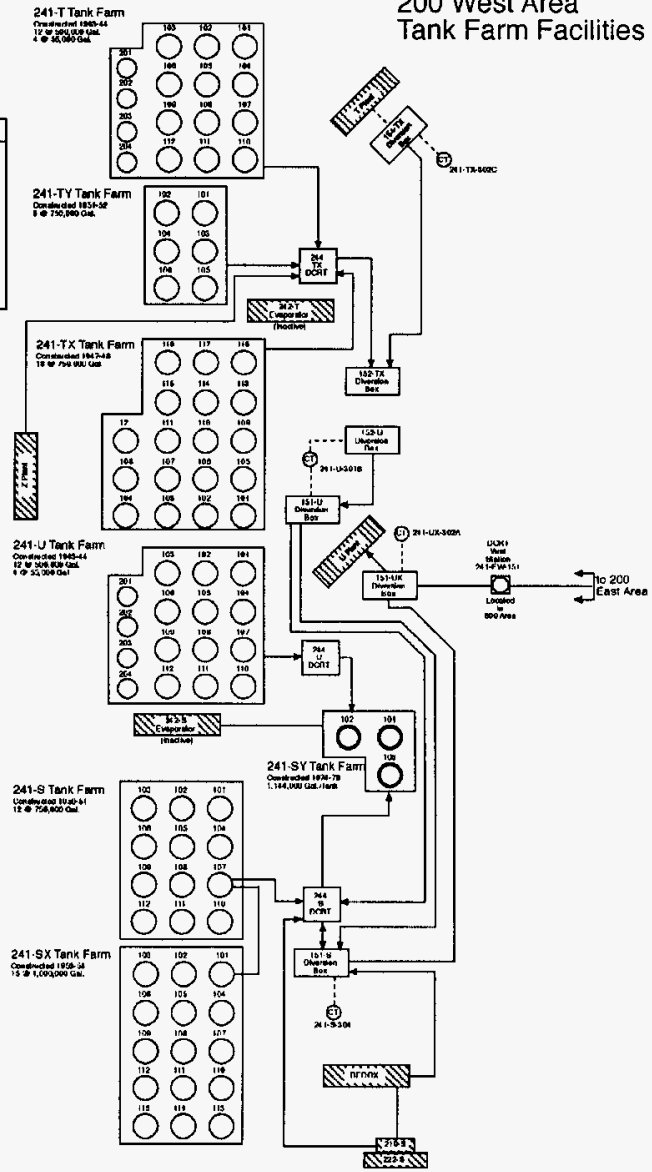

DCRT = Coubie-Contained REDOX $=$ Reduction Oxidation
1. Waste transler lines between factlitiestanks are only showm for illustrative purpose (some lines may not be under the contiol of tank tarms).

2. Miscelianeous underground storage tanks (MUSTS), vertical storage units, and the 90 -day RCRA storage pad are also tank tarm faclities but not shown to retain clarity.

3. Numerous cribs, ditches and trenches exist in the 200 East and 200 West Areas These additional tank farm facilities are nol shown on this drawing.

Not drawn to scale

R96030010.2 
Figure 2-9. Current Tank Farm Operations - 200 East Area.
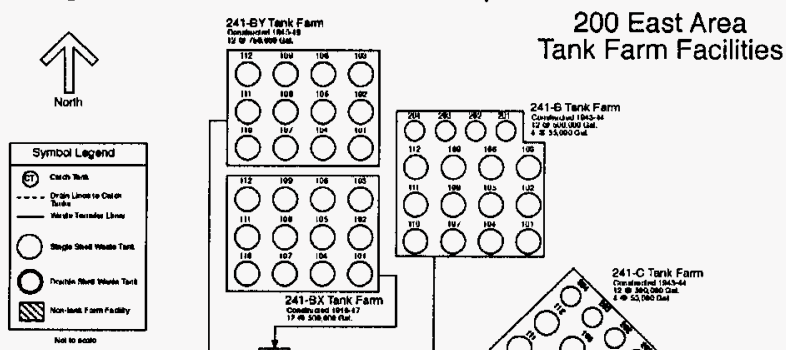

\section{Tank Farm Facilities}

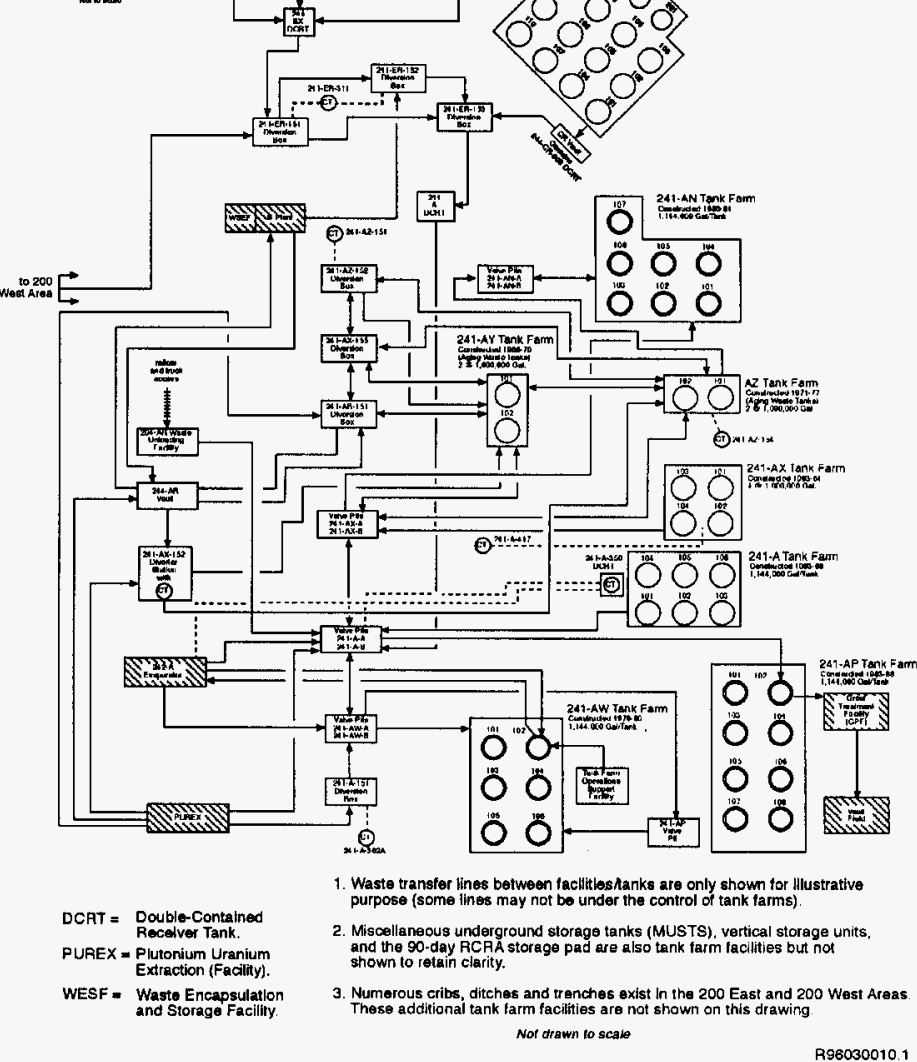


Figure 3-1. Cross-Section of 241-SX-115 Showing Maximum Heat Distribution and Construction Pours.

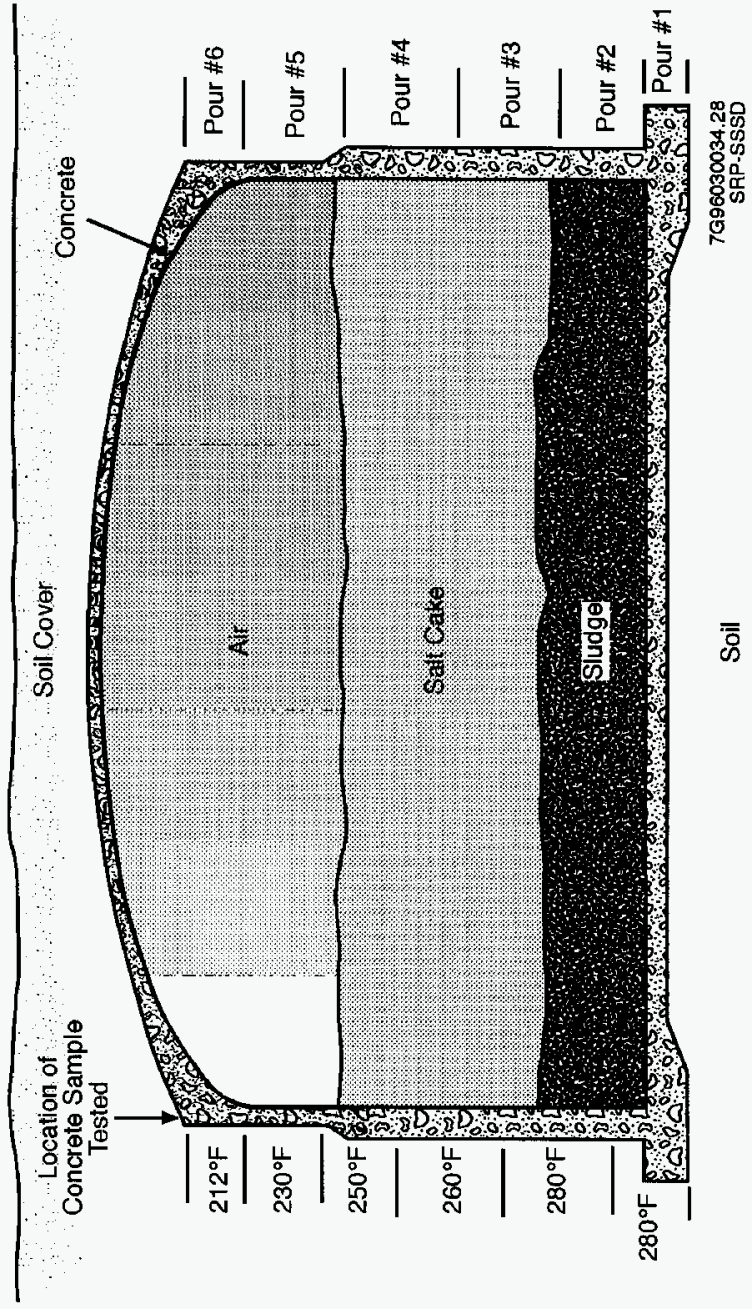


Figure 3-2. Detail of Wall and Drilling Caisson.

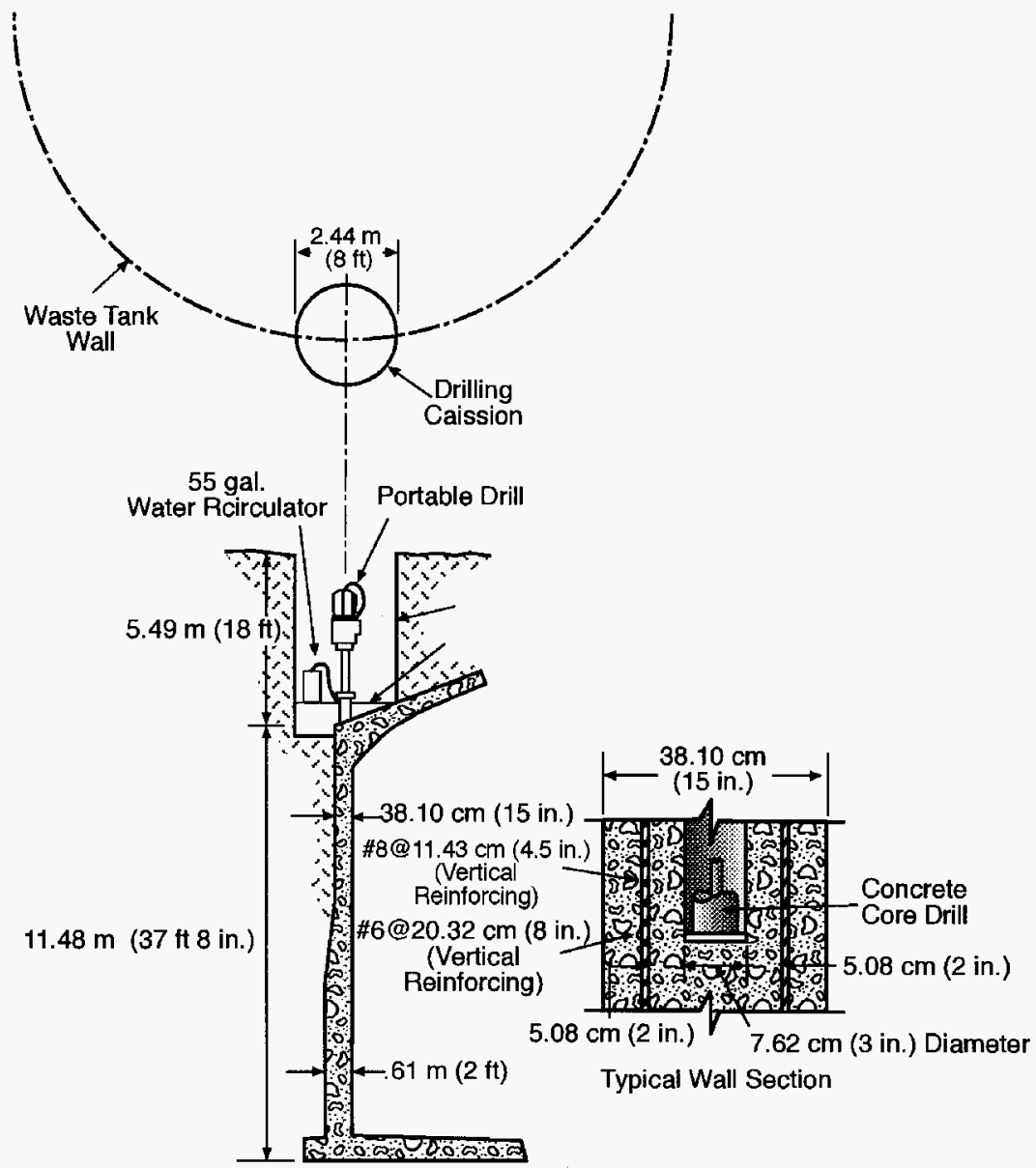

7G96030034.27 SRP.SSSD 
Figure 3-3. Load-Strain Relation of Reinforcement After Exposure to Waste Solution.
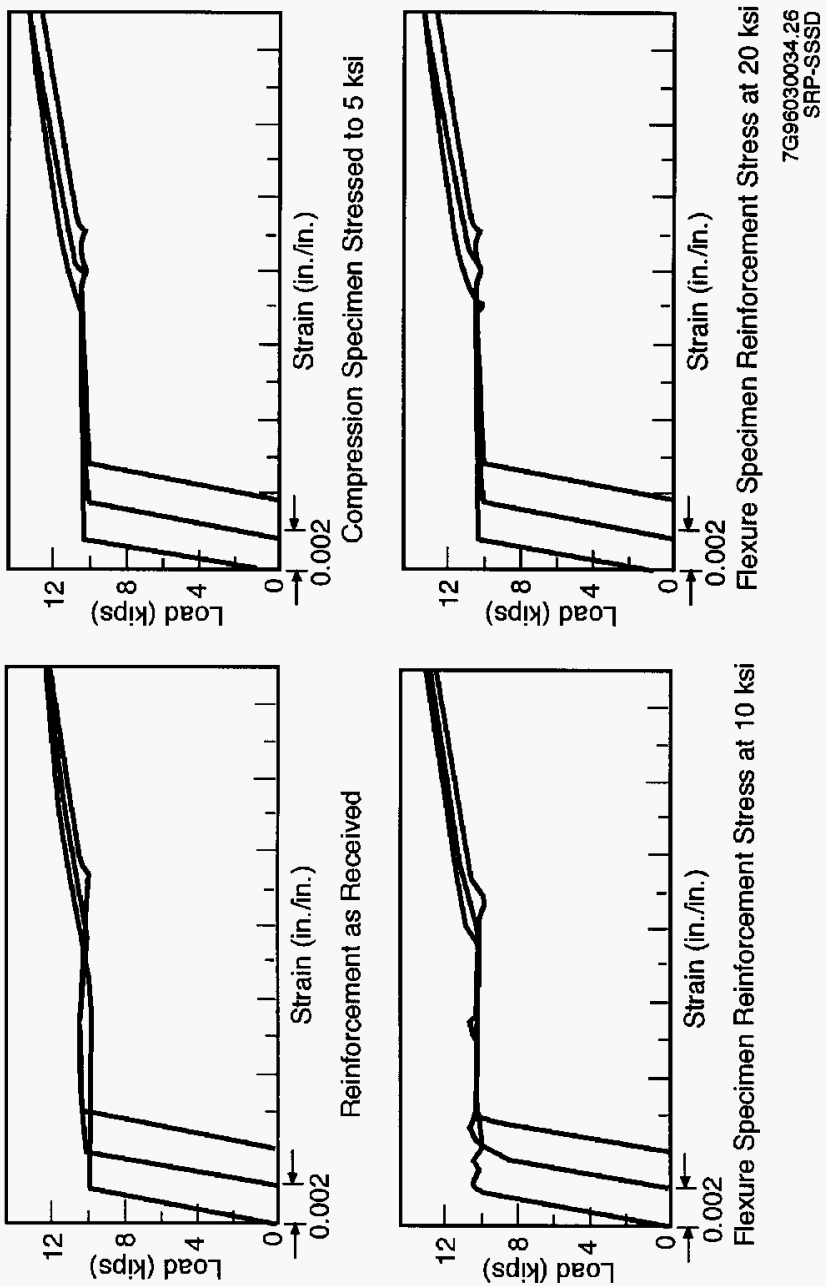
Figure 4-1. Response Spectra - $0.25 \mathrm{~g}$. Frequency $(\mathrm{Hz})$

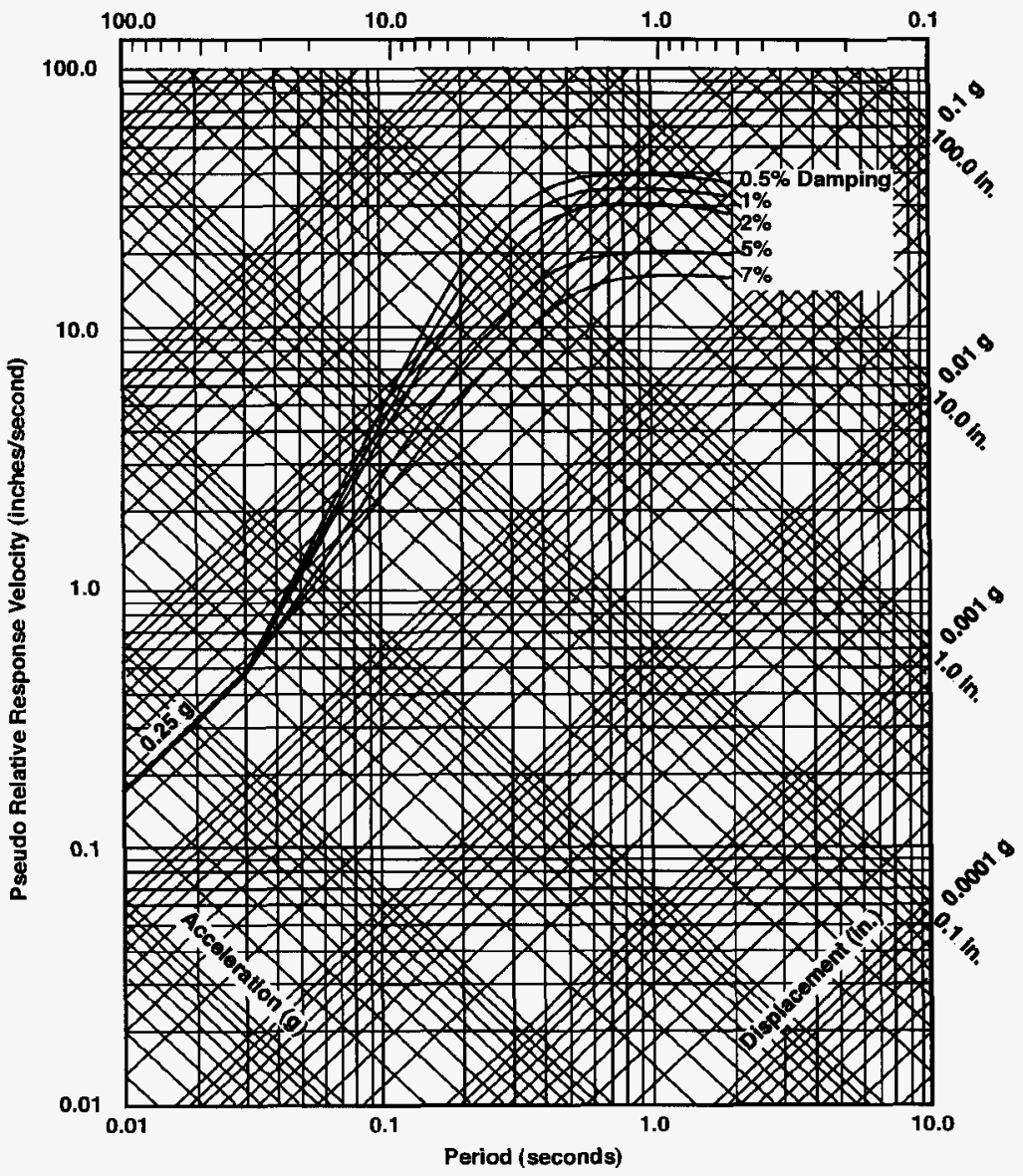

Response Spectra $-0.25 \mathrm{~g}$

Safe-Shutdown Earthquake for Existing Reactors $(0.5 \%, 1 \%, 2 \%, 5 \%$, and $7 \%$ Critical Damping)

Note: 1 in. $=25.4 \mathrm{~mm}$ 
Figure 4-2. Response Spectra $-0.20 \mathrm{~g}$.

Frequency $(\mathbf{H z})$

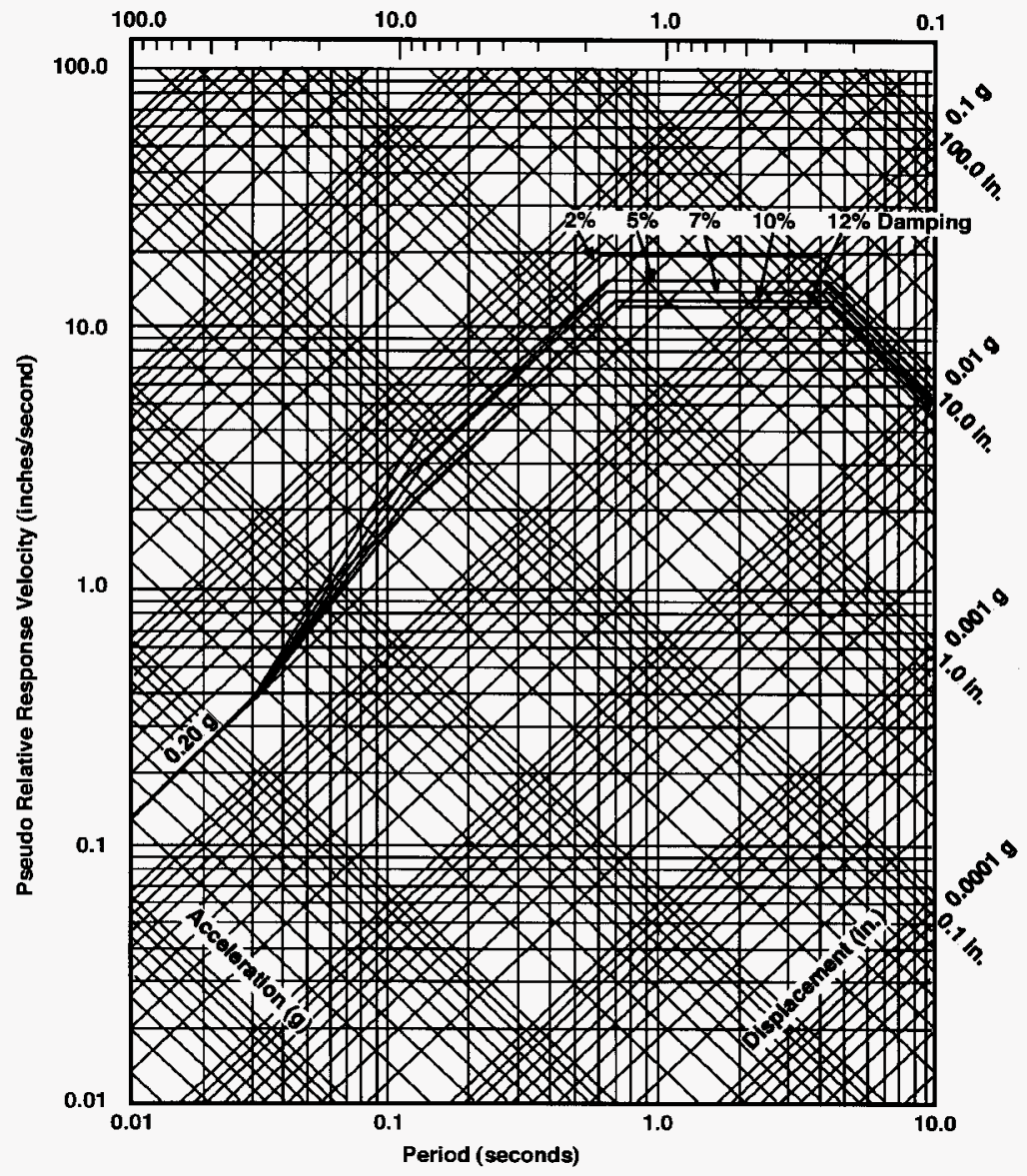

\author{
Response Spectra - $0.20 \mathrm{~g}$ \\ Non-Reactor Safety Class 1 \\ (2\%, $5 \%, 7 \%, 10 \%$, and $12 \%$ Critical Damping)
}

Note: 1 in. $=25.4 \mathrm{~mm}$ 
Figure 4-3. Response Spectra - $0.12 \mathrm{~g}$.

Frequency $(\mathrm{Hz})$

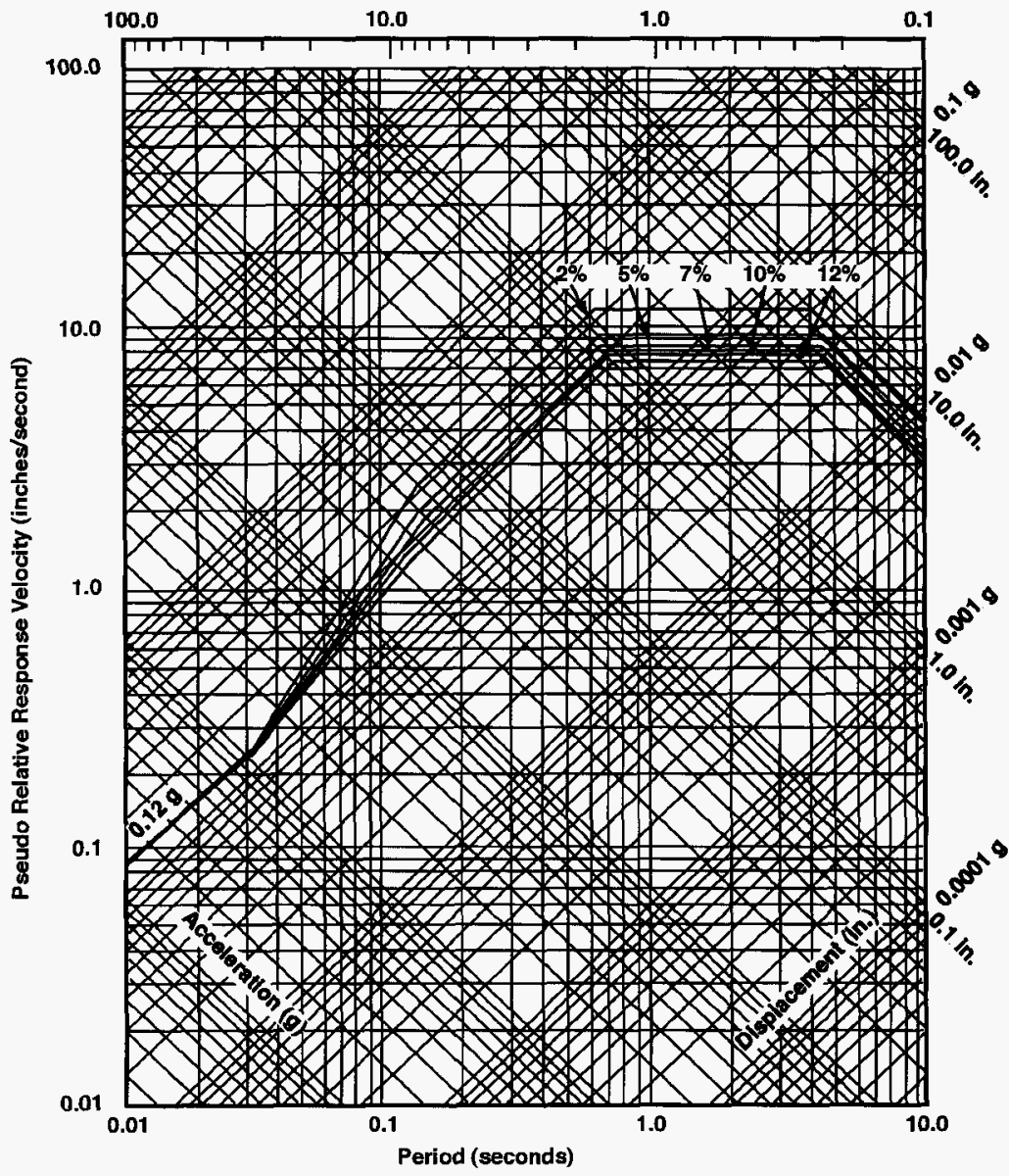

Response Spectra - $0.12 \mathrm{~g}$

Non-Reactor Safety Class 2

(2\%, $5 \%, 7 \%, 10 \%$, and $12 \%$ Critical Damping)

NOte: 1 in. $=25.4 \mathrm{~mm}$

7696030034,31
3AP-S3\$D 
Figure 4-4. Axisymmetric Temperature Isotherms.

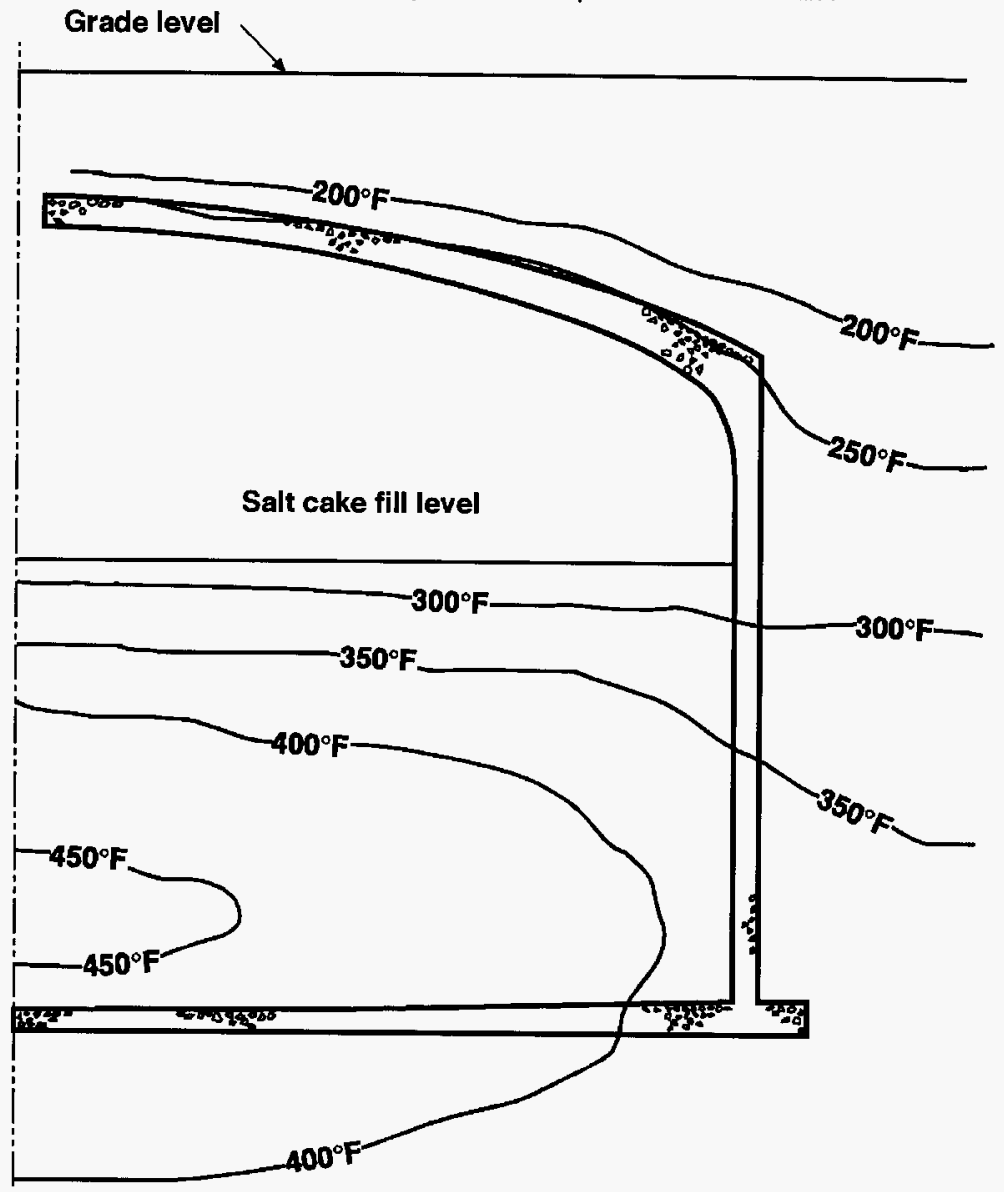

Salt cake heat generating $\left(Q=0.265 \mathrm{Btu} / \mathrm{h}-\left(\mathrm{ft}^{3}\right)\right.$

Soil conductivity $\left(0.20 \mathrm{Btu} / \mathrm{h}-\left(\mathrm{ft}-{ }^{\circ} \mathrm{F}\right)\right.$ 
WHC-SD-TWR-RPT-002 REV 0

Figure 4-5. Temperature Time-History.

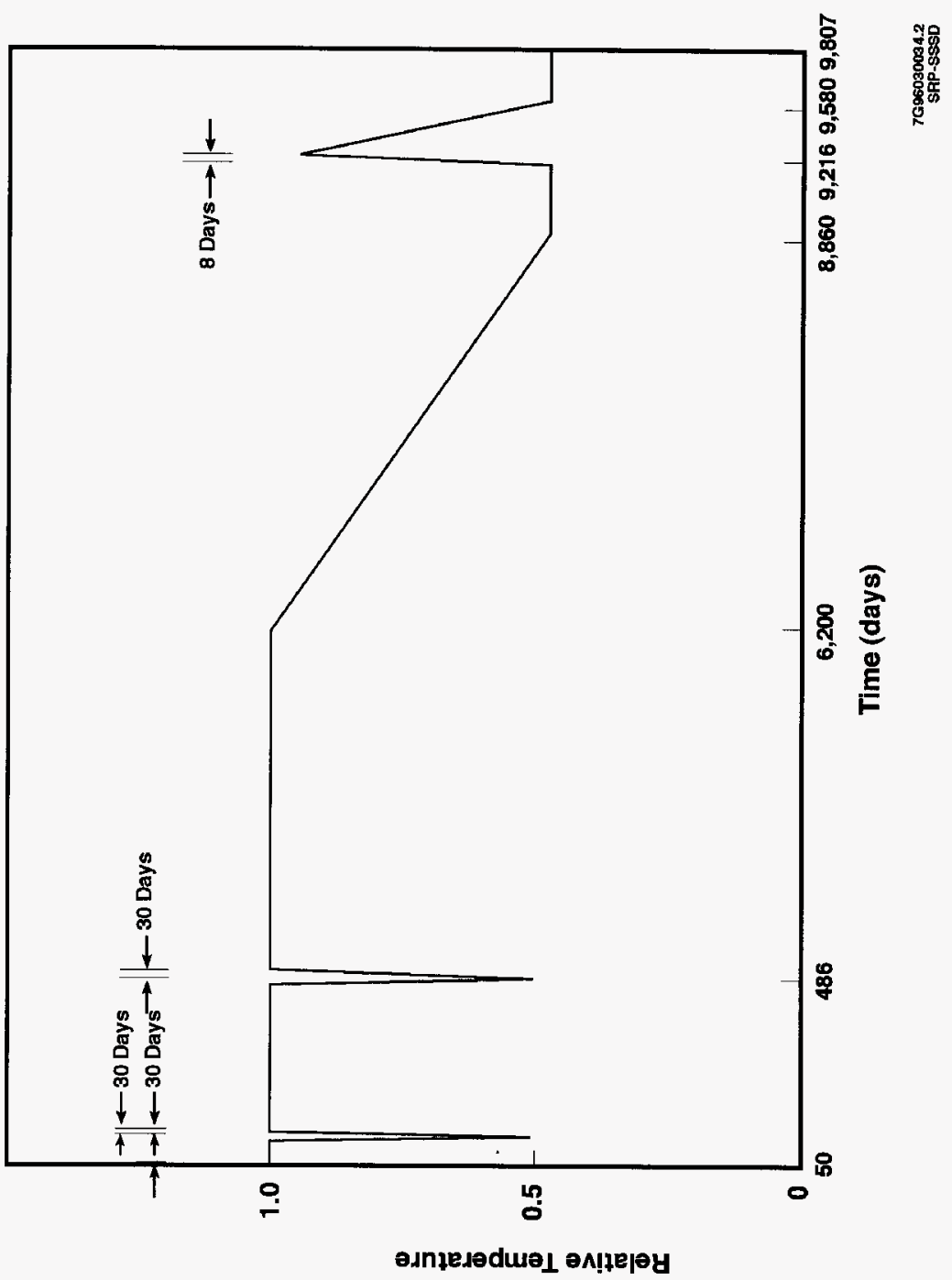




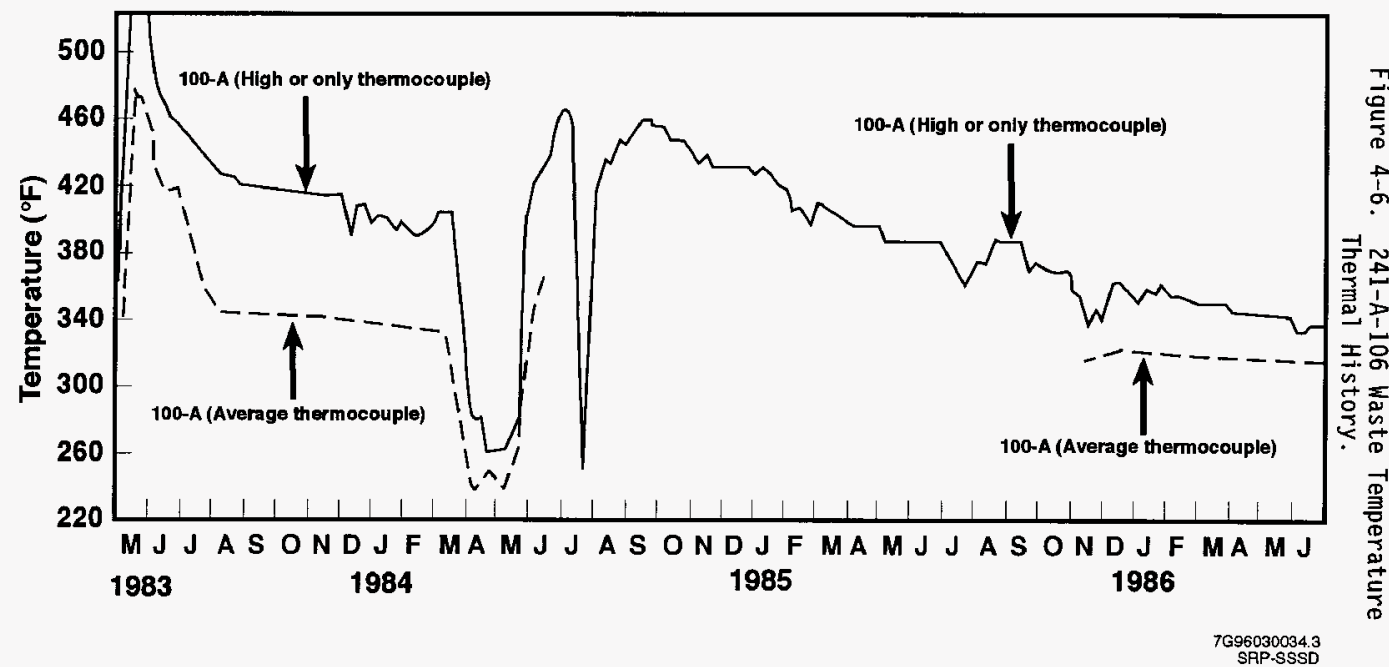


Figure 4-7. Typical P-M Diagram.

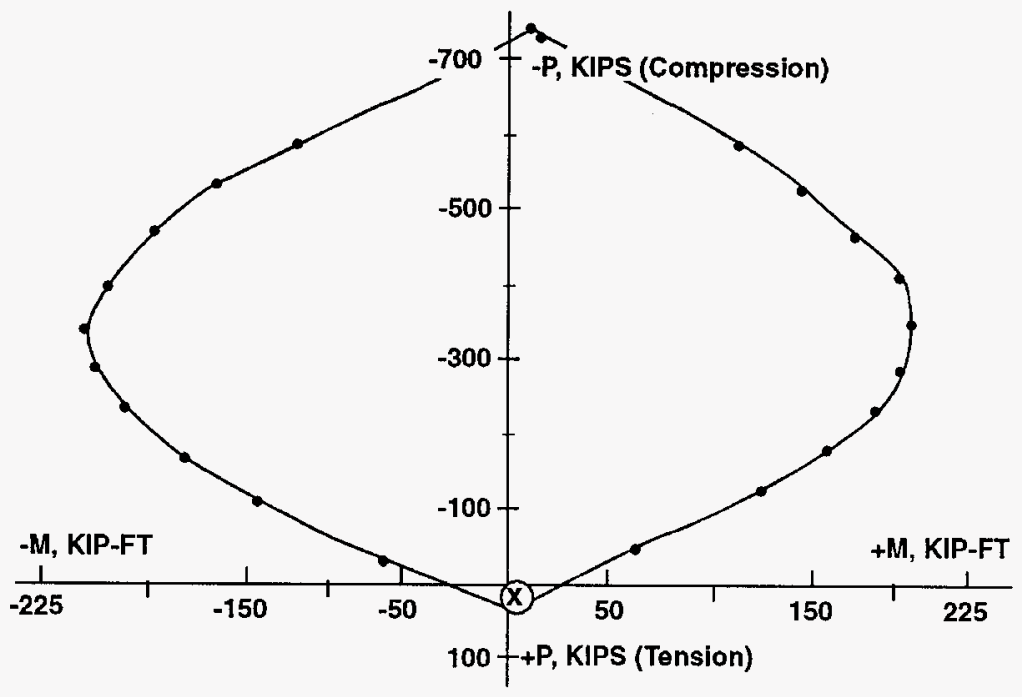

(x) - The maximum combination of $M$ and $P$ for section resulting from to seismic motions.

Note: $1 \mathrm{KIP}=4,448 \mathrm{~N}$

$1 \mathrm{KIP}-\mathrm{FT}=1,357 \mathrm{~N}-\mathrm{m}$

$1 \mathrm{ft}=0.3 \mathrm{~m}$ 
WHC-SD-TWR-RPT-002 REV 0

Figure 4-8. Tanks 241-AX, Finite Element Model.

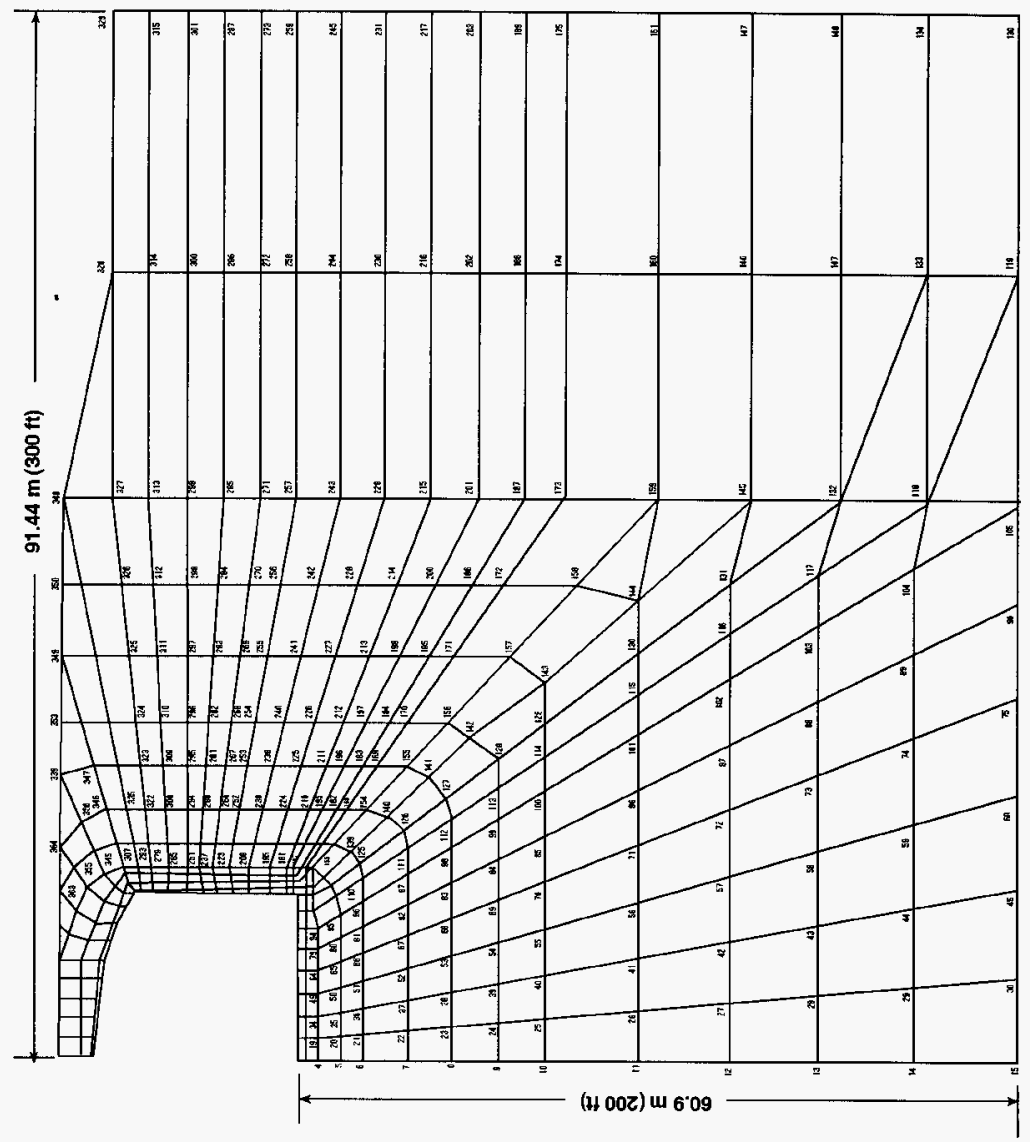


Figure 4-9. Locations of P-M Diagrams.

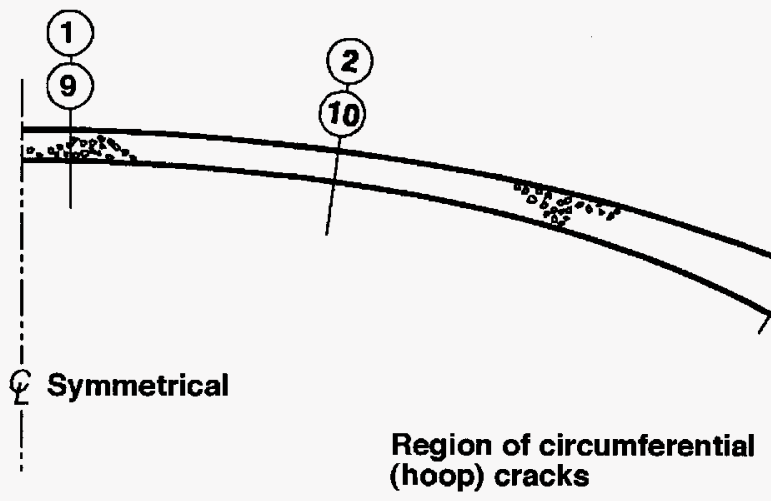

Sections in tank

for checking reserve capacities

Sections 1-8 are longitudinal

Sections 9-12 are circumferential

Region of longitudinal

(7)

(3)

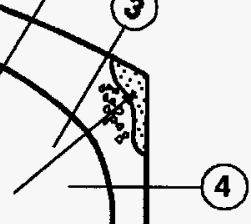

(5) cracks 
Figure 4-10. P-M Diagrams of Sections 1 and 2.

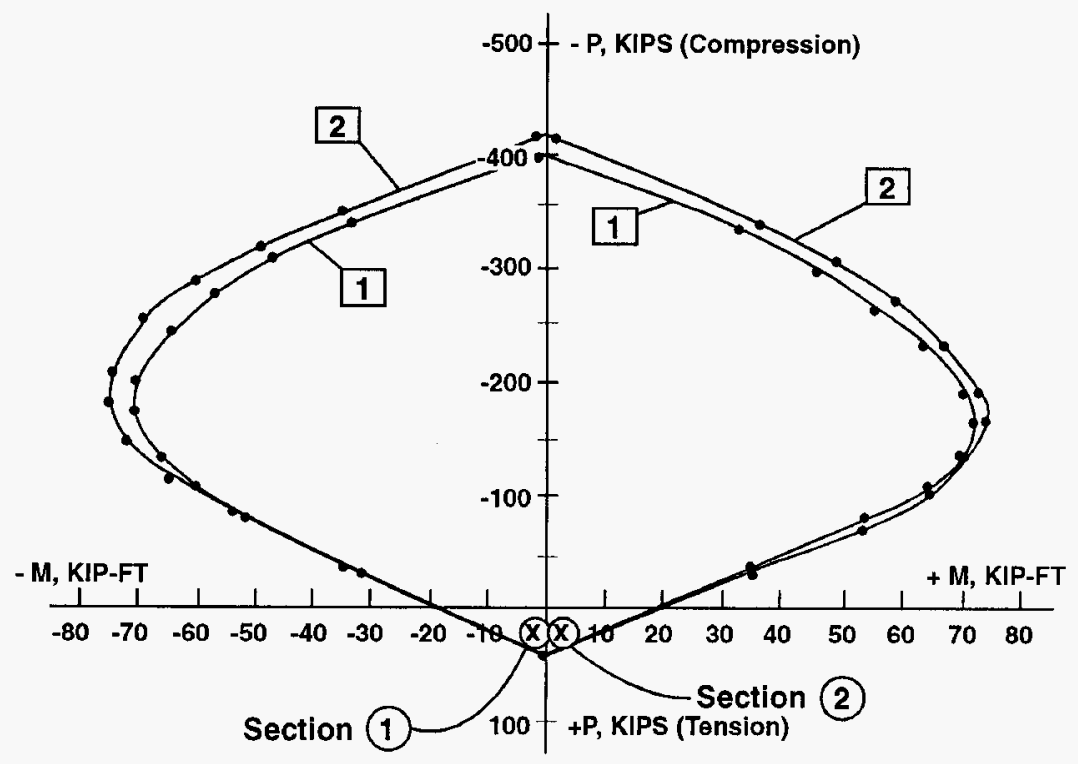
$\otimes$ - The maximum combination
of $M$ and $P$ for a given section

Note: $1 \mathrm{KIP}=4,448 \mathrm{~N}$

$1 \mathrm{KIP}-\mathrm{FT}=1,357 \mathrm{~N}-\mathrm{m}$

$1 \mathrm{ft}=\mathbf{0 . 3} \mathrm{m}$ 
Figure 4-11. P-M Diagram of Section 3 .

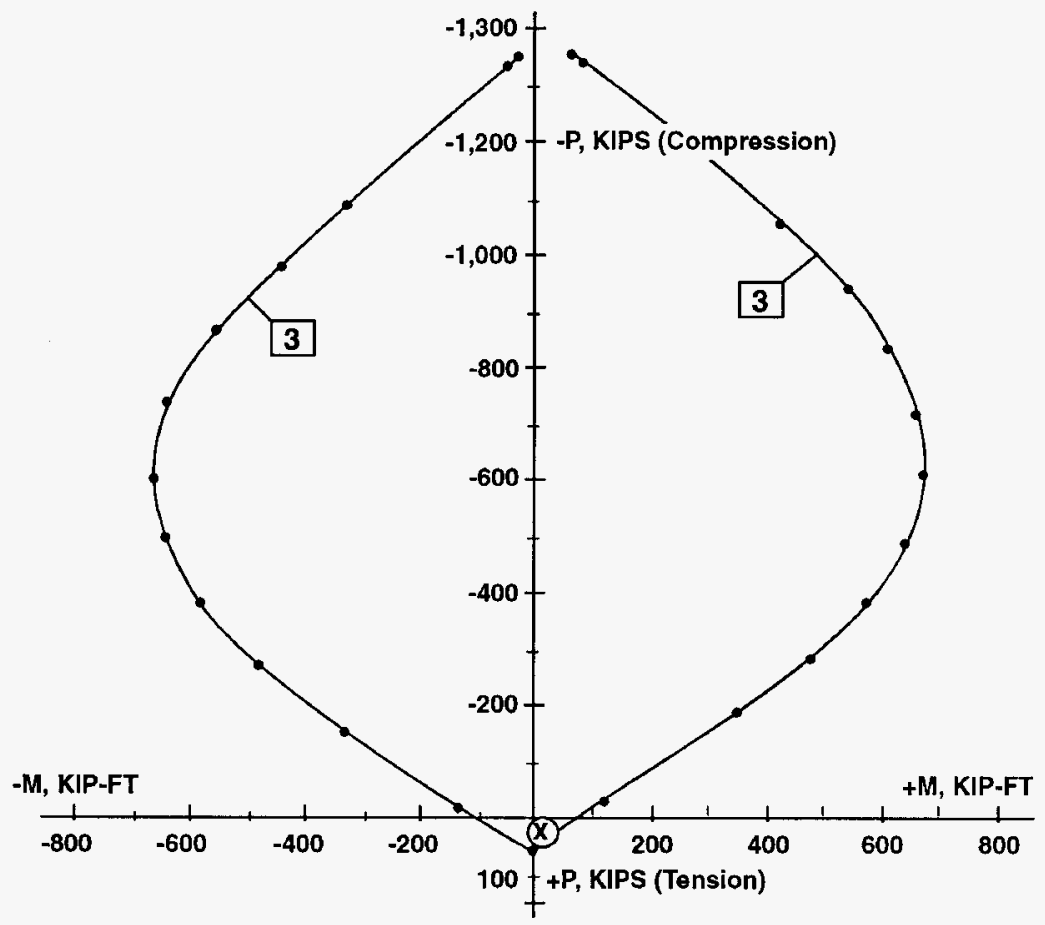

(x) - The maximum combination

of $M$ and $P$ for section 3

Note: $1 \mathrm{KIP}=4,448 \mathrm{~N}$

$1 \mathrm{KIP}-\mathrm{FT}=1,357 \mathrm{~N}-\mathrm{m}$

$1 \mathrm{ft}=0.3 \mathrm{~m}$ 


\section{WHC-SD-TWR-RPT-002 REV 0}

Figure 4-12. P-M Diagrams of Sections 4 and 5.

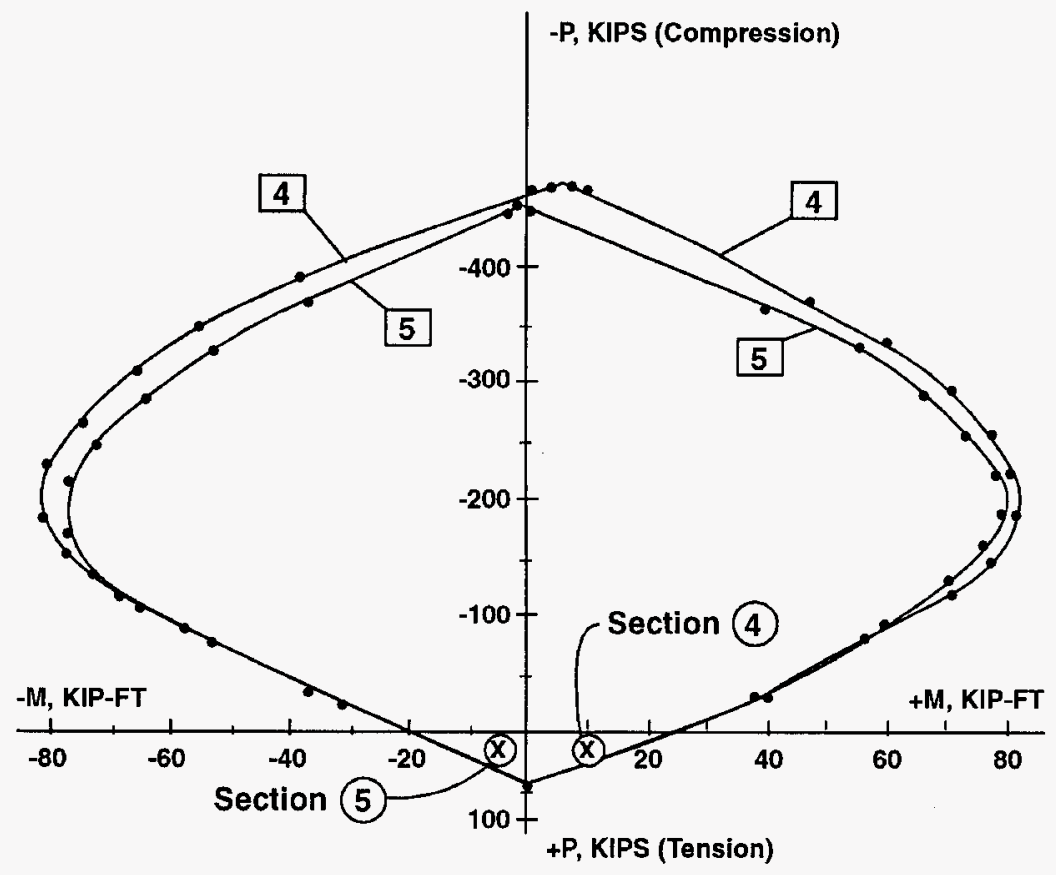

$(\boldsymbol{X}$ - The maximum combination of $M$ and $P$ for a given section

Note: $1 \mathrm{KIP}=4,448 \mathrm{~N}$

$1 \mathrm{KIP}-\mathrm{FT}=1,357 \mathrm{~N}-\mathrm{m}$

$1 \mathrm{ft}=0.3 \mathrm{~m}$ 
Figure 4-13. P-M Diagram of Section 6 .

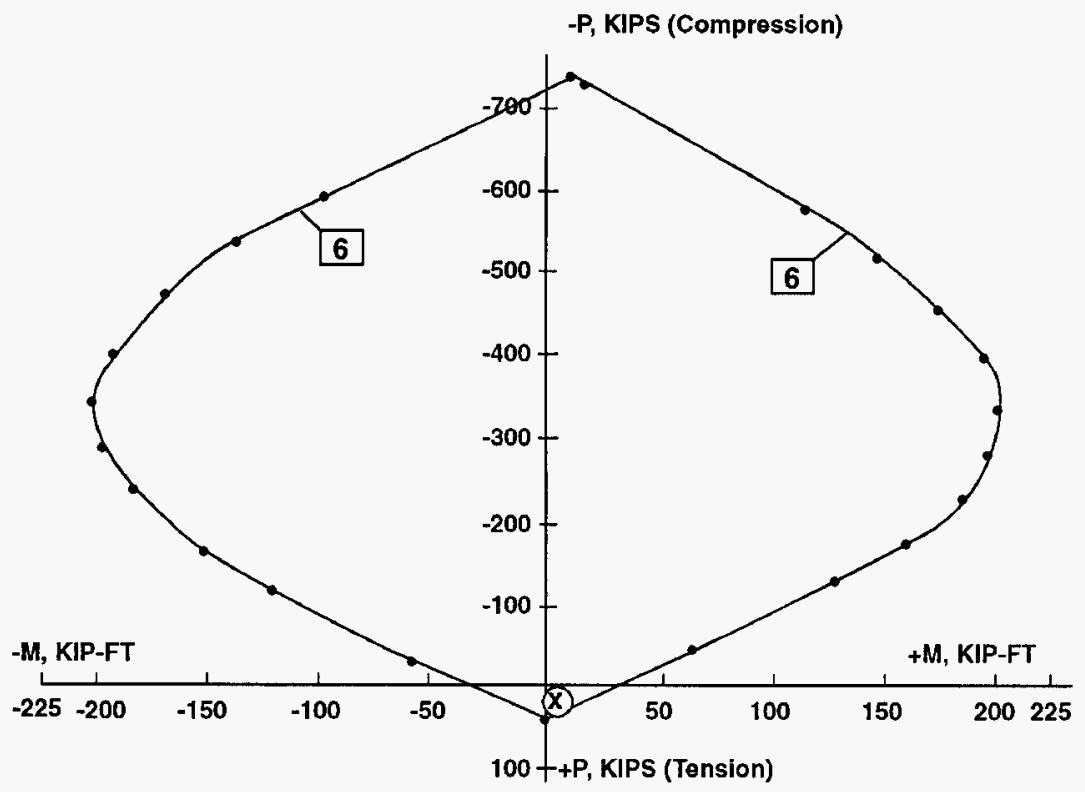

(メ) - The maximum combination of $M$ and $P$ for section 6

Note: $1 \mathrm{KIP}=4,448 \mathrm{~N}$

$1 \mathrm{KIP}-\mathrm{FT}=1,357 \mathrm{~N}-\mathrm{m}$

$1 \mathrm{ft}=0.3 \mathrm{~m}$ 
Figure 4-14. P-M Diagrams of Sections 7 and 8 .

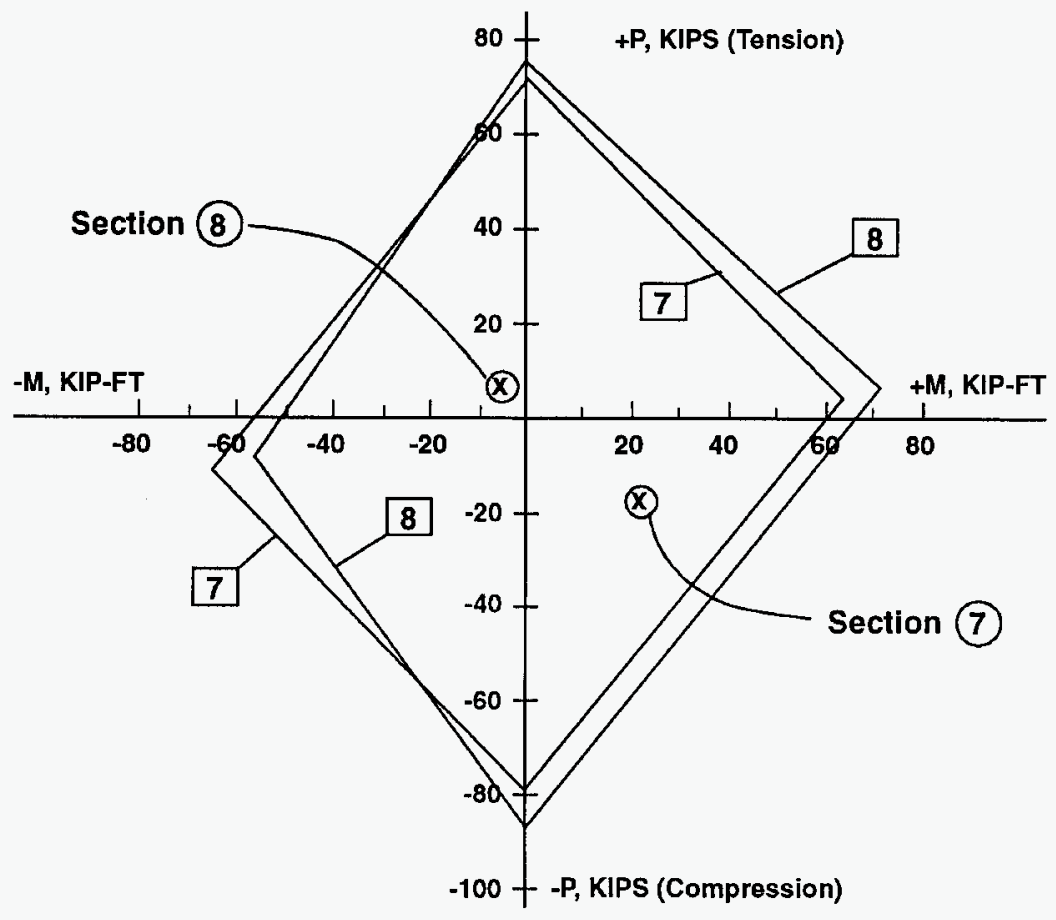

$\otimes$ - The maximum combination of $M$ and $P$ for $a$ given section

$$
\begin{array}{ll}
\text { Note: } & 1 \mathrm{KIP}=4,448 \mathrm{~N} \\
& 1 \mathrm{KJP}-\mathrm{FT}=1,357 \mathrm{~N}-\mathrm{m} \\
& 1 \mathrm{ft}=0.3 \mathrm{~m}
\end{array}
$$


Figure 4-15. P-M Diagrams of Sections 9 and 10.

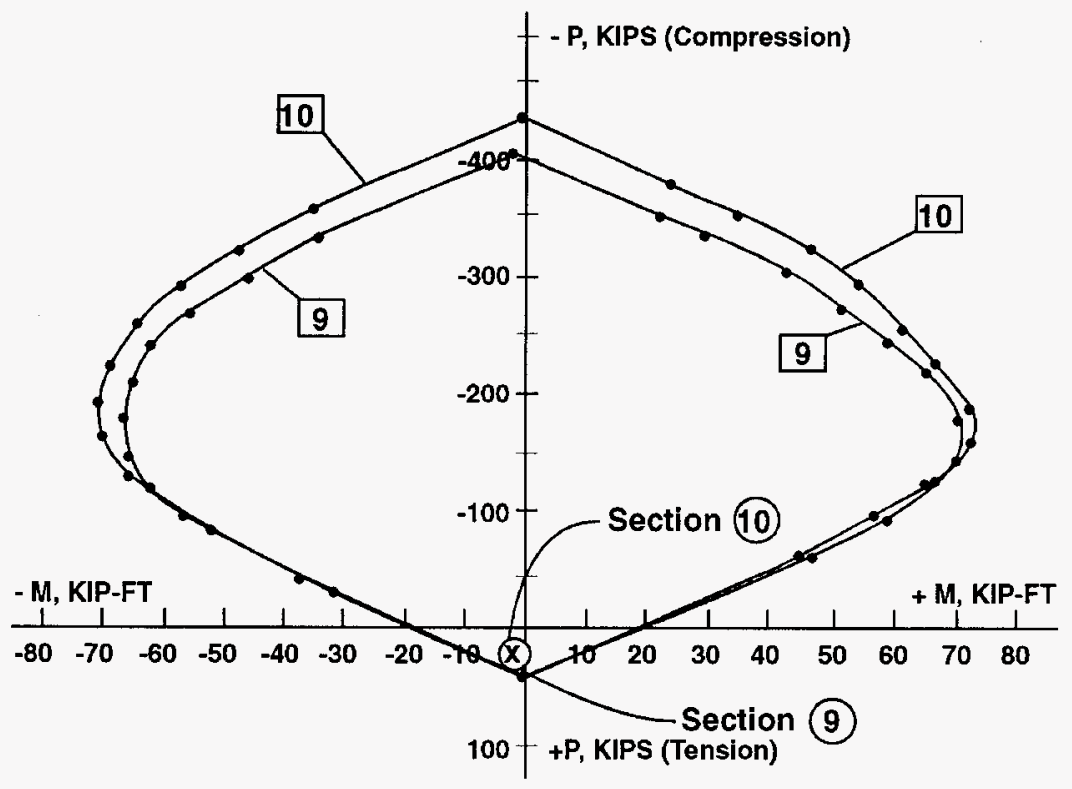

(D) - The maximum combination of $M$ and $P$ for a given section

Note: $1 \mathrm{KIP}=4,448 \mathrm{~N}$

$1 \mathrm{KIP}-\mathrm{FT}=1,357 \mathrm{~N}-\mathrm{m}$

$1 \mathrm{ft}=0.3 \mathrm{~m}$ 
Figure 4-16. P-M Diagrams of Sections 11 and 12.

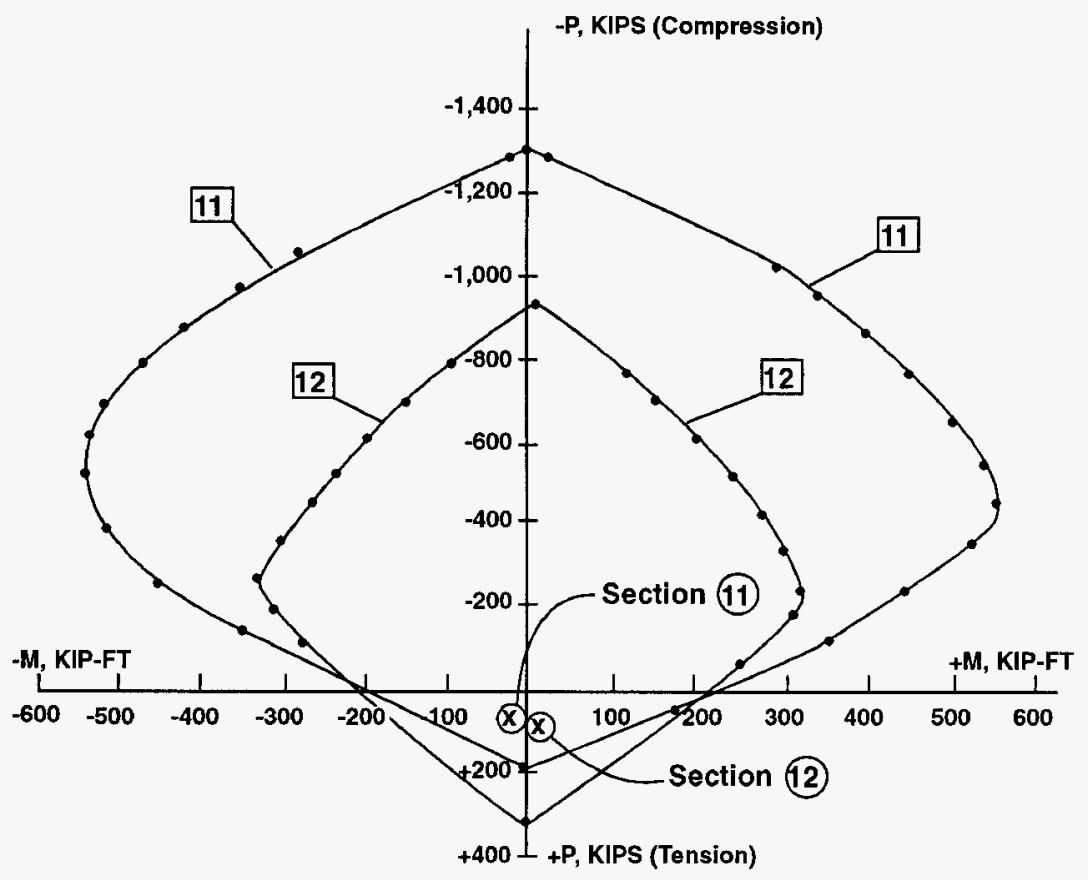

()-The maximum combination of $M$ and $P$ for a given section

Note: $1 \mathrm{KIP}=4,448 \mathrm{~N}$

$1 \mathrm{KIP}-\mathrm{FT}=1,357 \mathrm{~N}-\mathrm{m}$

$1 \mathrm{ft}=0.3 \mathrm{~m}$ 
Figure 5-1. Typical Dome Reinforcement of 2.9-ML (758,000-gal) Capacity SSTs.

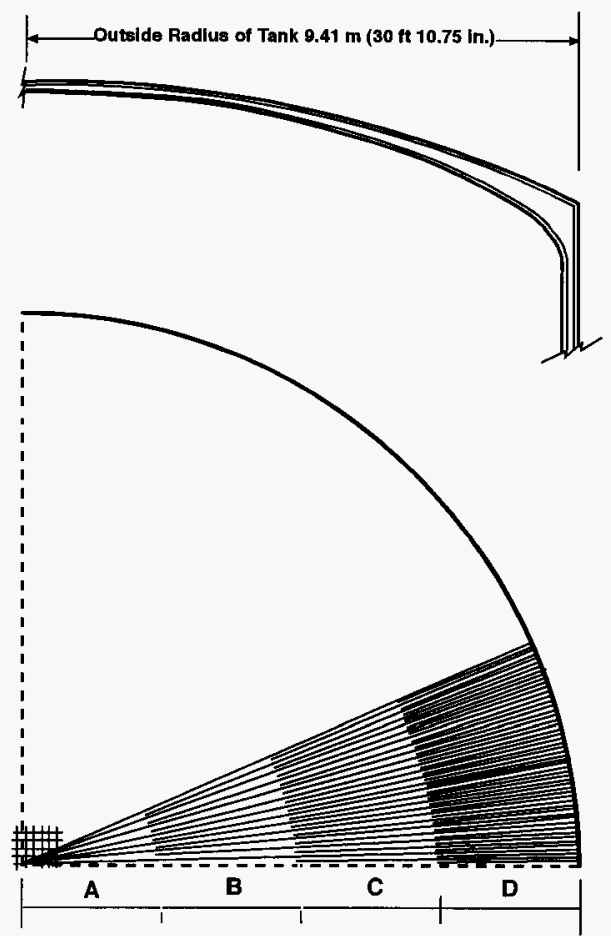

Radial Bars: A $\rightarrow \# 6$ @ $30.48 \mathrm{~cm}$ (12 in.) EF $B \rightarrow \# 6 @ 60.96 \mathrm{~cm}(24$ in.) EF $C \rightarrow 6 @ 30.48 \mathrm{~cm}(12 \mathrm{in}$.) EF $\mathrm{D} \rightarrow \# 6 @ 7.62 \mathrm{~cm}(3 \mathrm{in}$.) spc $<30.48 \mathrm{~cm}$ (12 in.) EF 
Figure 5-2. Typical Dome Reinforcement of 3.8-ML (1-Mgal) Capacity SSTs.

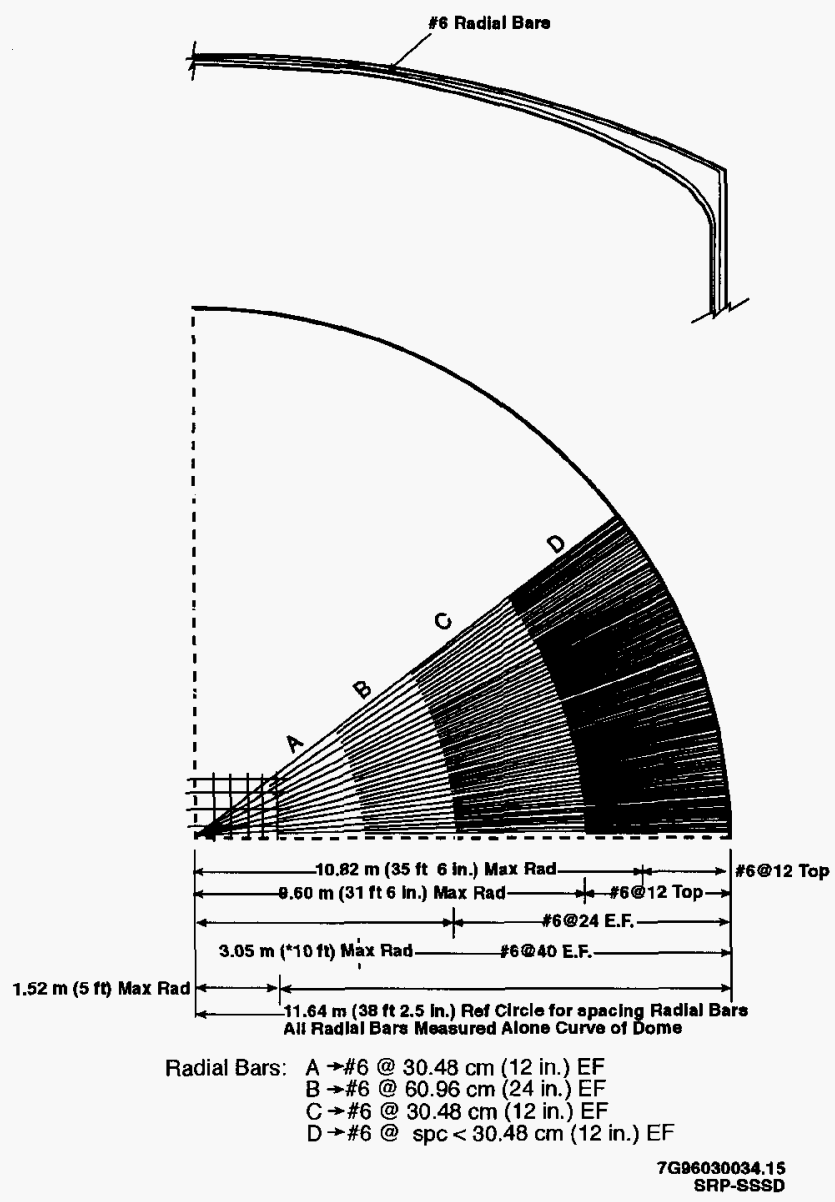


Figure 5-3. Typical Wall Reinforcement of 2.9-ML (758,000-gal) Capacity SSTs.

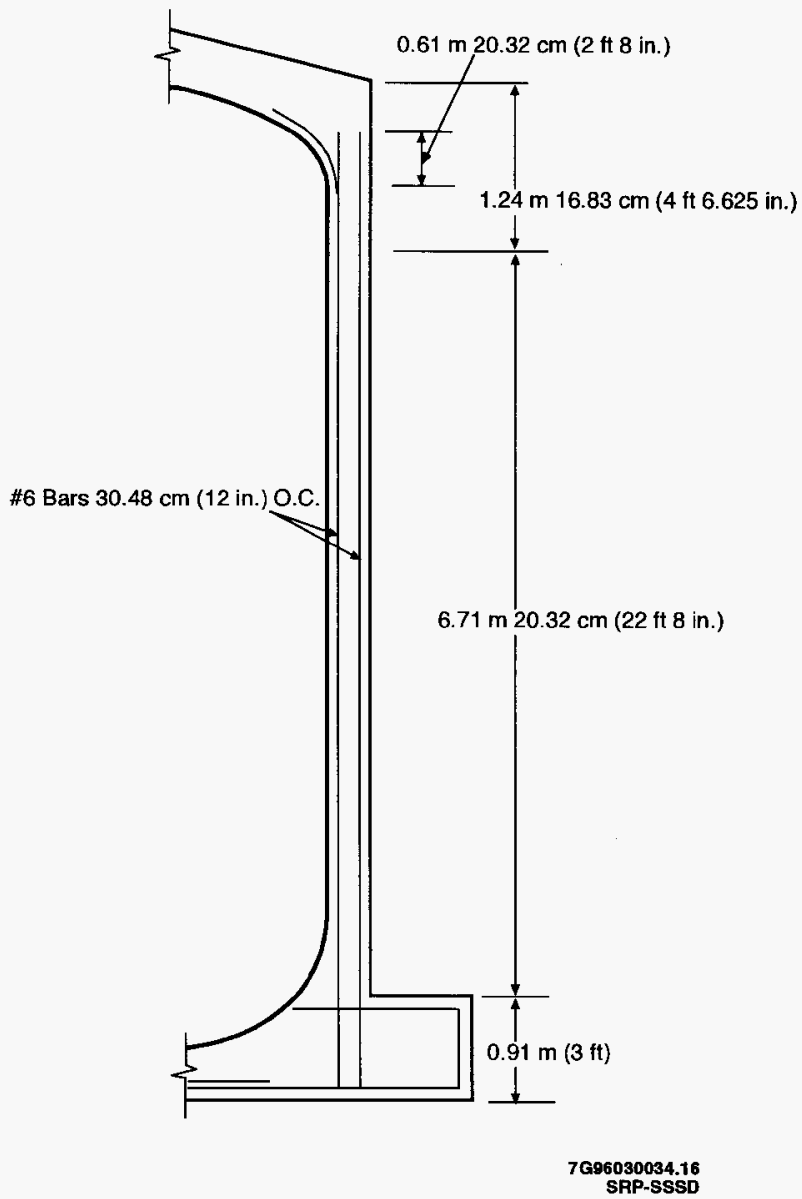


Figure 5-4. Typical Wall Reinforcement of 3.8-ML (1-Mgal) Capacity SSTs.

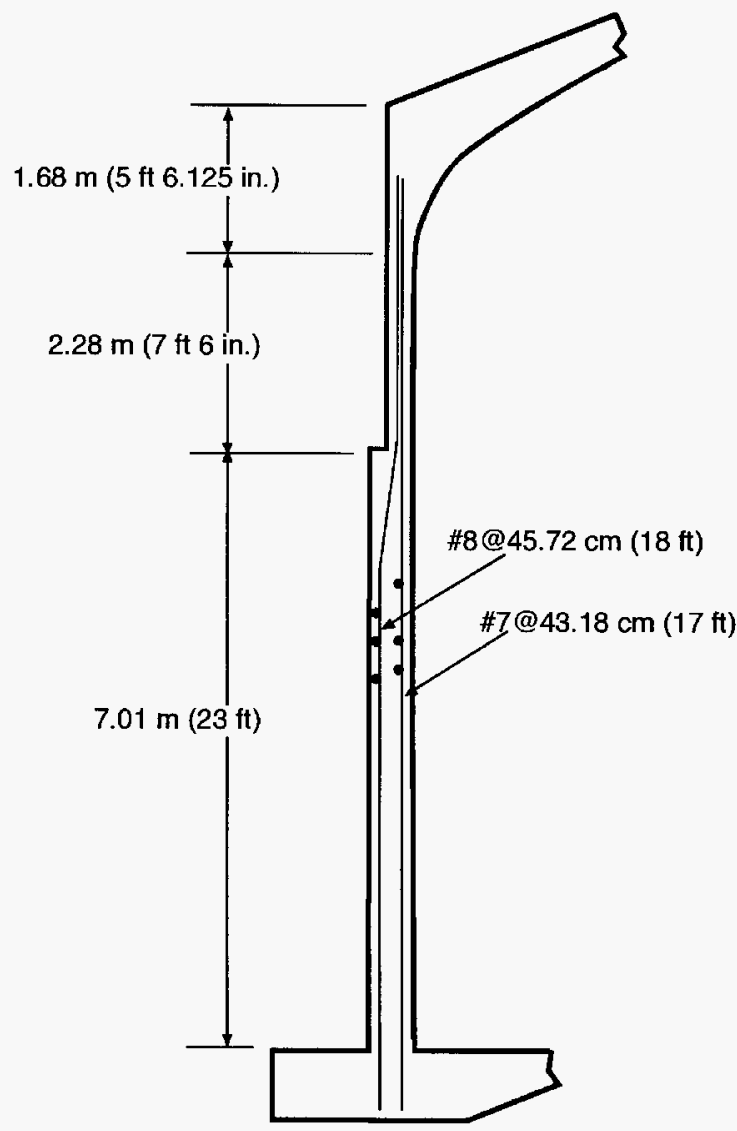

7G96030034.17

SRP-SSSD 
Figure 5-5. Stress-Strain Curves for Steel Liner and Reinforcement.

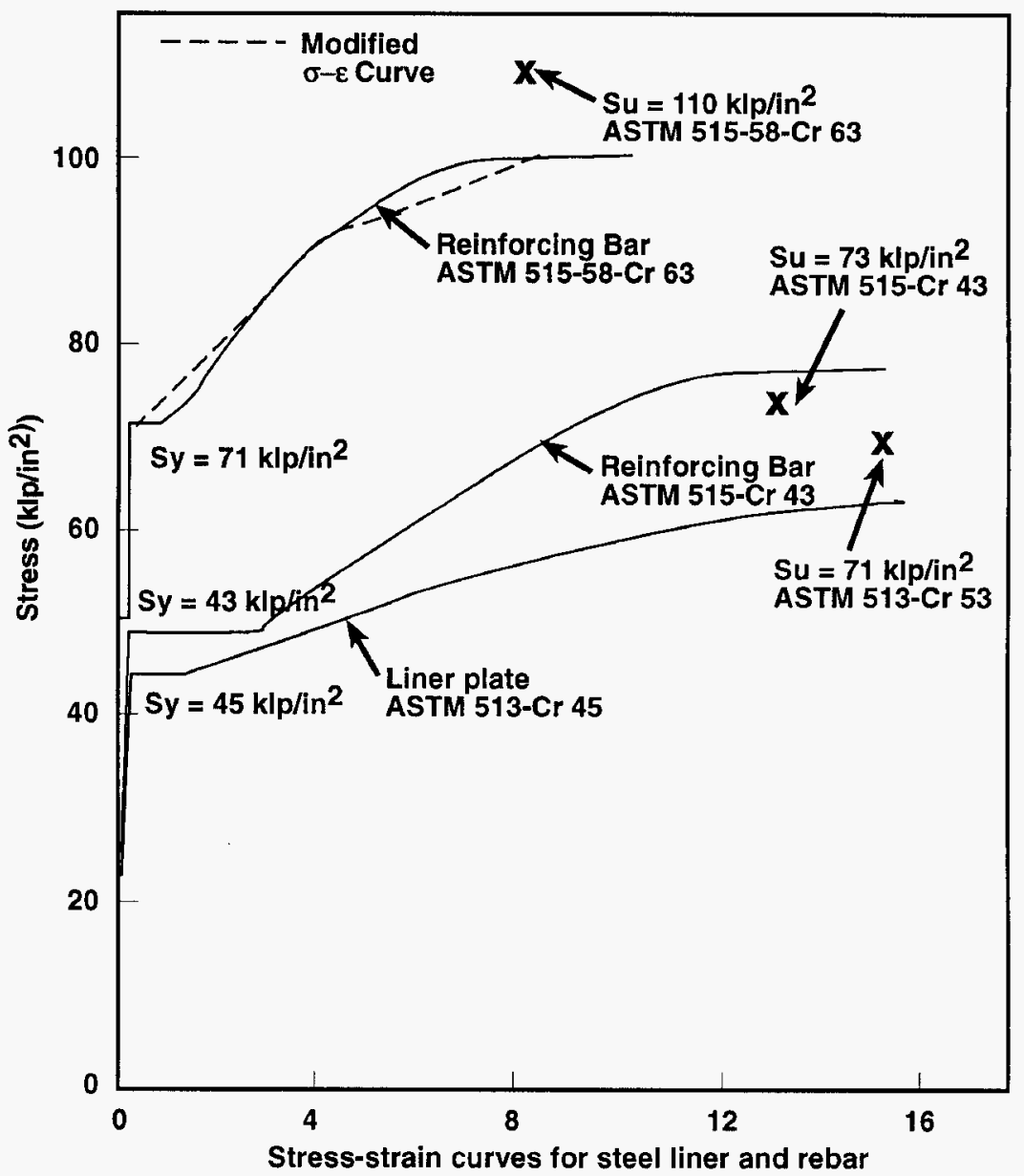


Figure 5-6. Primary and Secondary Steel Tanks of DSTs.

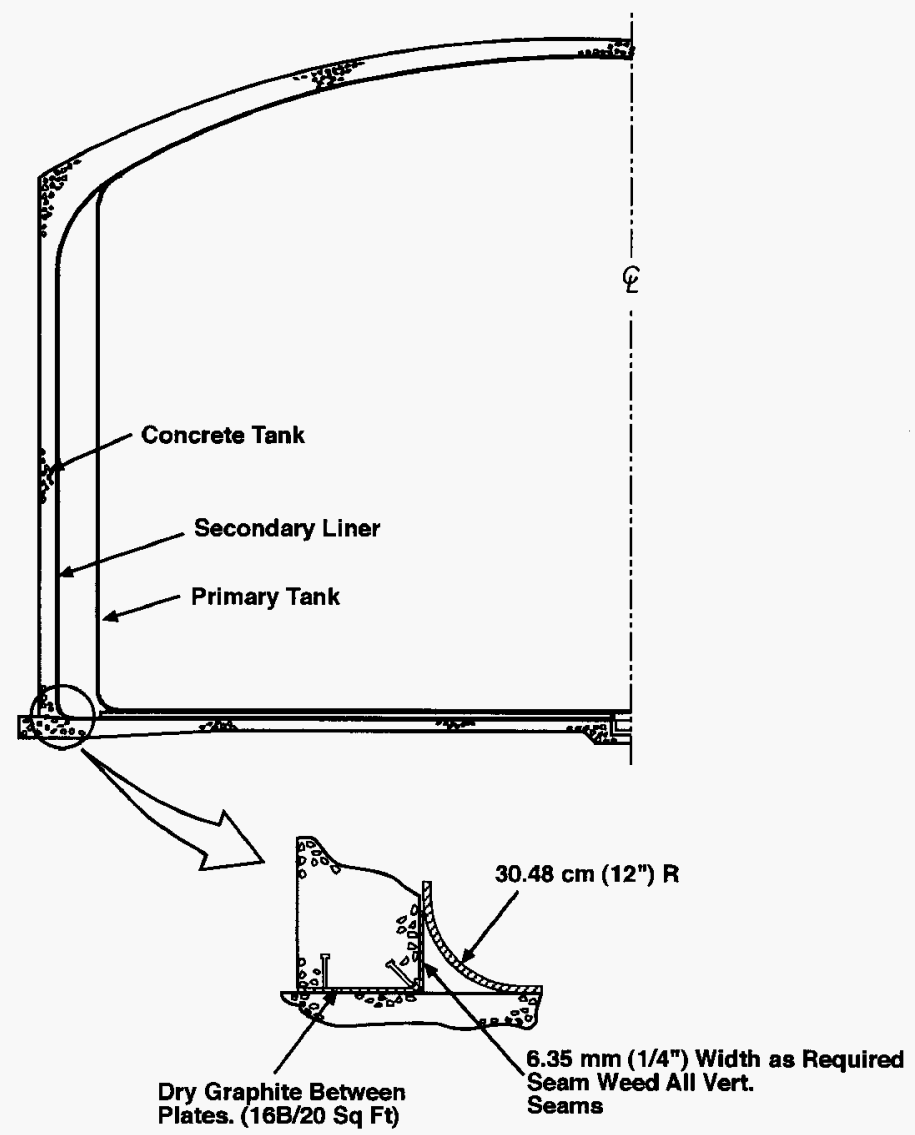

7G96030034.19

SRP-SSSD 
Figure 5-7. Typical Dome Reinforcement of DSTs.

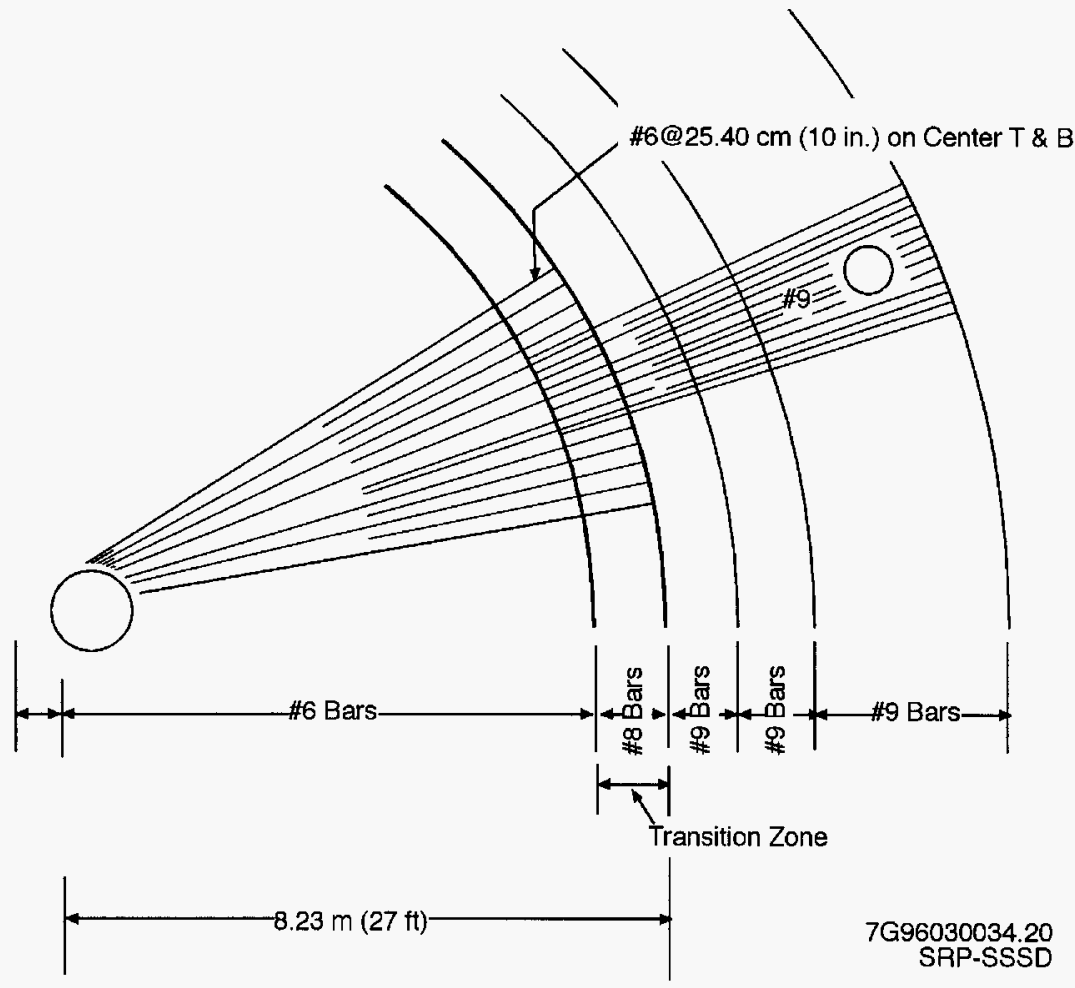


WHC-SD-TWR-RPT-002 REV 0

This page intentionally left blank. 
Table 2-1. Single-Shell Tank Design Parameters.

\begin{tabular}{|c|c|c|c|c|c|c|c|c|c|c|c|c|c|}
\hline \multirow{2}{*}{ Type } & \multirow{2}{*}{$\begin{array}{c}\text { No. } \\
\text { of } \\
\text { tanks }\end{array}$} & \multicolumn{2}{|c|}{$\begin{array}{c}\text { Inside } \\
\text { diameter }\end{array}$} & \multicolumn{2}{|c|}{$\begin{array}{c}\text { Wal1 } \\
\text { height }\end{array}$} & \multicolumn{2}{|c|}{$\begin{array}{c}\text { Capacity } \\
\left(10^{3}\right)\end{array}$} & \multicolumn{2}{|c|}{$\begin{array}{c}\text { Liner } \\
\text { thickness }\end{array}$} & \multicolumn{2}{|c|}{$\begin{array}{c}\text { Wa11 } \\
\text { thickness }\end{array}$} & \multicolumn{2}{|c|}{$\begin{array}{c}\text { Dome } \\
\text { thickness }\end{array}$} \\
\hline & & m & $\mathrm{ft}$ & m & $\mathrm{ft}$ & L & gal & $\mathrm{cm}$ & in. & $\mathrm{cm}$ & in. & $\mathrm{cm}$ & in. \\
\hline 200-Series & 16 & 6.1 & 20 & 7.63 & 25 & 208 & 55 & 0.64 & 0.25 & 33 & 13 & $30.5^{c}$ & $12^{c}$ \\
\hline $\begin{array}{c}\text { 100-Series } \\
\text { Type } 1\end{array}$ & 60 & 22.9 & 75 & 5.19 & 17 & 2,017 & 533 & $\begin{array}{l}0.64 / \\
0.953^{d}\end{array}$ & $\begin{array}{l}0.25 / \\
0.375\end{array}$ & 30.5 & 12 & $38.1^{e}$ & $15^{e}$ \\
\hline $\begin{array}{c}\text { 100-Series } \\
\text { Type } 3\end{array}$ & 25 & 22.9 & 75 & 9.61 & 31.5 & 3,785 & 1,000 & 0.953 & 0.375 & $30.5 / 61$ & $15 / 24$ & $38.1^{e}$ & $15^{e}$ \\
\hline
\end{tabular}

${ }^{\mathrm{a} T o}$ top of steel liner.

${ }^{b}$ Concrete tank wall.

c200-Series tanks have a flat surface instead of a dome.

Double numbers is where dimensions vary with height.

eDome thickness varies from haunch to the apex. 
Table 2-2. Comparison of Nominal Capacity Million-Gallon Double-She11 Tanks with Million-Gallon Single-Shell Tanks.

\begin{tabular}{|c|c|c|c|c|c|c|c|c|c|c|c|c|c|c|c|}
\hline \multirow[t]{2}{*}{ Type } & \multirow{2}{*}{$\begin{array}{l}\text { No. } \\
\text { of } \\
\operatorname{tank}\end{array}$} & \multicolumn{2}{|c|}{$\begin{array}{c}\text { Inside } \\
\text { diameter }\end{array}$} & \multicolumn{2}{|c|}{$\begin{array}{c}\text { Wall } \\
\text { height }\end{array}$} & \multicolumn{2}{|c|}{$\begin{array}{c}\text { Capacjity } \\
\left(10^{3}\right)\end{array}$} & \multicolumn{2}{|c|}{$\begin{array}{c}\text { Primary } \\
\text { tank } \\
\text { thickness }\end{array}$} & \multicolumn{2}{|c|}{$\begin{array}{l}\text { Linerb } \\
\text { thickness }\end{array}$} & \multicolumn{2}{|c|}{$\begin{array}{l}\text { Concrete } \\
\text { wall } \\
\text { thickness }\end{array}$} & \multicolumn{2}{|c|}{$\begin{array}{c}\text { Dome } \\
\text { thickness }\end{array}$} \\
\hline & & $m$ & $\mathrm{ft}$ & m & $\mathrm{ft}$ & $\mathrm{L}$ & gal & $\mathrm{cm}$ & in. & $\mathrm{cm}$ & in. & $\mathrm{cm}$ & in. & $\mathrm{cm}$ & in. \\
\hline SSTS & 25 & 23 & 75 & 9.6 & 31.5 & 3,785 & 1,000 & $\mathrm{~N} / \mathrm{A}$ & N/A & 0.95 & 0.37 & $38 / 61$ & $15 / 24$ & 38 & 15 \\
\hline DSTs & 28 & $23^{d}$ & $75^{d}$ & 9.9 & 32.5 & 3,785 & 1,000 & $1.3 / 2.2$ & $0.5 / 0.9$ & $0.62 / 0.95$ & $0.25 / 0.37$ & 45.7 & 18 & 38 & 15 \\
\hline
\end{tabular}

a Base to construction joint below haunch.

Primary tank, thickness varies with tank farm.

concrete tank wal1.

$\stackrel{1}{\sim} \quad$ Internal primary tank. 
Table 2-3. Summary of Single-Shell Tank Materials and Specifications. (2 sheets)

\begin{tabular}{|c|c|c|c|c|c|c|c|c|c|c|c|c|c|}
\hline \multirow{3}{*}{$\begin{array}{l}\text { Tank } \\
\text { farm } \\
241-\end{array}$} & \multirow{3}{*}{$\begin{array}{l}\text { Constr. } \\
\text { dates } \\
\text { (start/ } \\
\text { end) }\end{array}$} & \multirow{3}{*}{$\begin{array}{l}\text { Hanford } \\
\text { constr. } \\
\text { spec. }\end{array}$} & \multicolumn{4}{|c|}{ Steel liner } & & & & \multicolumn{3}{|c|}{ Reinforcing steel } & \multirow{3}{*}{$\begin{array}{l}\text { Seismic } \\
\text { criteria }\end{array}$} \\
\hline & & & \multirow{2}{*}{$\begin{array}{l}\text { Steel } \\
\text { design } \\
\text { code }\end{array}$} & \multirow{2}{*}{$\begin{array}{l}\text { Tank steel } \\
\text { ASTM spec. } \\
\text { (Repl. AsTM) } \\
\text { yield stress }\end{array}$} & \multicolumn{2}{|c|}{ Weld specifications } & \multicolumn{3}{|c|}{$\begin{array}{l}\text { Concrete specification } \\
\text { compressive strength }\end{array}$} & \multirow{2}{*}{$\begin{array}{l}\text { Rebar } \\
\text { (ASTM) } \\
\text { Yield } \\
\text { Strength }\end{array}$} & \multirow{2}{*}{$\begin{array}{l}\text { Cross-ties } \\
\text { (ASTM) } \\
\text { Yield } \\
\text { Strength }\end{array}$} & \multirow{2}{*}{ Welds } & \\
\hline & & & & & Proc. & Qual. & Dome & Hall & FDN & & & & \\
\hline \multirow[t]{2}{*}{$B$} & \multirow{2}{*}{$\begin{array}{l}1943 \\
1944\end{array}$} & \multirow[t]{2}{*}{ HWS- 1946} & \multirow[t]{2}{*}{ AWHA } & \multirow{2}{*}{$\begin{array}{c}A 7-39 \\
(A 283, G R \text { D) } \\
F_{Y}=33 \mathrm{ksi}\end{array}$} & \multirow[t]{2}{*}{ AWS } & \multirow[t]{2}{*}{ AWS } & \multicolumn{3}{|c|}{ PCA ST -58} & \multirow{2}{*}{$\begin{array}{c}A 15-39 \\
F_{Y}=40 \mathrm{ksi}\end{array}$} & \multirow{2}{*}{$\begin{array}{c}A 15-39 \\
F_{Y}=40 \mathrm{ksi}\end{array}$} & \multirow[t]{2}{*}{ UNSP } & \multirow[t]{2}{*}{ UNSP } \\
\hline & & & & & & & $3 \mathrm{ksi}$ & $3 \mathrm{ksi}$ & $3 \mathrm{ksi}$ & & & & \\
\hline \multirow[t]{2}{*}{ c } & \multirow{2}{*}{$\begin{array}{l}1943 \\
1944\end{array}$} & \multirow[t]{2}{*}{ HWS- 1946} & AWWA & A7-39 & AWS & AWS & & CA ST-5 & & A15-39 & A15-39 & UNSP & UNSP \\
\hline & & & & $\begin{array}{l}A 283, G R \quad D) \\
F_{Y}=33 \mathrm{ksi}\end{array}$ & & & $3 \mathrm{ksi}$ & $3 \mathrm{ksi}$ & $3 \mathrm{ksi}$ & $F_{Y}=4$ & & & \\
\hline$T$ & 1943 & HWS- 1946 & AWWA & A7-39 & AUS & AWS & & CA ST -5 & & A15-39 & A15-39 & UNSP & UNSP \\
\hline & & & & $\begin{array}{l}\text { (A283,GR D) } \\
F_{Y}=33 \mathrm{ksi}\end{array}$ & & & $3 \mathrm{ksi}$ & $3 \mathrm{ksi}$ & $3 \mathrm{ksi}$ & & & & \\
\hline$u$ & 1943 & HWS- 1946 & AWWA & A7-39 & AWS & AWS & & CA ST-5 & & A15-39 & A15-39 & UNSP & UNSP \\
\hline & & & & $\begin{array}{l}\text { A28s, GR D) } \\
F_{y}=33 \mathrm{ksi} \\
\end{array}$ & & & $3 \mathrm{ksi}$ & $3 \mathrm{ksi}$ & $3 \mathrm{ksi}$ & & & & \\
\hline $\mathrm{BX}$ & 1946 & NRA & AWHA & A7-39 & AWS & AWS & & ST-55\& & & A15-39 & A15-39 & NRA & NRA \\
\hline & & & & $F_{Y}=33 \mathrm{ksi}$ & & & $3 \mathrm{ksi}$ & $3 \mathrm{ksi}$ & $3 \mathrm{ksi}$ & & & & \\
\hline$T X$ & 1947 & HH-3061 & AWWA & A285-46 & AWS & AWS & & ST $-55 \&$ & & A15-39 & A15-39 & NRA & NRA \\
\hline & & & & $\begin{array}{l}\text { Grade Unknown } \\
F_{y}=24-30 \mathrm{ksi}\end{array}$ & & & $3 \mathrm{ksi}$ & $3 \mathrm{ksi}$ & $3 \mathrm{ksi}$ & & & & \\
\hline BY & 1948 & HW-3783 & NRA & A283-46T & ASME & ASME & & ST-55\& & & A15-39 & A15-39 & NRA & NRA \\
\hline & & & & $\begin{array}{l}\text { Grade Unknown } \\
F_{y}=24-33 \text { ks } i\end{array}$ & & & $3 \mathrm{ksi}$ & $3 \mathrm{ksi}$ & $3 \mathrm{ksi}$ & & & & \\
\hline$s$ & 1950 & HW-3937 & NRA & A283-46T & ASME & ASME & & ST $-55 \&$ & & A15-39 & A15-39 & NRA & NRA \\
\hline & 1951 & & & $\begin{array}{l}\text { Grade Uknown } \\
F_{y}=24-33 \mathrm{ksi}\end{array}$ & Sect. VIIII & Sect. IX & $3 \mathrm{ksi}$ & $3 \mathrm{ksi}$ & $3 \mathrm{ksi}$ & & $F_{Y}=4 C$ & & \\
\hline$T Y$ & 1951 & HH-4696 & NRA & A283-49T & ASME & HW-4595 & & ST-55\& & & A15-39 & A15-39 & NRA & MRA \\
\hline & 1952 & & & $\begin{array}{c}\text { Grade Unknown } \\
F_{y}=24-33 \mathrm{ksi}\end{array}$ & & $\begin{array}{l}\text { ASHEE } \\
\text { Sect. IX }\end{array}$ & $3 \mathrm{ksi}$ & $3 \mathrm{ksi}$ & $3 \mathrm{ksi}$ & $F_{Y}=4$ & $F_{Y}=4$ & & \\
\hline sx & 1953 & $\mathrm{HW}-4957$ & NRA & A283-52T & HW-4925-S & HW-4900-S & & ST-55\& & & A15-50t & A15-50T & NRA & MRA \\
\hline & & & & $\begin{array}{l}\text { Grade Unknown } \\
F_{Y}=24-33 \mathrm{ksi}\end{array}$ & & & $3 \mathrm{ksi}$ & $3 \mathrm{ksi}$ & $3 \mathrm{ksi}$ & & & & \\
\hline A & $\begin{array}{l}1954 \\
1955\end{array}$ & HiWs-5614 & ASME & A283-52T & $\begin{array}{ll}\mathrm{HH}-4924-\mathrm{S} \\
\mathrm{HH}-4926-\mathrm{S}\end{array}$ & HW-4900-S & & ST-55\& & & $A 15-50 \mathrm{~T}$ & $A 15-50 T$ & NRA & NRA \\
\hline & & & & $\begin{array}{l}\text { Grade Unknown } \\
F_{y}=24-33 \mathrm{ksi}\end{array}$ & & & $3 \mathrm{ksi}$ & $3 \mathrm{ksi}$ & $3 \mathrm{ksi}$ & & & & \\
\hline
\end{tabular}


Table 2-3. Summary of Single-Shell Tank Materials and Specifications. (2 sheets)

\begin{tabular}{|c|c|c|c|c|c|c|c|c|c|c|c|c|c|}
\hline \multirow{4}{*}{$\begin{array}{l}\text { Tank } \\
\text { farm } \\
241-\end{array}$} & \multirow{4}{*}{$\begin{array}{l}\text { Constr. } \\
\text { dates } \\
\text { (start// } \\
\text { end) }\end{array}$} & \multirow{4}{*}{$\begin{array}{l}\text { Hanford } \\
\text { constr. } \\
\text { spec. }\end{array}$} & \multicolumn{4}{|c|}{ Steel liner } & & & & \multicolumn{3}{|c|}{ Reinforcing steel } & \multirow{4}{*}{$\begin{array}{l}\text { Seismic } \\
\text { criteria }\end{array}$} \\
\hline & & & \multirow{3}{*}{$\begin{array}{l}\text { Steel } \\
\text { design } \\
\text { code }\end{array}$} & \multirow{3}{*}{$\begin{array}{l}\text { Tank steel } \\
\text { ASTM spec. } \\
\text { (Repl. ASTM) } \\
\text { yield stress }\end{array}$} & \multicolumn{2}{|c|}{ Weld specifications } & \multicolumn{3}{|c|}{$\begin{array}{l}\text { Concrete specification } \\
\text { compressive strength }\end{array}$} & \multirow{3}{*}{$\begin{array}{l}\text { Rebar } \\
\text { (ASTM) } \\
\text { Yield } \\
\text { strength }\end{array}$} & \multirow{3}{*}{$\begin{array}{c}\text { Cross-ties } \\
\text { (ASTM) } \\
\text { Yield } \\
\text { strength }\end{array}$} & \multirow{3}{*}{ Welds } & \\
\hline & & & & & \multirow[t]{2}{*}{ Proc. } & \multirow[t]{2}{*}{ Qual. } & & & & & & & \\
\hline & & & & & & & Dome & Wall & FDN & & & & \\
\hline \multirow[t]{2}{*}{$A X$} & \multirow{2}{*}{$\begin{array}{l}1963 \\
1964\end{array}$} & \multirow{2}{*}{$\begin{array}{l}\text { HW-4798-S } \\
\text { HWS-8237 }\end{array}$} & \multirow{2}{*}{$\begin{array}{l}\text { ASME } \\
\text { Sect. } \\
\text { VIII }\end{array}$} & \multirow{2}{*}{$\begin{array}{c}\text { A201-61T } \\
\text { Grade A } \\
F_{Y}=30 \mathrm{ksi}\end{array}$} & \multirow{2}{*}{$\begin{array}{l}\text { ASME } \\
\text { Sect. VIII }\end{array}$} & \multirow{2}{*}{$\begin{array}{l}\text { ASME } \\
\text { Sect. IX }\end{array}$} & \multicolumn{3}{|c|}{ ACI $318-56$} & \multirow{2}{*}{$\begin{array}{c}A 15-58 \mathrm{~T} \\
\mathrm{~F}_{\mathrm{Y}}=40 \mathrm{ksi}\end{array}$} & \multirow{2}{*}{$\begin{array}{l}A 15-58 \mathrm{~T} \\
\mathrm{~F}_{\mathrm{Y}}=40 \mathrm{ksi}\end{array}$} & \multirow[t]{2}{*}{ NRA } & \multirow[t]{2}{*}{ UBC } \\
\hline & & & & & & & $4 \mathrm{ksi}$ & $4 \mathrm{ksi}$ & $4 \mathrm{ksi}$ & & & & \\
\hline
\end{tabular}

ACI = American Conerete Institute.

ASME = American Society of Mechanical Engineers.

ASTM = American Society for Testing and Materials

AWS = American Welding Society.

$\begin{array}{ll}\rightarrow & \text { FDN }=\text { Foundat ion base mat. } \\ + & \text { HWS }=\text { Hanford Works Specification. } \\ \rightarrow & \text { NRA }=\text { not readily avai lable. }\end{array}$

PCA = Portland Cement Association.

UBC = Uniform Building Code

UNSP = unspecified. 
Table 2-4. Double-Shell Tank Materials and Specifications.

\begin{tabular}{|c|c|c|c|c|c|c|c|c|c|c|c|c|}
\hline \multirow{2}{*}{$\begin{array}{l}\text { Tank } \\
\text { farm } \\
241-\end{array}$} & \multirow{2}{*}{$\begin{array}{l}\text { Construction } \\
\text { completed }\end{array}$} & \multirow{2}{*}{$\begin{array}{l}\text { Project } \\
\text { number }\end{array}$} & \multirow{2}{*}{$\begin{array}{c}\text { Hanford } \\
\text { specification }\end{array}$} & \multirow{2}{*}{$\begin{array}{l}\text { Tank } \\
\text { steel } \\
\text { liner }\end{array}$} & \multirow{2}{*}{$\begin{array}{c}\text { Steel } \\
\text { design } \\
\text { code }\end{array}$} & \multicolumn{3}{|c|}{$\begin{array}{l}\text { Concrete specification } \\
\text { compressive strength" }\end{array}$} & \multirow{2}{*}{$\begin{array}{l}\text { Concrete } \\
\text { rebar yield } \\
\text { strength" } \\
\text { (ksi) }\end{array}$} & \multirow{2}{*}{$\begin{array}{c}\text { Welding } \\
\text { specification }\end{array}$} & \multirow{2}{*}{$\begin{array}{l}\text { Rebar } \\
\text { specification } \\
\text { (ASTM) }\end{array}$} & \multirow{2}{*}{$\begin{array}{l}\text { Seismic } \\
\text { criteria }\end{array}$} \\
\hline & & & & & & Dome & Wall & FON & & & & \\
\hline \multirow{2}{*}{ AY } & \multirow{2}{*}{1970} & \multirow{2}{*}{ |AP-7789 } & \multirow{2}{*}{$\begin{array}{l}\text { HWS-7789 } \\
\text { HWS-7791 }\end{array}$} & \multirow{2}{*}{$\begin{array}{r}A 515 \\
\text { GR } 60\end{array}$} & \multirow{2}{*}{$\begin{array}{c}\text { ASME } \\
1965\end{array}$} & \multicolumn{3}{|c|}{$\mathrm{ACl}-318$ (1963) } & \multirow{2}{*}{60} & \multirow{2}{*}{$\begin{array}{c}\text { ASME } \\
\text { Section IX }\end{array}$} & \multirow{2}{*}{ A432 } & \multirow{2}{*}{ UBC 1967} \\
\hline & & & & & & $3 \mathrm{ksi}$ & $3 \mathrm{ksi}$ & $3 \mathrm{ksi}$ & & & & \\
\hline \multirow{2}{*}{$A Z$} & \multirow{2}{*}{1977} & \multirow{2}{*}{ IAP- 647} & \multirow{2}{*}{$\begin{array}{l}\text { HWS-8982 } \\
\text { HWS-8986 }\end{array}$} & \multirow{2}{*}{$\begin{array}{l}\text { A515 } \\
\text { GR } 60\end{array}$} & \multirow{2}{*}{$\begin{array}{c}\text { ASME } \\
\text { Sect. III } \\
1968\end{array}$} & \multicolumn{3}{|c|}{$\mathrm{ACl}-318(1963)$} & \multirow{2}{*}{60} & \multirow{2}{*}{$\begin{array}{c}\text { ASME } \\
\text { Section IX }\end{array}$} & \multirow{2}{*}{ A615 } & \multirow{2}{*}{$\begin{array}{l}0.25 \mathrm{~g}(\mathrm{H}) \\
0.17 \mathrm{~g}(\mathrm{~V}) \\
\mathrm{TID}-7024\end{array}$} \\
\hline & & & & & & $3 \mathrm{ksi}$ & $3 \mathrm{ksi}$ & $3 \mathbf{~ k s i}$ & & & & \\
\hline \multirow{2}{*}{$5 Y$} & \multirow{2}{*}{1977} & \multirow{2}{*}{ B-101 } & B-101-C1, & A516 & $\begin{array}{c}\text { ASME } \\
\text { Sect. VIII }\end{array}$ & & -318 & & & HWS-220-W & & $\operatorname{SDC} 4.1$ \\
\hline & & & $\mathrm{C} 2, \mathrm{C} 3, \mathrm{P} 6$ & GR 60 & $\begin{array}{l}\text { Div. } 1 \\
1971\end{array}$ & $4.5 \mathrm{ksi}$ & $4.5 \mathrm{ksi}$ & $4.5 \mathrm{ksi}$ & 60 & Section IX & A615 & TID.7024 \\
\hline & & & B-130 D1, & A537 & ASME & & -318 & & & HWS-220-W & & $0.25 \mathrm{~g}(\mathrm{H})$ \\
\hline & & & $61-61$ & Class I & $\begin{array}{l}\text { Div. } 2 \\
1974\end{array}$ & $5 \mathrm{ksi}$ & $5 \mathrm{ksi}$ & $4.5 \mathrm{ksi}$ & 00 & Section IX & Dors & $\begin{array}{l}\text { TID-7024 } \\
\text { SDC } 4.1\end{array}$ \\
\hline AW & 1980 & R-1?0 & B-120 D1. & A537 & $\begin{array}{l}\text { ASME } \\
\text { Sect. V!II }\end{array}$ & & $-318 \mid 19$ & & & HWS- 220-W & & $0.25 g(\mathrm{H})$ \\
\hline 然 & 1300 & 5.120 & $\mathrm{Cl} \cdot \mathrm{C7}$ & Class 1 & $\begin{array}{l}\text { Div. } 2 \\
1974\end{array}$ & $5 \mathrm{ksi}$ & $5 \mathrm{ksi}$ & $4.5 \mathrm{ksi}$ & $\infty$ & Section IX & Aols & $\begin{array}{l}\text { TID-7024 } \\
\text { SDC } 4.1\end{array}$ \\
\hline AP & 1986 & B-340 & B-340 D1, & A537 & $\begin{array}{l}\text { ASME } \\
\text { Sect. VIII }\end{array}$ & & 9318 & & 60 & $\begin{array}{l}\text { AWS D1.1 } \\
\text { ASME }\end{array}$ & A615 & $\begin{array}{l}0.25 \mathrm{~g}(\mathrm{H}) \\
0.17 \mathrm{~g}(\mathrm{~V})\end{array}$ \\
\hline & & & $\mathrm{C1}-\mathrm{C} 7, \mathrm{Cg}$ & Class & $\begin{array}{l}\text { Div. } 2 \\
1980\end{array}$ & $5 \mathrm{kgi}$ & $5 \mathrm{ksi}$ & $4.5 \mathrm{ksi}$ & & Section IX & 80 & $\begin{array}{c}\text { TID.7024 } \\
\text { SDC 4.1, Rev. } 7\end{array}$ \\
\hline
\end{tabular}

ASME = American Society of Mechanical Engineers.

ASTM = American Society for Testing and Materials.

AWS $=$ American Weiding Society.

FDN = Foundation base mat.

$H=$ Horizontal.

HWS $=$ Hanford Works Specification

SDC $=$ Standard Design Critoria

UBC = Uniform Building Code.

$\checkmark=$ Vertical.

'Nominal values. 
Table 3-1. Results Summary of Double-She11 Tank Useful Life Estimates Models.

\begin{tabular}{|c|c|c|c|}
\hline Tank & $\begin{array}{l}\text { CF model } \\
\text { Liquid (Breach year) }\end{array}$ & $\begin{array}{l}\text { Atmospheric model } \\
\text { Vapor (Breach year) }\end{array}$ & $\begin{array}{l}\text { Condensate model } \\
\text { vapor (Breach year) }\end{array}$ \\
\hline 104-AW & 2056 & 5154 & 3680 \\
\hline 107-AN & 2072 & 2602 & 2205 \\
\hline 102-AN & 2075 & 2593 & 2187 \\
\hline 107-AP & 2096 & $>10000$ & 8256 \\
\hline $101-S Y$ & 2099 & $>10000$ & 5266 \\
\hline $101-A N$ & 2104 & 2704 & 2551 \\
\hline $105-A N$ & 2109 & 2602 & 2205 \\
\hline $101-A H$ & 2110 & $>10000$ & 2410 \\
\hline 104-AP & 2111 & 7794 & 7226 \\
\hline $102-S Y$ & 2112 & $>10000$ & 5001 \\
\hline $103-A N$ & 2112 & 2593 & 2187 \\
\hline $102-A Z$ & 2116 & $>10000$ & 2083 \\
\hline $104-A N$ & 2117 & 2584 & 2171 \\
\hline $103-A W$ & 2120 & 6626 & 4140 \\
\hline $101-A Y$ & 2130 & $>>10000$ & 3945 \\
\hline 102-AY & 2133 & $>>10000$ & 4730 \\
\hline $103-s \gamma$ & 2134 & $>10000$ & 5215 \\
\hline $106-\mathrm{AN}$ & 2137 & 2739 & 2751 \\
\hline $101-A Z$ & 2139 & $>10000$ & 2063 \\
\hline 105-AW & 2141 & $\gg 10000$ & 3945 \\
\hline 106-AW & 2143 & 3741 & 2225 \\
\hline 102-AW & 2144 & $>10000$ & 2623 \\
\hline $101-A P$ & 2146 & $>10000$ & 5646 \\
\hline 103-AP & 2147 & $>10000$ & $>10000$ \\
\hline 108-AP & 2148 & $>10000$ & 5486 \\
\hline 105-AP & 2149 & $>10000$ & 5806 \\
\hline 106-AP & 2149 & $>10000$ & 6286 \\
\hline $102-A P$ & 2157 & $>10000$ & 5056 \\
\hline
\end{tabular}

Anantatmula and 0h1 1996 
Table 4-1. Safety and Performance Category Correlation.

\begin{tabular}{|c|c|c|c|c|c|c|c|}
\hline $\begin{array}{l}\text { Facility } \\
\text { type }\end{array}$ & $\begin{array}{l}\text { Reactor or } \\
\text { PSO- } \\
\text { designated }\end{array}$ & \multicolumn{4}{|c|}{ Hazardous or essential non-reactor facility } & General use & $\begin{array}{l}\text { No safety } \\
\text { function }\end{array}$ \\
\hline $\begin{array}{c}\text { Hazard } \\
\text { category }\end{array}$ & $H C-1^{b}$ & \multicolumn{2}{|c|}{$\mathrm{HC}-2^{b}$} & \multicolumn{2}{|c|}{$H C-3^{b}$} & & \\
\hline Hazard class ${ }^{c}$ & & High $(H H)^{c}$ & Moderate $(\mathrm{MH})^{\mathrm{c}}$ & \multicolumn{2}{|c|}{ Low $(\text { LH })^{c}$} & & \\
\hline \multirow{4}{*}{$\begin{array}{c}\text { Safety } \\
\text { classification }\end{array}$} & \multicolumn{2}{|c|}{ Safety class ${ }^{d}$} & \multicolumn{3}{|c|}{ Safety significant ${ }^{d}$} & $\begin{array}{l}\text { General } \\
\text { services }\end{array}$ & \\
\hline & \multirow[t]{2}{*}{$\begin{array}{l}\text { Performs or } \\
\text { preserves } \\
\text { reactor } \\
\text { safety } \\
\text { function }\end{array}$} & $\begin{array}{c}\text { Prevents or } \\
\text { mitigates } \\
\text { significant } \\
\text { consequences } \\
\text { to: }\end{array}$ & \multicolumn{2}{|c|}{$\begin{array}{c}\text { Defense-in-depth. Prevents } \\
\text { or mitigates unacceptable } \\
\text { risk to: }\end{array}$} & $\begin{array}{l}\text { Worker } \\
\text { safety. } \\
\text { Prevents or } \\
\text { mitigates } \\
\text { serious } \\
\text { injury not } \\
\text { controlled } \\
\text { by ISPe to: }\end{array}$ & $\begin{array}{c}\text { Occupant and } \\
\text { worker safety } \\
\text { controlled by } \\
\text { building code } \\
\text { and ISPe }\end{array}$ & \\
\hline & & \multicolumn{2}{|c|}{ Offsite public } & $\begin{array}{l}\text { Onsite } \\
\text { worker }\end{array}$ & $\begin{array}{l}\text { Facility } \\
\text { worker }\end{array}$ & Any occupant & \\
\hline & \multicolumn{3}{|c|}{$S C-1^{f}$} & $S C-2^{f}$ & $S C-3^{f}$ & & \\
\hline $\begin{array}{c}\text { Performance } \\
\text { category }\end{array}$ & $P C-4^{g}$ & \multicolumn{2}{|c|}{$P C-3^{9}$} & $P C-2^{g}$ & \multicolumn{2}{|c|}{$P C-1^{9}$} & $P C-0^{g}$ \\
\hline
\end{tabular}

Note: This table depicts the step-by-step safety analysis process that culminates with the selection of Performance Category. DDE Program Secretarial Officer (PSO) may designate a facility to a higher Performance Category.

Hazard Category (HC) for nuclear facilities per DOE Order 5480.23 (DOE 1992). Hazard Category drives the level and rigor of analysis in the FSAR

and $\mathrm{its}$ references.

dHazard Class for non-nuclear facilities per DOE Order 5481.1B (DOE 1986).

Safety Class and Safety Signigicant classification per WHC-CM-4-46, Chapter 9.0, Revision 2.

Institutional Safety Program (ISP) per DOE Order 5480.23 (DOE 1992).

Obsolete Safety Class (SC) designation per WHC-CM-4-46, Chapter 9.0, Revision 1 . These designations no longer apply. They are used for existing

SELS and reference documentation until they are revised.

9performance category (PC) per DOE-STD-1020 (DOE 1994). 
Table 4-2. Original Specific Gravities of Single-Shell Tanks.

\begin{tabular}{|c|c|}
\hline Tank farm type & Maximum specific gravity \\
\hline $241-\mathrm{T}, \mathrm{U}, \mathrm{B}, \mathrm{C}, \mathrm{BX}$ & 1.9 \\
\hline $241-\mathrm{S}, \mathrm{BY}, \mathrm{TX}, \mathrm{TY}$ & 1.2 \\
\hline $241-\mathrm{SX}$ & 1.5 \\
\hline $241-\mathrm{A}$ & 2.2 \\
\hline
\end{tabular}

Table 4-3. Specific Gravity and Waste Level.

\begin{tabular}{|c|c|c|}
\hline Tank farms & Specific gravity & Waste level \\
\hline \multicolumn{3}{|c|}{ Single-shell tanks } \\
\hline$A, A X$, and $S X$ & 2.0 & $<927 \mathrm{~cm}$ (365 in.) \\
\hline $\mathrm{BY}, \mathrm{S}, \mathrm{TX}$, and $\mathrm{TY}$ & 2.0 & $<714 \mathrm{~cm}$ (281 in.) \\
\hline$B X$ & 2.0 & $<480 \mathrm{~cm}$ (189 in.) \\
\hline$B, C, T$, and $U$ & 2.0 & $<480 \mathrm{~cm}$ (189 in.) \\
\hline \multicolumn{3}{|c|}{ Double-she11 tanks } \\
\hline$A N$ and $A Z$ & 1.6 & $<940 \mathrm{~cm}(370$ in. $)$ \\
\hline$A N, A P$, and $A W$ & 2.0 & $<1,057 \mathrm{~cm}(416$ in. $)$ \\
\hline sY & 1.7 & $<1,057 \mathrm{~cm}(416$ in. $)$ \\
\hline
\end{tabular}

"Tank 102 of AW has maximum level of $1,041 \mathrm{~cm}(410 \mathrm{in.})$. 
Table 4-4. Soil Density and Cover at Apex.

\begin{tabular}{|c|c|c|}
\hline $\begin{array}{c}\text { Tank farm site } \\
241-\end{array}$ & $\begin{array}{c}\text { Average in-situ density } \\
\mathrm{kg} / \mathrm{m}^{3}\left(1 \mathrm{bs} / \mathrm{ft}^{3}\right)\end{array}$ & $\begin{array}{c}\text { Soil cover at apex } \\
\mathrm{m}(\mathrm{ft})\end{array}$ \\
\hline \multicolumn{3}{|c|}{ Double-she11 tanks } \\
\hline AP & $1,898(118.5)$ & $2.13(7)$ \\
\hline AN & $1,917(119.7)$ & $2.13(7)$ \\
\hline AW & $1,960(122.4)$ & $2.10(6.9)$ \\
\hline SY & $1,856(115.9)$ & $2.10(6.9)$ \\
\hline AY & $1,754(109.5)$ & $2.47(8.1)$ \\
\hline AZ & $1,867(116.6)$ & $2.19(7.2)$ \\
\hline A & $1,949(121.7)$ & $2.29(7.5)$ \\
\hline AX & $2,002(125.0)$ & $2.29(7.5)$ \\
\hline B & $2,002(125.0)$ & $2.44(8.0)$ \\
\hline BX & $2,002(125.0)$ & $2.56(8.4)$ \\
\hline BY & $2,002(125.0)$ & $2.95(9.7)$ \\
\hline C & $2,002(125.0)$ & $1.80(5.9)$ \\
\hline S & $1,842(115.0)$ & $2.01(6.6)$ \\
\hline SX & $1,798(112.3)$ & $2.07(6.8)$ \\
\hline T & $1,842(115.0)$ & $2.08(6.8)$ \\
\hline TX & $1,842(115.0)$ & $3.05(10.0)$ \\
\hline TY & $1,842(115.0)$ & $2.26(7.4)$ \\
\hline U & $1,842(115.0)$ & $2.19(7.2)$ \\
\hline B, T, U & $1,842(115.0)$ & $3.66(12.0)$ \\
\hline
\end{tabular}

References: WHC-SD-WM-SOIL-001 (Pianka 1994). WHC-SD-WM-TI-665 (Pianka 1995). 
Table 4-5. Seismic Peak Ground Acceleration Correlation.

\begin{tabular}{|l|l|l|l|}
\hline \multicolumn{2}{|c|}{ Current Correlation } & \multicolumn{1}{|c|}{ Future (DOE Order 5480.28) } & Correlation \\
\hline $\mathrm{SC}$ (Reactor) & $=0.25 \mathrm{~g}$ & $\mathrm{PC}-4$ (Reactor) & $=0.48 \mathrm{~g}(0.37)$ \\
\hline $\mathrm{SC}-1$ (High Hazard) & $=0.20 \mathrm{~g}$ & $\mathrm{PC}-3$ (Safety Class) & $=0.26 \mathrm{~g}(0.19)$ \\
\hline $\mathrm{SC}-2$ (Moderate Hazard) $=0.12 \mathrm{~g}$ & $\mathrm{PC}-2$ (Safety Significant) & $=0.20 \mathrm{~g}(0.12)$ \\
\hline $\mathrm{SC}-3$ (Low Hazard) & $=0.12 \mathrm{~g}$ & $\mathrm{PC}-1$ (Occupational Safety) & $=0.20 \mathrm{~g}(0.09)$ \\
\hline $\mathrm{SC}-4$ (General Use) & $=0.09 \mathrm{~g}$ & $\mathrm{PC}-0$ (No Safety Significance) $=0.0 \mathrm{~g}$ \\
\hline
\end{tabular}

*Tentative values for 200 West Area, based on new seismic hazard studies. () Site-specific for existing structures with seismic hazard exceedance probability of twice the recommended value for new structures.

Table 4-6. 75-ft Diameter Tank Thermal-Creep and Ultimate Load Input Data Analyses. (Ramble 1983)

\begin{tabular}{|c|c|c|c|c|c|c|}
\hline \multirow{2}{*}{$\begin{array}{l}\text { Tank } \\
\text { type }\end{array}$} & \multirow{2}{*}{$\begin{array}{l}\text { Capacity } \\
\text { (gal) }\end{array}$} & \multicolumn{2}{|c|}{$\begin{array}{l}\text { Soil depth at } \\
\text { crown (ft) }\end{array}$} & \multirow{2}{*}{$\begin{array}{c}\text { Analysis } \\
\text { length } \\
\text { (days) }\end{array}$} & \multirow{2}{*}{$\begin{array}{c}\text { Maximum wall } \\
\text { temperature } \\
\left({ }^{\circ} \mathrm{F}\right)\end{array}$} & \multirow{2}{*}{$\begin{array}{l}\text { Heat up } \\
\text { rate } \\
\left({ }^{\circ} \mathrm{F} / \text { day }\right)\end{array}$} \\
\hline & & $\begin{array}{c}\text { As } \\
\text { built }\end{array}$ & Maximum & & & \\
\hline $241-B X$ & 533,000 & 7 & 20 & 33 & 387 & 21.1 \\
\hline $241-U$ & 533,000 & 7 & 20 & 3,650 & 315 & 4.9 \\
\hline 241-BY & 758,000 & 7 & $N / A$ & 900 & 250 & 3.7 \\
\hline $241-5 X$ & $1,000,000$ & 6 & 27 & 3,752 & 387 & 10.4 \\
\hline 241-AX & $1,000,000$ & 8 & 29 & 2,000 & 350 & 2.9 \\
\hline $241-A$ & $1,000,000$ & 6 & 20 & 15 & 511 & 48.4 \\
\hline
\end{tabular}


Table 4-7. Sections in Tank for P-M Diagrams.

\begin{tabular}{|c|c|c|c|c|c|c|c|c|c|c|c|c|}
\hline \multirow{3}{*}{$\begin{array}{l}\text { Sect ion } \\
\text { number }\end{array}$} & \multirow{2}{*}{\multicolumn{6}{|c|}{ Section properties }} & \multicolumn{4}{|c|}{ Thermal-creep stresses } & \multirow{2}{*}{\multicolumn{2}{|c|}{$\begin{array}{l}\text { Conbined seismic and } \\
\text { hydrostatic responses }\end{array}$}} \\
\hline & & & & & & & \multicolumn{2}{|c|}{ Concrete } & \multicolumn{2}{|c|}{ Steel } & & \\
\hline & $\begin{array}{l}\text { H } \\
\text { (in.) }\end{array}$ & $\begin{array}{c}\text { B } \\
(\text { in. })\end{array}$ & $\begin{array}{c}\text { As1 } \\
\text { (in.2) }\end{array}$ & $\begin{array}{l}\text { AS2 } \\
\text { (in.2) }\end{array}$ & $\stackrel{0}{(i n .)}$ & $\begin{array}{l}p p \\
\text { (in.) }\end{array}$ & $\sigma_{1}(\mathrm{ksi})$ & $\sigma_{2}(\mathrm{ks} i)$ & $\sigma \mathrm{S}_{1}(\mathrm{ksi})$ & $\sigma s_{2}(k s i)$ & $p^{*}$ (kips) & $H^{*}(k-f t)$ \\
\hline \multicolumn{13}{|c|}{ Uncracked Longi tudinal } \\
\hline 1 & 15 & 12 & .44 & .44 & 2.5 & 13 & -.49 & -.33 & -5.63 & -4.90 & 28.49 & -3.26 \\
\hline 2 & 15 & 12 & .44 & .44 & 2.5 & 13 & -.29 & -.35 & -4.14 & -5.10 & 25.83 & 1.72 \\
\hline 3 & 44.4 & 12 & .88 & .44 & 2.5 & 42.4 & +.09 & -.20 & +.31 & -3.12 & 19.18 & 24.23 \\
\hline 4 & 15 & 12 & .53 & .42 & 2.5 & 13 & +.10 & -.25 & +.40 & -3.81 & 16.56 & 8.92 \\
\hline 5 & 15 & 12 & .53 & .42 & 2.5 & 13 & -.25 & -.07 & -3.63 & -1.15 & 14.41 & -3.35 \\
\hline 6 & 24 & 12 & .53 & .42 & 2.5 & 22 & 0 & -.10 & +.20 & -1.13 & 10.64 & 1.34 \\
\hline \multicolumn{13}{|c|}{ Cracked Longi tudinal } \\
\hline 7 & 24 & 12 & .85 & 1.05 & 2.5 & 22 & 0 & 0 & +0.94 & +1.44 & -15.76 & 20.62 \\
\hline 8 & 24 & 12 & .85 & 1.05 & 2.5 & 22 & 0 & 0 & +4.59 & -3.52 & 8.47 & -6.01 \\
\hline \multicolumn{13}{|c|}{ Uncracked Hoop } \\
\hline 9 & 15 & 12 & .44 & .44 & 3.5 & 12 & -.50 & -.30 & -6.30 & -4.47 & 28.71 & -3.64 \\
\hline 10 & 15 & 12 & .44 & .44 & 3.5 & 12 & -.27 & -.22 & -3.59 & -3.05 & 24.51 & -2.17 \\
\hline 11 & 36 & 12 & 2.67 & 2.67 & 9.0 & 27.5 & +.11 & +.02 & +1.55 & +1.04 & 45.42 & -3.59 \\
\hline 12 & 24 & 12 & 3.80 & 3.80 & $\begin{array}{c}5.5 \\
\text { (ave.) }\end{array}$ & $\begin{array}{c}18 \\
\text { (ave.) }\end{array}$ & -.14 & -.17 & -2.74 & -3.07 & 56.14 & 0.63 \\
\hline
\end{tabular}

Motes: Positive moment creates tension on interior face of tank.

Positive axial force is tension. 
Table 4-8. Maximum Stresses in Steel Liner.

\begin{tabular}{|c|c|c|}
\hline Soil-tank model nodal point & Longitudinal (ksi) & Circumferential (ksi) \\
\hline 16 & -.34 & -.82 \\
\hline 31 & -.34 & -1.20 \\
\hline 46 & -.44 & -1.58 \\
\hline 61 & -.64 & -1.98 \\
\hline 76 & -.66 & -2.32 \\
\hline 91 & 1.32 & 2.17 \\
\hline 106 & 1.42 & 2.97 \\
\hline 121 & 8.26 & 4.58 \\
\hline 135 & 12.16 & 4.93 \\
\hline 149 & 11.78 & 4.81 \\
\hline 163 & 12.15 & 4.90 \\
\hline 176 & 10.61 & 4.65 \\
\hline 190 & 7.40 & 4.00 \\
\hline 204 & 5.34 & 3.60 \\
\hline 218 & 4.17 & 3.49 \\
\hline 232 & 3.57 & 3.23 \\
\hline 246 & 2.46 & 3.11 \\
\hline 260 & 1.28 & 2.71 \\
\hline 274 & 1.01 & 2.74 \\
\hline 288 & .89 & 2.79 \\
\hline 302 & .67 & 2.72 \\
\hline 316 & -.91 & 3.14 \\
\hline
\end{tabular}

Note: Includes hydrostatic, hydrodynamic, vertical seismic, and horizontal seismic loads. Maximum may occur at inside face or outside face of tank. 
Table 4-9. Thermal-Creep Stresses in Steel Liner."

\begin{tabular}{|c|c|c|c|}
\hline $\begin{array}{c}\text { Thermal-creep } \\
\text { mode1 element }\end{array}$ & $\begin{array}{c}\text { Corresponding } \\
\text { AXIDYN model } \\
\text { nodal point }\end{array}$ & $\begin{array}{c}\text { Longitudinal } \\
\text { (ksi) }\end{array}$ & $\begin{array}{c}\text { Circumferential } \\
\text { (ksi) }\end{array}$ \\
\hline 698 & 176 & .13 & -29.39 \\
\hline 697 & 190 & -2.46 & -17.75 \\
\hline 695 & 204 & -3.69 & -8.96 \\
\hline 692 & 218 & -4.66 & -5.40 \\
\hline 689 & 232 & -4.80 & -5.15 \\
\hline 686 & 246 & -3.22 & -4.35 \\
\hline 683 & 260 & -1.92 & -3.17 \\
\hline 681 & 274 & -.69 & -1.88 \\
\hline 678 & 288 & 1.05 & 1.48 \\
\hline 674 & 302 & -.05 & .88 \\
\hline 671 & 316 & -2.72 & .48 \\
\hline
\end{tabular}

*Includes gravity loads.

Table 4-10. Steel Properties for Thermal-Creep Analysis. Liner

Elastic modulus $27.4 \times 10^{6} \mathrm{psi}$

Yield stress 39,000 psi

Poisson's Ratio 0.3

Coefficient of thermal expansion $6.6 \times 10^{-6}$ in. $/$ in. $/{ }^{\circ} \mathrm{F}$ Reinforcement

Elastic modulus $27.4 \times 10^{6} \mathrm{psi}$

Yield stress 53,000 psi

Coefficient of thermal expansion $6.6 \times 10^{-6} \mathrm{in.} / \mathrm{in} . /{ }^{\circ} \mathrm{F}$ 
Table 5-1. Summary of FSAR Solvent Pool Fire Cases.

\begin{tabular}{|c|c|c|c|c|c|c|c|c|}
\hline Case & $\begin{array}{l}\text { Tank } \\
\text { type }\end{array}$ & $\begin{array}{c}\text { Solvent pool } \\
\text { size }\end{array}$ & $\begin{array}{l}\text { Bounding } \\
\text { parameter }\end{array}$ & $\begin{array}{c}\text { Ventilation } \\
\text { type }\end{array}$ & Vent path size & $\begin{array}{l}\text { Peak } \\
\text { pressure/vacuum } \\
\text { (psid) }\end{array}$ & $\begin{array}{l}\text { Radiological } \\
\text { release (kg } \\
\text { solvent) }\end{array}$ & $\begin{array}{c}\text { Toxicological } \\
\text { release }(\mathrm{kg} / \mathrm{s} \text { of } \\
\left.\mathrm{P}_{2} \mathrm{O}_{5}\right)\end{array}$ \\
\hline$a$ & SST & Puddle & Pressure & Passive & HEPA & $0.9 /-0.1$ & 0.26 & $2.8 \mathrm{E}-5$ \\
\hline$b$ & SST & Puddle & Vacuum & Passive & HEPA/F l apper & $0.9 /-0.1$ & 0.26 & $2.8 \mathrm{E}-5$ \\
\hline c & SST & Puddle & Radiological & $100 \mathrm{cfm}$ & HEPA & $0.9 /-0.1$ & 13.1 & $5.6 \mathrm{E}-5$ \\
\hline$d$ & SST & Puddle & Toxicological & $100 \mathrm{cfm}$ & HEPA & $0.9 /-0.1$ & 13.1 & $5.6 \mathrm{E}-5$ \\
\hline e & SST & Large & Pressure & Passive & HEPA/F lapper & $29 /-0.1$ & 0.64 & $7.7 E-4$ \\
\hline f & SST & Large & Vacuum & Passive & HEPA/F l apper & $1.8 /-6.8$ & 0.76 & $1.6 \mathrm{E}-2$ \\
\hline 9 & SST & Large & Radiological & Passive & HEPA/F l apper & $1.8 /-6.8$ & 0.76 & $1.6 \mathrm{E}-2$ \\
\hline $\mathrm{h}$ & SST & Large & Toxicological & Passive & HEPA & $1.8 /-6.8$ & 0.76 & $1.6 \mathrm{E}-2$ \\
\hline$i$ & DST & Large & Pressure & None & None & $30.8 / 0$ & 0 & 0 \\
\hline j & DST & Large & Vacuum & Passive & Flapper & $2.1 /-8$ & 0.86 & $1.8 \mathrm{E}-2$ \\
\hline$k$ & DST & Puddle & Radiological & Active & Vent pipe & $0.2 /-0.1$ & 13.9 & $5.2 \mathrm{E}-3$ \\
\hline I & DST & Large & Toxicological & Active & Flapper/pipe & $2.0 /-5.2$ & 2.8 & $1.8 E-2$ \\
\hline In & DCRT & Large & Pressure & None & None & $30.5 / 0$ & 0 & 0 \\
\hline$n$ & DCRT & Large & Vacurm & Passive & 4 in. orifice & $18.3 /-1.2$ & $2 E-2$ & $8.6 E-4$ \\
\hline 0 & DCRT & Large & Radiological & Passive & 4 in. orifice & $18.3 /-1.2$ & $2 E-2$ & $8.6 \mathrm{E}-4$ \\
\hline$p$ & DCRT & Large & Toxicological & Passive & 4 in. orifice & $18.3 /-1.2$ & $2 E-2$ & $8.6 \mathrm{E}-4$ \\
\hline
\end{tabular}

FSAR = Final Safety Analys is Report.

SST = Single-shell tank

DST = Double-shell tank

DCRT = Double-containment receiver tank .

HEPA = High-efficiency particulate air (filter) .

psid $=1 \mathrm{bf} / \mathrm{in}^{2}$ differential. 
WHC-SD-TWR-RPT-002 REV 0

\section{APPENDIX A \\ ACCIDENT LOADS}

A-1 


\section{WHC-SD-TWR-RPT-002 REV 0}

This page intentionally left blank.

A-2 


\section{G \& P Consulting, Inc. \\ P. O. BOX 576 \\ RICHLANO, WASHINGTON 99352}

जT0: Francis C. Han (WHC)

cC: Bob M. Marusich (WHC)

Craig Carro (Chew \& Associates)

Dan Simpson (WHC)

Subject: FINAL UNMITIGATED PRESSURE TRANSIENT RESULTS FOR SOLVENT FIRES IN SSTS, DSTs, and DCRTS.

Final unmitigated solvent fire peak pressures/vacuums have been calculated with POOLFIRE.4. POOLFIRE. 4 is the solvent pool fire model that has been peer reviewed by Hughes Associates. Inc. as being acceptably conservative. The results are included in the attached table. Please note the following bounding cases and results:

1. SSTs: Bounding peak pressure is 29 psig (Case e) assuming no venting due to structural cracking. Bounding peak vacuum is -6.8 psig (Case $f$ ).

2. DSTs: Bounding peak pressure is 30.8 psig (Case $i$ ) assuming no venting at a11. Peak vacuum is -8.0 psig (Case $j$ ).

3. OCRTS: Bounding peak pressure is 18.3 psig (Case $n$ ) assuming minimum 4 inch pipe vent. Bounding peak vacuum is -1.2 psig (Case $n$ ).

We have calculated the amount of material (solvent fire smoke and vaporized aqueous 7 iquids that are released from the tanks due to the fire. In order to calculate final unmitigated dosed. please provide the materiai releases associated with any structural failure that might be caused by the fire transient. The solvent fire "controls" meeting is scheduled for April 26. 1996. In order to properly prepare for this critical meeting. please provide the material release information by April 22, 1996.

If you have any questions. please call me as soon as possible.

Thank you.

Mike Grigsby

FED $358-B$

372-1907 
SUMMARY OF FSAR SOLVENT POOL FIRE CASES

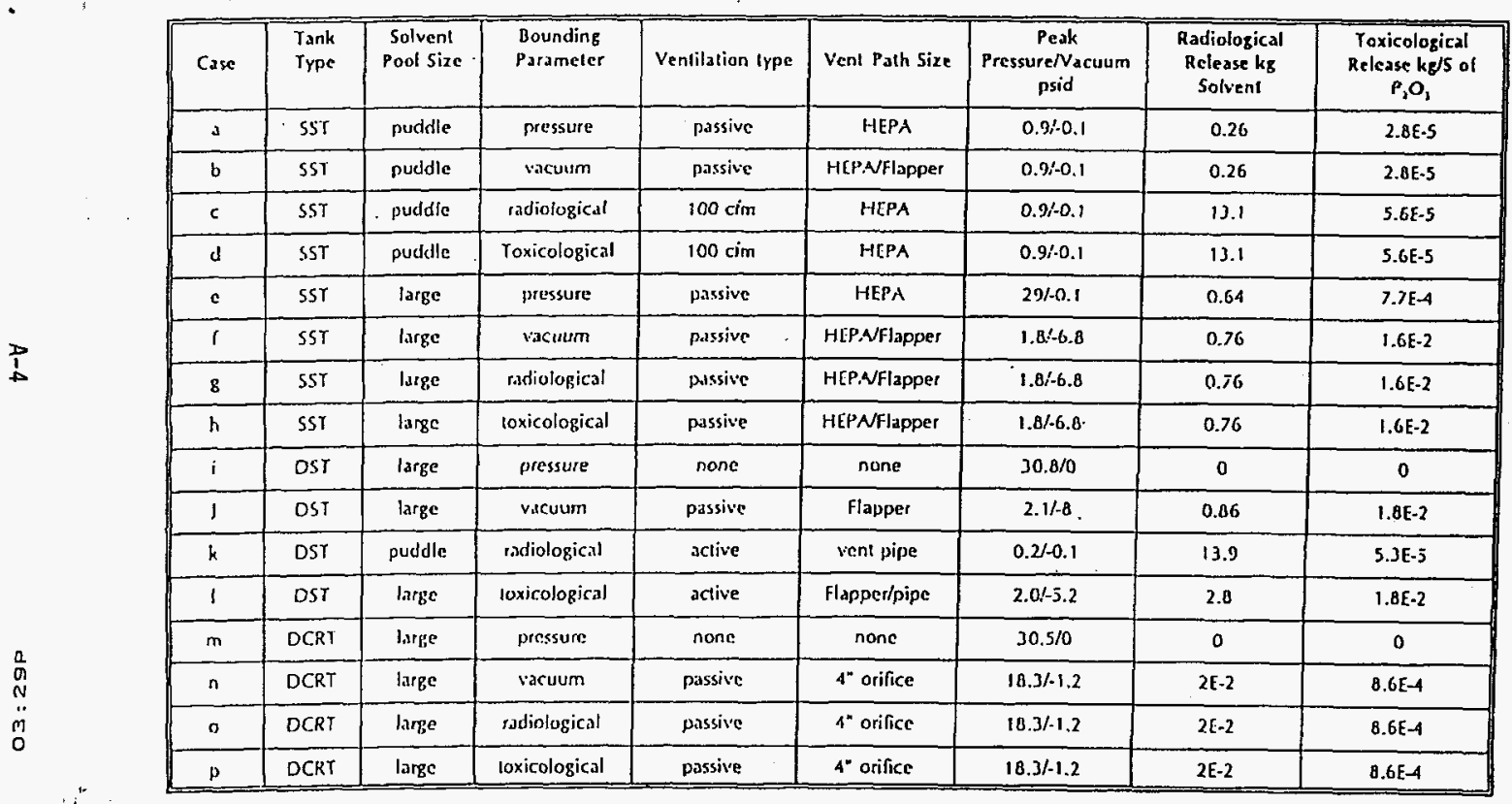




\section{KEY ASSUMPTIONS OF FSAR POOL FIRE CASES}

1. Tank structure remains intact.

2. Thermal hydraulics predicted with Poolfire.3

- Bounding fire parameters as recommended by Hughes Associates.

- Fire extinguishes at $13 \% \mathrm{O}_{2}$.

3. HEPA vent is minimal vent on SSTs.

4. Flapper vent opens at 1 psid, is 50 " diameter.

5. Large pool is one which does not limit fire spread.

6. Puddle fire is $0.28 \mathrm{~m}^{2}\left(3.04 \mathrm{ft}^{2}\right)$, contains sufficient solvent to burn $10 \mathrm{O}_{2}$ extinguishment.

7. DST minimal vent is small (assumed zero).

8. Air volummes $\left(170,000 \mathrm{ft}^{3} \mathrm{SST}+187,100 \mathrm{ft}^{3}\right.$ DST $)$ are bounding high values.

9. DCRT analyzed is large design (244-BX).

10. DCRT minimal vent is smail (assumed sero).

11. ARF values based on Mishima handbook

12. Acrosol depletion is neglected. 
From: TWRS SAR Engineering

Phone: $\quad 373-2238$ A3-37

$8 M 100-A B H-96031$

Date: April 16, 1996

Subject: WESTINGHOUSE HANFORD COMPANY INPUTS REQUIRED FOR THE ORGANIC SALT NITRATE TECHNICAL SUPPORT TASK

To:
E. P. DiVincenzo
A3-37
G. L. Dunford
A2- 34
D. L. Leach
A3 -34
E. J. Lipke
$57-14$
A. M. Umek
S7-81

\begin{tabular}{|c|}
\hline $\begin{array}{l}\text { C. Carro, Chew } \\
\text { R. T. Hailen, PNNL } \\
\text { F. C. Han } \\
\text { F. J. Markowski, PNN } \\
\text { R. M. Marusich } \\
\text { T. B. Powers } \\
\text { D. E. Simpson } \\
\text { T. W. Wood, PNNL } \\
\text { M. D. Zentner, PNNL } \\
\text { DAT: ABW File/LB }\end{array}$ \\
\hline
\end{tabular}

Reference: WHC-SD-WM-SARR-033, "Preliminary Safety Criteria for Organic Watch List Tanks at the Hanford Site," dated October 1995.

The reference report was issued to address the safety issues dealing with the potential for SST waste to undergo organic salt - nitrate reactions which could lead to overpressure events and releases of radioactive and toxic materials from damaged waste tanks. A team composed of WHC/PNNL/FAI personnel is working to update the reference with new information and approaches. The results of these additional safety studies will also be used as input in the TWRS FSAR.

The Organic Salt - Nitrate Reactions Safety Issue input to Chapter 3 (Accident Analysis) of the TWRS FSAR is being prepared by the PNNL/FAI team under WHC direction. This input (Draft SARR-033, Revision 1) is due to WHC on May 7, 1996. This date must be met in order to meet our FSAR commitments. Any delay in meeting the May 7 date will result a day for day sTip in our FSAR input. There are several key technical inputs that the PNNL/FAI team requires in order to provide a technically defensible product by May 7 . The inputs 1 isted below must be transmitted to the team by $\mathrm{COB}$, Thursday, Apri1 18:

A. Final set of initiator frequencies for controlled and unmitigated scenarios for initiators which could ignite organic salt - nitrate reactions (e.g. very hot lamp filaments). 
G. L. Dunford, et al.

Page 2

Aprit 16, 1996

$8 M 100-A B W-96031$

B. Final determination of tank dome responses to overpressurizations and temperature transients resulting from organic salt - nitrate reactions and any toxicological and radiological doses which would result from structural faitures.

C. HEPA filter rupture mechanical dispersion toxicological and radiological doses for actively ventilated SSTs and passively ventilated SSTs.

D. Decisions on risk acceptance guidelines (e.g., DOE letter of Aprif 8, 1996).

Note that if DOE decides to impose lower risk acceptance guidelines that significant impacts to our work schedule will be incurred.

In order to meet the May 7 date, certain other key assumptions have been made. If conditions change in the following areas it would have a severe effect on our ability to meet this date. The following key assumptions have been made in our planning:

1. The sum of fractions method of calculating toxicological doses is satisfactory for the purposes of the FSAR and that making bounding calculations for the 5 representative chemical compounds resulting from organic salt - nitrate reactions will meet FSAR needs. There will be no changes to the toxicological risk acceptance guidelines.

2. The Hanford Site Boundary will not be changed from the reference site boundary location currently used.

We are working with the individuals responsible for providing the technical information enumerated above. However, your support is urgently requested in ensuring that this technical information is available by April 18, as required.

We will be glad to discuss details regarding our needs at any time with you. Please contact A. B. Webb (376-1339) or D. A. Turner (373-2238).

\section{aB Webb}

A. B. Webb, Organic Salts Coordinator TWRS SAR Engineering

cab

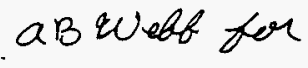

D. A. Turner, TWRS Safety Basis Safety Programs 


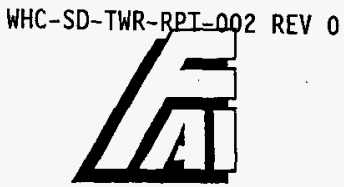

Fauske \& Associates, Inc.
DATE:
April 3, 1996
TO:
Francis C. Han
cc:
Craig Carro, Robert M. Marusich, Allen B. Webb, David A. Turner

FROM:

Sung Jin Lee, Martin G. Plys

SUBJECT: $\quad$ Cracked Dome Area During Solid Organic Reaction

It is postulated that when the pressure inside the tank exceeds $11 \mathrm{psig}$, the dome wall will start to crack, relieving further pressure build-up in the tank. In fact, there would be just enough crack area opening up to keep the dome pressure at near 11 psig. Let's consider tank $\mathrm{U} 107$, which has headspace volume of $1514 \mathrm{~m}^{3}$. The waste in this tank is currently wet but we hypothesized the tank to be drained and the waste dried. We ran two cases: one without allowing the dome to crack and another with dome cracking. We assumed the reaction to initiate at the center of the salt cake and propagate at velocities of $1.2 \mathrm{~mm} / \mathrm{sec}$ radially outward and 0.6 $\mathrm{mm} / \mathrm{sec}$ downward. Total reactive waste volume of $400 \mathrm{~m}^{3}$ was assumed.

Figures 1 and 2 show the results for the first case. Initially, the reaction propagates in a conical shape. As the headspace gas heats up, it radiates back to the unreacted salt cake. When the salt cake surface reaches $500 \mathrm{~K}\left(440^{\circ} \mathrm{F}\right)$, the entire salt cake surface starts to react and the reaction propagates downward. This massive reaction causes the tank pressure to reach $350 \mathrm{bar}(5000 \mathrm{psia})$ and the dome wall temperature to reach $1150 \mathrm{~K}\left(1610^{\circ} \mathrm{F}\right)$. Of course, this is not a realistic simulation; the dome cannot not sustain such a high pressure.

Figures 3 and 4 show the tank response when the dome is allowed to crack open and Figure 5 shows the corresponding crack area required to maintain the tank pressure at $11 \mathrm{psig}$. As desired, the tank pressure is maintained at 11 psig after the dome starts to crack due to overpressure. The dome wall surface temperature reaches about $1050 \mathrm{~K}\left(1430^{\circ} \mathrm{F}\right)$. However, the temperature has penetrated only about $10 \mathrm{~cm}$ into the wall during the transient. After the salt cake crust ignites, about $2 \mathrm{~m}^{2}$ of crack area is required to vent the reaction effluent.

16W070 West 83rd Street $\bullet$ Burr Ridge, Illinois 60521 $\bullet$ (708) 323-8750

Telefax $(708)$ (7-8 $986-5481$ 
Figure A-1. Dome Pressure - Without Crack.

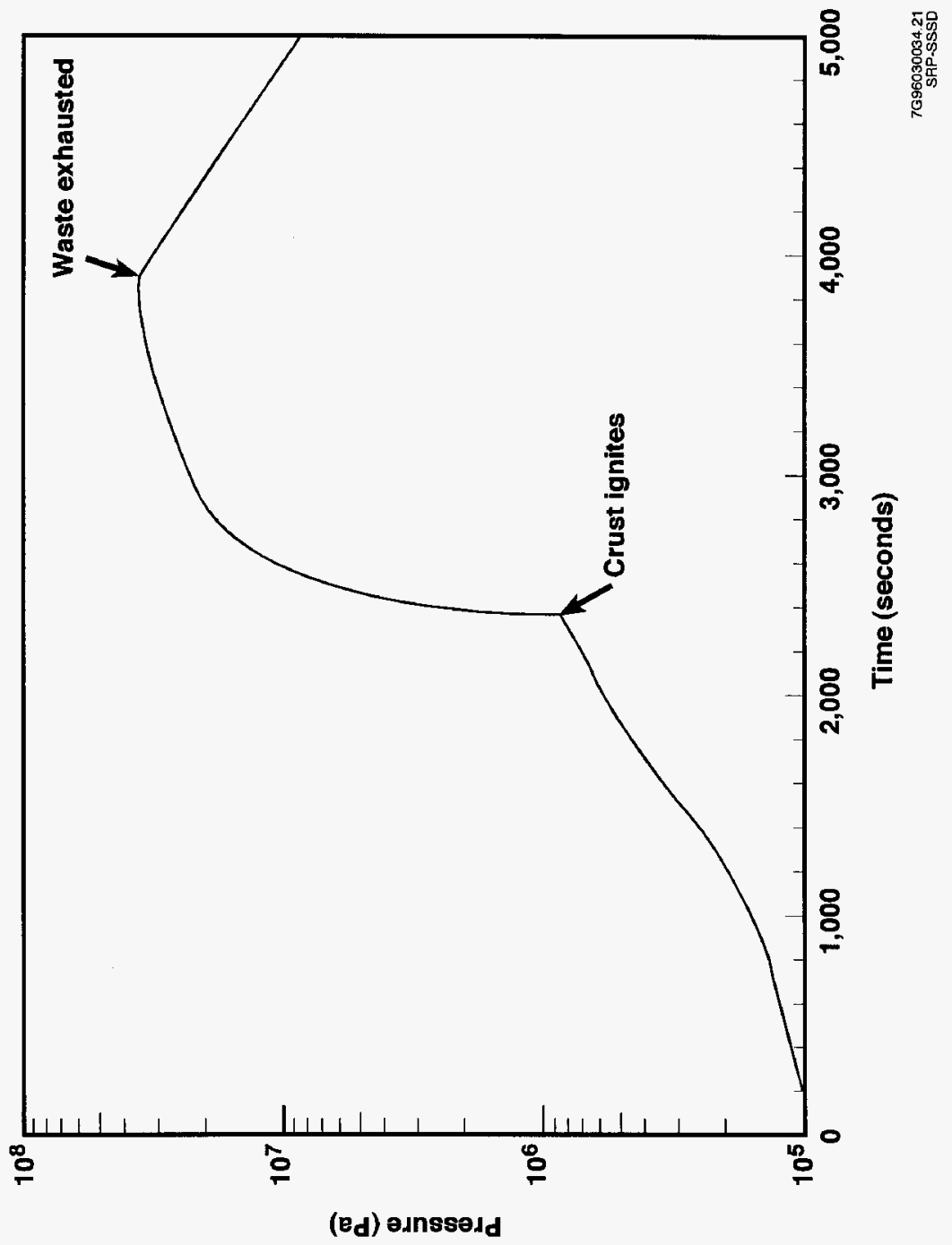




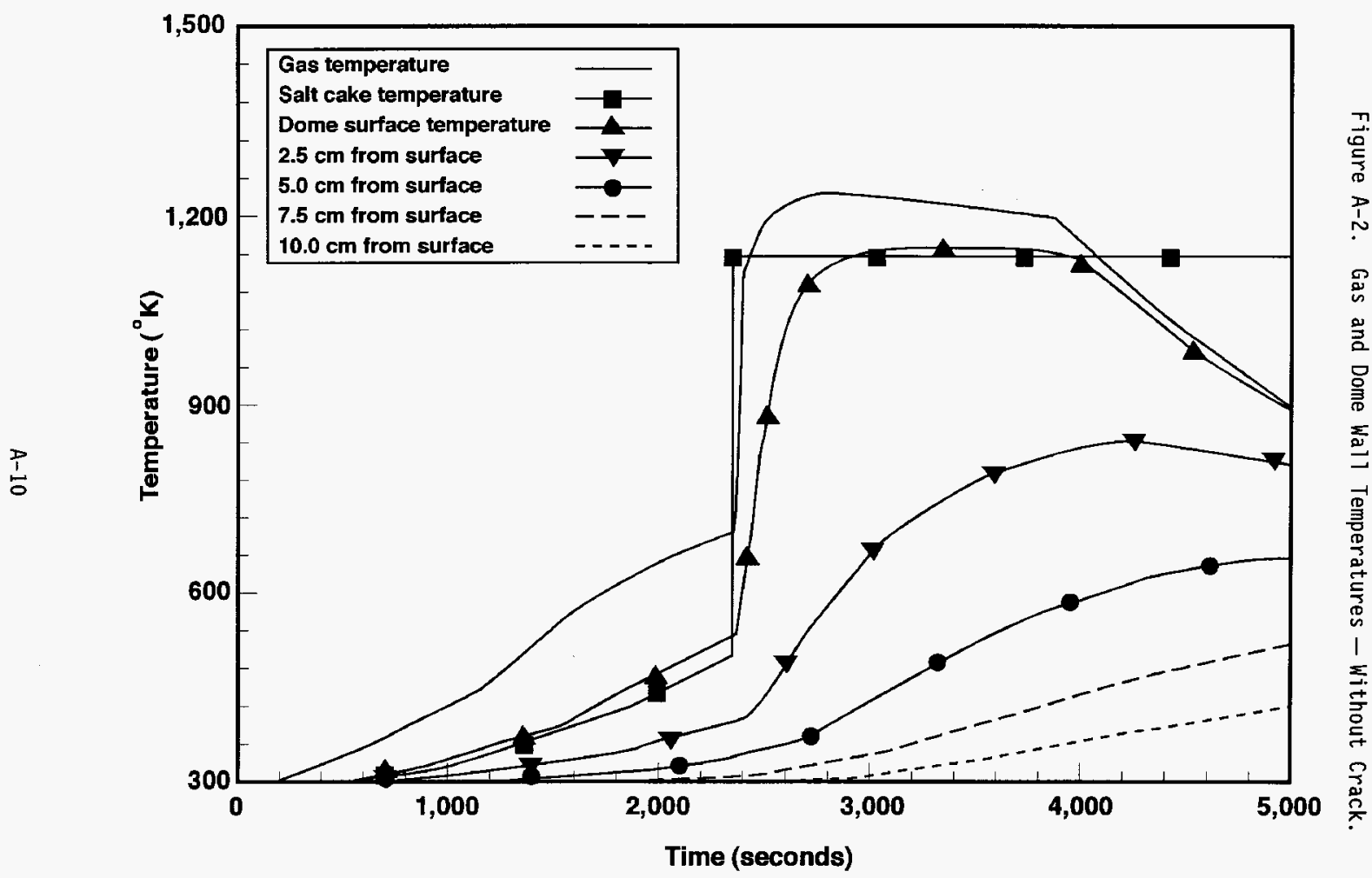


Figure A-3. Dome Pressure - With Crack.

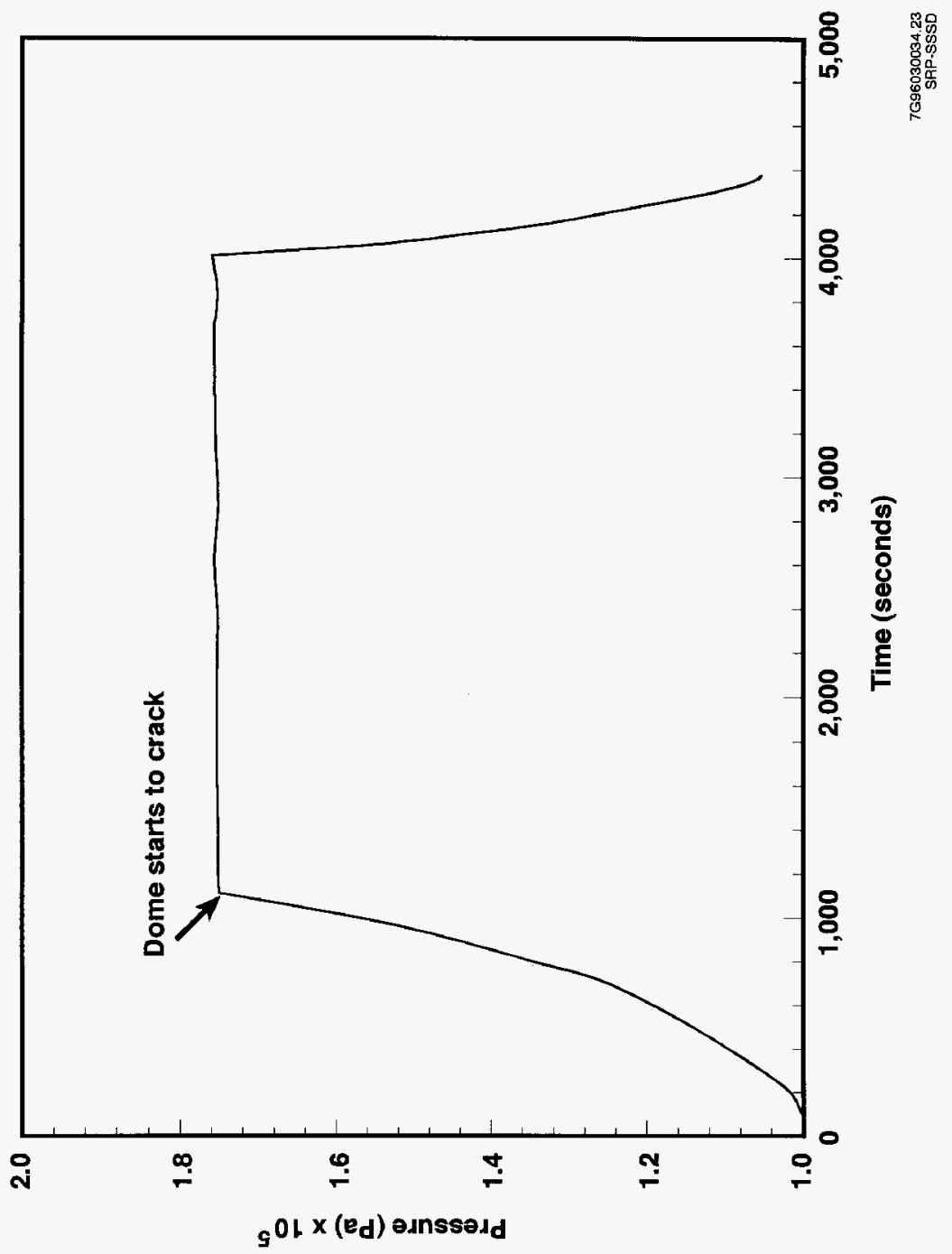




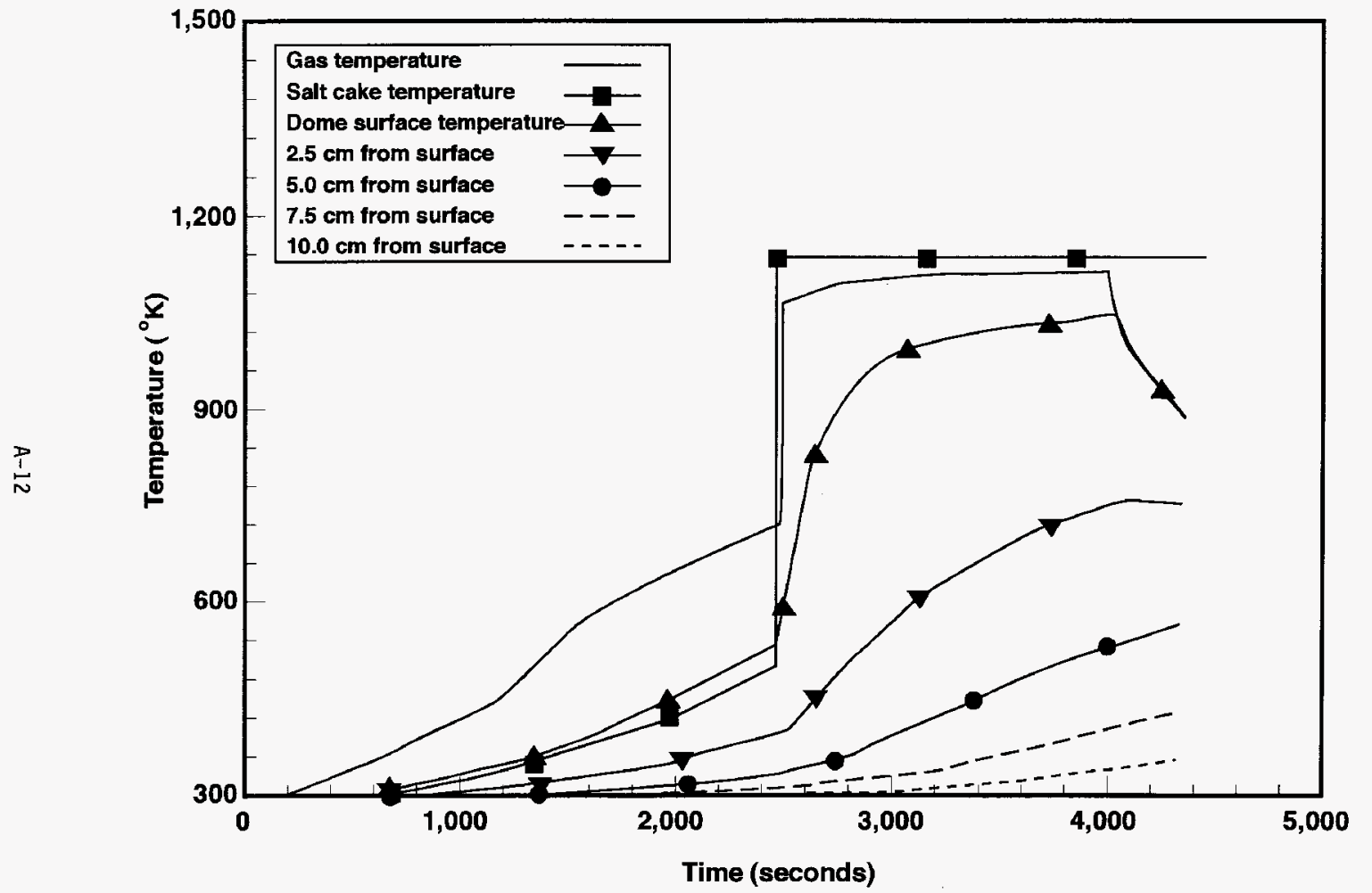

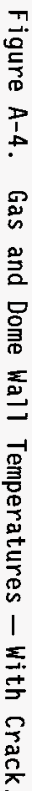

$7 \mathrm{G} 96030034.24$ SRP-SSSD 
WHC-SD-TWR-RPT-002 REV 0

Figure A-5. Crack Area.

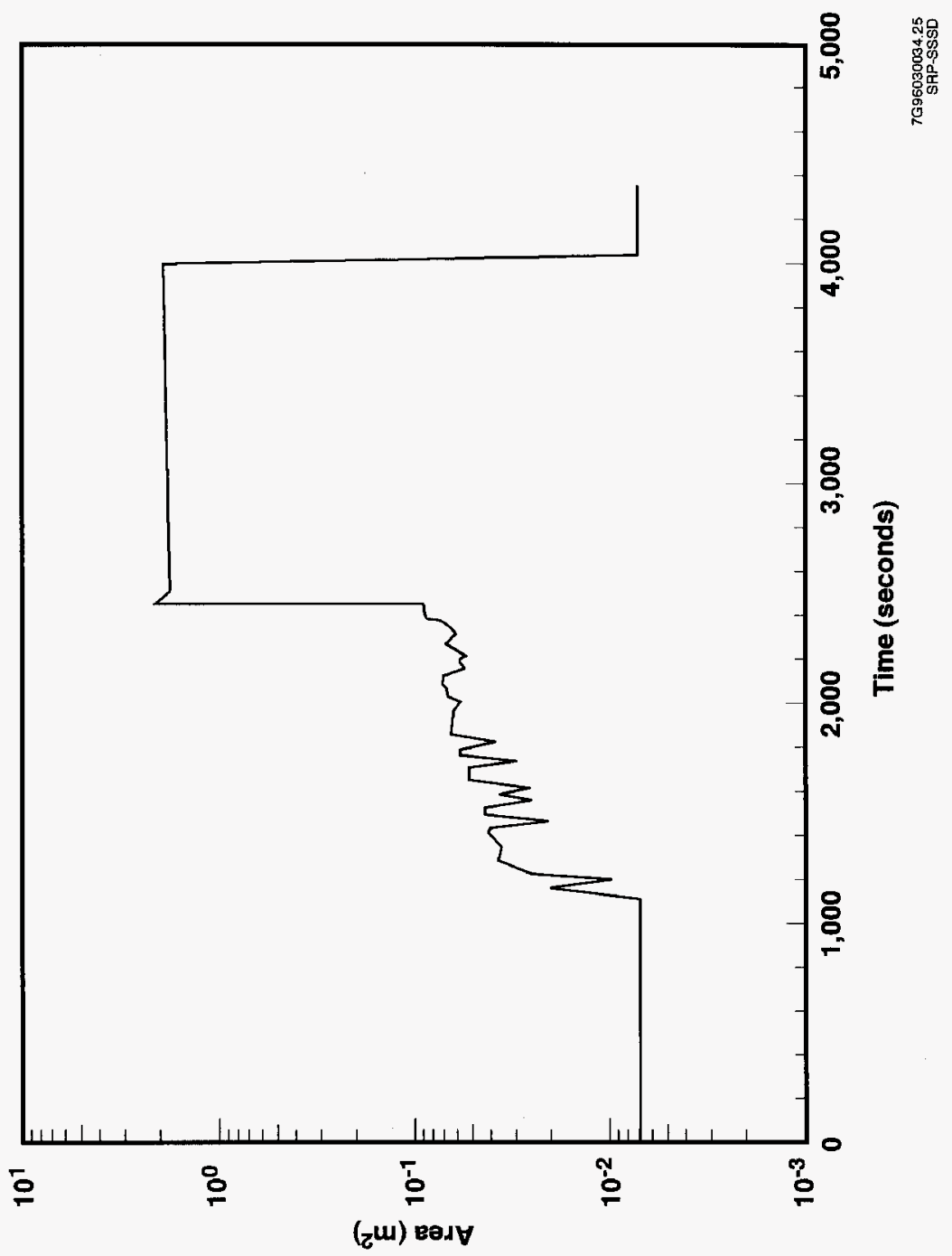


[27] From: Rick J Van Vleet at "BCS78 5/17/96 9:23AM (5531 bytes: I In)

To: Robert M Marusich

Receipt Requested

Daniel E Simpson at BCS7, Dirk S Leach, Craig Carro at -BCS7,

Lawrence $J$ Kripps at WHC186, Gary L Dunford at BCS4, Francis $C$ Han at

WHC53, jbxemstec.com at -SMTPLink

Subject: Re: Calculated Waste Tank Deflagration Pressures

Francis,

Message Contents

The peak pressure in the DSTs is higher because the gas composition greatly differs from tank to tank. Tank 101-SY had 1arge releases

$-300 \mathrm{~m} 3$ with $28 \%$ hydrogen. According to Blaine Barton's calculations on stored gas volumes in the tank, 101-sY used to hold around 1546 standard cubic meters of gas. The largest releases were calculated to be $-300 \mathrm{~m} 3$. This is $20 \%$ of the gas volume. My adiabatic calculation says at a $20 \%$ release, the pressure should be $372 \mathrm{kPa}$ (54 psig). However, work done at PNNL would indicate that double she11 tanks can have releases of around 40 to $50 \%$ of their stored gas volumes during natrual GREs. For example, the stored gas volume of AN-105 is estimated by Barton to be 1318 standard cubic meters. The gas monitoring data supports the fact that the release gas should contain $67 \%$ hydrogen. So, for a $20 \%$ release of the stored gas, the calculated pressure is $481 \mathrm{kPa}$ ( $69.7 \mathrm{psig}$ ). A release of $50 \%$ of the gas in AN-105 results in a pressure of $960 \mathrm{kPa}$ (139 psig).

Rick

Reply Separator

Subject: Calculated Waste Tank Deflagration Pressures

Author: Francis C Han at WHC53

Date: $\quad 5 / 17 / 96 \quad 7: 40$ AM

Bob,

The new pressure load due to $\mathrm{H} 2$ deflagration for DST is 2.5 times the pressure calculated for 101-SY tank under the same assumed condition, i.e. no vent path or dome openings. As shown below the 101-SY internal pressure is $58 \mathrm{psi}$ and the internal pressure of the new analysis is 141 psig. In order to properly evaluate the structural behavior, we need to know why the new load is so much higher than the 101-SY.

The opening of the DST dome due to internal pressure is $12^{\prime}$ diamater rather than a $3^{\prime}$ crack. Please see DSI from F. Han/J, Beaver to R. Marusich, dated $4 / 5 / 96$.

We are proceeding the writting of the structural topical report based on the assessments of the various loads we have made so far. If you foresee any change in the loads which differ from what we have used in our assessment please let us know as soon as possible. Any change of load from now on would result delay in writting the report.

Francis 
Francis,

Rick Van Vleet has calculated his tank pressure for deflagrations. the calculation was based on having no relief path and no dome failure. The peak pressures for DST's are $10.6 \mathrm{~atm}$ absolute $(1 \mathrm{~atm}=14.7 \mathrm{psi})$ or $141 \mathrm{psig}$. the peak pressure for SST's are $7.5 \mathrm{~atm}$ absolute or 88 psig.

Our concern is that these are so much above the $60 \mathrm{psi}$ for DST and 11 psig for SST's that surely the dome will be affected much more than what the Delphi Panel thought. We are aware that you will tell us that the tank will open more to relieve the "excess pressure" and the dome will not fail, but we have information that shows that opening up additional area really does not reduce doses that much.

We have data for 101-SY that shows the following

H2 deflagration - no vent path or dome openings - peak pressure is 58 psi.

With a 42 inch dia riser open ( 9.6 sqft area), the peak pressure is 55 psi

With 2-42 inch dia risers open (19.2 sqft area), the peak pressure is 53

It is not clear. to us that the dome can open wide enough to relieve a 141 psi pressure spike to $60 \mathrm{psi}$. Note that for the can lid opening failure mode in the DST, for a peak open gap of $3 \mathrm{ft}$, the weld must fail (ie, must be open) over $20 \%$ of the weld circumference to equal 19.6 sqft. This opening only decreases the pressure from 58 psi to 53 psi.

We need to be assured that the Structural Topical can actually contain an arguement that the dome will open to the point that it will not collapse under the conditions described above. That is, that the failure mode remains the same, but the hole weld zippers open more or the SST dome has more open gaps. We need this asurance by $5 / 28$.

Bob Marusich 
WHC-SD-TWR-RPT-002 REV 0

This page intentionally left blank.

A-16 
WHC-SD-TWR-RPT-002 REV 0

\section{APPENDIX B \\ POSTULATED EXTREME DETRIMENTAL CONDITIONS}

B-1 
WHC-SD-TWR-RPT-002 REV 0

This page intentionally left blank.

B-2 
[9] From: Robert M Marusich at "BCS78 4/16/96 9:00AM (2593 bytes: 39 In)

To: Francis C Han at WHC53, jbxemstec.com at -SMTPLink

CC: Daniel E Simpson at -BCS7, Robert M Marusich, J M (Mike) Grigsby at WHC396,

Rick J Van Vleet, William L. (Bill) Cowley

Subject: Added Structural Analys is

Francis,

Jim,

During the week of $4 / 8$, I asked you to do two more analyses

for the Topical; dome collapse due to the floating of the

primary tank of a DST and the deflagration of flammable gas

in the annulus of a DST. You asked for further

clarification. Here it is. Let me know if you need any more

information. I understand that with this information you

will provide a date by which you can tell me the structural

response. this date is needed by Friday of this week.

Case 1: Assume that the annulus fills entirely with tank 1 iquids with a SpG of 1.4. Assume that the primary tank is empty, or filled with waste in 50kgal increments until it does not float anymore. Does the dome collpse or just break away due to the uniform load underneath?

Case 2; Assume that the annulus is fill with 20 gallons of gasoline that has entirely vaporized. The heat of combustion is $10 \mathrm{kcal} / \mathrm{gm}$. Using a specific gravity of $0.7 \mathrm{~g} / \mathrm{cc}$ and assuming alf of it burned, the energy given off is $5.3 \mathrm{~EB}$ cal. The volume of the annulus based on a $0 D$ of $80 \mathrm{ft}$ and ID of $75 \mathrm{ft}$ and height of $34 \mathrm{ft}$ is $5.8 \mathrm{E} 5 \mathrm{~L}$. The mass of air in the annulus is (at $1.29 \mathrm{~g} / \mathrm{L}$ ) $7.55 \mathrm{E} 5 \mathrm{~g}$. The final temperature of the air using a value for $C_{p}$ of $0.24 \mathrm{cal} / \mathrm{g}-\mathrm{C}$ and initial temp of $40 \mathrm{C}$ is $2965 \mathrm{C}$. The pressure in the annulus is 10 atm guage.

It is also possible to fill the annulus half full of waste. If it is left to sit for 30-40 days, the $\mathrm{H} 2$ concentration above the waste will exceed the LFL. Assume a concentration of $10 \% \mathrm{H} 2$ in half of the volume. This yields $2580 \mathrm{~g}$ of $\mathrm{H} 2$. the heat of combustion of $\mathrm{H}_{2}$ is $29 \mathrm{kcal} / \mathrm{g}$ for a total of $0.7 \mathrm{E} 8 \mathrm{cal}$ or about $1 / 8$ of that of $20 \mathrm{gal}$ lons of gas.

The gasoline deflagration is the worse case.

Bob Marusich 
[12] From: Robert M Marusich at -BCS78 4/18/96 7:32AM (6698 bytes: 118 In)

To: Francis $C$ Han at "WHC53, jbxemstec.com at -SMTPLink, Daniel E Simpson at BCS7, Gary L Dunford at "BCS4

CC: J M (Mike) Grigsby at WHC396, Wi1liam L (Bi11) Cowley, Rick J Van Vleet, Allen B Webb, Robert M Marusich, Lawrence J Kripps at -WHC186, Craig Carro at -BCS7, Dirk S Leach

Subject: Structural Tasks Needed to Support the ScheduTe

Francis, Dan, Message Contents

I appreciated recieving the DSI with the effect of the tank to various accident loads. However that is not the end of what was needed for the accident analysis on structural failure. Below are two lists of data needs. the first list are primarily data needs for the response to "normal" load and variations in normal loads. this data is needed for the OSR meeting so that we can come up with meaningful OSR's. The second list are either accident loads not addressed adequately in the DSI or new loads from our further work.

Items $1,2,3$, and 4 are needed by noon Monday April 22 inorder not to affect the schedule.

Items 7,8 and 11 are needed by $4 / 26$ to support the schedule. We need your best judgement to go to the OSR Meetings with, and to complete the writeups. The Topical must then support the judgements.

Item 5 and 10 will have a longer schedule. I will provide it shortly.

OSR's :

In going over the notes for the meeting to be held on Monday on "Necessary OSR's", I find that I need the following:

1. The Topical must discuss the effect of variations in normal loads such as waste level, waste density, temperature, etc. These should be trivial to determine as WHC-SD-WM-DA-150 (the structural sensitivity analysis written for the ASA) has all of this information in it. You just need to make it so the load cases are recognizable. I will tell the OSR meeting that there is no need to control waste level or density. This data has been requested for a ong time.

2. I need to know in general the response of the tank to the types of corrosion mechanisms so that we can determine if a corrosion control is needed. The concern is corrosion of the liner, corrosion of the concrete behind the liner and the corrosion in the dome. They and $\mathrm{I}$ are interested in mechanisins of pitting corrosion, gross or general or full surface corrosion (corrosion of large areas not pits), corrosion at the interface of the waste and tank, the effect of long term buildup of solids at the wall/fioor interface or at welds, etc. this may not be in your area. this is a new reques.t. 
3. I need to know at what wall temperature, assuming the persistance of this temperature for a long period of time, will the structure fail, the first failure mode the tank will experience and the effect of that failure on the integrity of the dome. This is not a new request. I have been asking for the effect of temperature for a long time. We could simply limit the temperature to $350 \mathrm{~F}$ based on design and the fact that we only have analys is to $350 \mathrm{~F}$ in WHC-SD-WM-DA-150. that is what I am going to tell the OSR Team.

Accident Analys is Loads

Just to be complete, my notes show that I have asked you to evaluate the following:

4. By Friday, Apr 19, aging. Aging is defined as the degradation process that has occurred over time and includes past thermal cycling, storage of high temperature waste for some period of time (1-10 years), corrosion, changes in tank level over time, change in waste chemicals, and density over time, etc.

What I need is the likely tank failure mechanism and a discussion of whether or not thes process could possibly result in dome failure. Dont forget to evaluate the dome as well as the walls. The Apr 15 DSI did not adequately address this issue. This is not a new issue.

5. An assessment/analysis of dome collapse or other structural failure due to 20 gallons of gasoline vaporized within the annulus. I beieve this is a new issue.

6. Floating of the primary tank. DO NOT DO THIS CASE. I CAN HANDLE IT.

7. An assessment of the capability of the SST against a negative pressure of 8 psig below atmospheric with no prior pressurization. The previous results of the analysis was -5 psig. New analyses has resulted in a -8 psig case.

8. Tank Failure mechanisms for the Organic Nitrate reaction. temperature curves were recently provided. I have them if you misplaced yours. The curves show the following temperatures:

dome surface: peak of 1100K, duration at $1100 \mathrm{~K}$ of $1000 \mathrm{~s}$. Above $450 \mathrm{~K}$ (350F) for $1 \mathrm{hr}$.

$5 \mathrm{~cm}$ into the dome: Peak 700K. Above $450 \mathrm{~K}$ for $1 \mathrm{hr}$. $10 \mathrm{~cm}$ into the dome: Peak probably 450-500K.

Peak pressure is 11 psig because of cracking.

9. Resolution of Ed Rodriguez's comments on the Delphi results. If the Delphi Panel does not address these, the structural topical needs to address these.

10. Internal pressurization of DCRT's. The case regarding external loads has gone away. 
11. Looking at some possibly more severe cases for DST H2 deflagrations. Will let you know what they are when I get them. For now assume a peak pressure of 90 psig

(unvented) with a rise time of ls for now.

Bob Marusich 
[21] From: Robert M Marusich at BCS78 4/25/96 3:51PM (2843 bytes: 39 In)

To: John P Strehlow at WHC321, Francis C Han at -WHC53

Subject: Added Structural Analysis

From: Robert M Marusich at BCS78 4/16/96 9:00AM (2617 bytes: 39 in)

To: Francis C Han at "WHC53, jbxemstec.com at -SMTPLink

CC: Daniel E Simpson at BCS7, Robert M Marusich, JM (Mike) Grigsby at *WHC396,

Rick J Van Vleet, William L (Bi11) Cowley

Subject: Added Structurat Analysis

Francis,

Jim,

During the week of $4 / 8,1$ asked you to do two more analyses

for the Topical; dome collapse due to the floating of the

primary tank of a DST and the deflagration of flammable gas

in the annulus of a DST. You asked for further

clarification. Here it is. Let me know if you need any more

information. I understand that with this information you

will provide a date by which you can tell me the structural

response. this date is needed by Friday of this week.

Case 1: Assume that the annulus fills entirely with tank liquids with a SpG of 1.4. Assume that the primary tank is empty, or filled with waste in $50 \mathrm{kgal}$ increments until it does not float anymore. Does the dome collpse or just break away due to the uniform load underneath?

Case 2; Assume that the annulus is $f 111$ with 20 gallons of gasoline that has entirely vaporized. The heat of combustion is $10 \mathrm{kcal} / \mathrm{gm}$. Using a specific gravity of $0.7 \mathrm{~g} / \mathrm{cc}$ and assuming all of it burned, the energy given off is $5.3 \mathrm{E} 8$ cal. The volume of the annulus based on a 00 of $80 \mathrm{ft}$ and ID of $75 \mathrm{ft}$ and height of $34 \mathrm{ft}$ is $5.8 \mathrm{E} 5 \mathrm{~L}$. The mass of a ir in the annulus is (at $1.29 \mathrm{~g} / \mathrm{L}$ ) $7.55 \mathrm{E} 5 \mathrm{~g}$. The final temperature of the air using a value for $C_{p}$ of $0.24 \mathrm{cal} / \mathrm{g}-C_{\mathrm{C}}$ and initial temp of $40 \mathrm{C}$ is $2965 \mathrm{C}$. The pressure in the annulus is 10 atm guage.

It is also possible to fill the annulus half full of waste. If it is left to sit for 30-40 days, the $\mathrm{H} 2$ concentration above the waste will exceed the LFL. Assume a concentration of $10 \% \mathrm{H} 2$ in half of the volume. This yields $2580 \mathrm{~g}$ of $\mathrm{H} 2$. the heat of combustion of $\mathrm{H} 2$ is $29 \mathrm{kcal} / \mathrm{g}$ for a total of $0.7 E 8$ cal or about $1 / 8$ of that of 20 gallons of gas.

The gasoline deflagration is the worse case.

Bob Marusich 
WHC-SD-TWR-RPT-002 REV 0

This page intentionally left blank.

B- 8 
WHC-SD-TWR-RPT-002 REV 0

\section{APPENDIX C \\ CALCULATIONS OF SECTION CAPACITIES FOR ACCIDENT INTERNAL PRESSURES}


WHC-SD-TWR-RPT-002 REV 0

This page intentionally left blank. 


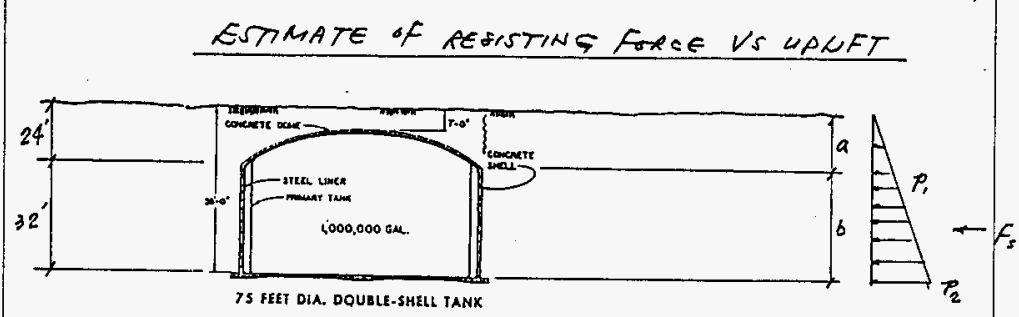

$$
\begin{aligned}
& \text { SolL DATA : Assume } \Gamma_{w}=116 \text { pof (DENSiry) } \\
& \text { LATEAM COCFF @ REST: } 0.5 \\
& \text { FR.eTIUNAC GJEFF BETWEeN don C. * } 50,1: 0.45
\end{aligned}
$$$$
\omega_{s}=7.426,000 \pm \text { (PIANKA's ante) }
$$

2. $f_{S}$ : falerion Between Sorc $\times$ core.

$P_{1}=(0.5)(24)(116)$

$=1,392$ pst

$P_{2}=(0.5)(56)(116)$

$=3,248$ pff

$F_{s}=$ FORCG ACTING ON wACC DNETO SOOC (PER FT)

$=(1 / 2)(1392+3248)(32)$

$=77,120$ \#/,

$f_{s}=(0.45)(>7,120 \%)(83 \pi)$

$=9.049,144$

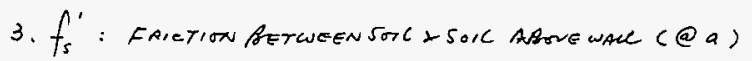

$$
\begin{aligned}
& F_{s}^{\prime}=\text { Force Betweensoll FACE @ a (PER ft) } \\
& =(1 / 2)(1392)(24) \\
& =16,704^{*} \\
& f_{s}^{\prime}=(0.4)(16>04)(83 \pi) \\
& =1,742,242
\end{aligned}
$$

4. Wc: Wt of corroreTe structure

$$
\begin{aligned}
W_{E} & =(0.785)\left(83^{2}-80^{2}\right)(32)(150)+\left(83^{2} \pi / 4\right)(1.5)(150) \\
& =3.059 .938^{4}
\end{aligned}
$$


5. WEIGHT OF STEEL $\not R$ :

$$
\begin{aligned}
& \text { PRimaRT TANE : } W_{s t p}=\left\{\left[75 \pi((4) 5 / 12)(11)+(9.5 / 12)(22+(0.315 / 12)(7)]+37.5^{2} \pi(4.175)\right) / 12\right\} 490 \\
& =210,500 \\
& \text { SEcondary tK : } \omega_{\text {sts }}=80 \pi(0.25 / 12)(39) 490 \\
& =106 \text {, doo }{ }^{*} \text { (BNSER NoT INCL.) }
\end{aligned}
$$

6. Doward pRessure and wt it waste.

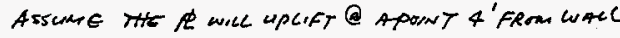

The interute pREssure: $P_{i}$

$$
\begin{aligned}
P_{D} & =\left(75^{2}-67^{2}\right)(9785) P_{i}+\left(75^{2}-67^{2}\right)(0.785)(62.4)(1.7)(32) \\
& =892 P_{i}+5,027,000
\end{aligned}
$$

Torar Downward Foxce:

$$
\begin{aligned}
F_{D} & =1+2+3+4+5+6 \\
& =24,621,0000^{*}+892 T_{i}
\end{aligned}
$$

THE INTERNAC PRESIURE IS 141 prig $\Rightarrow 20,304$ pSt.

$$
F_{D}=42,732,000 \text { (Assume SEcondor tANk wON'T ForL). }
$$

Total upLIFT ForeE:

$$
\begin{aligned}
F_{u} & =\left(75^{2} \pi / 4\right)(20,304) \\
& =89,700,000 *
\end{aligned}
$$




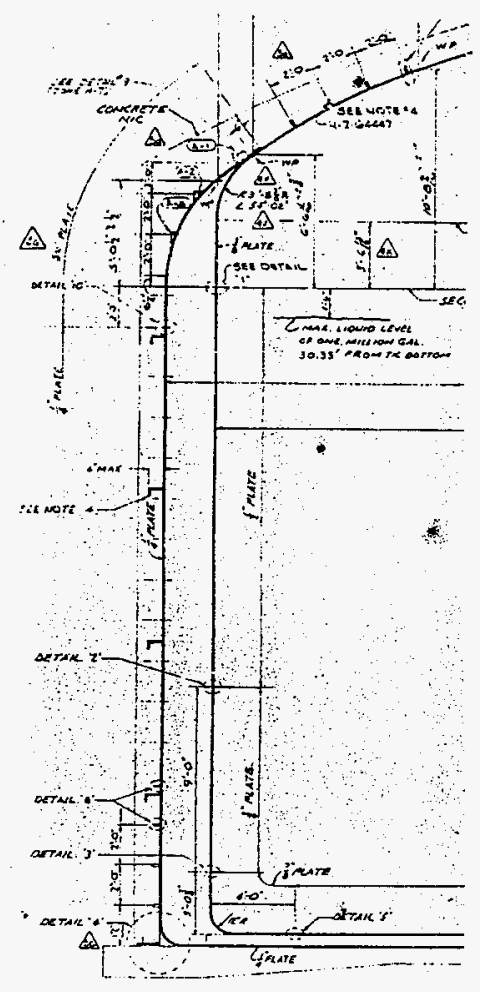

LENGHA of $m, n$ :

$\ell_{m-n}=12^{\prime \prime}(2) \cdot \pi / 4$

$=18.8^{\circ}$

$l_{m-q}=18.8^{\prime \prime}+12^{\prime \prime}$

$=30.8^{\prime \prime}$

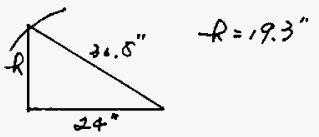

Dere to Host STiffuess of Bent correse

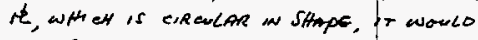
NuT STRAathen BeFore a Bewdong Devecuped of 4 pt ravar Fean The curver.

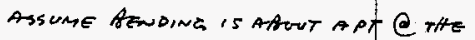
EOSe of The Fllles CONCRETE, with 15 ApP. 2' ARPOA THE CuAce Re.

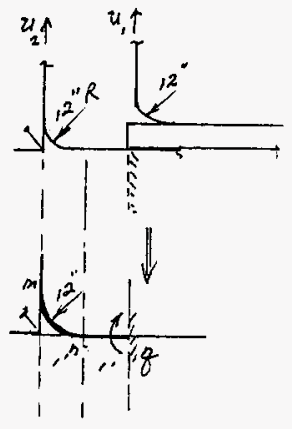

A

B

THE NET UPLIAT FoRCE WoulD BE pARTIATCY TAKEN AY Both TANAS.

for conservatism. Assume ach Cono GOES TO SECONDARY LINER.

Further AEsume Mortion of THE RewT CORNER EAN BE 5 TRAIG ItEENED, SVERY condervative).

AsSumE SECONDARY LINERWONO' FAIL:

19.3" - $12 "=7.3^{\circ}$ max. Herant rite wath

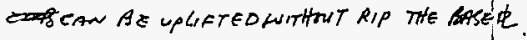
EXACT HESTH WOULD REQURRE DETAILD DYNAMIE ANACYSHS. 
WHC-SD-TWR-RPT-002 REV 0

$T$

CALCULATION IF STRESSES IN THE PRIMARY TANK:

RAD ruS : $R=37.5^{\prime}=450^{\prime \prime}$

(a) 3/8" Lever:

Hoop: $\sigma_{1}=141(450) /(0.375)(2)$

$$
=84.6 \mathrm{ki}
$$

Q $1 / 2 " \phi$ level:

$$
\text { Hoop } \begin{aligned}
\sigma_{2} & =141(450) /(0.5)(2) \\
& =63.5 \mathrm{~km}
\end{aligned}
$$

Q $3 \frac{1}{4}$ \& LEV E:

$$
\text { Hoop } \begin{aligned}
\sigma_{3} & =141(450)(0.75)(2) \\
& =42.3 \mathrm{ksi}
\end{aligned}
$$

THE PRIMARY TANE CONSISTS of 3 DIFFERENT THICKNESS IF

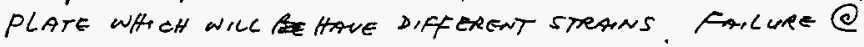
SEAMS OF TRASITION IS LIKELY.

AS SOON AS PRIMARP TANK IS FATLED THE SPACE ENCLUSED bY THE SECONDARY TANK WOULD DEPRESSURIZED.

SINCE THE PRESSURE LOAD IS A TRANSIENT CASE, A DYNAMIC FACTOR SHOULD BE USED. BY INSPECTION, THE STRANNS@VARIOUS CONSTRAINTS ATVO TREANITIOON SECTIONS WOULD EXcEeD the BREAKING POINT. THE PRIMARY TANK WILL FALL $Q$ A TRANSIENT PRESSURE IF 141 PSIS.

for stress - strain curves for STEEC Liner, see sheet 8 .

$C-6$ 
CHECK SECONDARY LINER ID Q THE JUNCTION WACl ANO BASEMAT:

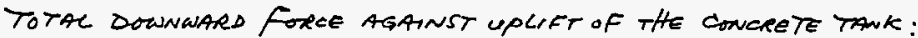

$$
F_{D}=21,594,000^{\#}
$$

NeT upLIFT Forie: :

$$
\begin{aligned}
F_{\text {uner }} & =89,700000 *-21594000 \\
& =68106,000
\end{aligned}
$$

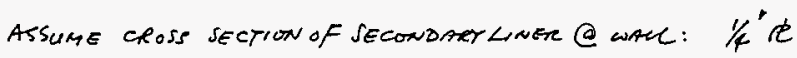

$$
\begin{aligned}
A & =(40)(12)(2)(\pi)(0.25) \\
& =754 \mathrm{in}^{2}
\end{aligned}
$$

STRESS IN SEconDARY LINER (ASSMME TENSICON ONLY'

$$
\begin{aligned}
\sigma_{l} & =68,106,0000^{*} / 754 \mathrm{~m}^{2} \\
& =90.3^{\mathrm{ksi}}
\end{aligned}
$$

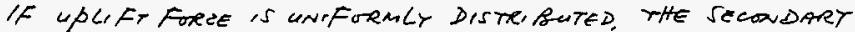

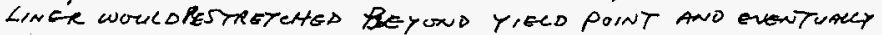
BREAKING OFF FROM THE BASE PLATE.

IT IS BELIEVED THAT DOME wOULD AE SUREeTEO TS THE MPULSE

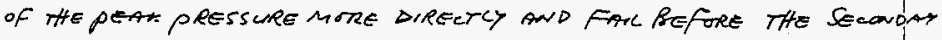
LINER BREAKING UFF.

To ThC Foree to PREAT the SECONDAT LINER:

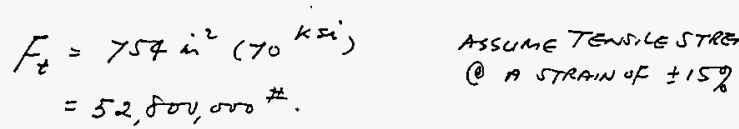




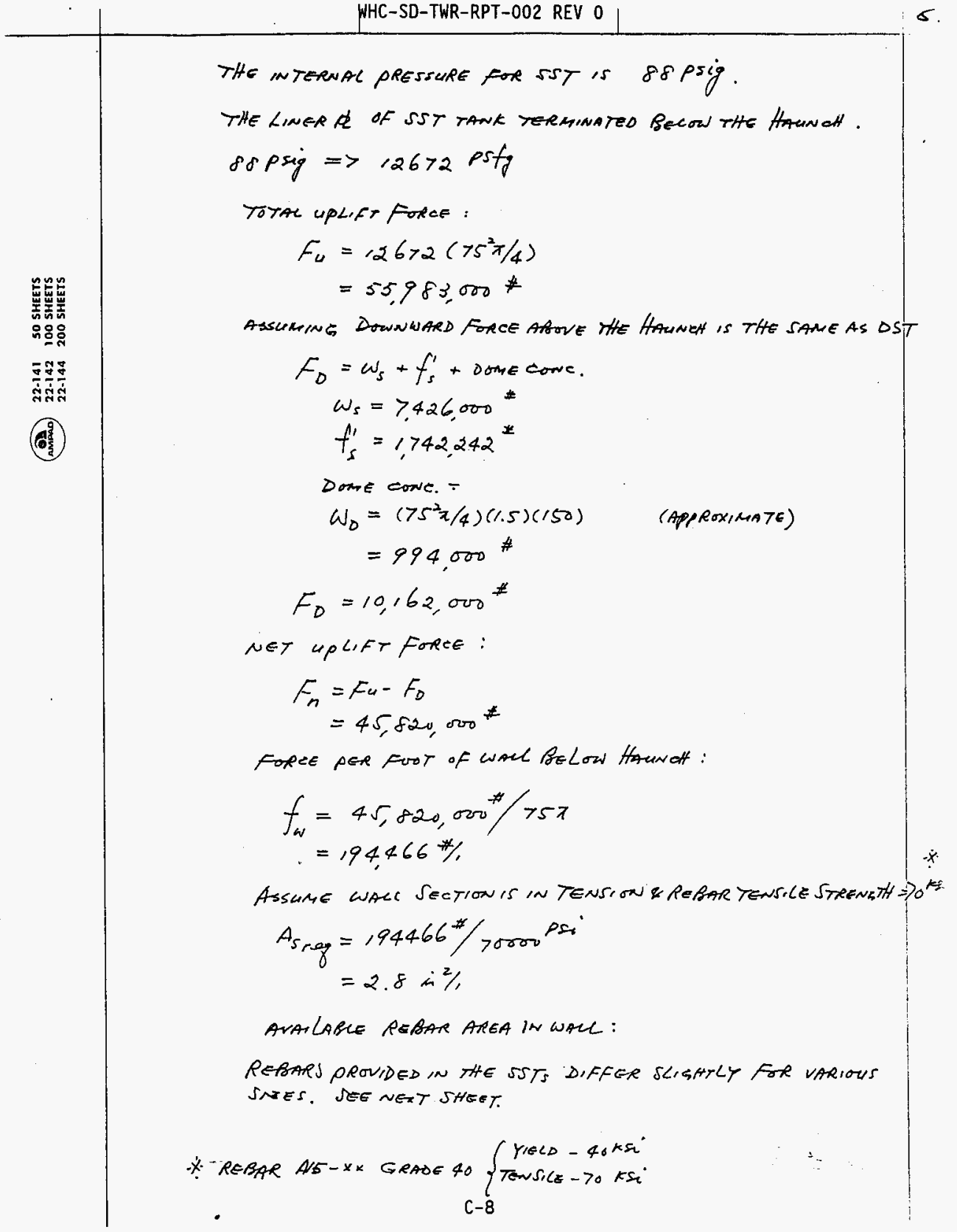




\begin{tabular}{|c|c|c|c|}
\hline TANK & REAAR (WPPER) & $A_{s}$ & DNG No. \\
\hline $241-A$ & $7 f @ 20 " 6 F$ & $0.94 \mathrm{in}^{2} \%$ & $H-2-55912$ \\
\hline $241 . A x$ & $\begin{array}{l}\# 80,18^{\prime \prime} \text { of } \\
\#>0,7^{\prime \prime} I f\end{array}$ & 0.95 in 2 & $4-2-44562$ \\
\hline $2417 y$ & $3 / 4 " \phi C 12^{4} \in F$ & $0.88 \mathrm{in}^{2} /$ & $H-2-2246$ \\
\hline $2417 x$ & $\# 6 Q 16^{\prime \prime} \mathrm{EF}$ & $0.68 \mathrm{in}^{2} \%$ & $H-2-395,2$ \\
\hline
\end{tabular}

Since ale thanks Have the Dame Daheter, the uplift foxce is THE SAME. THE REQUIRED Afrós THE SAME.

THE REQUREO REBAR AREA PER FoOT hength of WACL IS GREATER THAN EVERY SINGLE SHELC TANK.

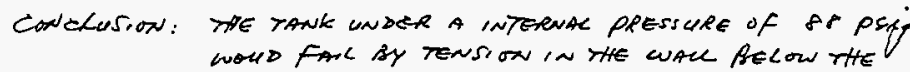
HARU CH REGRON.

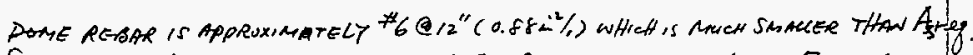

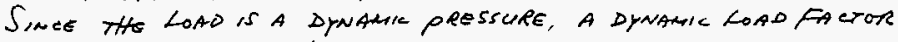
WOULD REQWIRE EVON LARGER STEEC AREA. ACSO RASED UN DUSS. THE DOAF REAAR WUANTIYY IS LIGAT AND DUE TO DYNAMiC PRESSURE The Done would BE shatrened and Farled open. THE Donte Farlure

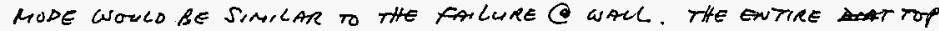
COULD BE BLTWN AWRY, 


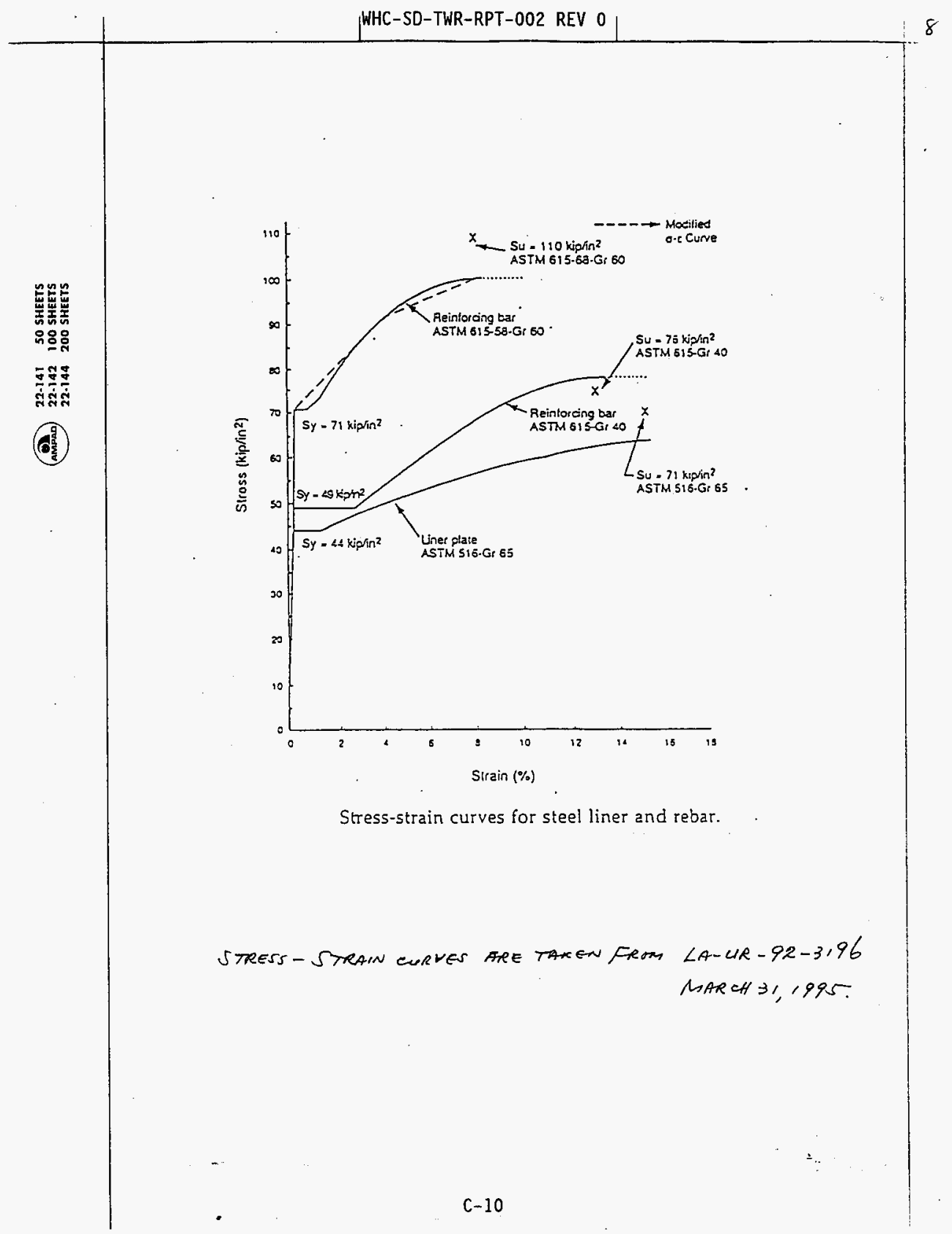




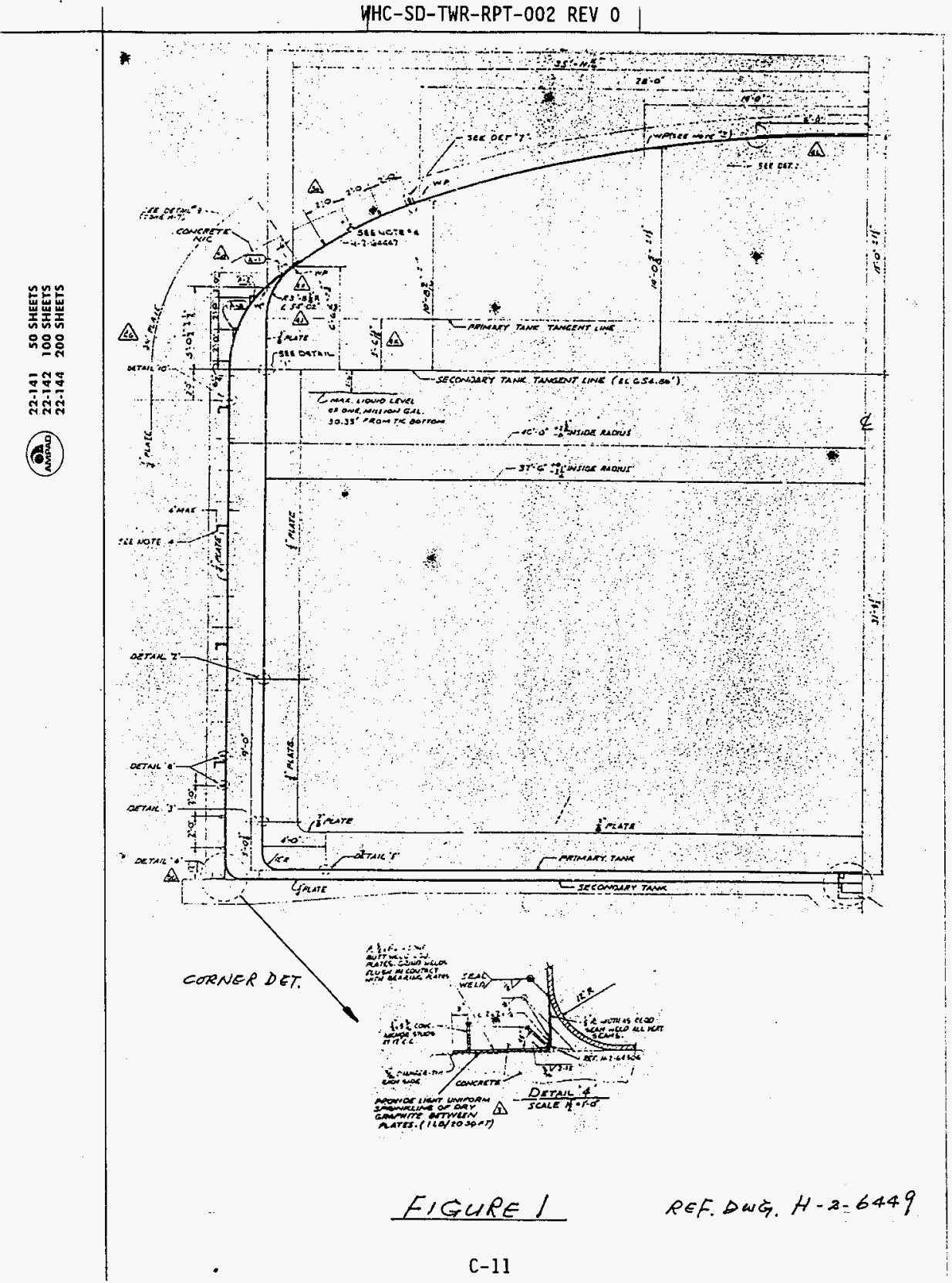




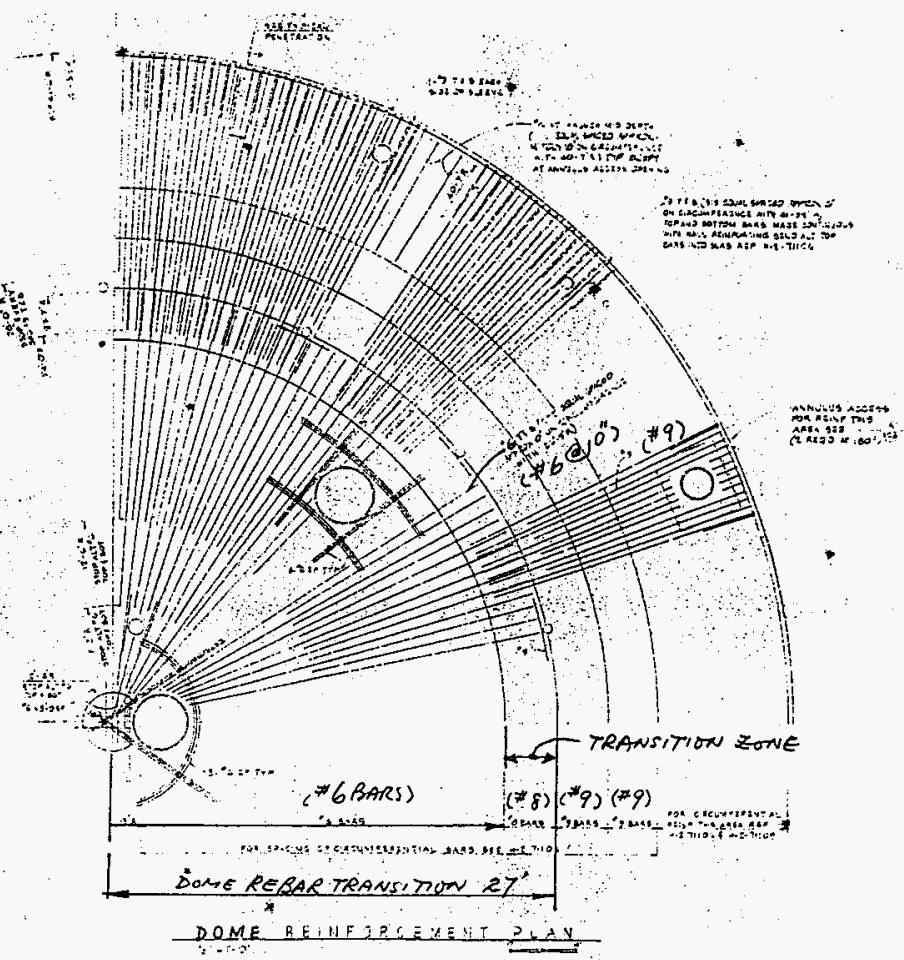

ElgURE 2

Ref. Dukg. $H-2-7110.7$ 

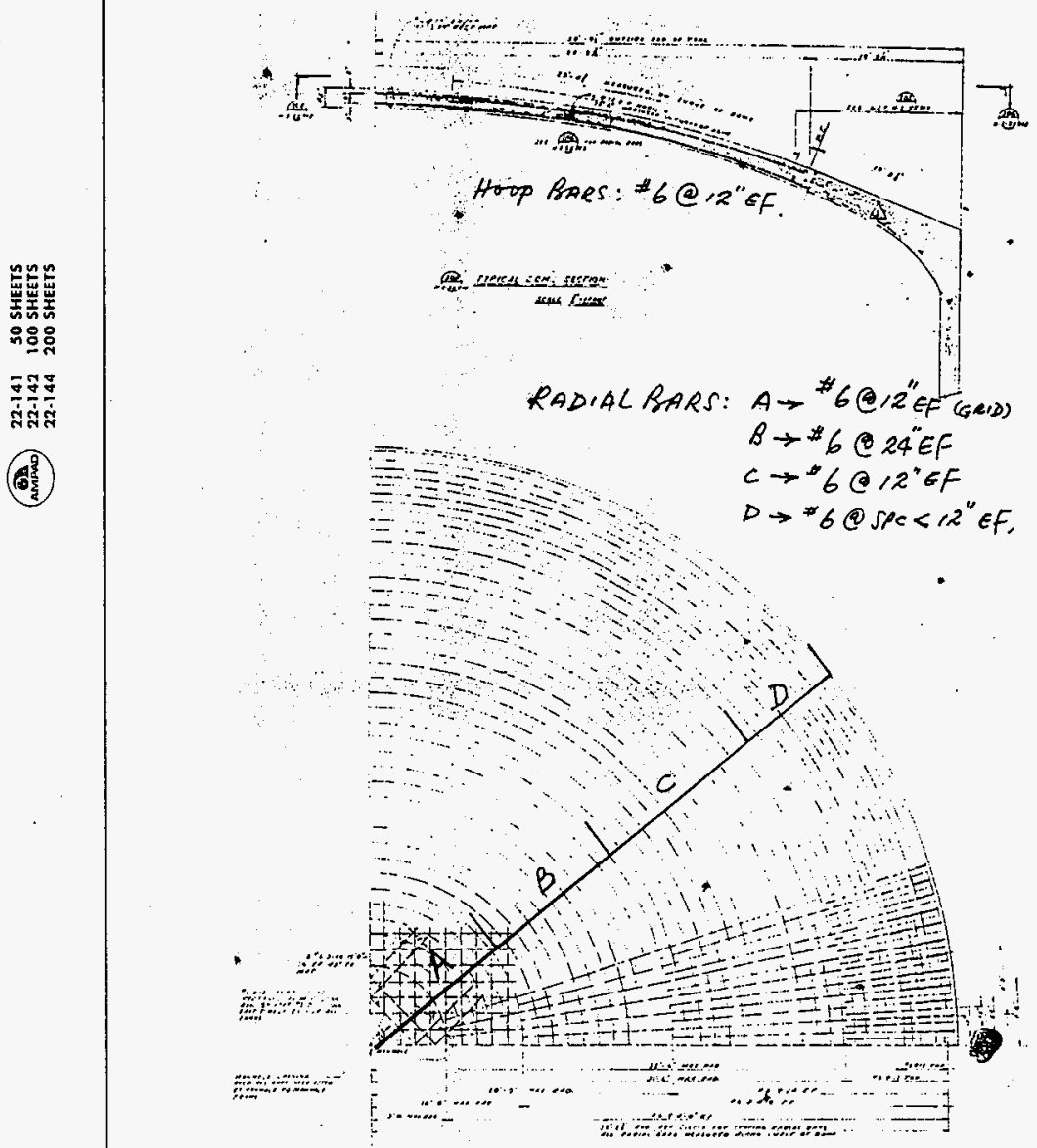

Figure 3

ReF. Dak. $H-2-55913$ 


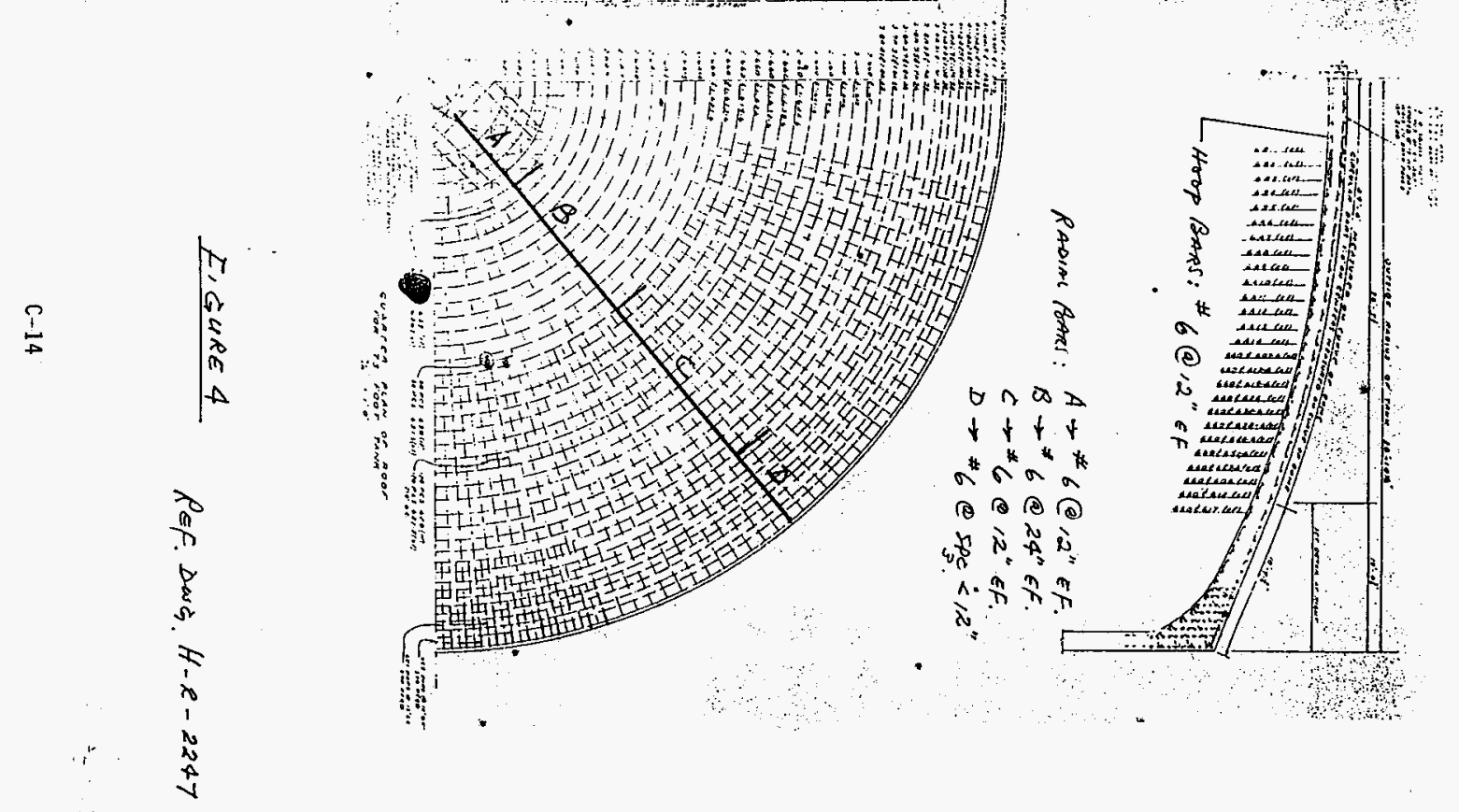




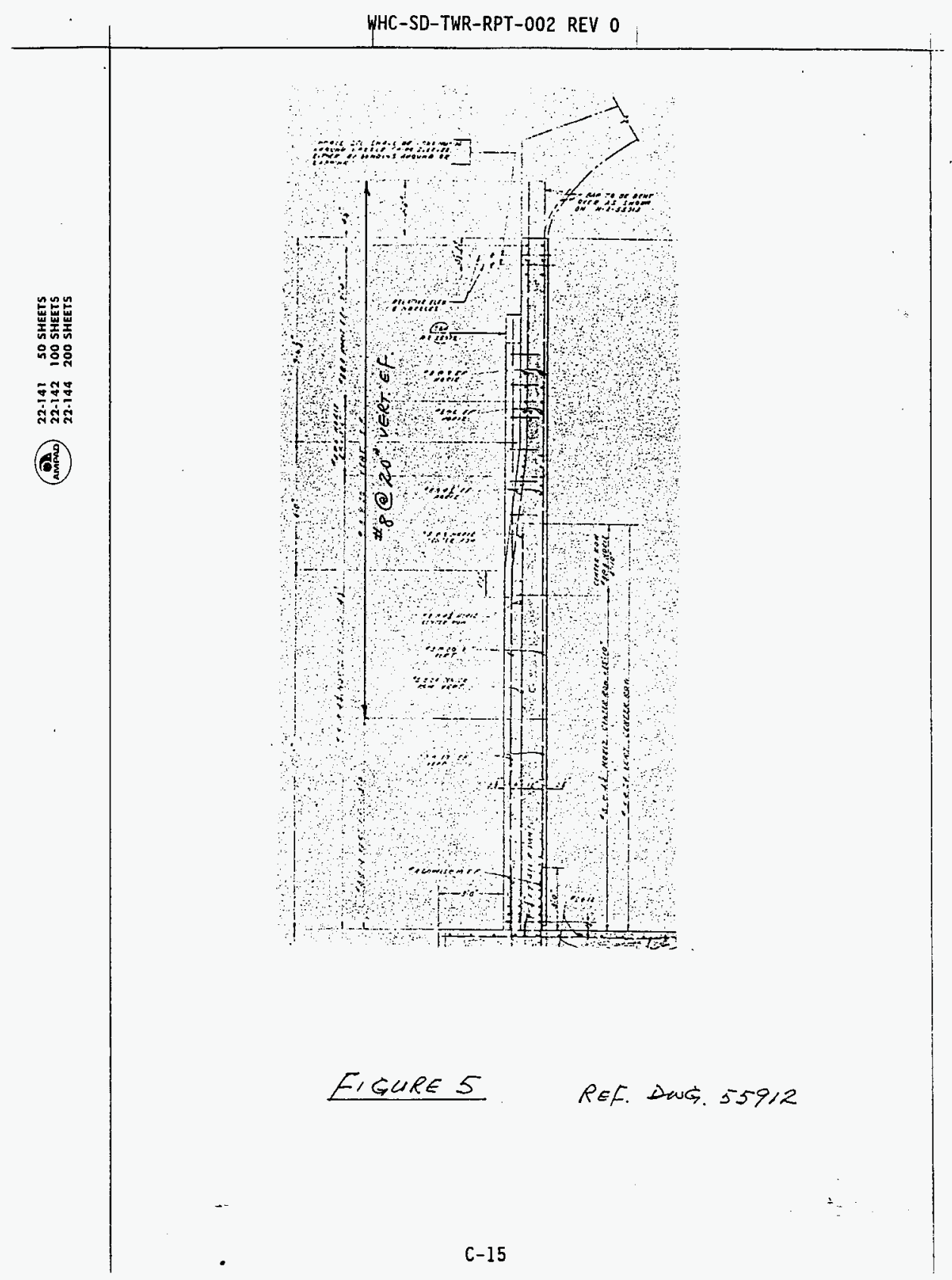




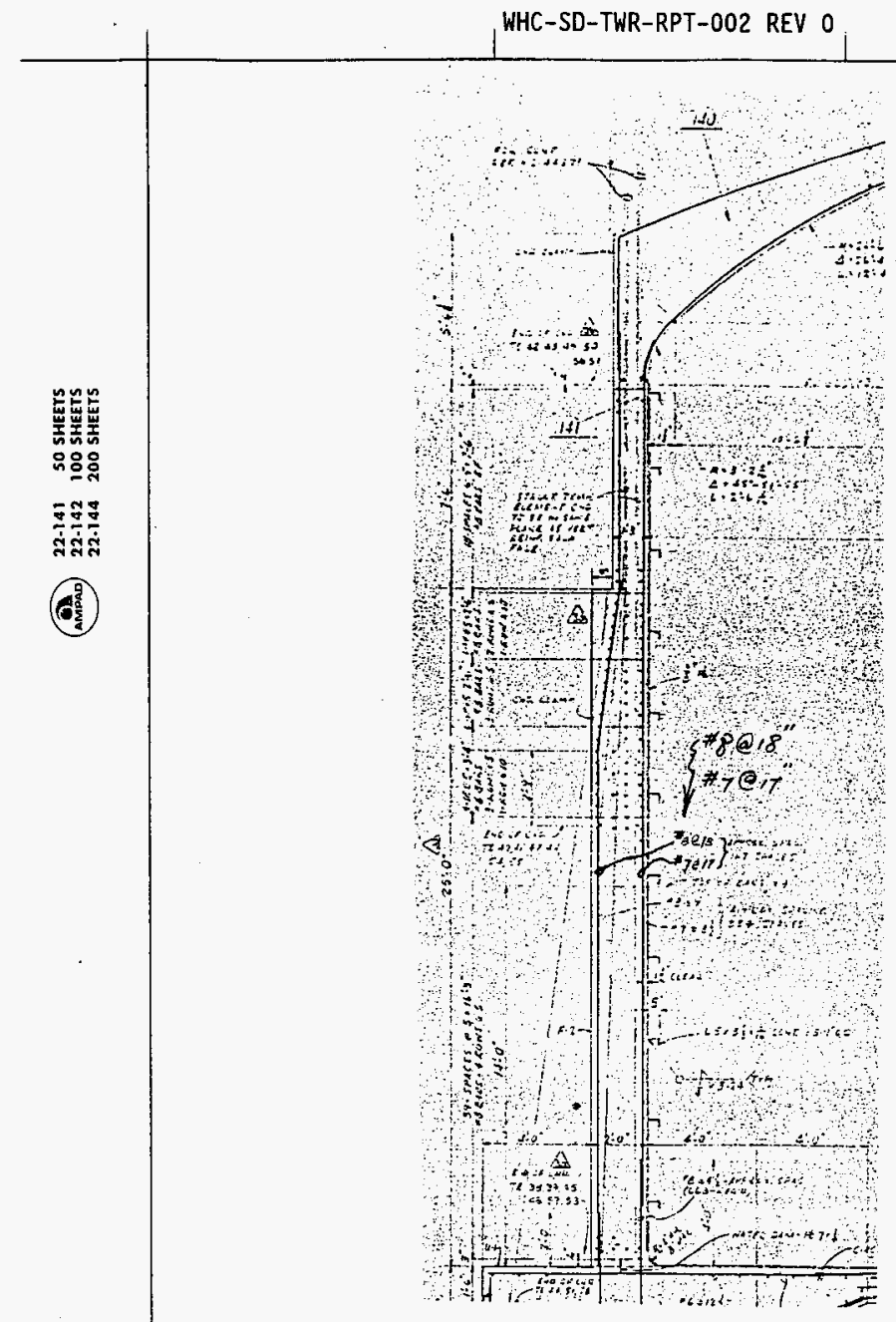

EIGURE 6 REF. DUG H-2-44562 


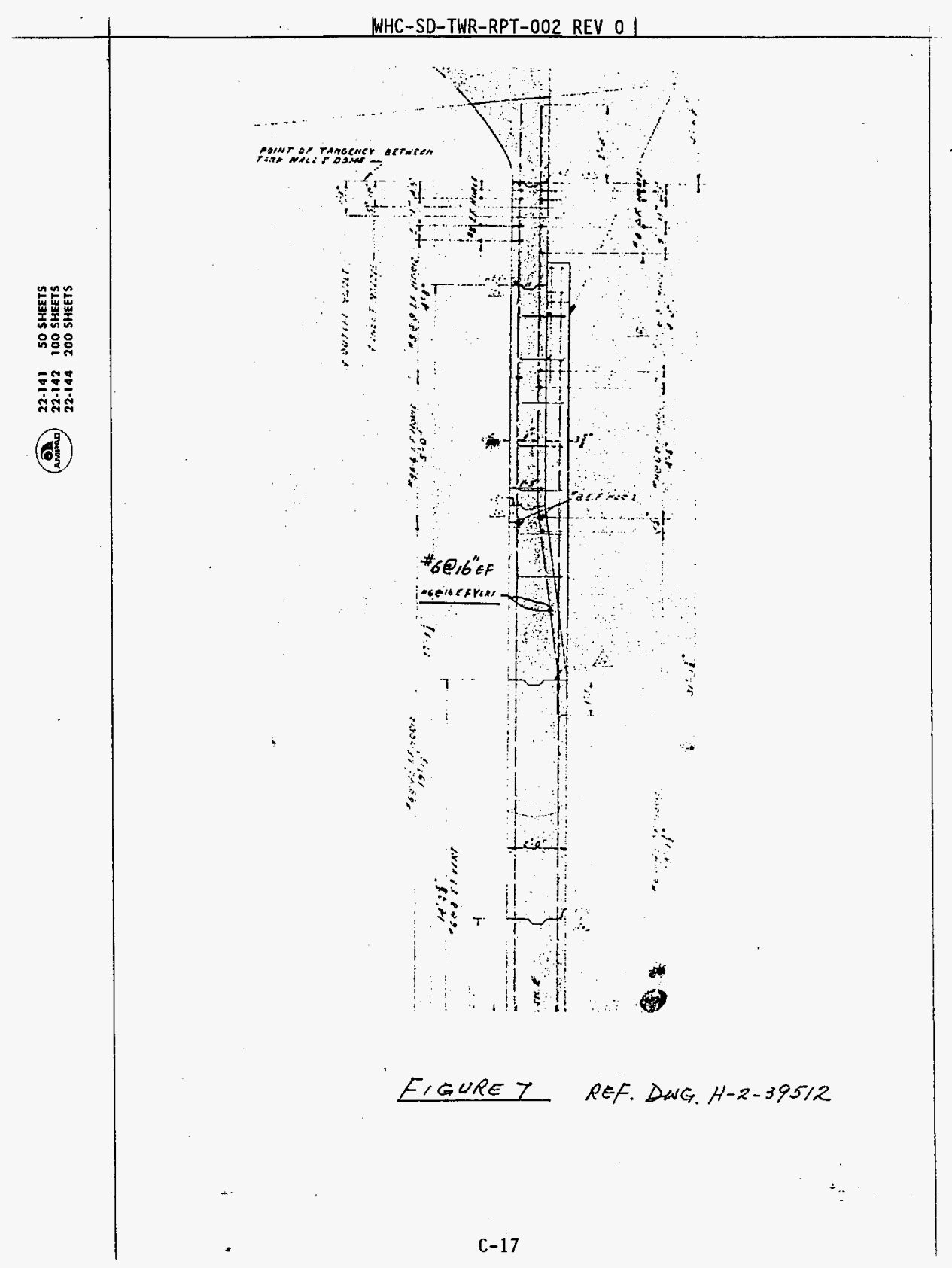



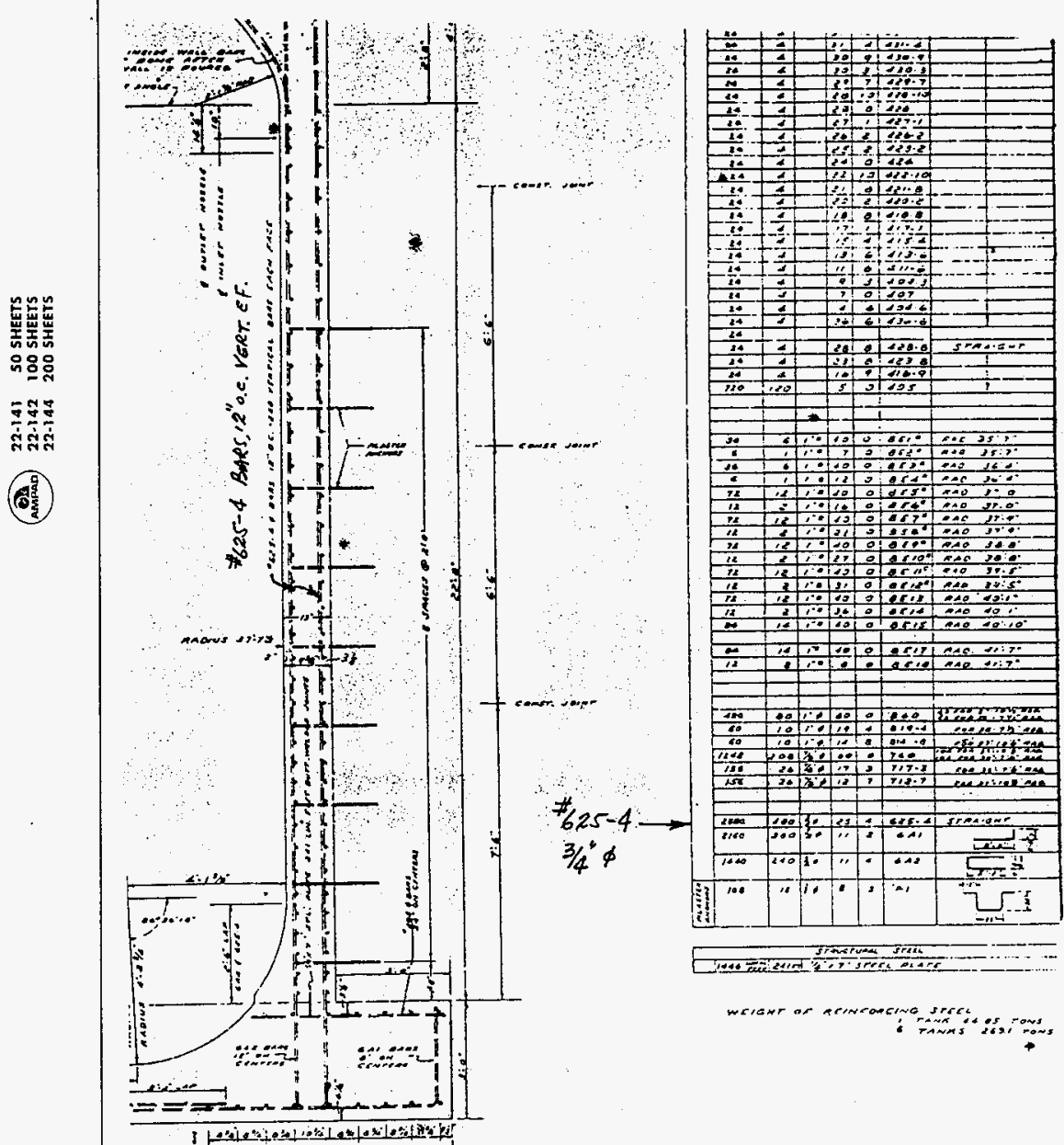

FIGURE 8. REF. Darg. H-2-2246 


\begin{tabular}{|c|c|c|c|c|c|c|}
\hline \multicolumn{7}{|c|}{ DISTRIBUTION SHEET } \\
\hline \multirow{2}{*}{$\begin{array}{l}\text { To } \\
\text { Distribution }\end{array}$} & \multirow{2}{*}{\multicolumn{4}{|c|}{$\begin{array}{l}\text { From } \\
\text { TWRS FSAR Development }\end{array}$}} & \multicolumn{2}{|l|}{ Page 1 of 1} \\
\hline & & & & & \multicolumn{2}{|c|}{ Date $09 / 25 / 96$} \\
\hline \multicolumn{5}{|l|}{ Project Title/Work Order } & \multicolumn{2}{|c|}{ EDT No. 606492} \\
\hline \multicolumn{5}{|c|}{$\begin{array}{l}\text { WHC-SD-TWR-RPT-002, Rev 0, (Interim). "Structural Integrity and } \\
\text { Potential Failure Modes of the Hanford High-Level Waste Tanks }\end{array}$} & \multicolumn{2}{|c|}{ ECN No. $\quad N / A$} \\
\hline Name & & MSIN & $\begin{array}{c}\text { Text } \\
\text { With All } \\
\text { Attach. }\end{array}$ & Text Only & $\begin{array}{c}\text { Attach./ } \\
\text { Appendix } \\
\text { Only }\end{array}$ & $\begin{array}{l}\text { EDT/ECN } \\
\text { Only }\end{array}$ \\
\hline \multicolumn{7}{|l|}{ WHC } \\
\hline $\begin{array}{l}\text { G.L. Dunford } \\
\text { F.C. Han } \\
\text { M.D. Hassebrock } \\
\text { L.J. Julyk } \\
\text { R.M. Marusich } \\
\text { S.H. Rifaey } \\
\text { P.L. Smith }\end{array}$ & & $\begin{array}{l}A 2-34 \\
A 2-34 \\
S 1-57 \\
R 1-56 \\
A 3-34 \\
R 1-56 \\
R 3-58\end{array}$ & $\begin{array}{l}x \\
x \\
X \\
X \\
x \\
x \\
X\end{array}$ & & & \\
\hline Centeal Filw $(02=8+1)$ & & $193-88$ & $x$ & & & \\
\hline
\end{tabular}

